\title{
SPECTRAL CONVERSION OF LIGHT USING CADMIUM SELENIUM ZINC SULFIDE CORE SHELL QUANTUM DOTS TO INCREASE THE EFFICENCY OF PHOTOVOLTAIC CELLS
}

\author{
A Thesis Presented to the Faculty of \\ California Polytechnic State University \\ San Luis Obispo
}

\author{
In Partial Fulfillment of the Requirements for the Degree \\ Master of Science in Engineering \\ With Specialization in Materials Engineering
}

By

Dan Madrid Marrujo

June $2^{\text {nd }}, 2008$ 


\section{AUTHORIZATION FOR REPRODUCTION OF MASTER'S THESIS}

I grant permission for the reproduction of this thesis in its entirety or any of its parts, without further authorization from me.

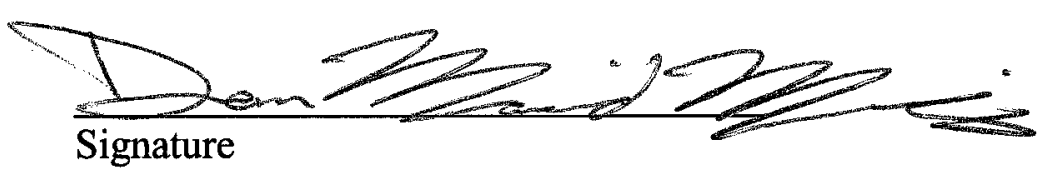

\section{$6 / 2 / 2008$}

Date 


\section{APPROVAL PAGE}

TITLE:

SPECTRAL CONVERSION OF LIGHT USING

CdSe/ZnS QUANTUM DOTS TO INCREASE THE EFFICENCY OF PHOTOVOLTAIC CELLS
AUTHOR:
Dan Madrid Marrujo

DATE SUBMITTED: June $2^{\text {nd }} 2008$

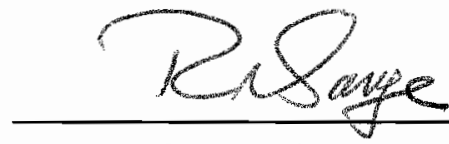

Professor of Materials Engineering Adviser and Committee Chair Dr. Richard Savage
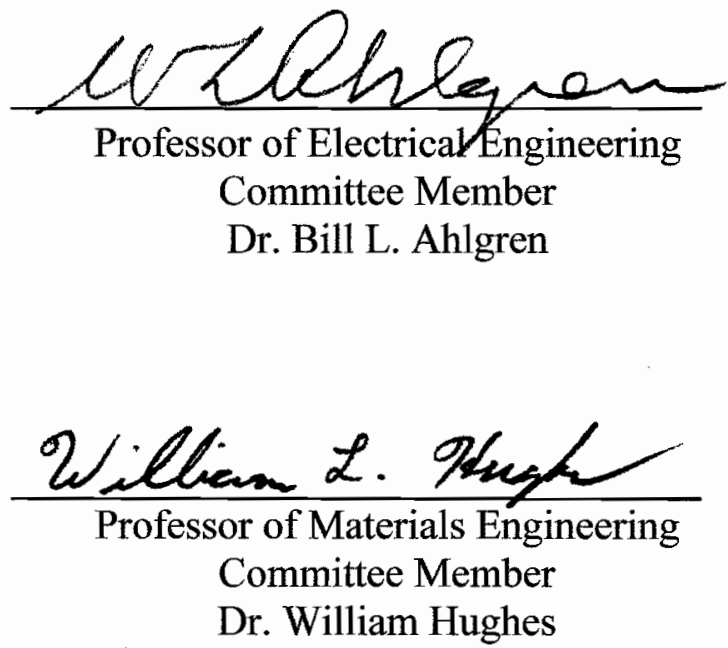


\title{
ABSTRACT \\ SPECTRAL CONVERSION OF LIGHT USING CADMIUM SELENIUM ZINC \\ SULFIDE CORE SHELL QUANTUM DOTS TO INCREASE THE EFFICENCY OF PHOTOVOLTAIC CELLS
}

\author{
By Dan Madrid Marrujo
}

Photovoltaics harness energy emitted from the sun. When the sun's energy is absorbed by a photovoltaic cell array, photons of light are converted into current. The amount of current produced by a photovoltaic cell is calculated by the difference between the energy of the incoming photon and the energy required for an electron to travel across the band gap of the photovoltaic cell. Traditional solar cells are commonly manufactured from silicon, which have a bandgap energy of $1.1 \mathrm{eV}$. If the photon's energy is equal to or greater than the band gap of silicon, electrons are excited from the valence band to the conduction band. Electron excitation between these respective bands enables current flow within the photovoltaic cell. Increasing the number of photons energies equal to the bandgap of the photovoltaic material will increase the amount of current produced.

The objective of this research was to explore the utilization of quantum dots to increase the amount of light collected by a silicon-based photovoltaic cell. Although the electromagnetic spectrum of the sun is broadband, only a finite portion of the spectrum can be harnessed by current solar cell technology. For example, the excess energy of ultraviolet light, when compared to the bandgap of silicon, is generally lost to thermalization; which prevents current production. Therefore the range of the electromagnetic spectrum that is available to a solar cell for electric current is limited. One mechanism to increase the efficiency of solar cells is to increase the electromagnetic spectrum collected. 
Quantum dots are known to down convert high-energy photons to lower energy photons; thereby expanding the useable electromagnetic spectrum. This study investigated the changes associated with dispersing quantum dots above the surface of a photovoltaic cell, as well as, measuring how the electric current of the device is affected. The quantum dots were purchased from Evident Technologies and were made from $\mathrm{CdSe} / \mathrm{ZnS}$. Once acquired, the quantum dots were suspended in microfluidic channels fabricated from polydimethylsiloxane (PDMS). Toluene and water were respectively chosen to disperse the quantum dots. The compatibility of these solvents with PDMS was explored. The change in current was investigated when the microfluidic channels filled with quantum dots were applied to the surface of the photovoltaic cell. 


\section{ACKNOWLEDGEMENTS}

I would first like to thank my brother Mike. You are more than a brother to me and have always been there no matter the circumstance. I have been extremely lucky to experience college with you. I wish you the best in your future endeavors. I would also like to thank my father and mother for their love and support. The advice you have given me has made me the person I am today.

I would next like to thank Dr. Richard Savage for all the help you have provided me during my master's program. It has been a pleasure working with you. The dedication that you have for your students allows them to not only excel but grow as people as well.

Dr. William L. Hughes and Dr. Bill Ahlgren, your advice throughout my thesis has had a major impact on my success. Thank you for your help and ideas.

Hans Mayer and Matt Lewis, I would like to thank both of you for spending time working with me on various experiments. You both are great friends and I hope the future brings you much success.

Finally I would like to thank God for giving me the strength and ability to do all that I have done. 


\section{TABLE OF CONTENTS}

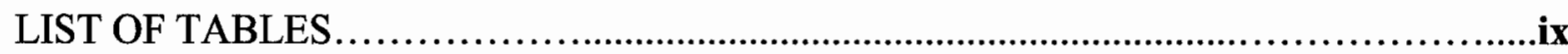

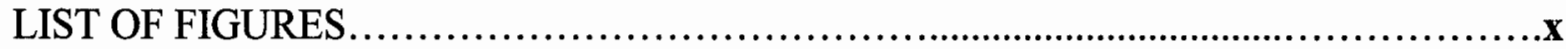

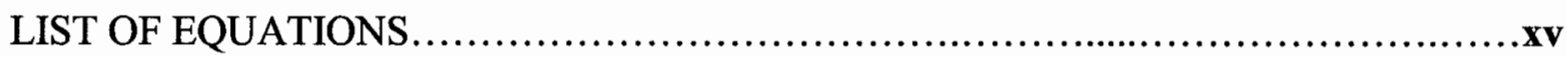

ABBREVIATIONS .................................................................

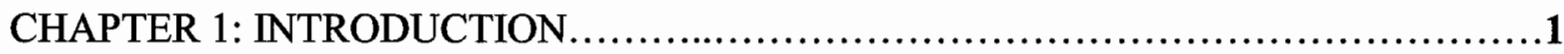

CHAPTER 2: PHOTOVOLTAIC CELL............................................ 6

CHAPTER 3: CADMIUM SELENIUM ZINC SULFIDE CORE SHELL QUANTUM

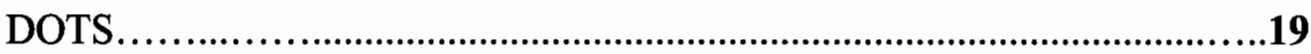

CHAPTER 4: QUANTUM DOTS SPUN ONTO SILICON ..............................32

CHAPTER 5: MICROFLUIDIC CHANNELS....................................47

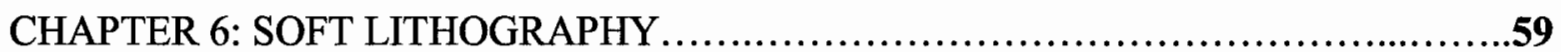

CHAPTER 7: CADMIUM SELENIUM ZINC SULFIDE CORE SHELL QUANTUM

DOTS SUSPENDED IN TOLUENE DISPERSED INTO MICROFLUIDIC

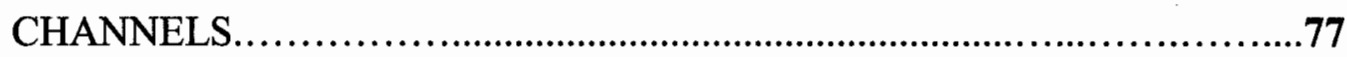

CHAPTER 8: CADMIUM SELENIUM ZINC SULFIDE CORE SHELL QUANTUM

DOTS SUSPENDED IN WATER...............................................................81

CHAPTER 9: SOLAR CELL WITH PDMS AND QUANTUM DOTS SUSPENDED IN

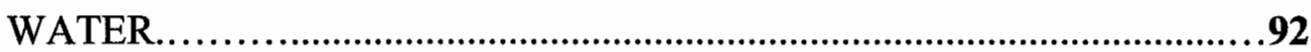

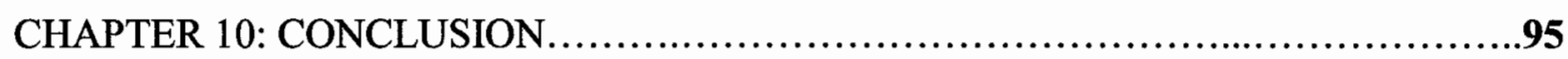

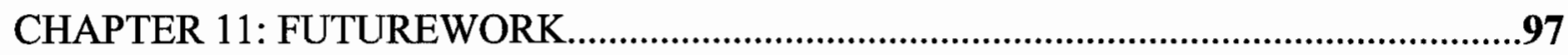

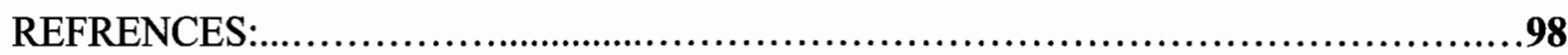

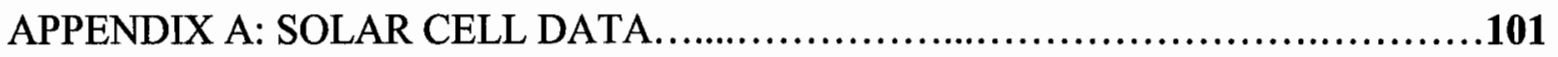


APPENDIX B: CROSS-SECTION DATA OF CADMIUM SELENIUM ZINC SULFIDE CORE SHELL QUANTUM DOTS USING ATOMIC FORCE

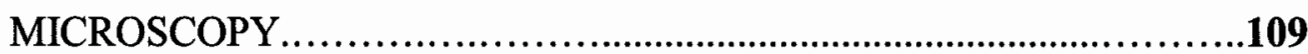

APPENDIX C: IMPORTANT CALCULATIONS.....................................117

APPENDIX D: PHOTORESIST THICKNESS VERSUS SPIN SPEED (2050)...............124

APPENDIX E: LITHOGRAPHIC MASKS..................................................125

APPENDIX F: PDMS SUBSTRATE FILLED WITH CADMIUM SELENIUM ZINC

SULFIDE CORE SHELL QUANTUM DOTS..............................................130 


\section{List of Tables}

Table 1 - AFM Height Measurements of Single Cadmium Selenium Zinc Sulfide Core

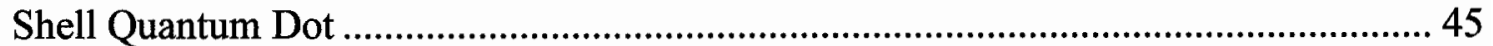

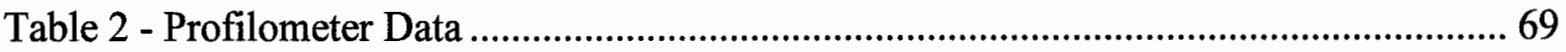




\section{List of Figures}

Figure 1-Tilt and Orbit of the Earth.................................................................................. 2

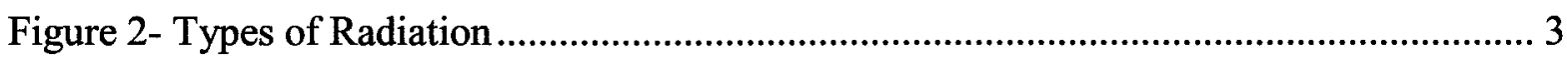

Figure 3 - Electromagnetic Spectrum .............................................................................. 3

Figure 4- Plank's Blackbody Radiation Spectra for Varying Temperatures [4] ..................... 4

Figure 5- Current Production in a Silicon-based Photovoltaic Cell ........................................... 8

Figure 6 -Light Interacting with Semiconductor Material.................................................... 8

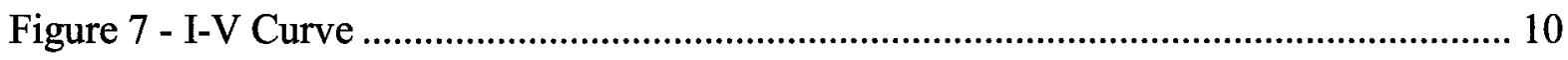

Figure 8 - Power vs. Voltage ........................................................................................... 11

Figure 9 - Set-up Used to Measure I-V Characteristics of Solar Cell with Black Box .......... 13

Figure 10 - Set up Used to Create I-V Curve .................................................................... 14

Figure 11 - Set-up Used to Measure I-V Characteristics of the Solar Cell ............................. 15

Figure 12 - Light Meter .......................................................................................... 16

Figure 13 - Power Vs. Voltage for a Photovoltaic Cell ..................................................... 17

Figure 14 - I-V Curve for Silicon Solar Cell ..................................................................... 18

Figure 15 - 3D Basic View of Quantum Dot ...................................................................... 19

Figure 16 - Photoluminescence From a Semiconductor Quantum Dot ................................... 21

Figure 17 - Quantum Dot exposed to Ultraviolet Light ........................................................ 22

Figure 18 - EviDot Absorption Spectra [13] …………................................................ 23

Figure 19 - Spectroscopy Set-up Used to Measure Transmittance and Absorption............... 25

Figure 20 - Neutral Density Filters ................................................................................. 26

Figure 21 - Light Intensity of Deuterium Light Source and Halogen Light Source................ 26

Figure 22 - Block Diagram for Measuring Transmittance ................................................... 27 
Figure 23 - Transmittance of light- No Cuvette, With a Cuvette and with Quantum Dots

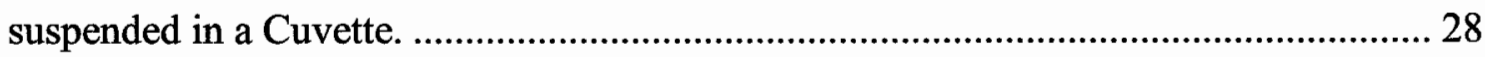

Figure 24 - Block Diagram for Measuring Florescence ..................................................... 29

Figure 25 - Florescence of CdSe/ZnS Quantum Dots ............................................................. 30

Figure 26 - Florescence of CdSe/ZnS Quantum Dots with Added UV Exposure................... 31

Figure 27 - Silicon Wafer with Piece of Silicon Adhered on Top Each With a Thickness of 0.1 in 33

Figure 28 - Basic Drawing of SEM Operation .................................................................. 35

Figure 29 - Cal Poly's Scanning Electron Microscope............................................................. 35

Figure 30 - Sample Prepared for SEM.............................................................................. 36

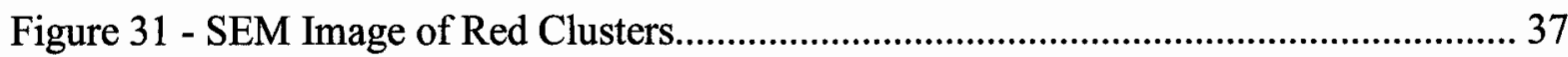

Figure 32 - SEM Image of a Single Cluster of Red Crust ...................................................... 38

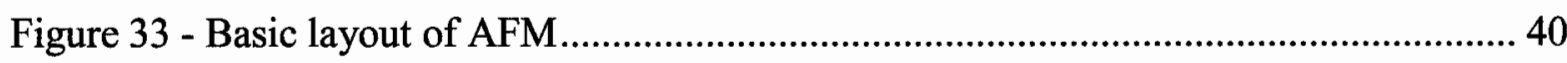

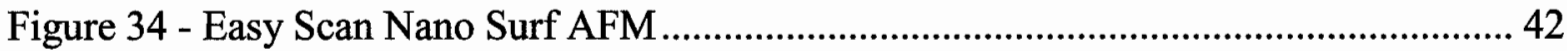

Figure 35 - Cal Poly's Atomic Force Microscope Made by Asylum ....................................... 43

Figure 36 - 4.8um x4.8um Scan of Silicon Substrate with CdSe/ZnS Quantum Dots ........... 45

Figure 37 - 1.8um x 1.8um Scan of Silicon Substrate with CdSe/ZnS Quantum Dots.......... 46

Figure 38 - 410nm x 410nm Scan of Silicon Substrate with CdSe/ZnS Quantum Dots ........ 46

Figure 39 - PDMS on Quartz Disk .................................................................................... 48

Figure 40 - Transmittance Percentage of Light Through PDMS............................................ 49

Figure 41 - Block Diagram of Michelson Interferometer.......................................................52

Figure 42 - Output of Michelson Interferometer ............................................................. 53

Figure 43 - Michelson Interferometer Top View.................................................................. 54 


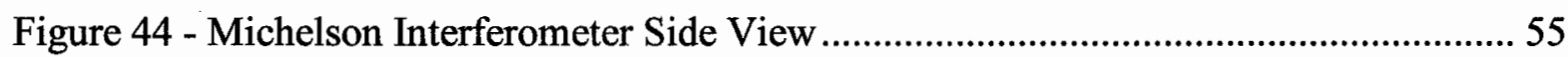

Figure 45 - Rudolph Research J57 Digital Refractometer.................................................. 56

Figure 46 - Diagram of Reflections and Transmission Between Materials.............................. 58

Figure 47 - Microfluidic Channels Filled with CdSe/ZnS Quantum Dots Placed on Top of

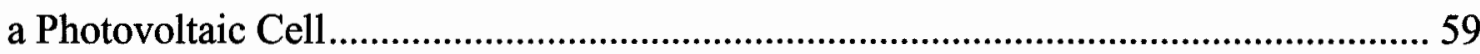

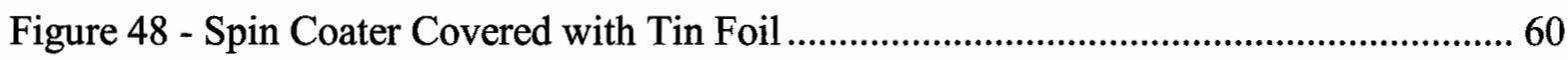

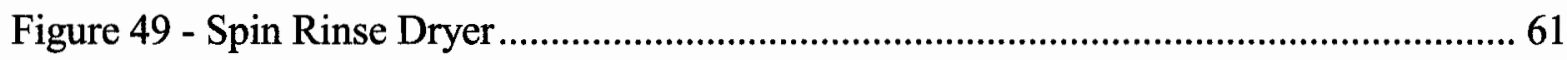

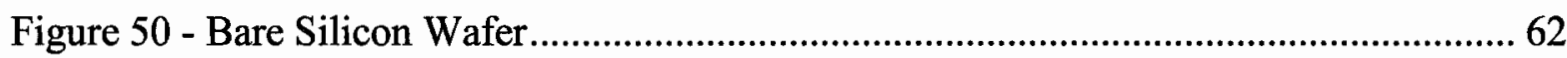

Figure 51 - Silicon Wafer with SU-8 Photoresist Applied ...................................................... 63

Figure 52 - Aligner Used to Expose the Negative Photoresist to Ultraviolet Light ............... 64

Figure 53 - Ultraviolet Light Exposure to SU-8 ………….................................................. 65

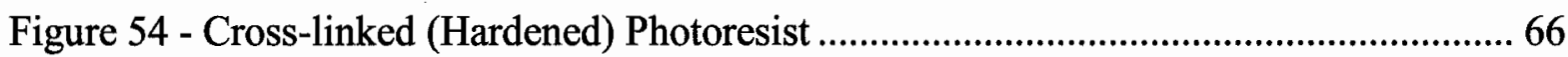

Figure 55 - Imprint Used to Create Microfluidic Channels...................................................67

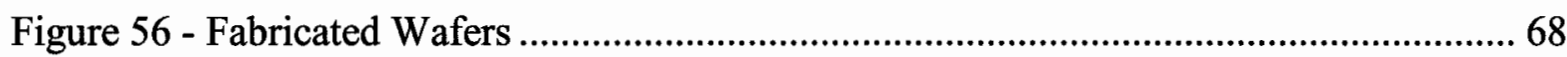

Figure 57 - Profilometer Height Measurement.................................................................... 69

Figure 58 - PDMS Degassing in Vacuum Chamber.......................................................... 70

Figure 59 - Solidified PDMS on Top of Silicon Wafer Mold ……....................................... 71

Figure 60 - Molded PDMS Placed on Top of Plane PDMS After Plasma Treatment........... 72

Figure 61 - Plasma Gun Used to Treat PDMS .................................................................... 72

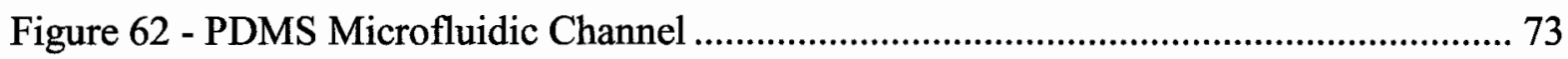

Figure 63 - Broken Microfluidic Channel ......................................................................... 75

Figure 64 - Torn Microfluidic Channel ............................................................................. 75 
Figure 65 - Microscope Image of CdSe/ZnS Quantum Dots Suspended in toluene in PDMS

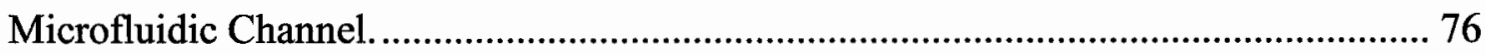

Figure 66 - CdSe/ZnS Quantum Dots Suspended in Toluene Solution Dispersed in

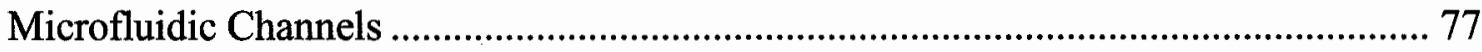

Figure 67 - Microfluidic Channel With no Toluene .............................................................. 78

Figure 68 - Microfluidic Channel with Toluene for 20 Seconds........................................... 79

Figure 69 - Closed Microfluidic Channel With Toluene for 2 Minutes ................................. 79

Figure 70 - Florescence of Quantum Dots Suspended in Water Using a Deuterium Light

Source 82

Figure 71 - Florescence of Quantum Dots Suspended in Water Using a Halogen Light

Source 83

Figure 72 - Florescence of Quantum Dots Suspended in Water Using a Deuterium and

Halogen Light Source 83

Figure 73 - Light Intensity of Deuterium Light Source and Halogen Light Source................ 85

Figure 74 - Raw Counts of Light Through Empty 1000uL Sample Holder ........................... 86

Figure 75 - Raw Counts of Light Through Water in 1000uL Sample Holder......................... 86

Figure 76 - Raw Counts of Light Through Quantum Dots suspended in water in 1000uL

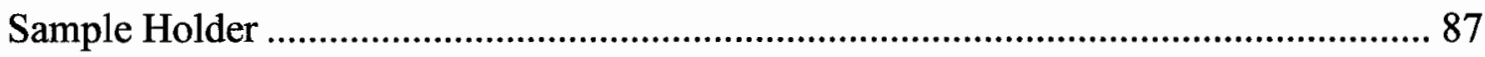

Figure 77 - Transmission of Light Using Deuterium and Halogen Light Sources.................. 88

Figure 78 - Channel Prior to Being Filled With Quantum Dots Suspended in Water............ 89

Figure 79 - Channel Being Filled With Quantum Dots Suspended in Water.......................... 90

Figure 80 - Channel Filled With Quantum Dots Suspended in Water .................................... 90 
Figure 81 - CdSe/ZnS Quantum Dots Suspended in Water Dispersed in Microfluidic

Figure 82 - Power Vs. Voltage Plot ....................................................................... 93

Figure 83 - I-V Curve of Solar Cell With PDMS Filled With CdSe/ZnS Quantum Dots

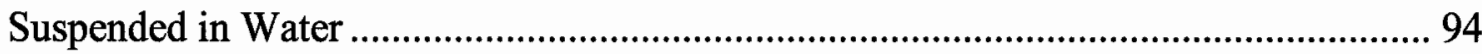

Figure 84 - Top View of First Mask Designed. The Numbers Below Each Channel are the

Line Width Associated With That Channel..................................................... 125

Figure 85 - Top View, Side View and 3-Dimention View of First Mask Drawn in Auto

CAD.

Figure 86 - Top View, Side View and 3-Dimention View of Mask 2 Drawn in Auto

CAD

Figure 87 - Dimensions of Each Microfluidic Channel on Mask 2..

Figure 88 - Number of Lines In Each Set of Channels and the Spacing Between Each

Line 


\section{List of Equations}

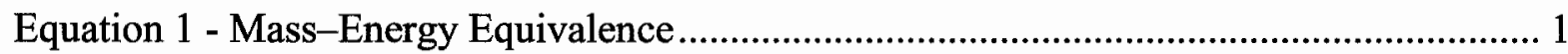

Equation 2 - Energy of a Photon Wavelength ...................................................................... 4

Equation 3 - Short Circuit Current................................................................................... 9

Equation 4 - Open Circuit Voltage .............................................................................. 10

Equation 5 - Maximum Power for a Photovoltaic Cell ........................................................ 11

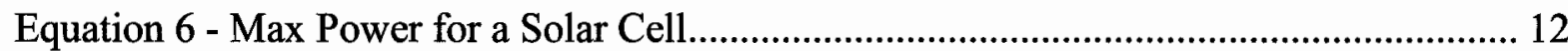

Equation 7 - Index of Refraction Calculation [24] .......................................................... 53

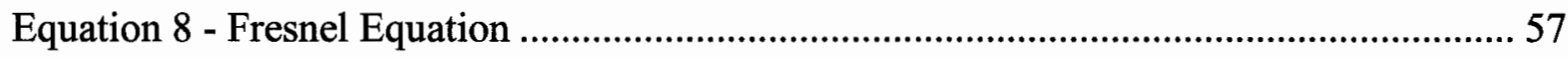

Equation 9 - Required $\mathrm{mL}$ of Base for Desired Thickness ...................................................... 70

Equation 10 - Required $\mathrm{mL}$ of Curing Age for Desired Thickness ..................................... 70

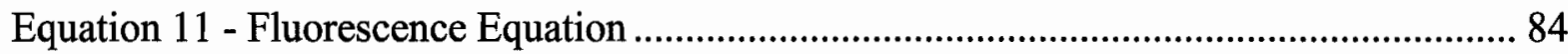



ABBREVIATIONS
h
$\mathrm{h}$ is planks constant $4.135 \times 10^{-15}$ (units: $\mathrm{eV}^{*} \mathrm{sec}$ )
v
$v$ is the frequency associated with a wave (units : $\mathrm{Hz}$ )
$\pi$
The symbol Pi which is equal to 3.14159 (units: none)
$\lambda \quad$ The wavelength of light (units: $\mathrm{nm}$ )
$\mathbf{\Omega}$ Ohm is the symbol used to describe resistance (units: Ohms)
c
The speed of light $3 \times 10^{8}$ (units: $\mathrm{m} / \mathrm{s}$ )
q The charge of an electron $1.602 \times 10^{-19}$ (units: Coulombs)
k Boltzmann's constant $1.381 \times 10^{-23}$ (units: $\mathrm{m}^{2} \mathrm{~kg} \mathrm{~s}^{-2} \mathrm{~K}^{-1}$ )
K Excitation coefficient (units: none)
$\alpha$
Absorption coefficient (units: $\mathrm{m}^{-1}$ )
n
index of refraction or refractive index (units: none) 


\section{CHAPTER 1 -INTRODUCTION}

\subsection{0 - The Sun and its Energy}

Since this project ultimately depends on the light that comes from the sun and hits the surface of the earth, it is important to have some background knowledge on how much light the sun produces as well as how it actually gets to the surface of the earth. Our sun is located at the center of our solar system and is made mostly of hydrogen. Hydrogen is converted to helium due to a very large thermonuclear reaction. This reaction causes mass to be converted into energy and follows the famous Einstein equation 1.

$$
\begin{gathered}
\mathrm{E}=\mathrm{mc} \mathrm{c}^{2} \\
\text { Equation 1- Mass-Energy Equivalence }
\end{gathered}
$$

This allows the sun to maintain a surface temperature of roughly $5800 \mathrm{~K}$ [1]. The energy is radiated in the form of light and heat in all directions and allows $800 \mathrm{Watts} / \mathrm{m}^{2}$ of light to hit the earth's surface.

The tilt of the earth affects the amount of light hours that are observed by the earth. There are more light hours during spring equinox than there are during the fall equinox and the angle at which the sun's rays hit the earth change as well. Some of the light energy is reflected off of the earth's atmosphere and only a portion is transmitted to the surface. This reflection of light decreases the intensity as well. 


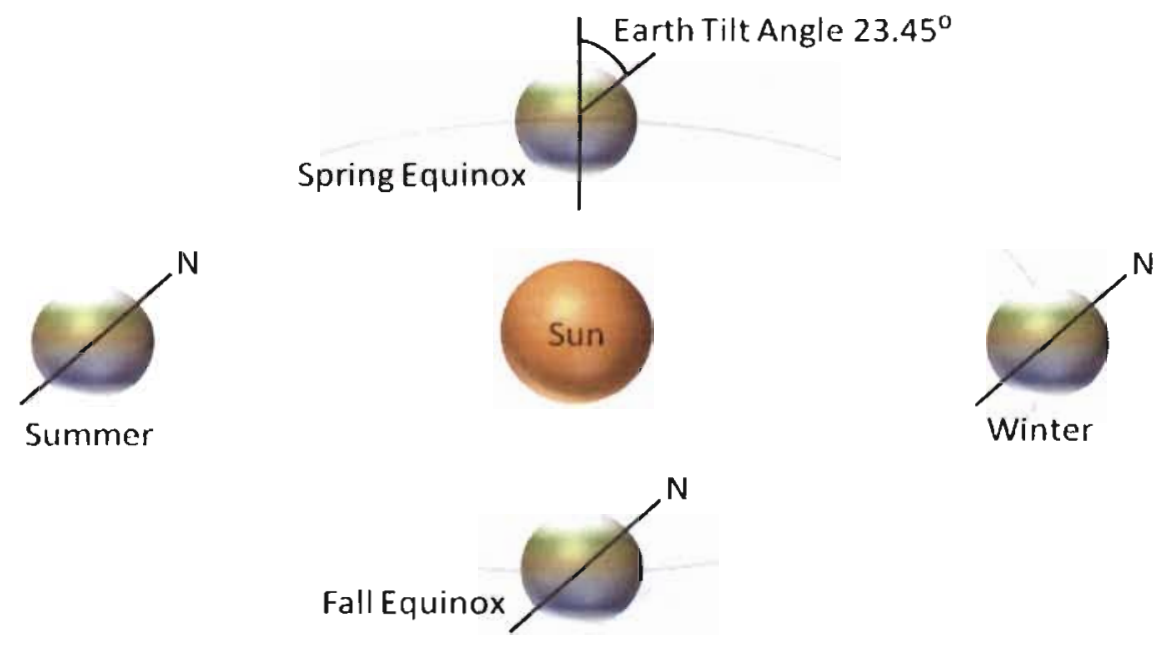

Figure 1-Tilt and Orbit of the Earth

There are 3 different mechanisms that influence the amount of light that strikes the surface of the earth as seen in figure 2. The first is direct radiation. This means that the light that passes through the earth's atmosphere travels directly to the surface of a photovoltaic cell with no disturbances. The second type is reflection radiation. Objects such as clouds interact with the incoming sunlight and cause the light to be reflected into different directions before it hits the surface of the earth. The final way is known as diffuse radiation. This occurs when incoming light interacts with particles in the air. The light will bounce off of these particles and eventually hit the surface of the earth. 


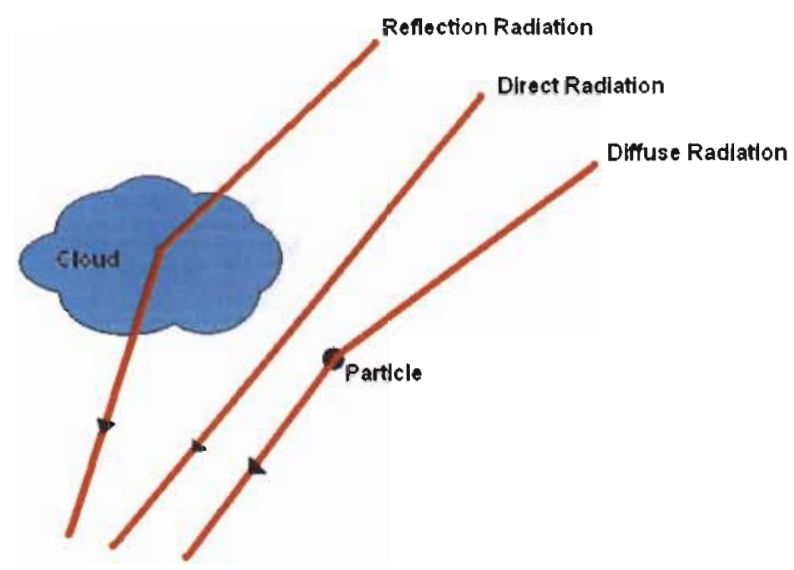

Figure 2- Types of Radiation

This information is important because a photovoltaic cell will operate differently depending on the time of day, month, weather conditions and location.

\subsection{1 - The Solar Spectrum}

The sun produces a wide range of electromagnetic radiation including visible light. The electromagnetic spectrum is broken up into categories according to the wavelength of light and its energy.

\begin{tabular}{c|c|c|c|c|c|c|} 
Radio Waves & Microwaves & Infrared & Visible Light & Ultraviolet & X-Rays & Gamma Rays \\
\hline$\lambda=1 \mathrm{~m}$ & $\lambda=1 \mathrm{~mm}$ & $\lambda=700 \mathrm{~nm}$ & $\lambda=400 \mathrm{~nm}$ & $\lambda=10 \mathrm{~nm}$ & $\lambda=.01 \mathrm{~nm}$ & $\lambda=10 \mathrm{pm}$ \\
to & to & to & to & to & to & to \\
$100,000 \mathrm{~km}$ & $1 \mathrm{~m}$ & $1 \mathrm{~mm}$ & $700 \mathrm{~nm}$ & $400 \mathrm{~nm}$ & $10 \mathrm{~nm}$ & $.01 \mathrm{~nm}$
\end{tabular}

Figure 3 - Electromagnetic Spectrum

Ultraviolet light is between the wavelength range of $\lambda=10 \mathrm{~nm}$ to $400 \mathrm{~nm}$ [2], visible light is between the wavelength range of $\lambda=400 \mathrm{~nm}$ to $700 \mathrm{~nm}$ and infrared light is between the wavelength range of $750 \mathrm{~nm}$ to $1 \mathrm{~mm}$ [3], to name a few which can be seen in figure 3 . Although these wavelengths of light all hit the earth's surface, the intensities associated with 
them are different. There is a higher intensity of visible light that hits the earth's surface than any of the other wavelengths. The intensity of light is not always a constant value; they depend on the surface orientation and the amount transmitted through the earth's atmosphere. The temperature on the outer portion of the sun determines the amount of intensity that is emitted by the sun. According to Plank's black body radiation, the relationship to temperature strongly influences the amount of electromagnetic energy that is received by the earth and varies as shown in figure 3 . The temperature of the surface of the sun is approximately constant at $5800 \mathrm{~K}$.

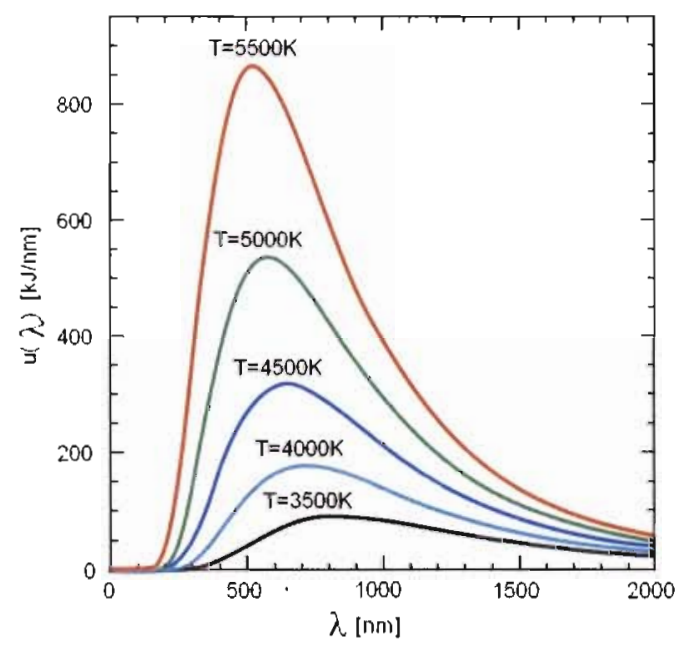

Figure 4- Plank's Blackbody Radiation Spectra for Varying Temperatures [4]

The wavelength of light striking the earth's surface is important to photovoltaic cells because there is a specific energy associated to each wavelength. Shorter wavelengths of light have a higher energy associated with them according to equation 1.

$$
E=\frac{h c}{\lambda}
$$


Photovoltaic cells produce current when the energy of the incident radiation matches the band-gap of the semiconductor, which can vary greatly depending on the doping and bulk element choices. Wavelengths that have less or more energy than the band-gap of a photovoltaic cell are not efficiently converted to useable electrons and will be explained in more detail in chapter 2. Additionally, the higher the intensity of light that hits the photovoltaic cell, the more current is produced. 


\section{CHAPTER 2 - PHOTOVOLTAIC CELL}

\subsection{0 - Photovoltaic Cells}

In order to harness the energy the sun emits, a photovoltaic cell, or solar cell, is used. This section will focus on basic background information to help understand how a photovoltaic cell works. This information is important because this project revolves around increasing the efficiency of a single crystalline silicon photovoltaic cell. Photovoltaic cells, also known as solar cells, are semiconductor devices that convert sunlight into electric current. Photovoltaic cells can be traced back to 1839, when Alexandre-Edmond Becquerel discovered that photo voltage resulted when light encountered an electrode that was immersed in an electrolyte solution [5]. This phenomenon is now used to create current flow in photovoltaic cells. As stated earlier, the majority of photovoltaic cells produced today are made of silicon because silicon is inexpensive compared to other semiconductor materials [6]. When light strikes a silicon crystal it can be reflected, transmitted or absorbed.

Light at low energy levels is transmitted; there is not enough energy associated with the photon to excite an electron from the valance band into the conduction band [7]. If the energy of the photon is too high then the photon will be absorbed by the material and the electron and hole will not be able to travel to the electrodes and produce current. Therefore, light must have energy equal to or slightly greater than the band gap of the semiconductor material to cause an electron to be excited from the valance band into the conduction band. When that happens, the light is absorbed. The size of the band gap is determined by how tightly the valence electrons are bound to the host atoms. Once an electron travels from the valence band into the conduction band, a vacancy is produced. The vacant area in the valance band or "hole" can move within the material if a neighboring electron takes its place. 
It is this interaction between electrons and holes that create current. The most popular way to increase the flow of current in a semiconductor material is to apply a dopant or impurity into the material. This will cause the band-gap to decrease and therefore require less energy to create electron hole pairs. Applying this impurity creates either an n-type material or a ptype material. An n-type material means that there is a higher concentration of electrons in the material due to the dopant. With a p-type material, there is a higher concentration of holes in the material due to the dopant. When the n-type material is in contact with a p-type material, a PN-Junction is created. The impurities in the PN-Junction cause more current to be produced than would be produced in the bulk semiconductor material. The reason that more current is produced is that doping creates energy levels near the conduction band (ntype) or the valence band (p-type).

A photovoltaic cell absorbs the sun's light and the energy of the incoming light excites an electron from the valence band into the conduction band. It is this light that produces current in the photovoltaic cell. The energy required to create the flow of electrons in a single crystalline silicon photovoltaic cell is $1.1 \mathrm{eV}$. Depending on the wavelength of light that encounters the solar cell, some of the light that is closest to the band gap of the material will be converted into current. Higher energy photons of light are absorbed near the crystal surface and are lost by recombination in the surface region [8]. 


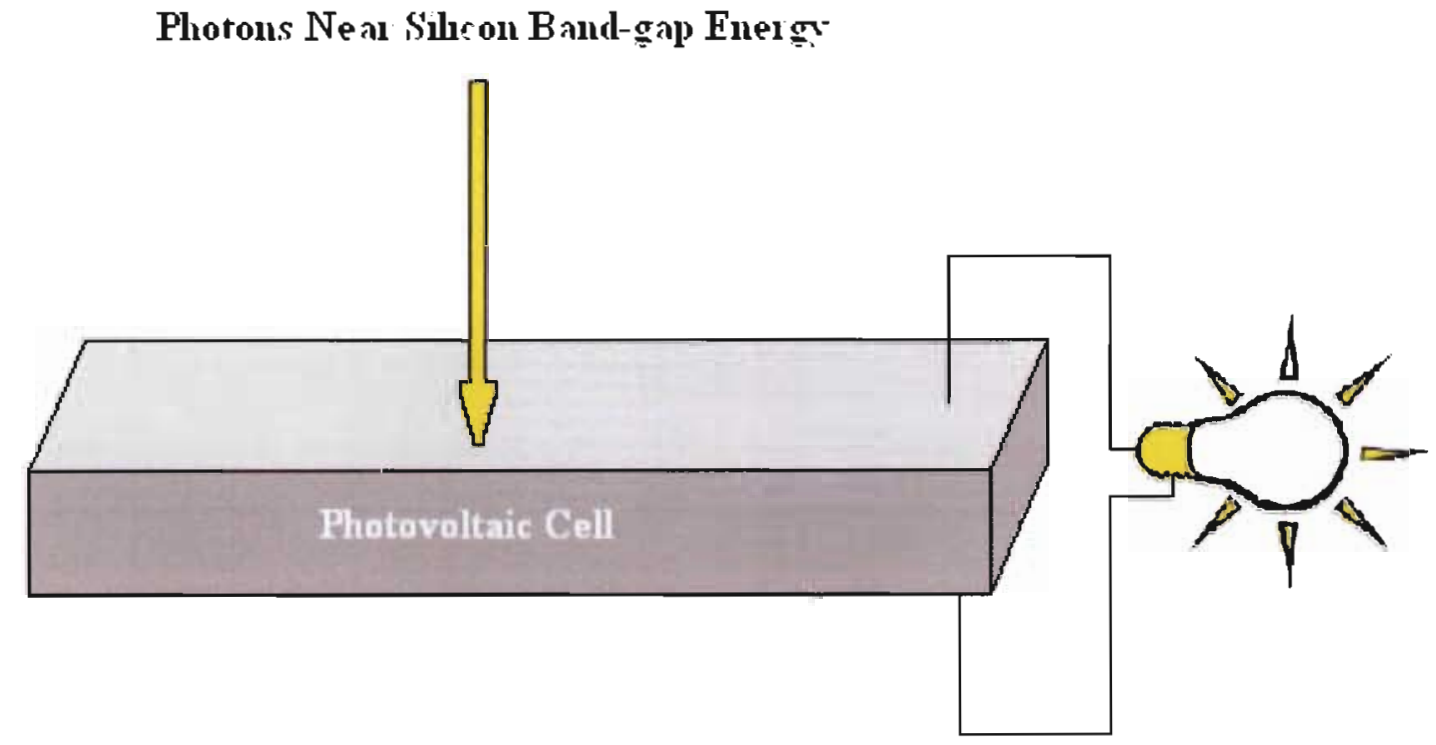

Figure 5- Current Production in a Silicon-based Photovoltaic Cell

Not all of the light that encounters a photovoltaic cell with energy close to the band-gap of the material is converted into electric current; there are also reflections that occur on the photovoltaic cell's surface. An untreated photovoltaic cell, a cell with no anti-reflective coating, reflects more than $30 \%$ of incident light off of the surface of a photovoltaic cell [9].
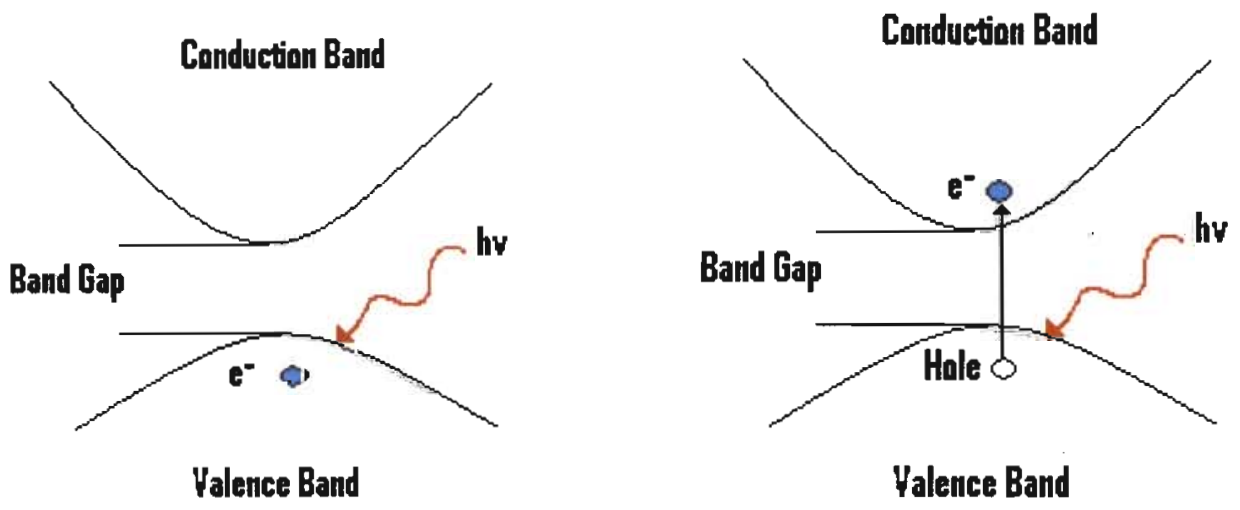

Figure 6 -Light Interacting with Semiconductor Material 
In order to minimize these reflections, an anti-reflective coating is placed on the surface of the photovoltaic cell. The type of anti-reflective coating used for a photovoltaic cell will vary depending on the material that comprises the photovoltaic cell. Although this minimizes the amount of inefficiency associated with a photovoltaic cell, there are other factors that affect the photovoltaic cell's efficiency. Imperfections in the solar cell crystal structure, such as impurities (other than the dopant) in the material, will cause less current in the photovoltaic cell. It is important to use very pure semiconductor material in order to improve the flow of electrons through the solar cell.

A solar cell produces current based on the intensity of light that hits its surface; if the intensity of light decreases, the current produced by the solar cell decreases as well. Since a diode has a current that will be lost internally, the total current that can be produced and sent to a load is seen below:

$$
I_{s c}=l_{l}=I_{o}\left(\mathrm{e}^{\frac{q V}{k T}}-1\right)
$$

Equation 3 - Short Circuit Current

Equation 3 represents the short circuit current produced by a photovoltaic cell where $q$ is the charge of an electron, $\mathrm{V}$ is voltage, $\mathrm{k}$ is Boltzmann's constant and $\mathrm{T}$ is temperature at ${ }^{\circ} \mathrm{K}$. A photovoltaic cell's output current is dependent on voltage and temperature; the temperature increases, the maximum power produced by the cell decreases. Equation 3 can be rearranged to represent the open circuit voltage as seen below: 


$$
V_{O C}=\frac{k T \ln \left(\frac{l+I_{O}}{I_{O}}\right)}{q}
$$

Equation 4 - Open Circuit Voltage

Unfortunately, the maximum power is not a simple multiplication of $\mathrm{V}_{\mathrm{oc}}$ and $\mathrm{I}_{\mathrm{sc}}$. The reason for this is that the voltage at Isc is 0 and the current at Voc is 0 . Having these zero values disagrees with the basic power equation which is $\mathrm{P}=\mathrm{IV}$. Fortunately, there is a way to find the maximum power using these equations. In order to find the maximum power associated with a solar cell, an I-V curve must be created. The voltage and current that is observed in figure 7 are produced by the photovoltaic cell. There is no external source connected to the circuit.

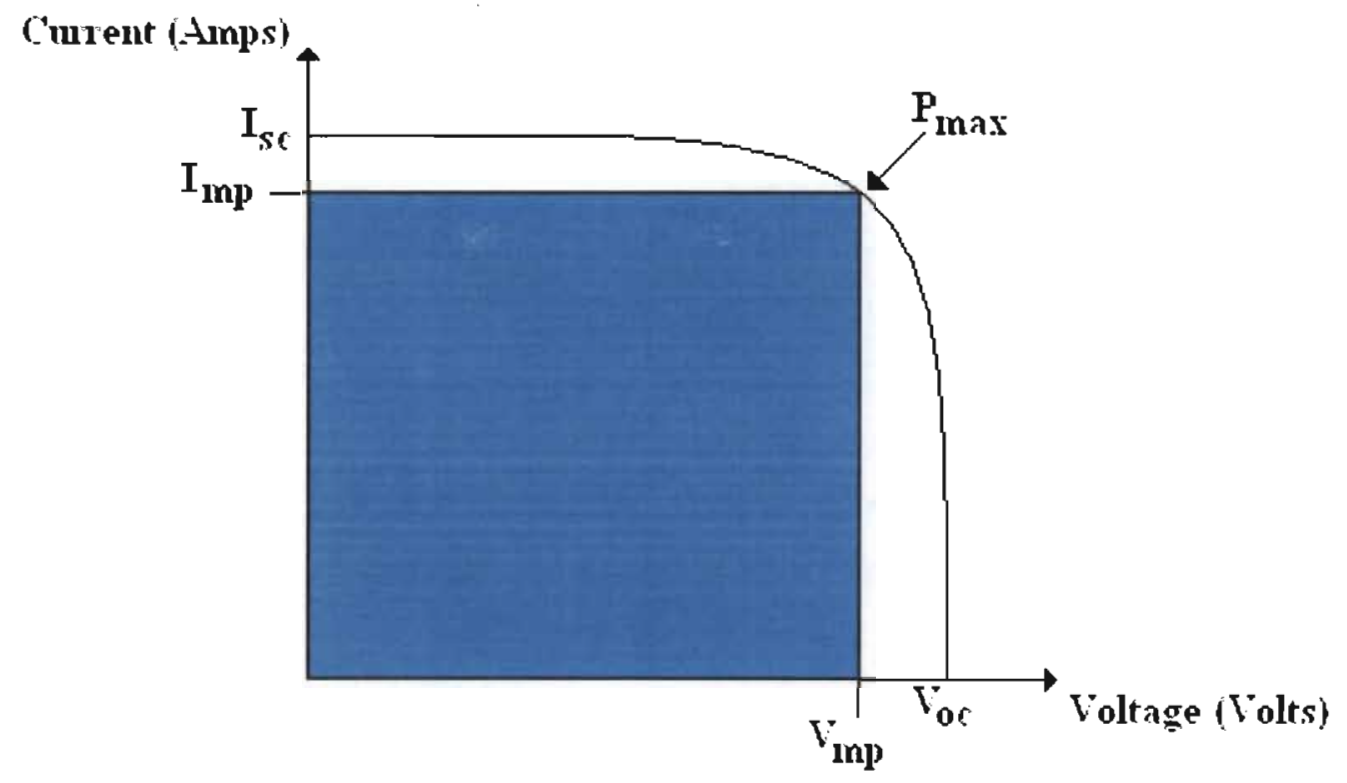

Figure 7 - I-V Curve

With an I-V curve the maximum power current $\left(I_{m P}\right)$ and maximum power voltage $\left(\mathrm{V}_{\mathrm{mP}}\right)$ are located where the power is at its maximum, and these values are produced by the 
solar cell. Multiplying these values will result in the maximum power that the photovoltaic cell can produce.

$$
P \max =\operatorname{Imp}(V m p)
$$

Equation 5 - Maximum Power for a Photovoltaic Cell

An alternative way of finding the maximum power is to plot power vs. voltage. This plot is useful because it easily finds the maximum power and $\mathrm{V}_{\mathrm{mP}}$. The point at which the plot peaks is where these values can be obtained.

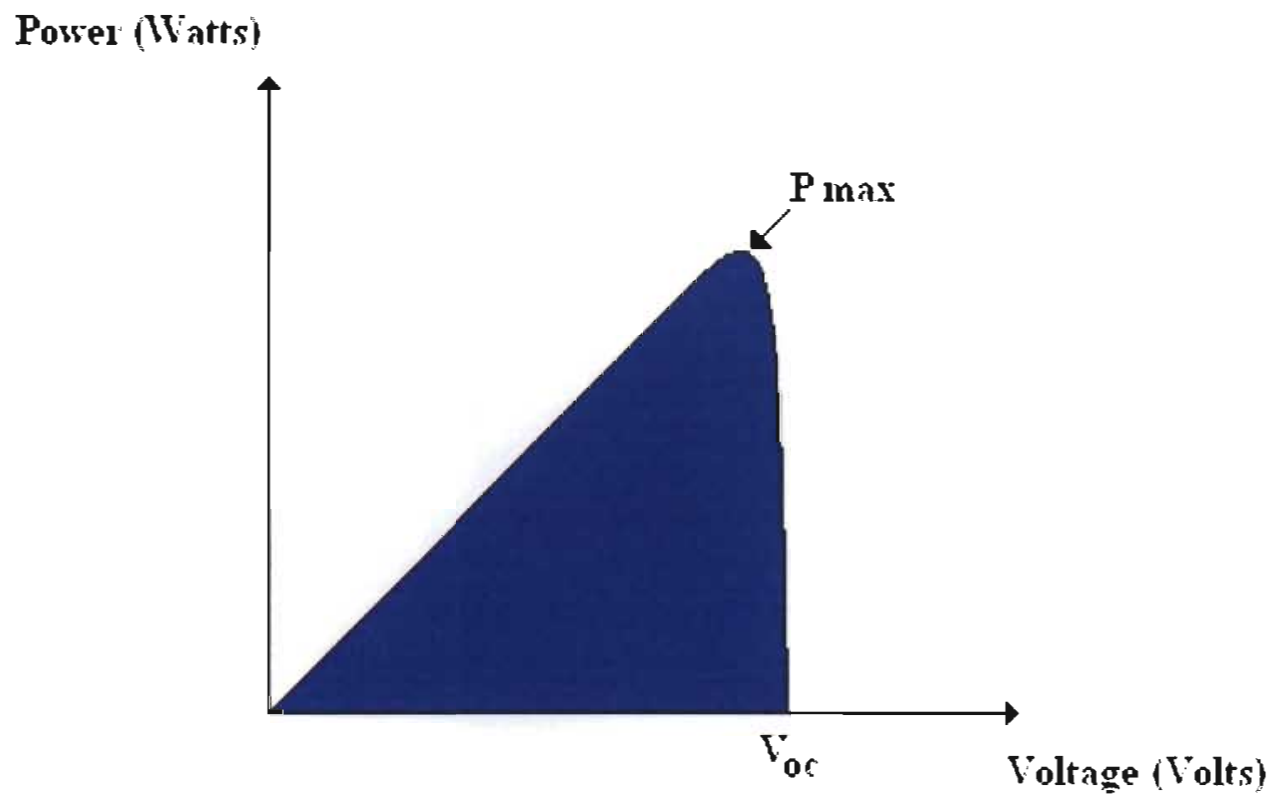

Figure 8 - Power vs. Voltage

This plot simplifies the work in finding $V_{m p}$ of the solar cell and is also a way to check the values obtained from the I-V curve.

Finding these values was important because they characterized the single crystalline silicon solar cell being used. The goal of this research was to increase the maximum power of a solar cell. Down converting high energy photons to lower energy photons near the band 
gap of silicon would increase the amount of current produced by a solar cell. Quantum dots were used to do this and having baseline values of the solar cell provided the ability to observe if there was an increase in the solar cell efficiency that occurred when quantum dots were placed onto the surface of the cell.

\subsection{0 - Photovoltaic Cell Characterization}

There are a wide range of available solar cells on the market today such as Gallium Arsenide (GaAs), Cadmium Telluride (CdTe) and Copper Indium Diselenide ( $\mathrm{CuInSe} 2)$, to name a few. This project used a single crystalline silicon solar cell because it is the most commonly used type of photovoltaic cell. The band-gap associated with this photovoltaic cell is $\mathrm{E}=1.12 \mathrm{eV}$. Characterization was necessary for this photovoltaic cell because it provided a set of baseline data to observe if there was any type of change in power output from the photovoltaic cell when quantum dots were implemented into the system. In order to understand the efficiency associated with this solar cell, an I-V curve was created and the maximum power or $\mathrm{P}_{\max }$ was calculated. This measurement provided an understanding of how much current the solar cell would produce at maximum power.

$$
P \max =F F \cdot I s c \cdot V o c=I m p \cdot V m p
$$

Equation 6 - Max Power for a Solar Cell

Equation 6 is used to calculate maximum power in a solar cell where FF is the fill factor, $\mathrm{I}_{\mathrm{SC}}$ is the short circuit current and $V_{O C}$ is the open circuit voltage. $I_{m p}$ is the current found at the maximum power and $\mathrm{V}_{\mathrm{mp}}$ is the maximum voltage found at max power. The fill factor is a measure of the quality of a photovoltaic cell. Photovoltaic cells with a large internal resistance will have a smaller fill factor. It was important to subject the photovoltaic cell to the same intensity of light during each measurement. Utilizing a 30-watt fiber optic 
illuminator with 3 different set light intensities controlled the amount of light that interacted with the solar cell during each measurement and allowed the reproduction of the experiment multiple times with the same parameters each time. The intensity of light was measured by a light meter which can be seen in figure 12. The lights on the ceiling of the room seemed to fluctuate a lot in intensity; to overcome this problem, a black box was placed on top of the solar cell to control the amount of light that interacted with the solar cell.

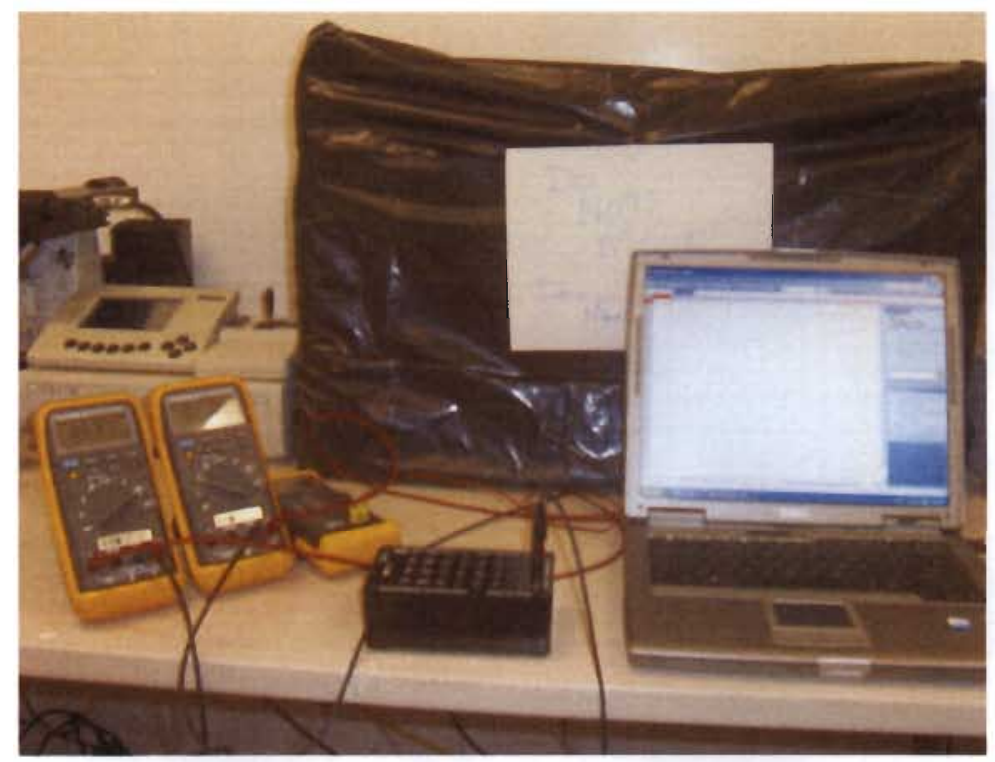

Figure 9 - Set-up Used to Measure I-V Characteristics of Solar Cell with Black Box

Although the black box blocked any type of outside light from interacting with the solar cell, the temperature inside the box raised from $74.5^{\circ} \mathrm{F}$ to $78.2^{\circ} \mathrm{F}$. It is important to note that a change in temperature such as this will slightly decrease the open circuit voltage that is produced in the solar cell. For the experiments any type of voltage that was sacrificed, due to change in temperature, would be negligible and merely be added to the noise of the system. 


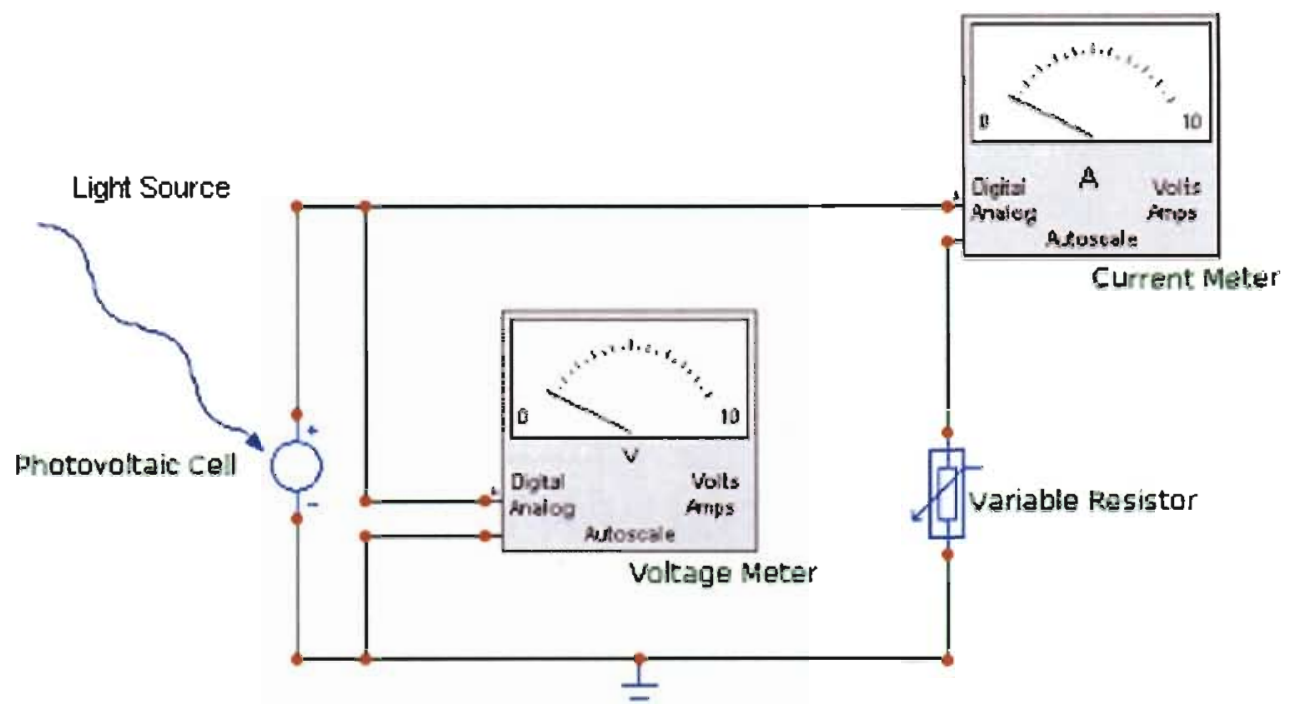

Figure 10 - Set up Used to Create I-V Curve

The first measurement taken was the open circuit voltage. In order to do this, light was directed onto the solar cell and a voltmeter directly connected to the solar cell which gave the DC voltage associated with the open circuit voltage. The short circuit current was then measured by connecting the meter directly to the solar cell and measuring the DCcurrent. These two points provided the maximum voltage and current that the solar cell would produce at a specific light intensity. The I-V curve $\mathrm{I}$ is displayed in figures 10 and 11 . 


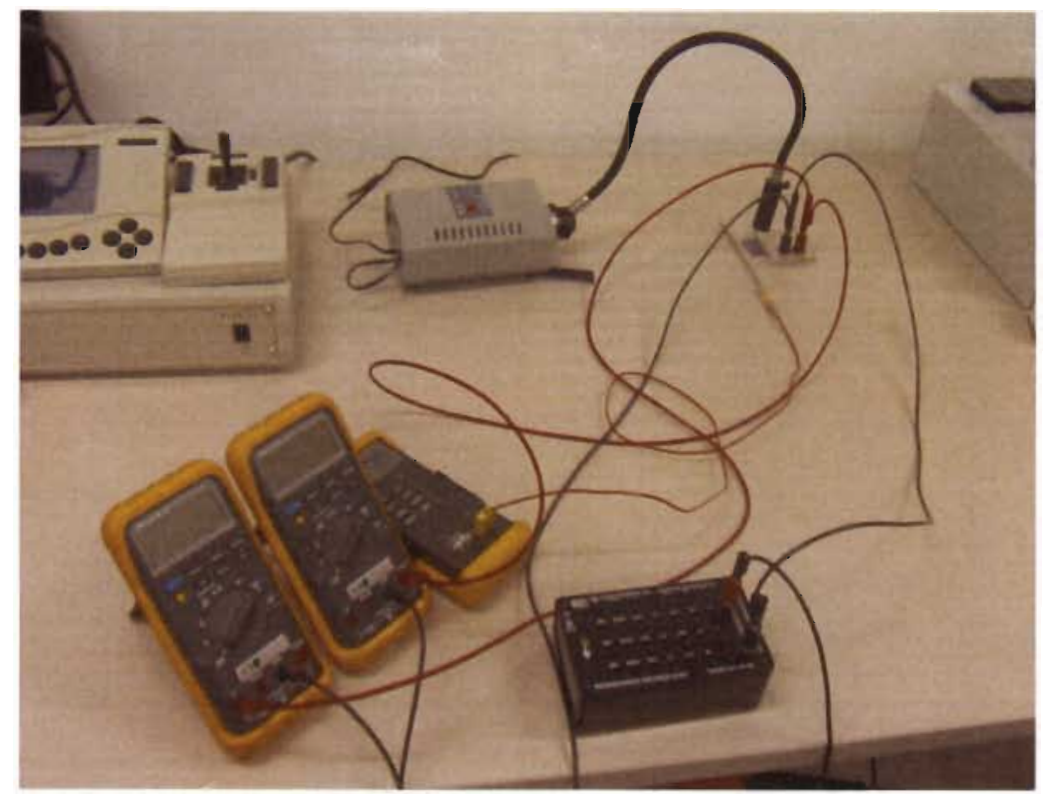

Figure 11 - Set-up Used to Measure I-V Characteristics of the Solar Cell

Keeping the light intensity constant, a load was applied to the circuit. The load was a variable resistor which was varied from $0 \Omega$ to $10 \Omega$.

In order to find the max power associated with the solar cell, power vs. voltage was plotted [10]. This plot found the $\mathrm{V}_{\mathrm{mp}}$ associated with the photovoltaic cell at the specific light intensity. An average of 10 separate measurements were taken which can be viewed in Appendix A, and an average value for each of the 12 points was calculated. The most important part of the circuit is the light source. If the light source fluctuated in light intensity drastically, the data gathered would be questionable. The light intensity of the light source was measured with a light meter, which can be seen in figure 12 . 


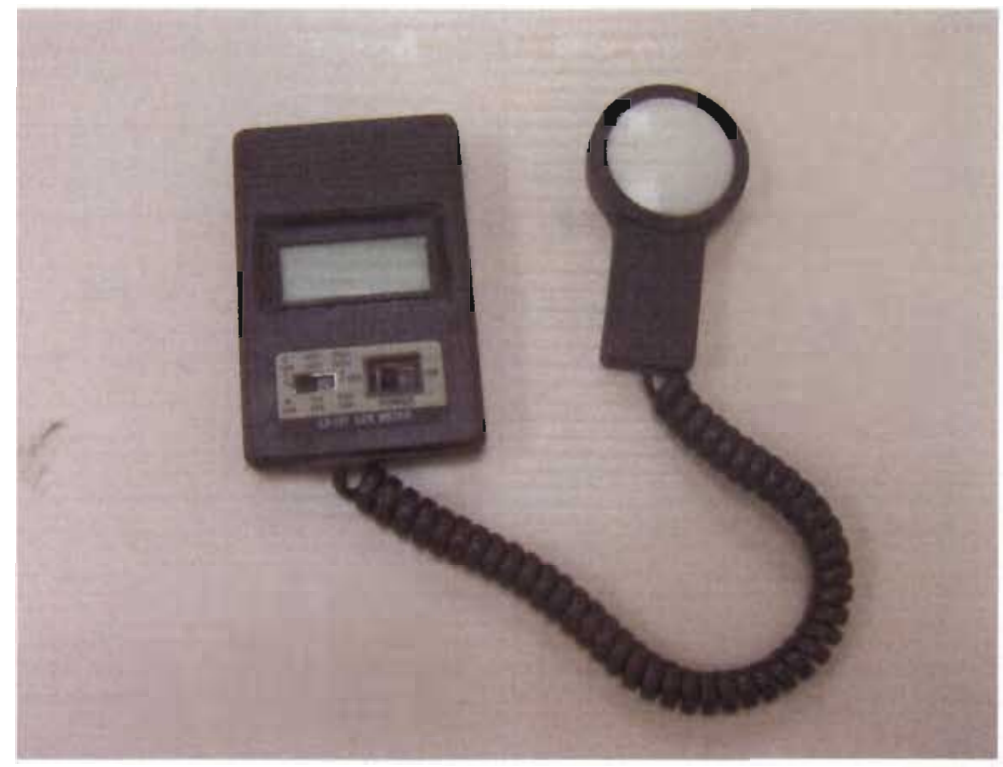

Figure 12 - Light Meter

The light meter output the light intensity in units of lux. Because a lux unit uses the fact that the human eye can detect 10 photons $/ \mathrm{sec}$ at a wavelength of $\lambda=555 \mathrm{~nm}$, the light meter measures the amount of photons at this wavelength. The way that a unit of lux relates to other light intensities is that a single unit of lux is equal to $11 \mathrm{umen} / \mathrm{m}^{2}$. A lumen is the photometric equivalent of the watt weighted to match the response of an eye. Finally, another way that lux can be related to light intensity measurements is that $1 \mathrm{~W} / \mathrm{cm}^{2}=$ $6.83 \times 10^{6} \mathrm{Lux}$ at $\lambda=555 \mathrm{~nm}$. As the intensity of light changes, so does the short circuit current produced by the solar cell. A decrease in short circuit current will decrease the maximum power that the solar cell can produce. Although the intensity of light affects the amount of current produced, the open circuit voltage remains the same. This is important because the amount of power that a solar cell can produce will affect the load that is connected to it. If a load requires 50 watts of power to operate and a solar cell's max power decreases from 60 watts to 40 watts, the load will be unable to operate. 


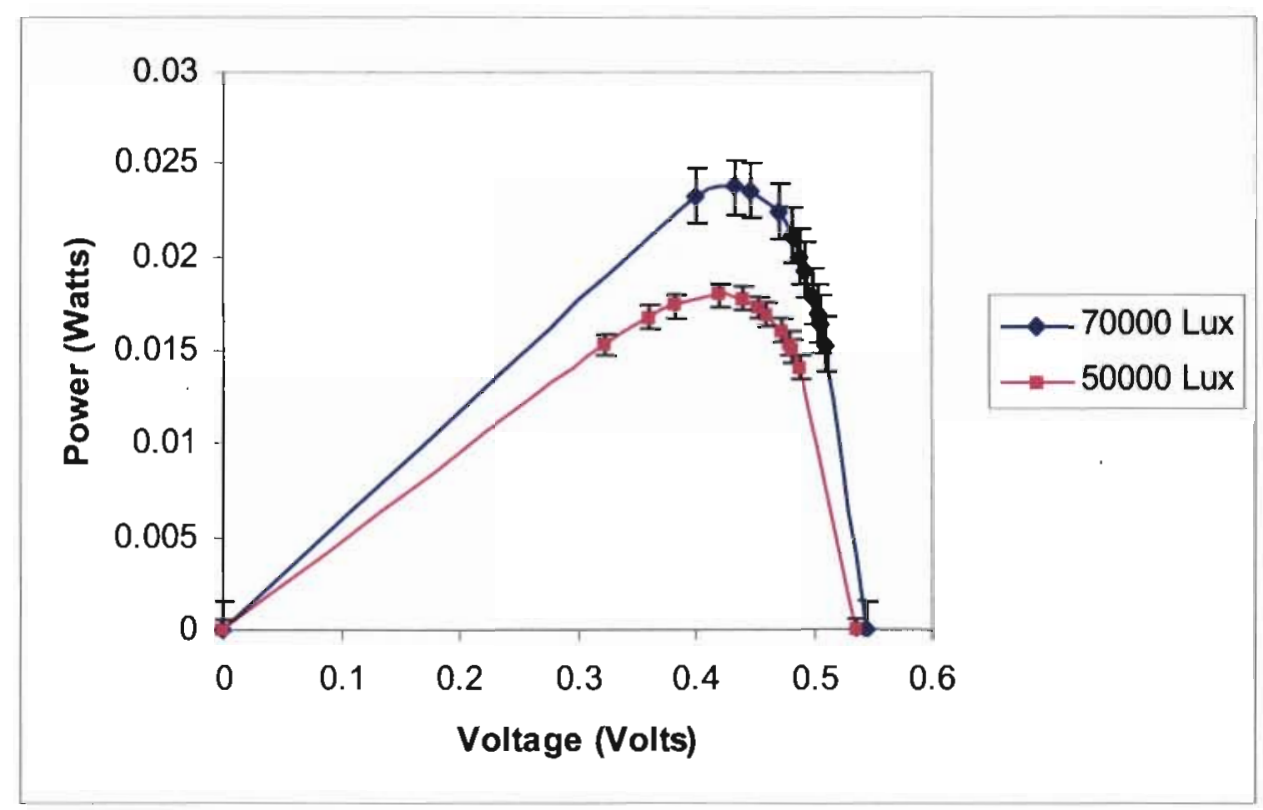

Figure 13 - Power Vs. Voltage for a Photovoltaic Cell.

In figure 13 , at an intensity of 70000 lux, the solar cell produced a $V_{m p}=0.447 \mathrm{~V}$ and at $50000 \operatorname{lux} \mathrm{V}_{\mathrm{mp}}=0.4395 \mathrm{~V}$.

Since a photovoltaic cell produces current when photons hit the surface, it is important to observe how the current changes in the solar cell as the intensity of light changes. The way that this is done is to plot Current vs. Voltage or an I-V curve. Just as in the Power vs. Voltage plot, an average of 10 separate measurements were taken for the 12 points to obtain the data for the I-V curve. Using the $V_{m p}$ value from the Power vs. Voltage plot, the $I_{m p}$ value associated with the solar cell on the I-V curve was determined. At 70000 Lux the $I_{m p}=52.7 \mathrm{~mA}$, and at 50000 Lux the $I_{m p}=40.28 \mathrm{~mA}$. This data provides a set of reference values. Any data obtained during the rest of the project will be compared to this data. In using this set up I could observe a change in power as low as 0.001 Watts. In order to observe a 0.001 Watt change in power the light intensity must increase by 3500 Lux or $512 \mu \mathrm{W} / \mathrm{cm}^{2}$. 


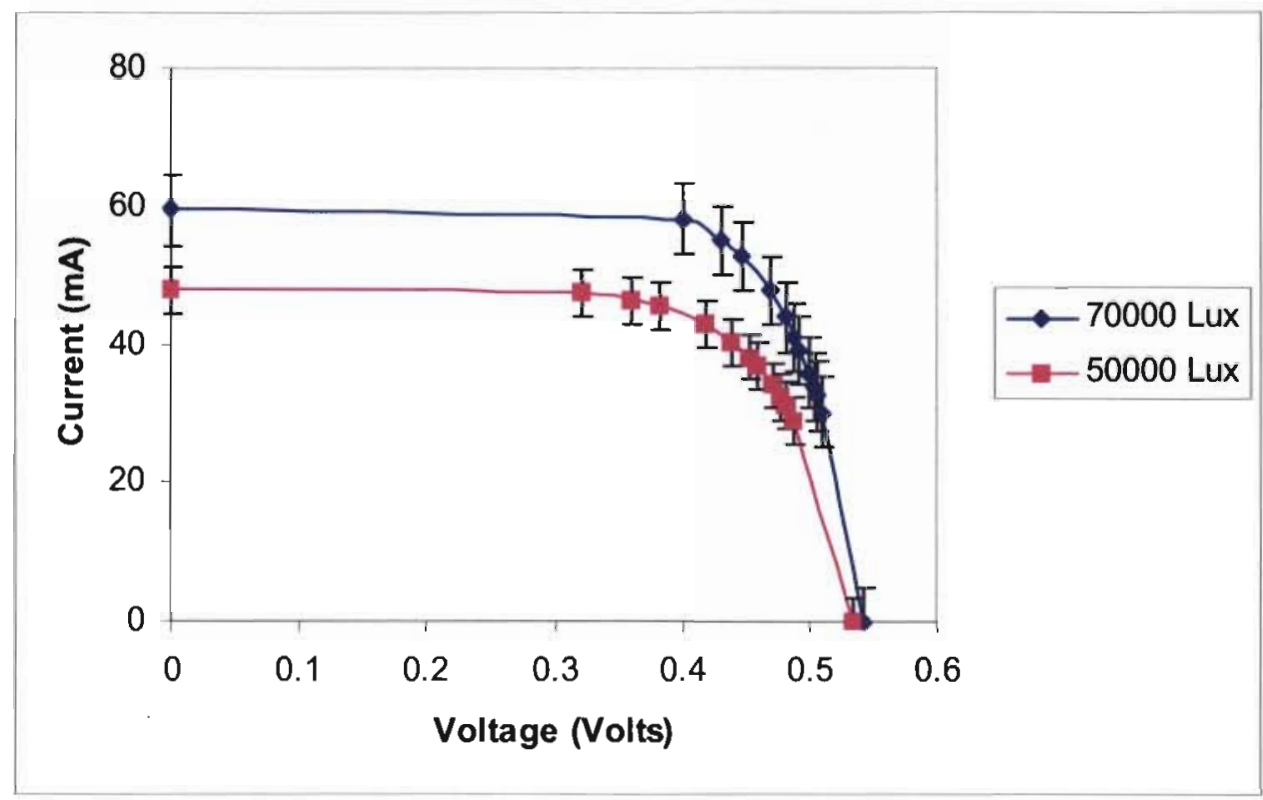

Figure 14 - I-V Curve for Silicon Solar Cell 


\section{CHAPTER 3 - CADMIUM SELENIUM ZINC SULFIDE CORE SHELL QUANTUM DOTS}

\subsection{0 - Basics of Quantum Dots}

The objective of this research is to use quantum dots to down convert high energy photons of light to lower energy photons of light close to the band gap of silicon. This will broaden the spectrum of light that a solar cell can use and increase the number of photons that interact with the photovoltaic cell. With a higher intensity of photons interacting with the photovoltaic cell, the production of electric current will be increased. This section will help explain why quantum dots fluoresce at a specific wavelength depending on their size and why this florescence is constant even though different energies of photons interact with them.

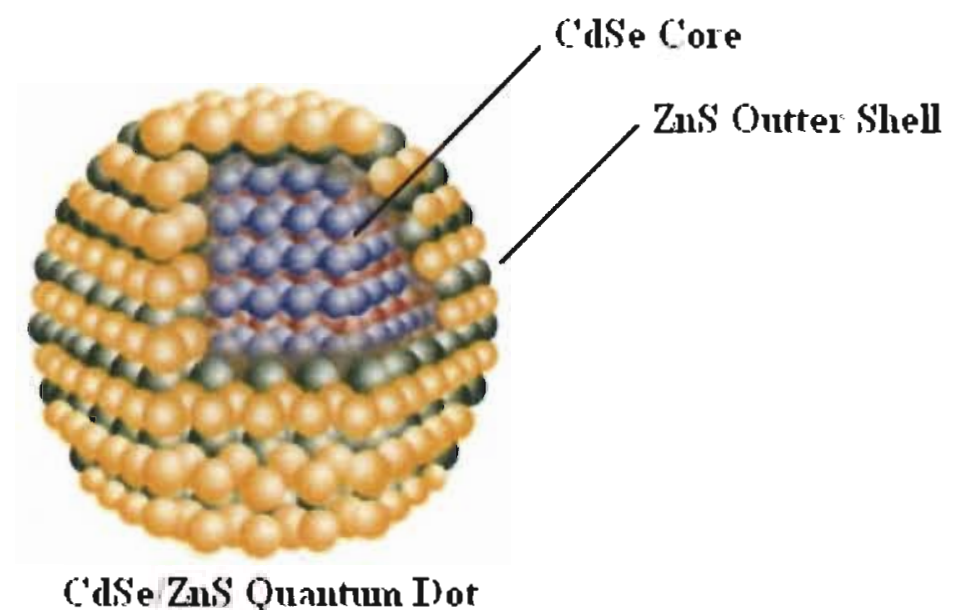

Figure 15 - 3D Basic View of Quantum Dot

Quantum dots, also known as a nanocrystal, are a cluster of tightly packed atoms. The quantum dots used in these experiments are characterized as II-VI semiconductor compounds and a single quantum dot can be as small as 2 to 10 nanometers in diameter. In a 
single quantum dot there can a volume of 100 to 100,000 atoms [11]. The size of the quantum dot will determine the size of the band-gap associated with it. The larger the quantum dot, the smaller the band-gap and the smaller the quantum dot the larger the bandgap. When light strikes a quantum dot with higher energy than its band-gap, it excites an electron that is in the valence band to travel into the conduction band. From here the electron will want to fall back into the valence band. In order for the electron to travel back into the valence band, it must lose energy. Emitting a photon of light that has energy equal to the band gap of the quantum dot will provide the electron sufficient energy loss to travel back into the valence band. The emission of a photon from the quantum dot causes fluorescence of light. Fluorescence occurs when a quantum dot returns to its ground state after being electrically excited [12]. The excess energy that the quantum dot does not use, if the photon is greater than the band-gap of the quantum dot, is converted into heat. Because no material is made up of pure elements, impurities will affect the energy that an electron must lose to travel back down from the conduction band to the valence band. Impurities will cause the electron to be held in a trapped state; the trapped state resides near the band edge of both the conduction band and the valence band. Since this trapped state is something to avoid the core of the quantum dot is coated with an outer shell of atoms. The outer shell of atoms must have a higher band-gap than the core atoms to allow for emission of light. 


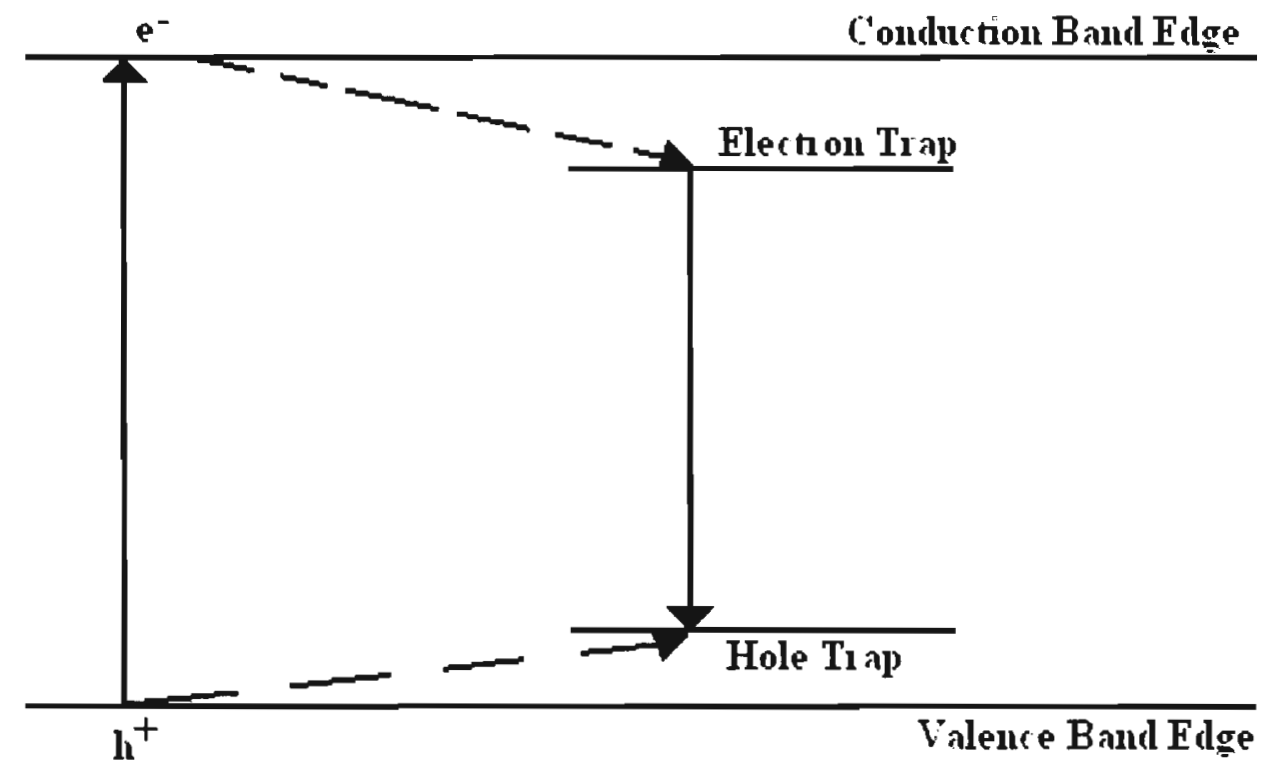

Figure 16 - Photoluminescence From a Semiconductor Quantum Dot

Since a quantum dot is so small, the energy levels available to the electrons can no longer be viewed as continuous but need to be treated as discrete energy levels. This is do to there being a small and finite separation between available energy levels. Due to its discrete energy levels, a quantum dot emits light at specific wavelengths. The wavelengths of light emitted by a quantum dot can be modified by geometrical size and shape of the quantum dot. The size of a quantum dot is inversely related to its band-gap. The larger the quantum dot, the smaller the band-gap energy. On the other hand, the smaller the quantum dot the larger the band-gap energy. The largest wavelength associated with a quantum dots florescence is in the infrared color spectrum and the smallest is blue. This effect might seem similar to a Light Emitting Diode (LED) but there is one major difference. With a quantum dot the bandgaps are easily tunable whereas the band-gap of an LED is not. It is therefore cheaper and easier to use quantum dots for emitting discrete wavelengths of light. 


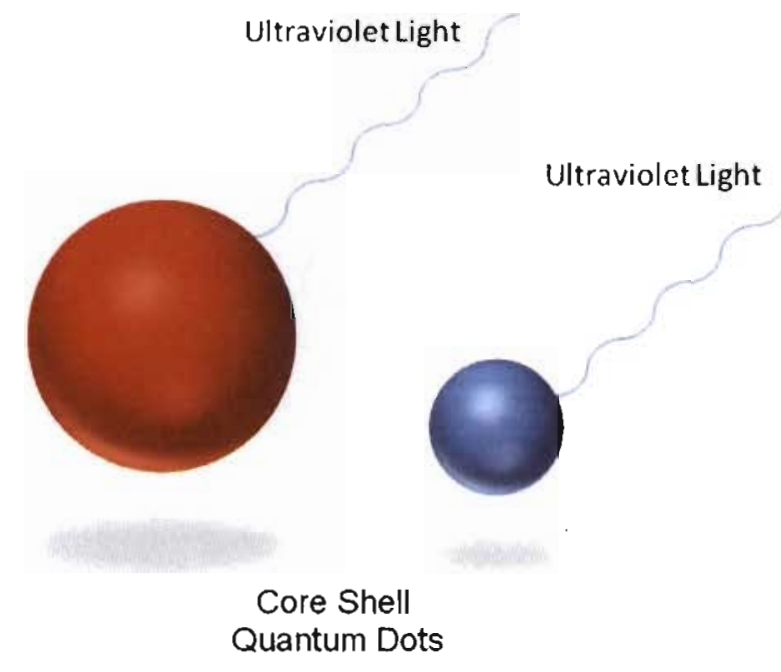

Figure 17 - Quantum Dot exposed to Ultraviolet Light

In order to find what wavelengths have enough energy to pass the band-gap of the quantum dot, the wavelength of the incoming light must be known. Using equation 1 to determine the energy of light can do this. The energy of the incoming wavelength of light is known as the excitation energy.

The excitation energy absorbed by quantum dots is ultraviolet light due to its high energy. Since the energy associated with ultraviolet light is larger than the band-gap of a quantum dot, the quantum dot absorbs the light. Figure 17 shows the wavelength of light that is absorbed by different sizes of quantum dots. The peak of each line shows what wavelength the quantum dot will fluoresce at. 


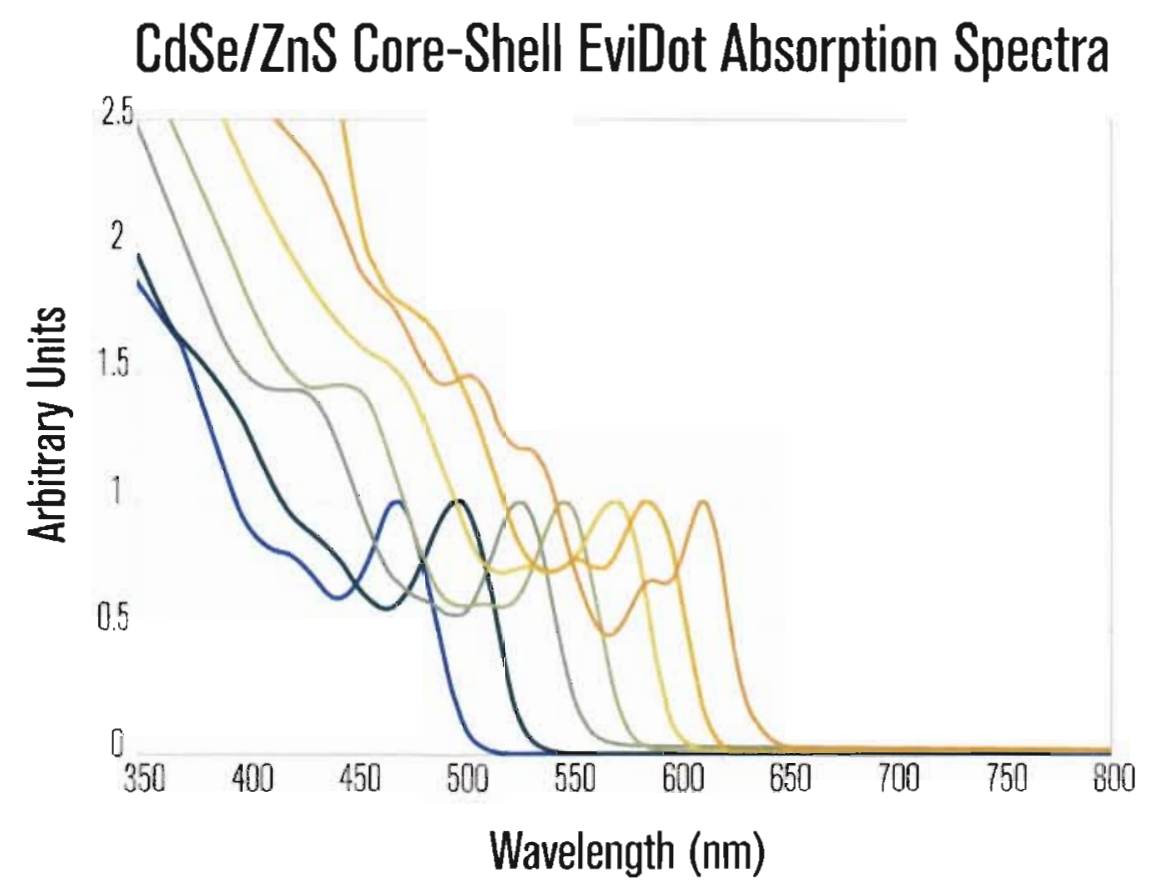

Figure 18 - EviDot Absorption Spectra [13]

By using quantum dots the idea is to expand the spectrum of light that the solar cell uses to produce current. Since a single crystalline silicon solar cell was used, quantum dots that emitted light with an energy closest to the band-gap of silicon were employed. The quantum dots fluoresced at $\lambda=620 \mathrm{~nm}(\mathrm{E}=2 \mathrm{eV})$. 


\subsection{0 - Optical Properties of Cadmium Selenium Zinc Sulfide Core Shell Quantum Dots}

The quantum dots used in these experiments were purchased from Evident Technologies. In order to understand the characteristics of quantum dots, it was important to measure the associated transmittance and fluorescence [14]. These measurements determine if the amount of florescence produced by the quantum dots could create more current flow in a photovoltaic cell thus making the cell more efficient. The amount of florescence is dependent on 2 parts: the concentration of quantum dots and the amount of high energy photons that interact with the quantum dots.

The concentration associated with the $\mathrm{CdSe} / \mathrm{ZnS}$ quantum dots were $2.2 \mathrm{mg} / \mathrm{mL}$ and were designed to fluoresce at a wavelength of $\lambda=620 \mathrm{~nm}$. The diameter of the quantum dots was approximately $5.8 \mathrm{~nm}$. The spectroscopy measurements showed how the amount of light, which was measured in counts, affected this concentration of quantum dots. The set up used for these spectroscopy measurements connected the UV-VIS light source to a cuvette holder using a fiber optic cable then connected the holder to the Avantes light detector using another fiber optic cable. There are advantages in using fiber optic cables. The advantage is the speed of the light being transmitted and there is a higher signal to noise ratio [15]. The light detector was then connected to a computer that analyzed the data from. The light source had two independent lighting mechanisms: a deuterium light source and a halogen light source. The deuterium light source produced high-energy light in the ultraviolet light range and the halogen light source produced lower energy light in the visible light range. The light detector was then connected to a laptop that analyzed the change in light associated with the measurement. 


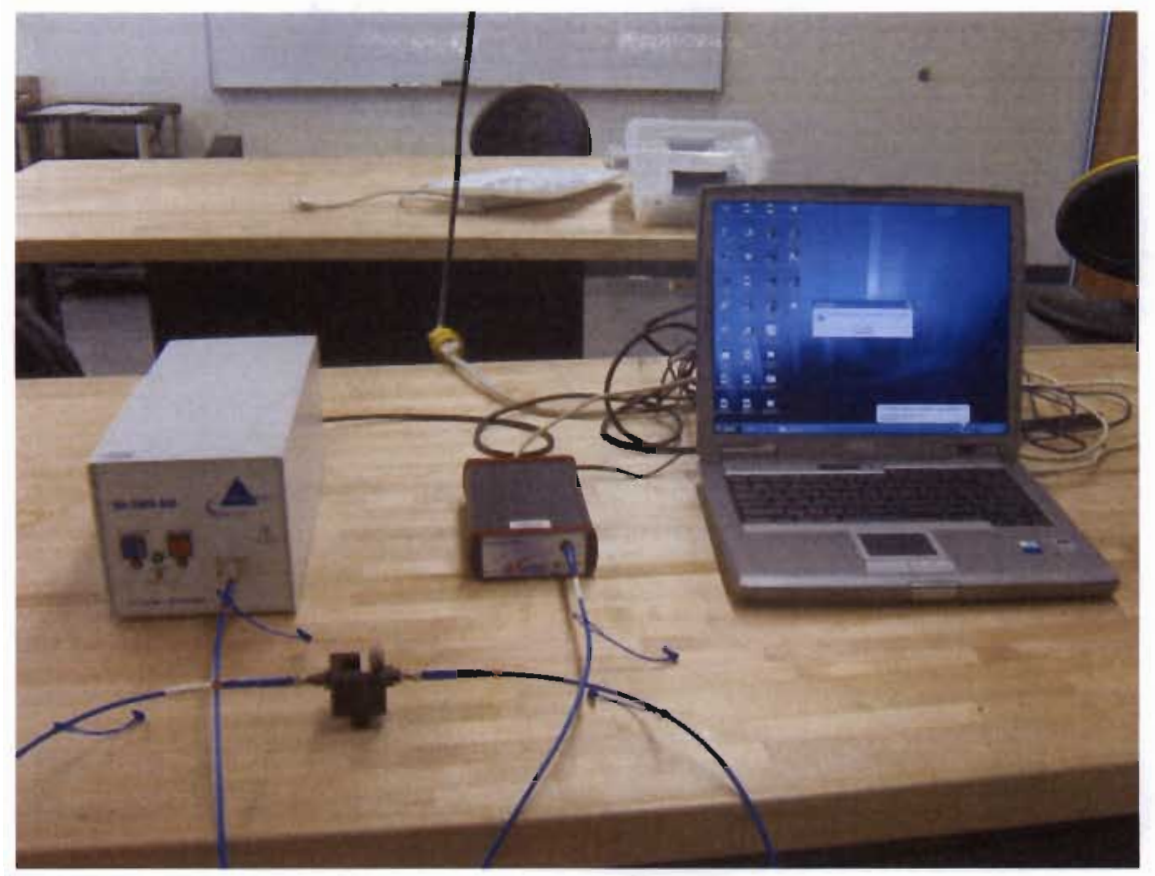

Figure 19 - Spectroscopy Set-up Used to Measure Transmittance and Absorption

It was important to use the same light source as well as the same fiber optic cable each time a measurement was taken. This was to ensure that the data stayed consistent and made it easier to reproduce the data. Because the light source output different intensities at different wavelengths it was important to take measurements in terms of sample counts. Before each measurement, the amount of raw counts that the light source transmitted was first measured. Since the light source is powerful, at times it would saturate the light detector. In order to decrease the amount to sample counts that transmitted to the light detector, a neutral density filter was used. The neutral density filter reduced all wavelengths that it encountered depending on the strength of the filter. The neutral density filter used for each spectroscopy experiment was 0.5 optical density (OD). Another factor that needed to be considered was keeping the integration time and the average number of scans consistent. 
The integration time used for each measurement was $5 \mathrm{~ms}$ and the average number of scans was 100 scans.

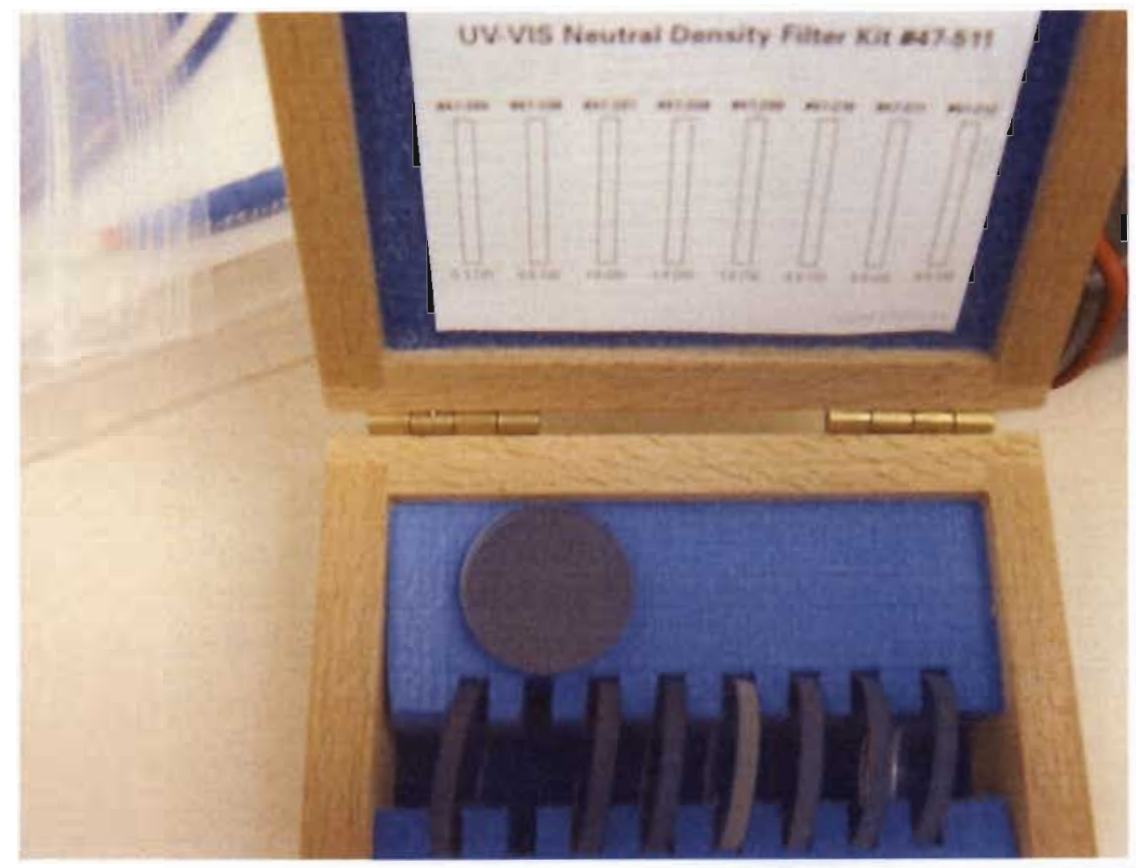

Figure 20 - Neutral Density Filters

Figure 21 displays the number of sample counts that was recorded by the detector from the incoming light source.

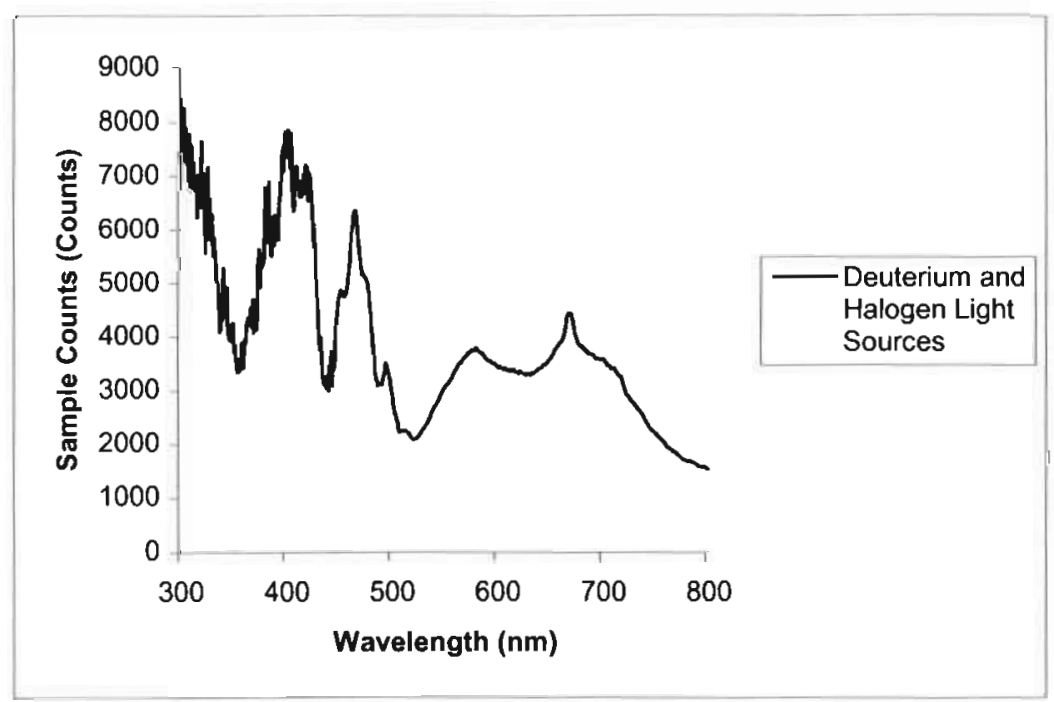

Figure 21 - Light Intensity of Deuterium Light Source and Halogen Light Source 


\subsection{1 - Transmittance of Light Associated With Cadmium Selenium Zinc Sulfide Core Shell Quantum Dots}

The quantum dots were placed on top of a solar cell to help increase the amount of light close to the band-gap of silicon that was available to the solar cell. Because the quantum dots were placed on top of the solar cell it, was important to investigate how much light would be able to transmit through the quantum dots. Since the CdSe/ZnS quantum dots were suspended in a Toluene liquid solution, the use of a cuvette was necessary for holding the quantum dots during this measurement. Although the cuvette is transparent from $\lambda=220$ $-900 \mathrm{~nm}$ there is still some light associated with this experiment that will either be absorbed or reflected by the cuvette. It is important to see the amount of light that is actually being transmitted through the cuvette in order to better analyze the quantum dots. Figure 22 shows a block diagram that represented the set up used for the experiment.

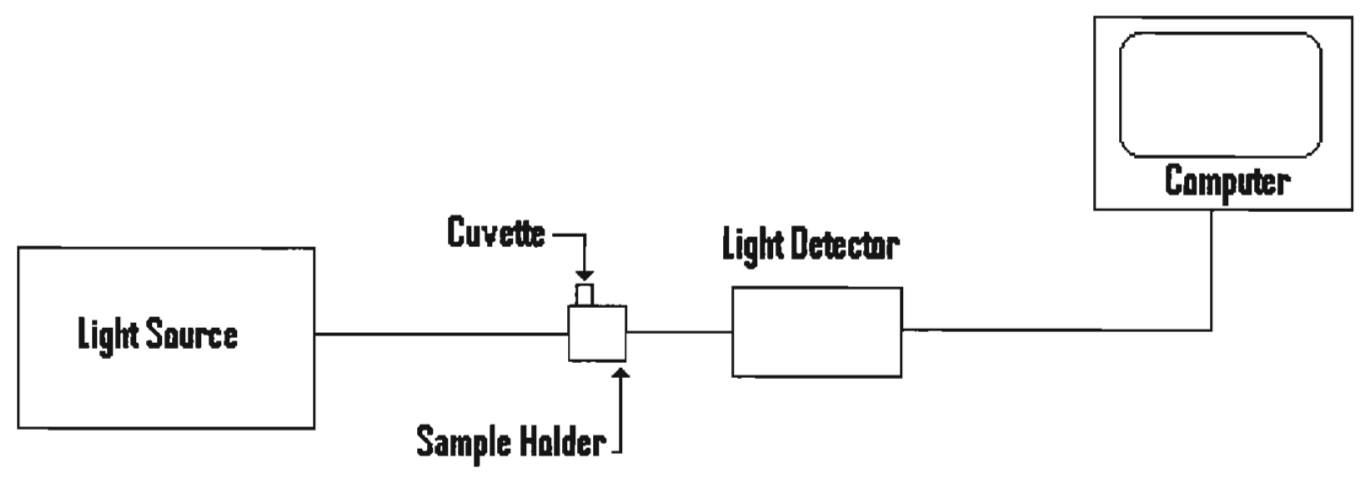

Figure 22 - Block Diagram for Measuring Transmittance

After recording the transmittance of light with an empty cuvette, the cuvette was then filled with the $\mathrm{CdSe} / \mathrm{ZnS}$ quantum dots. The only type of cuvette that was available was a UV Disposable Cuvette purchased from Ocean Optics. The measurement must be taken 
quickly since toluene, the solution the quantum dots are suspended in, will dissolve the plastic cuvette. Although it is ideal to measure the transmittance using a quartz cuvette, this gave a rough estimate of how the transmittance of light changed with quantum dots present.

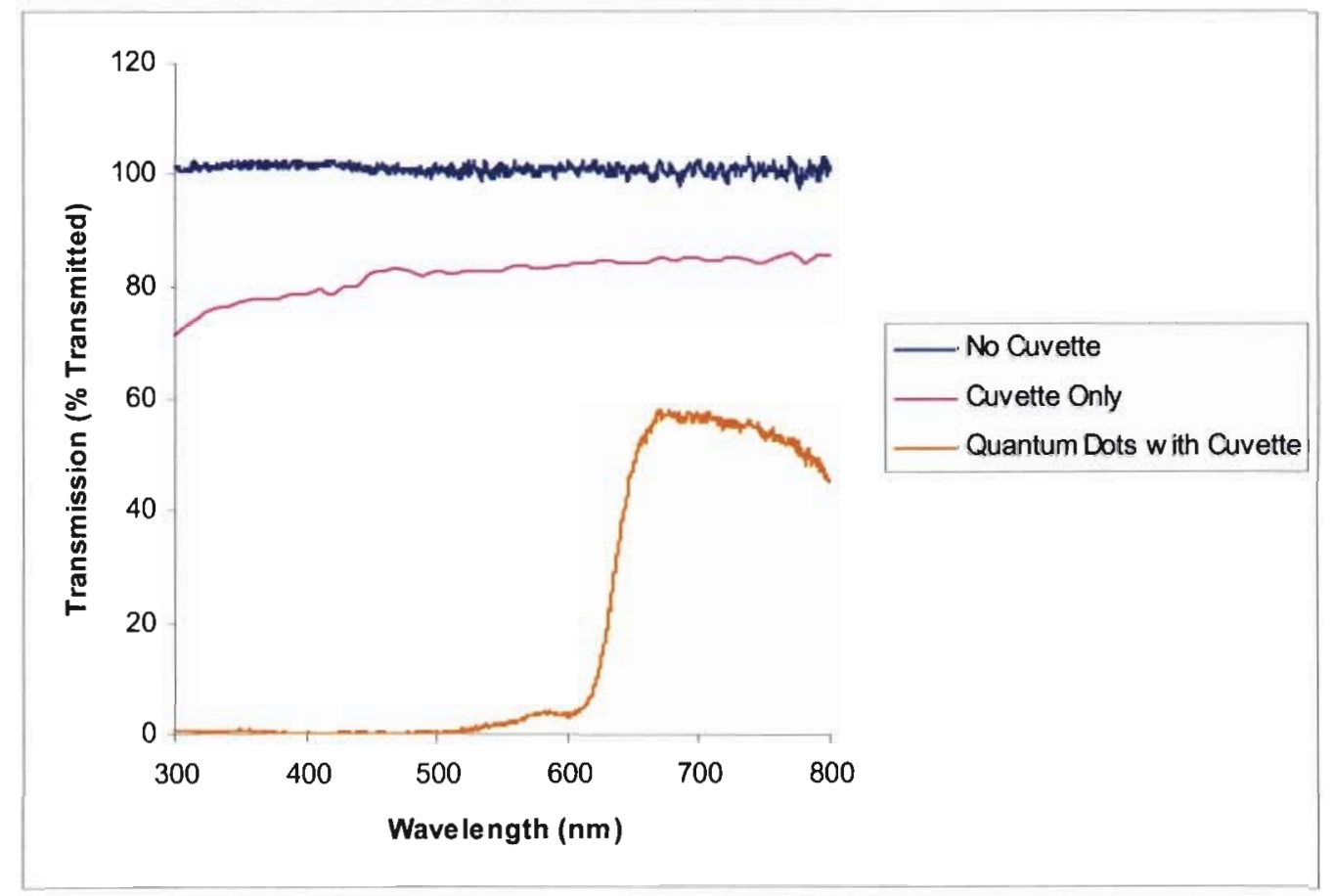

Figure 23 - Transmittance of light- No Cuvette, With a Cuvette and with Quantum Dots suspended in a Cuvette.

Figure 23 shows that the amount of light transmitted through the cuvette filled with quantum dots is lower than the empty cuvette. This could be because the toluene deteriorated the plastic cuvette, thus causing more reflections from the holder than when the cuvette was initially measured. The data shows that all of the ultraviolet light is being absorbed by the quantum dots. The only light that is being sent through is low energy light which is close to the band-gap of the single crystalline photovoltaic cell. 


\subsection{2 - Fluorescence Associated With Cadmium Selenium Zinc Sulfide Core Shell Quantum Dots}

Since the transmission experiment in section 3.1.1 showed that all of the ultraviolet light was being absorbed by the quantum dots it was decided that the amount of fluorescence that was occurring with the quantum dots should be measured. This measurement would indicate how much of the ultraviolet light would be converted to $\lambda=620 \mathrm{~nm}$ of light. The fluoresced light was used to increase the amount of current produced by the solar cell. In order to measure the florescence a slight change in the set up was needed. Instead of connecting the fiber optic cables straight through the sample holder, the fiber optic cable connected to the light detector was connected to a $90^{\circ}$ relative sample holder. This would measure the amount of light that the quantum dots fluoresce do to the down conversion of higher energy light. The incoming light, known as the excitation light, was sent directly to the sample of quantum dots. When the quantum dots became excited by the high energy light, light was emitted and sent to the light detector.

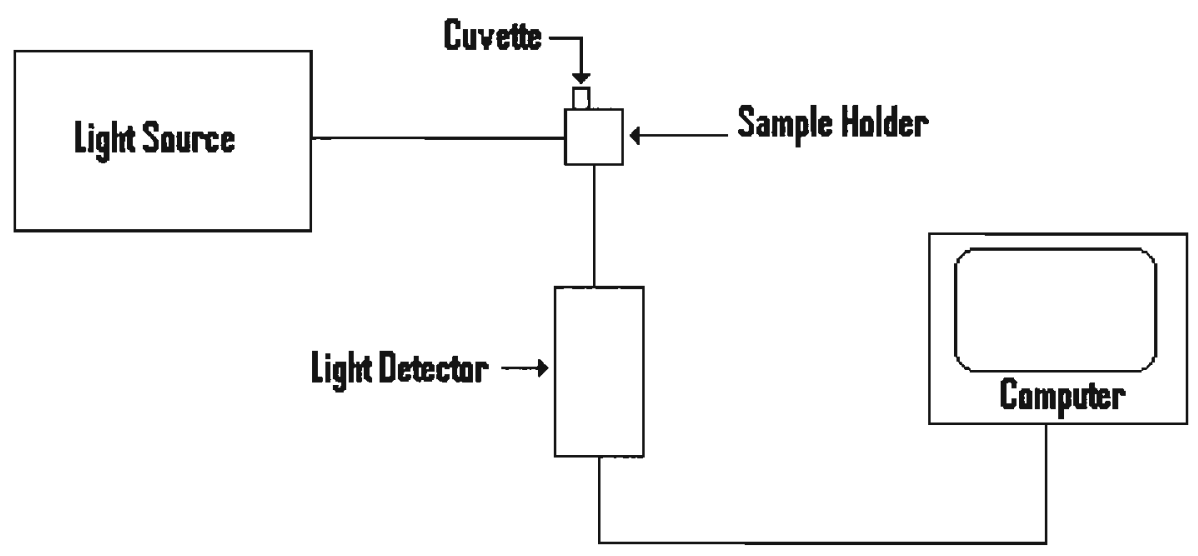

Figure 24 - Block Diagram for Measuring Florescence 
Light will only be fluoresced when the quantum dots are present; therefore, there was no need to take a measurement of the cuvette by itself. The amount of light that is fluoresced will be zero when no quantum dots are present.

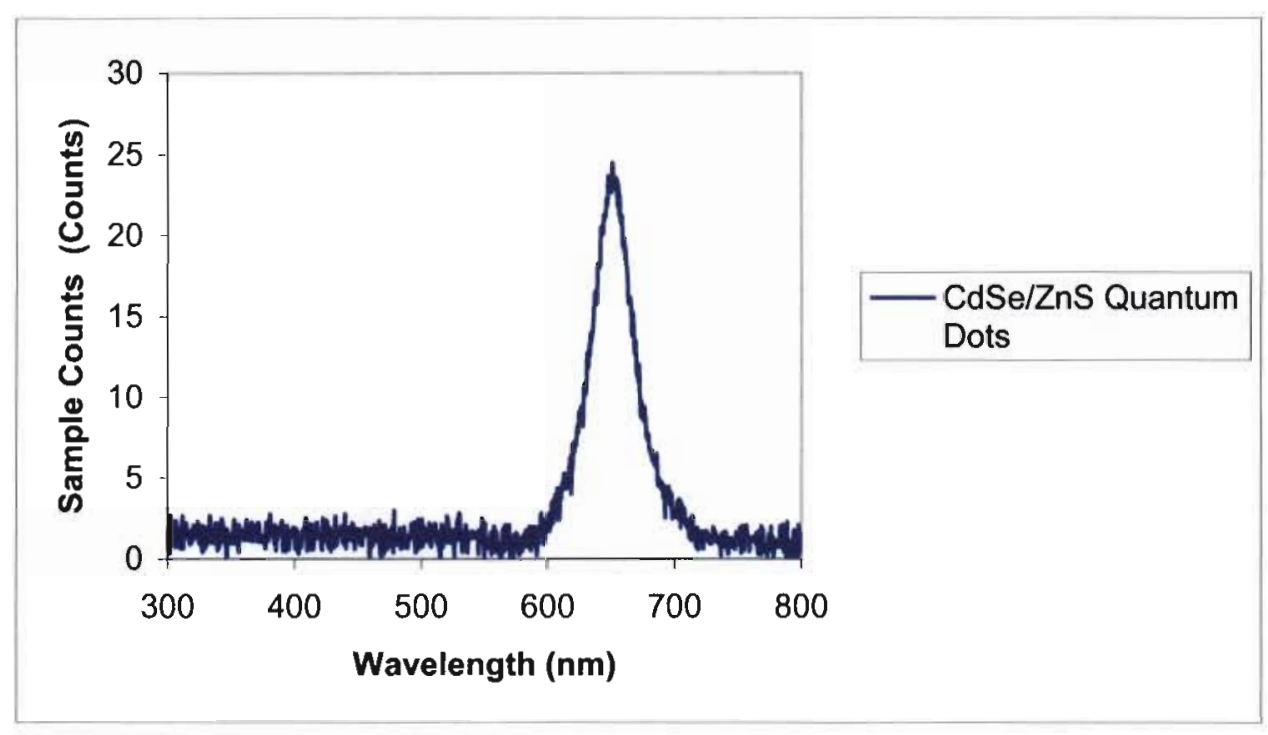

Figure 25 - Florescence of CdSe/ZnS Quantum Dots

Figure 25 shows that the light fluoresced ranged from $\lambda=600-680 \mathrm{~nm}$. This shows that the quantum dots used are large in size, since they are producing a large wavelength of light. The company Evident, who fabricates the quantum dots, lists the size of these quantum dots which fluoresce at $\lambda=620 \mathrm{~nm}$ to be approximately $5.8 \mathrm{~nm}$ in diameter. 


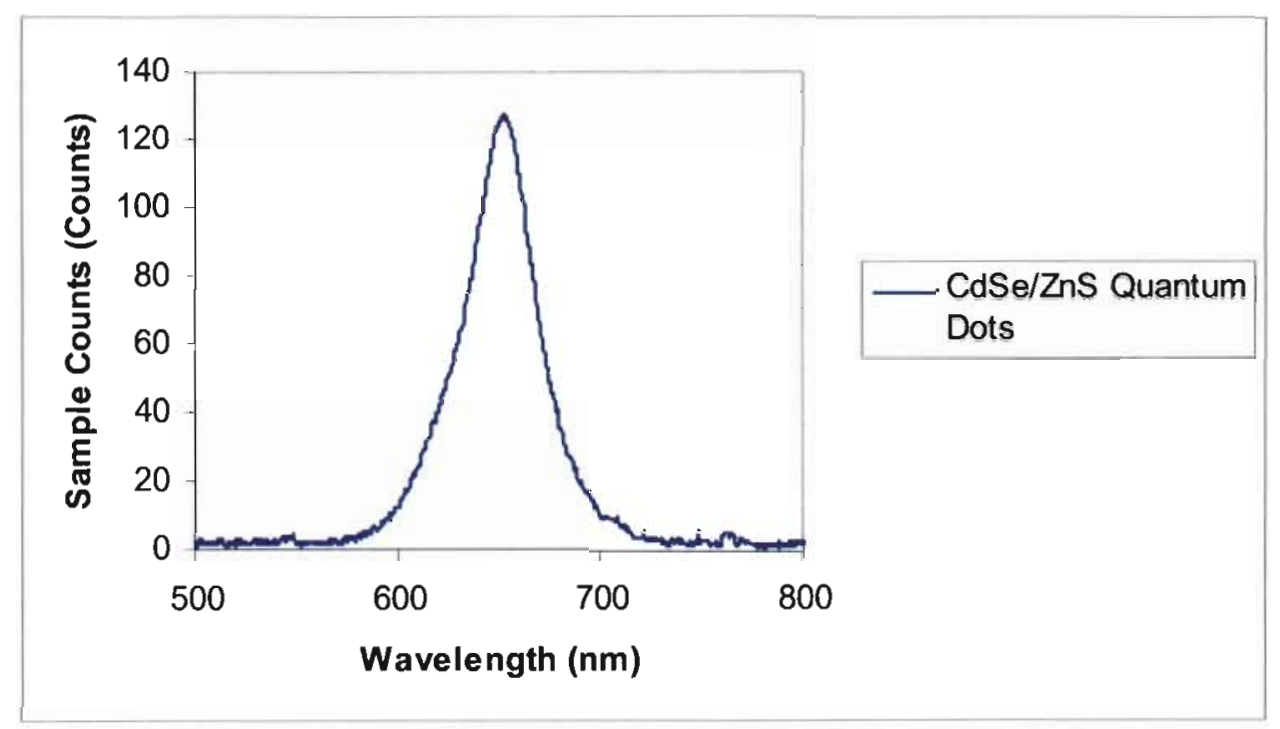

Figure 26 - Florescence of CdSe/ZnS Quantum Dots with Added UV Exposure

The same experiment was repeated but this time an external ultraviolet light was added to the top of the cuvette using a UV pen lamp and it appeared that the more ultraviolet light that the quantum dots were exposed to, the more they fluoresced. The result indicates that there wasn't enough ultraviolet light coming from the previous light source, when fluorescence was measured, to excite all the quantum dots. By adding this additional light source, which was not directly exposed to the quantum dots, the number of sample counts was increased by 100 . This means that all of the quantum dots were not excited with the previous experiment. Since the quantum dots were being excited, it was important to investigate what happened when the quantum dots dried directly to a silicon surface. 


\section{CHAPTER 4- QUANTUM DOTS SPUN ONTO SILICON}

\subsection{0 - Spin Coating Silicon With Cadmium Selenium Zinc Sulfide Core Shell Quantum Dots}

After it was observed that the quantum dots fluoresced light at $\lambda=620 \mathrm{~nm}$, as they were designed to do, the next step was to investigate how they interacted with a silicon substrate. The reason that silicon was used is because the photovoltaic cell that that was characterized previously, in section 2.2 , was made of single crystalline silicon. The objective was to evenly distribute the quantum dots onto this surface so that the entire surface was coated with quantum dots. In order to do this it was necessary to spin the solution of quantum dots onto the surface of a piece of silicon.

In order to prepare the silicon sample, a silicon wafer was piranha cleaned at $70^{\circ} \mathrm{C}$ for $20 \mathrm{~min}$ to remove any contaminates that were present on the surface of the silicon. The silicon was then placed into a hydrofluoric acid at $24^{\circ} \mathrm{C}$ for $15 \mathrm{~min}$ to remove any type of native oxide layer that might be present. The silicon was then rinsed with deionized water and dried with a nitrogen gun. Next, a diamond tipped pen was used to cut the surface of the wafer along the (110) plane. The surface was cut into a 0.5 inch $\times 0.5$ inch piece. Once this piece of silicon was cut, it was adhered onto the center of a full size wafer using double sided stick tape. Once again, a nitrogen gun was used to make sure there were no particles on the surface. 

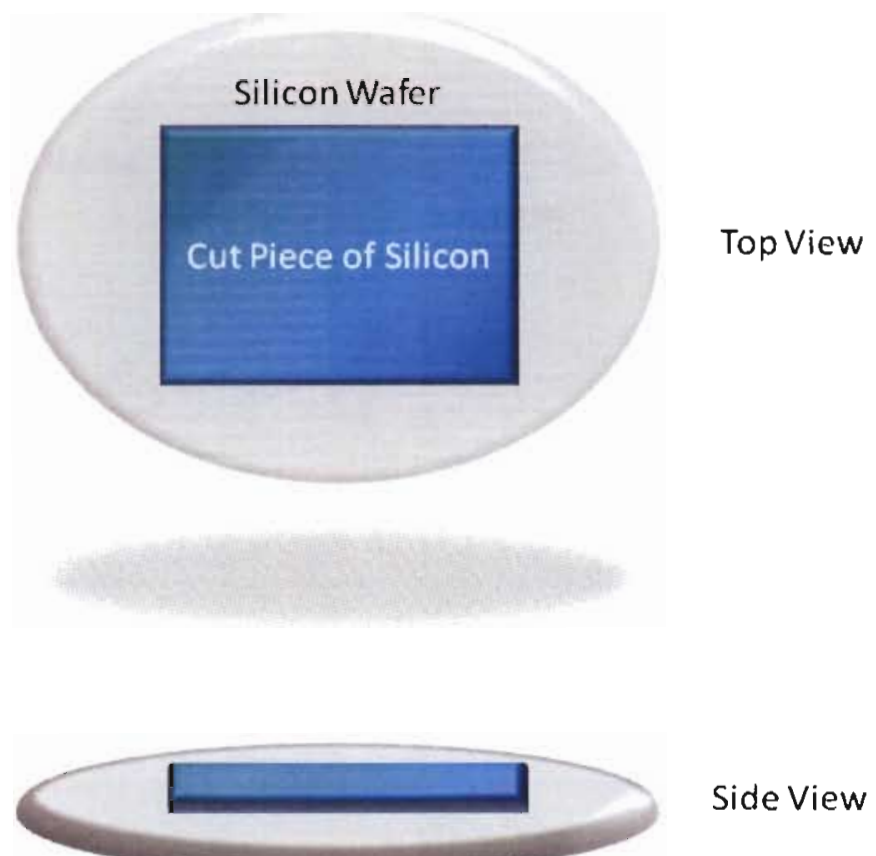

Figure 27 - Silicon Wafer with Piece of Silicon Adhered on Top Each With a Thickness of 0.1in

From here, a centering chuck was used to help center the wafer inside the spin coater. Once the wafer was centered onto the spin coater and a vacuum was applied to prevent the wafer from moving while spinning, a droplet of $\mathrm{CdSe} / \mathrm{ZnS}$ quantum dots in toluene solution was placed onto the surface of the cut piece of silicon. While the toluene was still in a liquid state the wafer was spun at $5500 \mathrm{rpm}$ for $25 \mathrm{sec}$ with an acceleration of 688 . This allowed the quantum dots to spread out on the silicon surface. When this was finished the toluene solution completely dried out. With the toluene completely dried, the remaining solution seemed to leave a red crust-like film on the surface of the silicon. When exposed to ultraviolet light this crusted area on the silicon substrate did not fluoresce. If the red curst was in fact quantum dots, it would mean that the quantum dots, in order to fluoresce, must be 
suspended in liquid. To image the red crust a Scanning Electron Microscope (SEM) and Atomic Force Microscope (AFM) were employed.

If the red crust was the $\mathrm{CdSe} / \mathrm{ZnS}$ quantum dots then conventional microscopy techniques could not be used because the quantum dots are only a few nanometers in diameter. Fortunately, Cal Poly has a Scanning Electron Microscope (SEM) as well as an Atomic Force Microscope (AFM). These devices allow objects to be viewed in the micro $\left(1 \times 10^{-6}\right)$ and nano $\left(1 \times 10^{-9}\right)$ scale $[16,17,18$ and 19$]$. Using these measuring techniques, clusters of $\mathrm{CdSe} / \mathrm{ZnS}$ quantum dots could be observed as well as a single quantum dot. From the data acquired in the previous experiment, it appeared that $\mathrm{CdSe} / \mathrm{ZnS}$ quantum dots tend to form clusters when the toluene evaporates. The SEM was first used to observe the red crust on the surface of the silicon, because the size that it is able to scale down to is not as great as the AFM.

\subsection{0 - Basics of how a Scanning Electron Microscope Works}

A Scanning Electron Microscope (SEM) is used to image surfaces down to $10 \mathrm{~nm}$. The California Polytechnic SEM however, was only able to resolve 100nm artifacts. Imaging at this scale provided a clue as to what the red curst was that formed on the surface of the silicon. As mentioned before, if the crust was in fact the quantum dots it would mean, that the quantum dots must be suspended in a liquid solution for them to work.

The SEM uses an electron gun that shoots out electrons onto a surface which interact with the atoms on the surface of the sample. A detector receives electrons that bounce off the surface and these electrons hold information about the topography of the surface. 


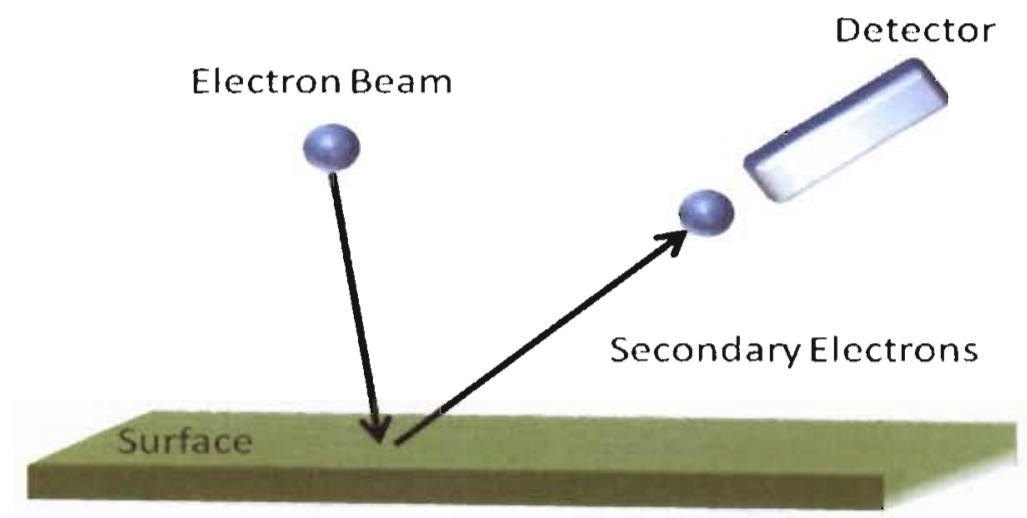

Figure 28 - Basic Drawing of SEM Operation

\subsection{1 - Using the SEM to Measure Cadmium Selenium Zinc Sulfide Core Shell}

\section{Quantum Dots}

Using Cal Poly's SEM was useful to gain an understanding of what the clusters of $\mathrm{CdSe} / \mathrm{ZnS}$ quantum dots looked like after the toluene evaporated.

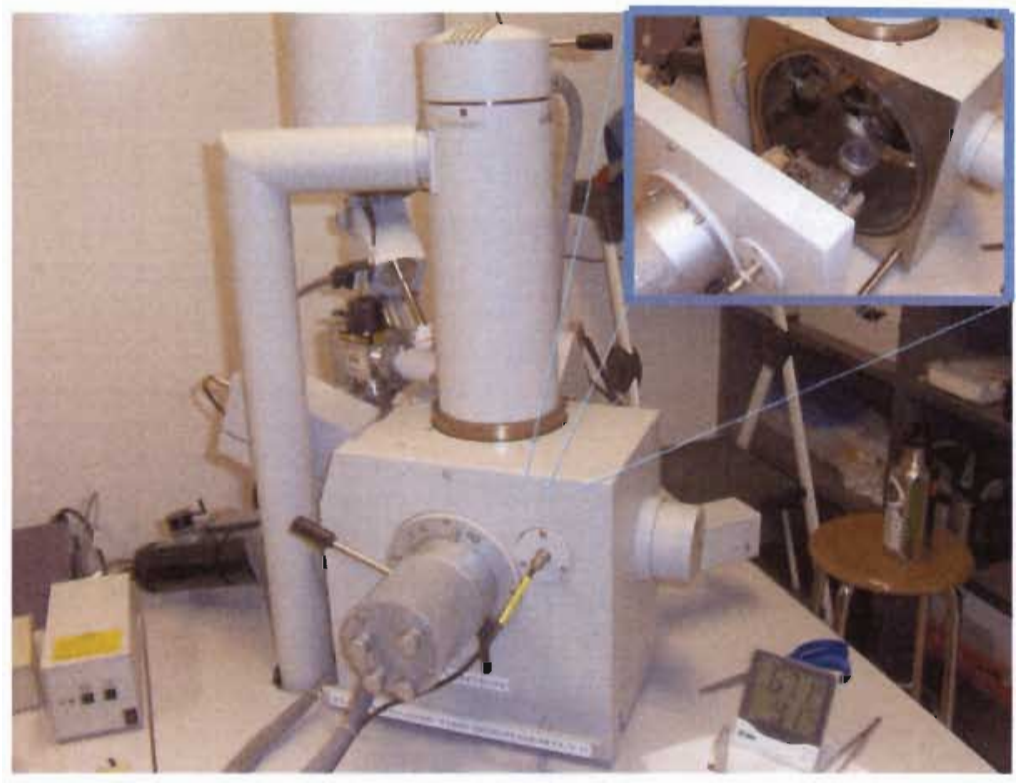

Figure 29 - Cal Poly's Scanning Electron Microscope 
In order to image the quantum dots the previous experiment of spinning the quantum dots onto a silicon surface needed to be recreated. The reason for doing this is that it allowed the sample to have minimal contaminates on its surface. The process that was used can be seen in section 4.1.0. Once this was done the sample was placed onto a stub and then into the SEM.

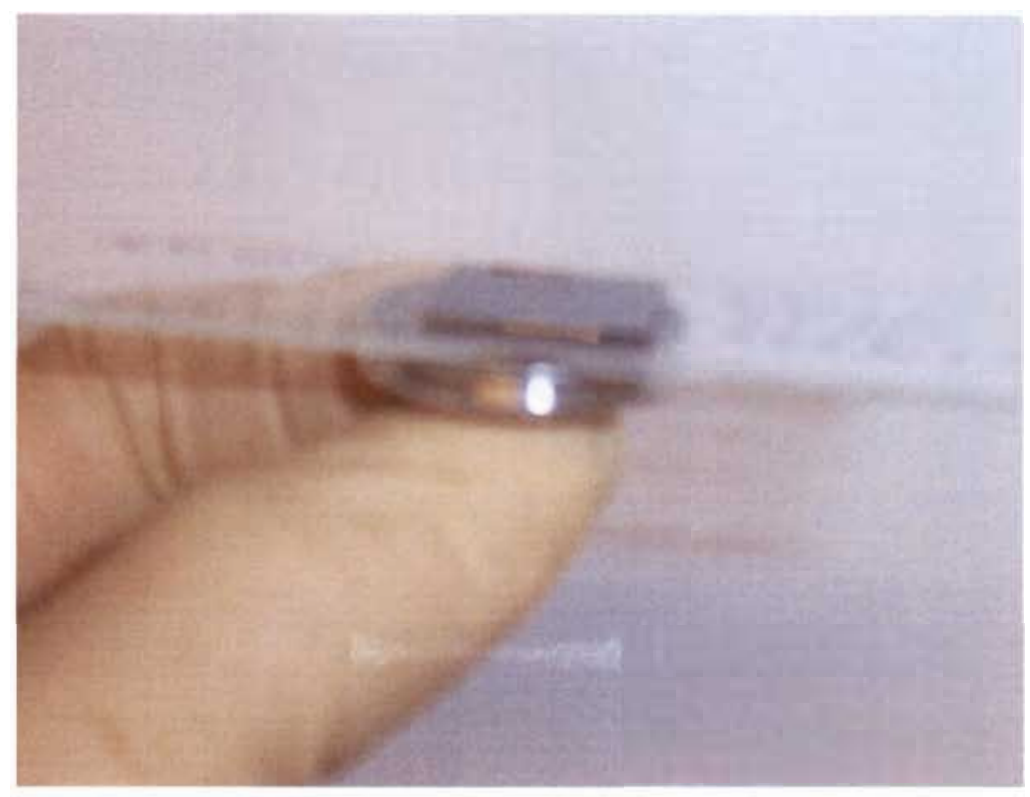

Figure 30 - Sample Prepared for SEM

After imaging there were distinct clusters of quantum dots that had formed. These clusters can be seen in figures 31 and 32 . 


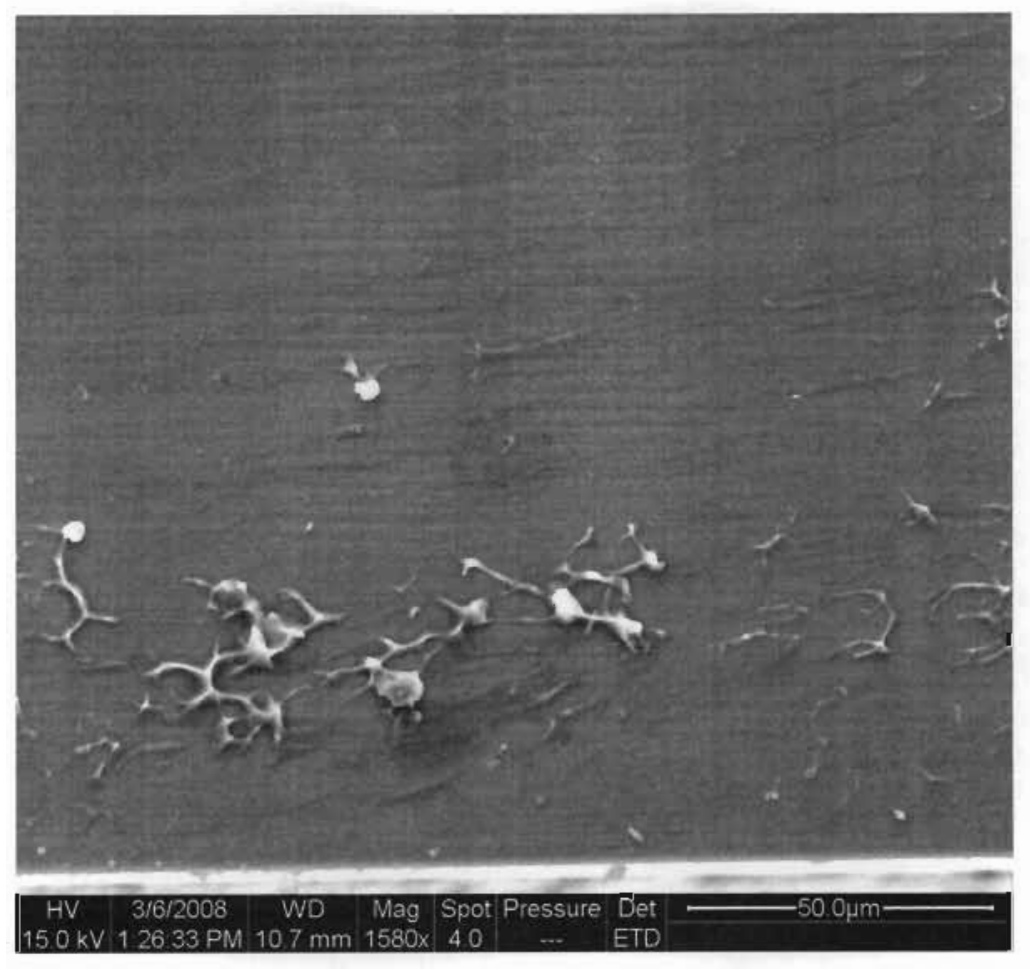

Figure 31 - SEM Image of Red Clusters

Figure 31 shows very distinct areas where clusters formed. The light gray streaks that are seen in the image, are thought to be where the toluene spun off and evaporated. Zooming into a single cluster of quantum dots allowed a visual of the clusters of quantum dots. It appears that there was no symmetry associated with the clusters and the clusters formed either in streaks or in round clusters. One observable round cluster was about 2 um in length and can be seen in figure 32 . 


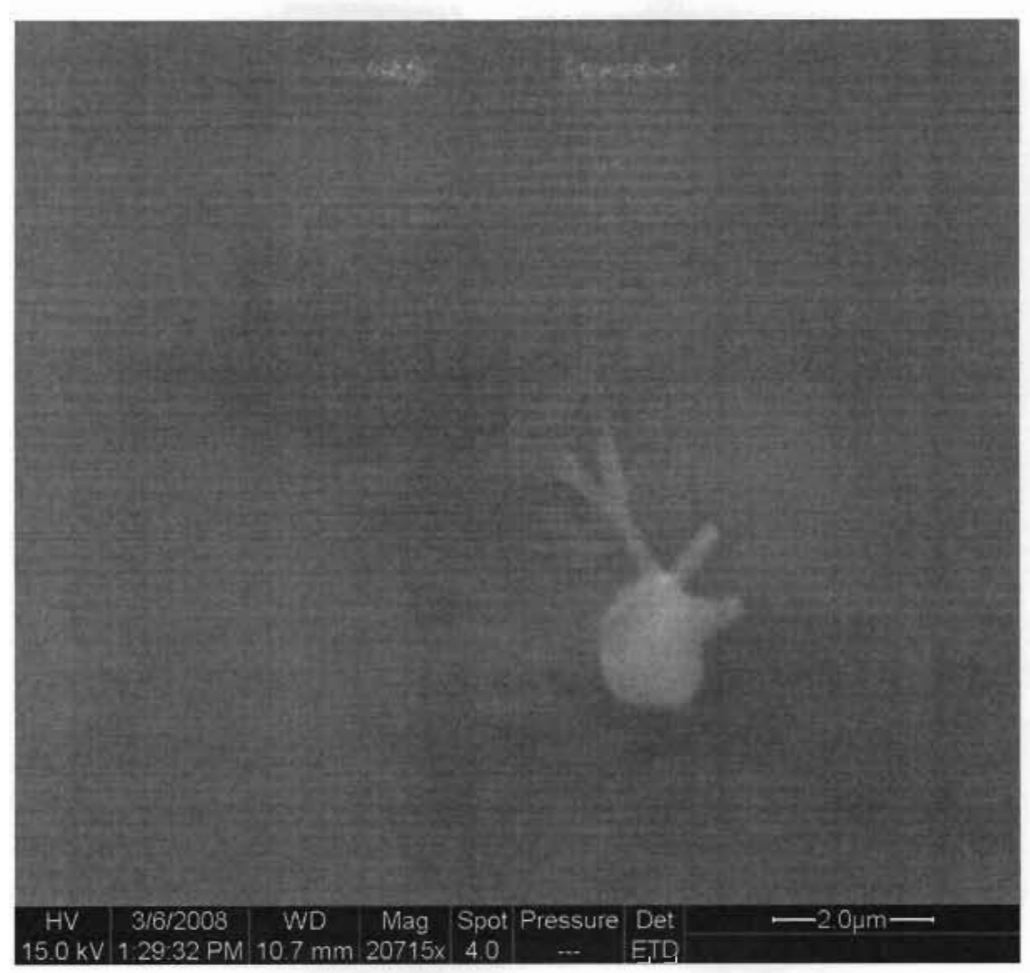

Figure 32 - SEM Image of a Single Cluster of Red Crust

\subsection{0 - Basics of How an Atomic Force Microscope Works}

In order to verify if these clusters were quantum dot clusters or contamination on the surface of the silicon, an atomic force microscope was used to measure height of the artifacts that were in these clusters. The main goal was to image a single quantum dot; in doing this it would allow a better assumption that the clusters could possibly be quantum dots that had been imaged in the SEM. This would then confirm that the red crust that was forming on the surface of the silicon once the toluene was evaporated actually was quantum dots and a conclusion could be reached that the quantum dots do not fluoresce when they are not in solution. If this were the case, an alternate way would need to be found of interacting the quantum dots with the solar cell to improve efficiency of electrical current produced by the solar cell. 
An AFM uses a cantilever that has a very sharp tip at the end that travels on the surface of a sample. When the tip encounters an artifact, it causes the cantilever to deflect do to the forces between the tip and the surface. A detector in the system measures the deflection that the cantilever makes and creates an image of the topography. The images that are produced can come in various forms such as height measurements and changes in phase (which is only present with $\mathrm{AC}$ mode), which compares the timing of the mechanical vibration of the cantilever compared to the movement of the cantilever on the surface of the substrate. When the cantilever interacts with the surface of a sample it must overcome forces between the tip of the cantilever and the surface. Although there are many forces that interact with the cantilever and the sample surface, there are two major types of forces: short range forces called Van der Waals force and long range forces called capillary forces. There are three types of Van der Waals forces that can occur, which are: dipole-dipole forces, dipole-induced dipole forces and induced dipole-induced dipole forces. The attraction of this force is only part time but is present during AFM measurements. Other forces that can become issues are electrostatic and magnetic forces. There are also two different ways to image using an AFM: contact mode and non-contact mode (or AC mode).

\subsection{1- Contact Mode AFM}

In this mode, the cantilever tip gently glides across the surface of the sample. The cantilever that is being used generally has a low spring constant, which is much lower than the effective spring constant holding the atoms together. This reduces the chances of damaging the sample as the cantilever travels across the surface of the sample. As the tip travels across the sample, a laser measures the deflection that the cantilever undergoes. The 
laser reflects off the back end of the cantilever into a photodiode that detects any change in the laser.

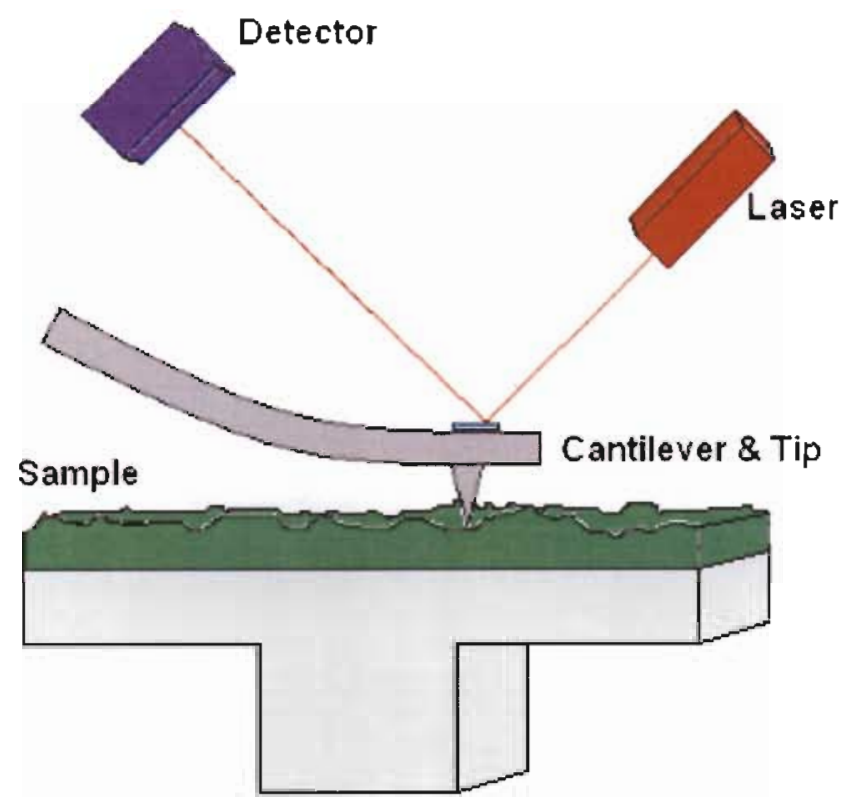

Figure 33 - Basic layout of AFM

In contact mode, there are two other major forces that are present. The first force is a capillary force, caused by a thin layer of water that is created on the cantilever tip. When the water is on the tip of the cantilever, it causes an attractive force between itself and the sample. The cantilever tip must penetrate through this thin layer of water and requires a force to do so. The other force that is associated with contact mode is the cantilever force. The sum of these two forces must be well-adjusted with the repulsive Van der Waals forces for a good image to be created.

With contact mode, the most common mode for measurement is setting a constant force on the cantilever. The deflection that the cantilever has is kept constant and as the cantilever moves in the $\mathrm{X}$ and $\mathrm{Y}$ direction, the detector monitors the change in Z-direction 
that the cantilever makes. By recording the change in Z-direction that the cantilever makes a topographical image is created.

\subsection{2 - Non-Contact Mode or AC Mode}

The other mode of operation for an AFM is non-contact mode or AC mode. In noncontact mode, a stiff cantilever is used to overcome the attractive forces associated with the sample. The cantilever oscillates at a resonant frequency specific to the cantilever being used. The system measures a change in the resonant frequency, or vibration amplitude, as the tip travels across the surface. This mode of measurement is useful for samples that are soft or are easily moved around. Since the cantilever resonates up and down with small force applied to the surface of the sample it allows soft objects to not be damaged or moved.

\subsection{3 - Using AFM To Measure Cadmium Selenium Zinc Sulfide Core Shell Quantum Dots}

There were a few different techniques that were used in trying to image the quantum dots. Nanosurf manufactured the first AFM that was used and the model of the AFM was named easyScan 2 AFM System. 


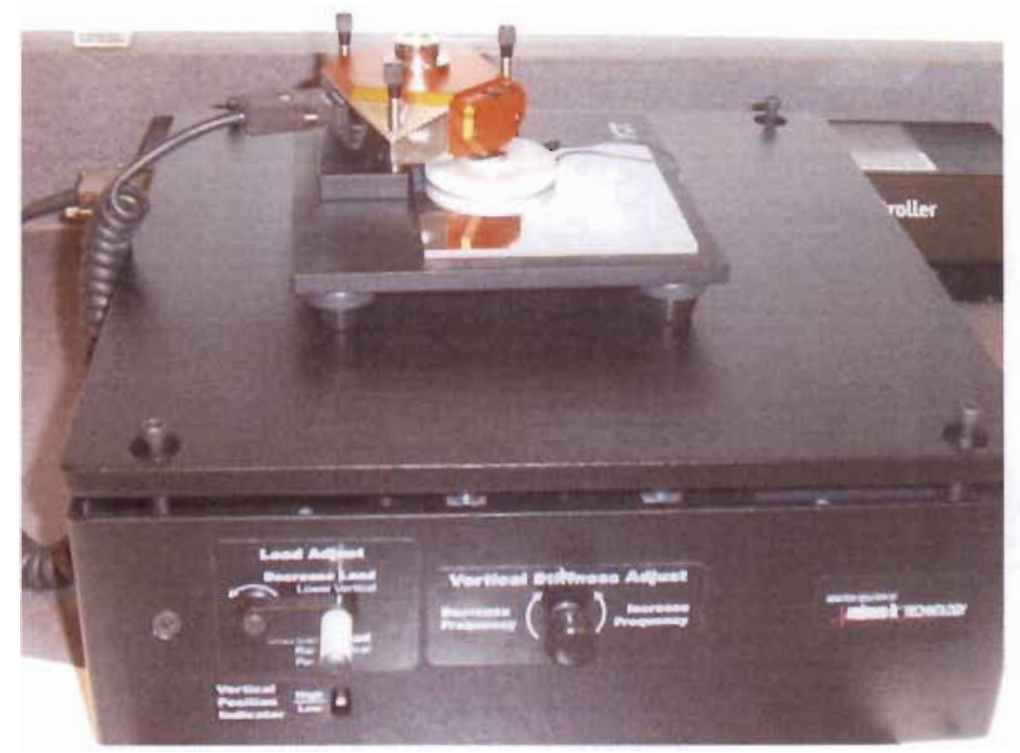

Figure 34 - Easy Scan Nano Surf AFM

When utilizing this AFM a cantilever is used in the contact mode to image the sample, using a glass slide, which was cleaned in a piranha solution for $20 \mathrm{~min}$ at $70^{\circ} \mathrm{C}$. The glass slide was taken out of the solution and a droplet of $\mathrm{CdSe} / \mathrm{ZnS}$ quantum dots was placed on the surface. It took 3 minutes for the toluene solution to evaporate and the sample to be ready for imaging. The glass slide was then placed under the AFM tip head and a trial image was produced. Unfortunately, no successful image was taken due to the contact mode of imaging. By using this mode to image the $\mathrm{CdSe} / \mathrm{ZnS}$ quantum dots, the probe tip seemed to displace the quantum dots as it moved across the samples surface. In moving the artifacts around the cantilever, the cantilever was unable to raster back and forth over the same artifact and produce an image. Another issue that was encountered when trying to image the $\mathrm{CdSe} / \mathrm{ZnS}$ quantum dots, was that the glass slide had an inconsistent surface. This inconsistency across the surface created a lot of noise that was picked up during measurements and degraded the image that was produced. As the cantilever tip moved the quantum dots around, the tip became contaminated with quantum dots. This contamination 
also affected the resolution of the images. Finally, after running a number of scans, it was observed that the resolution that the Easy Scan Nano Surf 2 AFM could perform was not high enough to image $\mathrm{CdSe} / \mathrm{ZnS}$ quantum dots. It was decided to move the sample to the Asylum AFM, which can image artifacts that are as small as $0.1 \AA$.

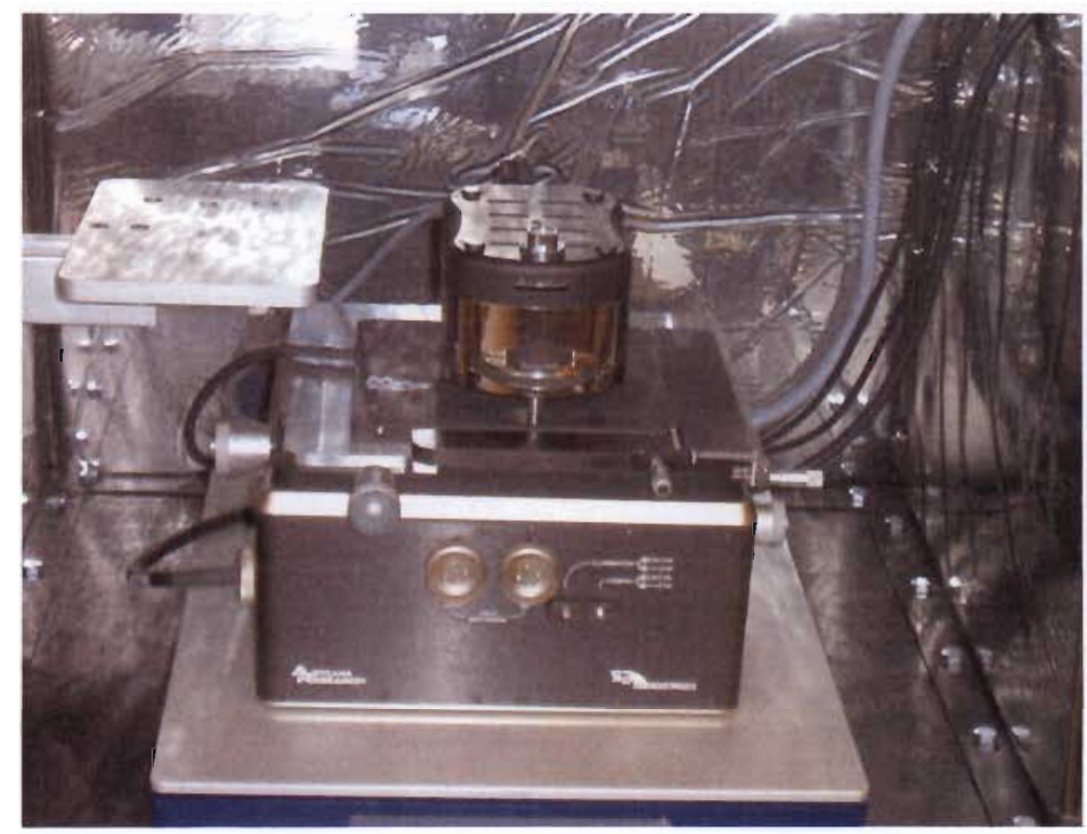

Figure 35 - Cal Poly's Atomic Force Microscope Made by Asylum

Since the glass slide had too rough of a surface, which created peaks higher than the height of a quantum dot, it was decided that silicon should be used as the substrate that the quantum dots would be dried onto. Samples were prepared the night before imaging with the Asylum AFM. Contamination also affected the samples when they were prepared the night before imaging. It was determined that samples had to be prepared the day of the test. The preparation of the sample is laid out in section 4.1.0. The reason for using the same set up was to investigate the red crust on the surface of the silicon when the quantum dots were spun onto it. 
Since the quantum dots tended to cluster when the toluene solution evaporated it was important to image in areas where the concentration of quantum dots was the lowest, and to focus on the edge of the clusters of quantum dots in order to increase the chances of imaging a single quantum dot. The $\mathrm{AC}$ mode on the AFM was used to minimize the amount of movement the quantum dots made due to the AFM cantilever tip. To get a rough idea of what the surface looked like, a quicker scan using 256 points per line was performed and then 256 lines per scan. Quickly zooming in to an image that represented artifacts seemed to result in the quantum dots moving around on the silicon surface; once a desired location was found, the points per line were increased to 1024 as well as the lines per scan to 1024 .

Doing this created a longer scan time but a more vivid image of the sample was produced. To help increase the quality of the image a cantilever tip that had a small spring constant was used. The spring constant was $1.6901 \mathrm{nN} / \mathrm{nm}$ with a resonant frequency of $76.294 \mathrm{kHz}$. This type of cantilever is more sensitive to objects on the surface thus decreases the chance of the quantum dots moving on the surface. Changing the set point to $685 \mathrm{mV}$ allowed the cantilever to softly hit the surface and also allowed for less movement of the quantum dots while they were being imaged.

For the successful scans the average height of the quantum dot was $6.48 \mathrm{~nm}$ with a standard deviation of 0.86 . The data that was obtained can be viewed in Appendix B. It was discovered that the red crust that was observed on the surface of the silicon when it was spun on was, in fact, quantum dots, therefore the conclusion was reached that spinning on quantum dots was not a good approach to increase solar cell efficiency. Once the quantum dots were out of the liquid solution they did not fluoresce. This could be do to a native oxide layer forming on the surface of the quantum dots restricting the fluorescence. Therefore, the 
next investigation that was needed was to find a way to keep the quantum dots in a liquid solution and place them on top of a solar cell.

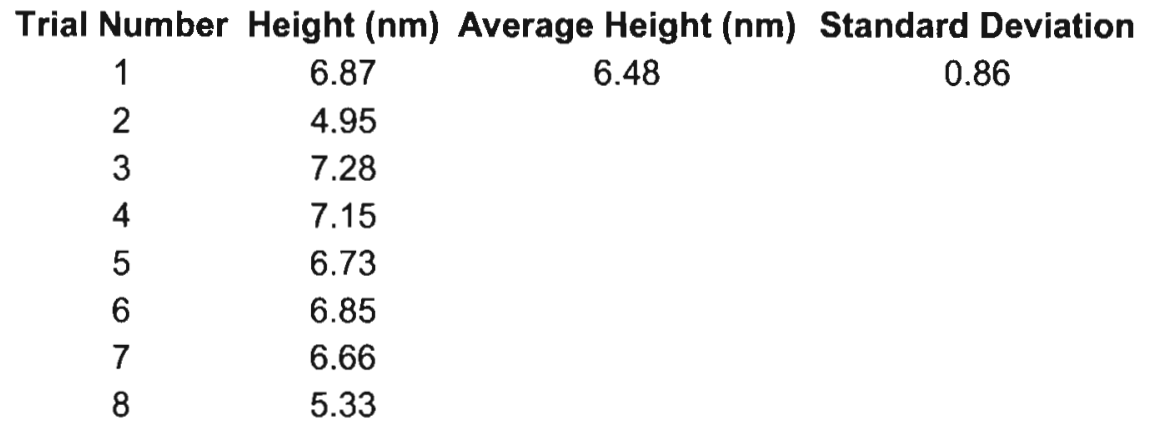

Table 1 - AFM Height Measurements of Single Cadmium Selenium Zinc Sulfide Core Shell Quantum Dot

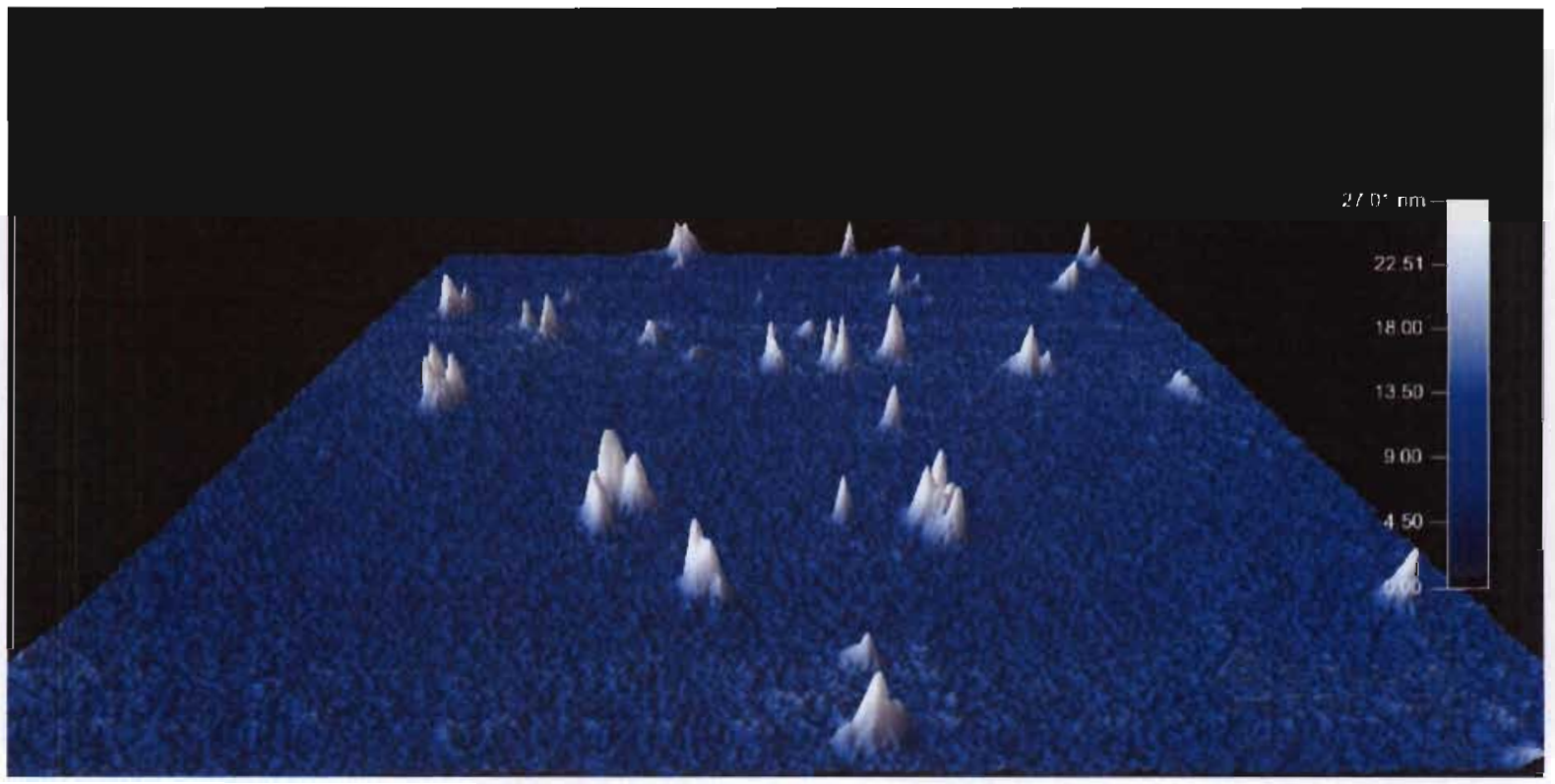

Figure 36 - 4.8um x4.8um Scan of Silicon Substrate with CdSe/ZnS Quantum Dots 


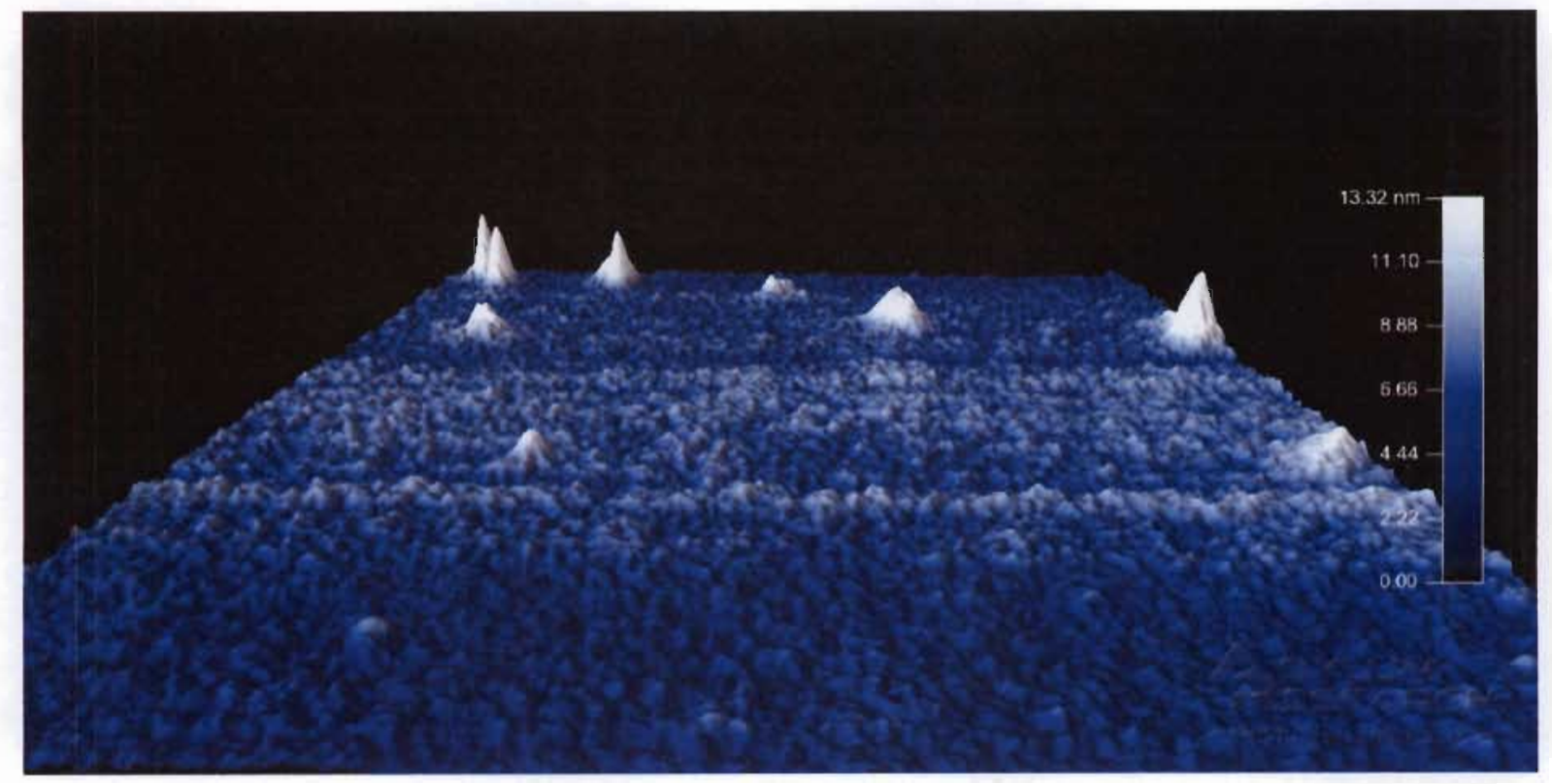

Figure 37 - 1.8um x 1.8um Scan of Silicon Substrate with CdSe/ZnS Quantum Dots

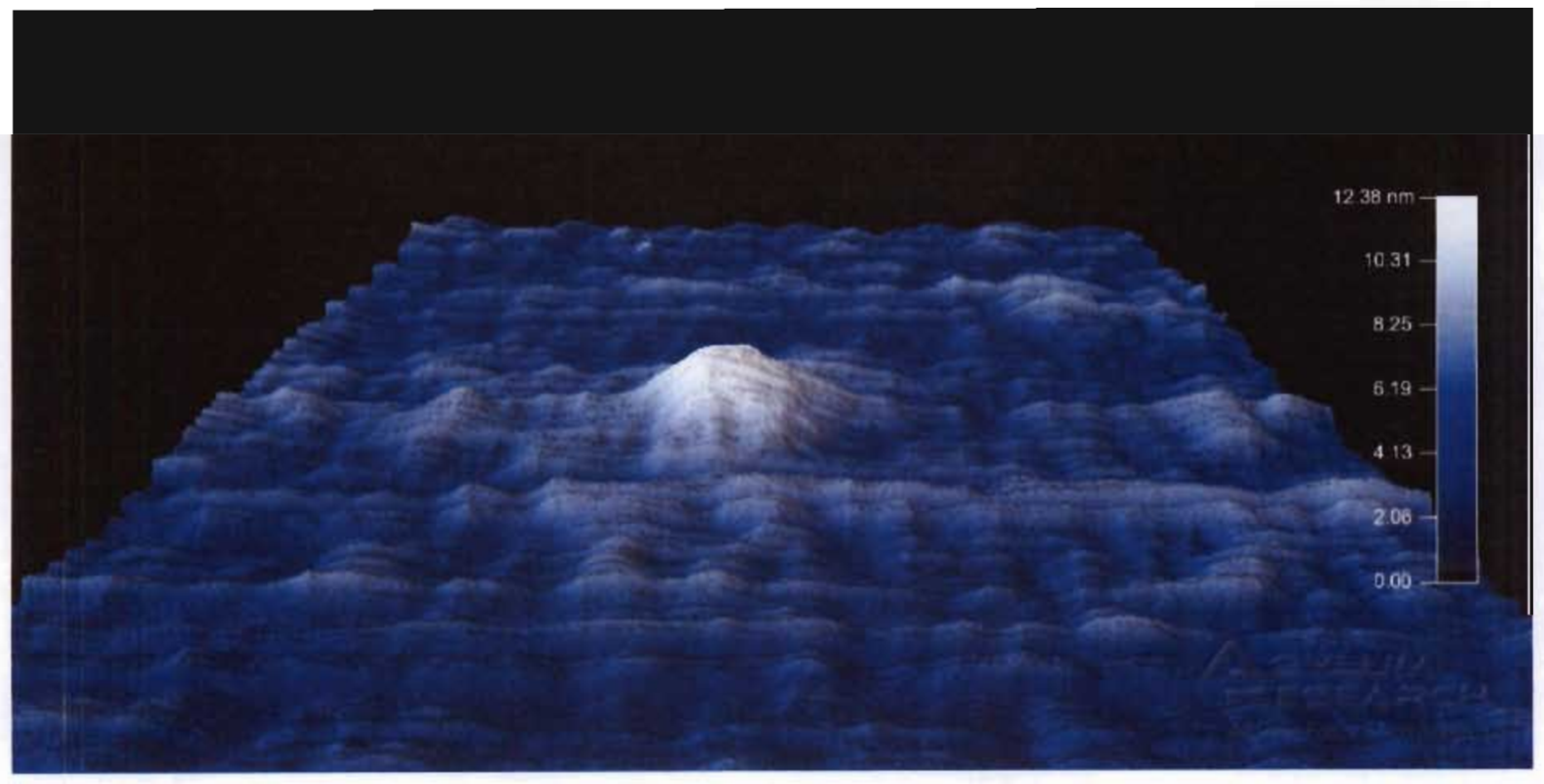

Figure 38 - 410nm x 410nm Scan of Silicon Substrate with CdSe/ZnS Quantum Dots 


\section{CHAPTER 5- MICROFLUIDIC CHANNELS}

In the previous experiment $\mathrm{CdSe} / \mathrm{ZnS}$ quantum dots were spun onto the surface of a silicon substrate. Although the quantum dots covered the entire surface of the piece of silicon, when the toluene solution evaporated the quantum dots did not fluoresce. It appeared that the only way to have the quantum dots fluoresce was to keep them in their liquid state.

The next experiment used a process known as soft lithography to fabricate microfluidic channels that would hold the quantum dots in their liquid state. Soft lithography is a process that uses molds and lithography masks to produce desired structures into polymers. A microfluidic channel is an open path that is created inside a polymer that allows for the flow of liquid. By creating a mold in PDMS a channel housing can be created for a solution to be suspended in it. The reason for using this type of structure is that it is easy to fabricate and place on top of a solar cell. The biggest concern is the need to use a polymer that would allow ultraviolet light to be transmitted through the PDMS and have minimal reflection losses of incoming light. If the fluorescence of the quantum dots is not greater then the amount of reflection losses, than this idea would not be advantageous.

The polymer chosen for this experiment was polydimethylsiloxane (PDMS) because it easily molds to any shape that is desired and it is a transparent polymer.

\subsection{0-Polydimethylsiloxane}

Polydimethylsiloxane (PDMS) is an organic polymer that Cal Poly purchased from Dow Corning. This polymer is a silicone due to the alternating Si-O-Si backbone of the structure [20 and 21]. Each silicon part in PDMS has two methyl groups connected to it, therefore, creating a repeating $\left(\mathrm{CH}_{3}\right)_{2} \mathrm{SiO}$ unit [22]. Silicones come from a combination of silicon and methyl chloride in a process known as "direct reaction" or "direct process" [23]. 
This organic polymer is used for fabrication because of its ability to easily form into any desired structure and because it was readily available in the lab.

\subsection{0 - Transmission of Light in Polydimethylsiloxane}

The microfluidic channels that the quantum dots were dispersed into were fabricated out of PDMS. Since the CdSe/ZnS quantum dots were suspended in a PDMS it was important that the optical properties associated with the polymer had a high transmission of light above $95 \%$. If the polymer does not allow ultraviolet light to transmit through to the quantum dots, the quantum dots would not be able to fluoresce and would not provide an increase in light near the band-gap of silicon for the solar cell. The method for measuring the percentage of light that is transmitted through the PDMS was the same set up as for measuring the transmittance associated with the quantum dots in the cuvette, which is described in section 3.1.1. The use of a cuvette was not needed because PDMS is a solid. Even though PDMS is a solid, it is a very flexible polymer and it tended to bend when placed in the sample holder. This caused a lot of reflections in the measurements taken. In order to overcome this problem, the PDMS was placed on top of a quartz disk that transmits ultraviolet light much better than glass and will keep the PDMS at a fixed position during the measurement.

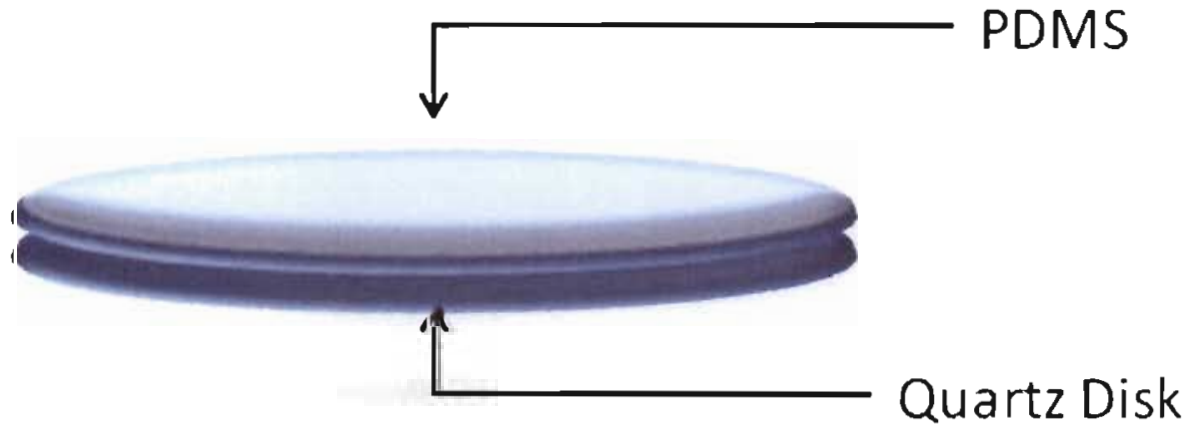

Figure 39 - PDMS on Quartz Disk 


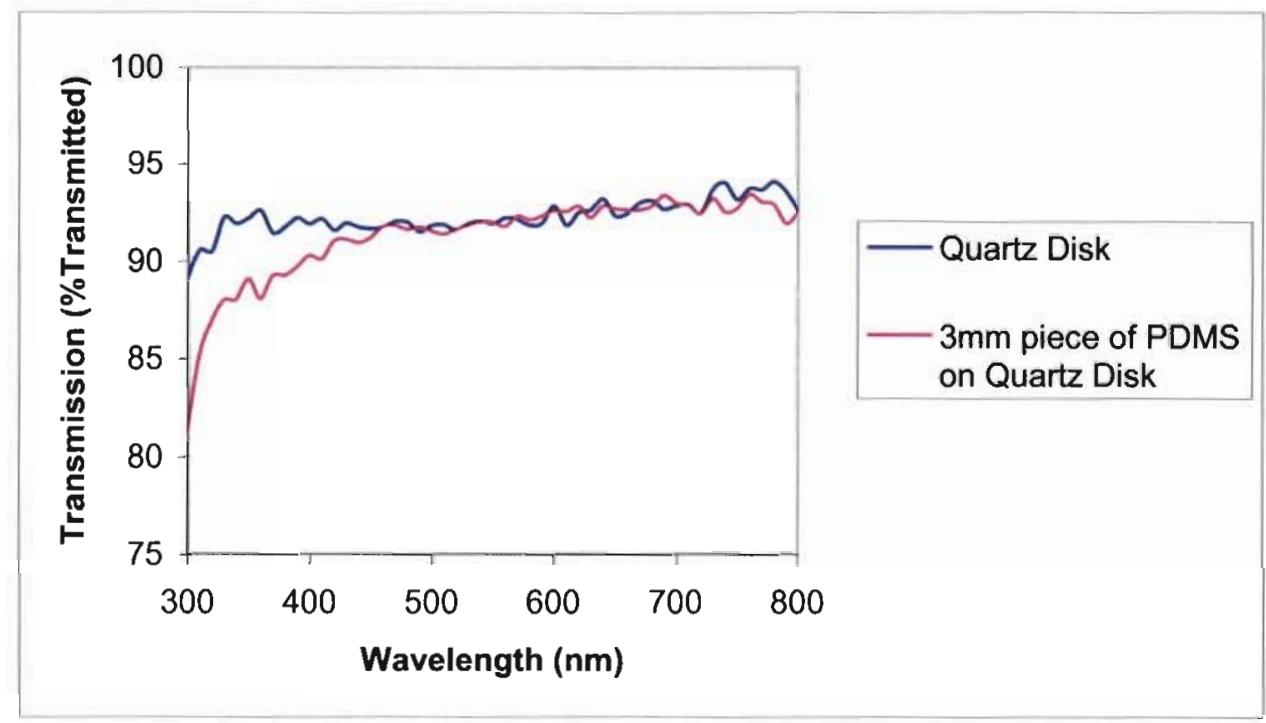

Figure 40 - Transmittance Percentage of Light Through PDMS

In order to have a good overall measurement of the polymer, measurements were taken at various points on the PDMS, rotating it six times and taking the average of each of the six points of measurement. This was done because the surface of PDMS was slightly irregular. Figure 40 shows that PDMS slightly absorbs light that is in the ultraviolet range but transmits all of the light in the visible range, which is $\lambda=400 \mathrm{~nm}-700 \mathrm{~nm}$. The quartz disk seemed to slightly block the incoming light, creating a transmittance at less than $100 \%$. 


\subsection{0 - Index of Refraction Measurements}

In the previous section the amount of light that is transmitted through the polymer PDMS was measured. The next step was to find out the percentage of reflections that would occur in the entire substrate of PDMS and quantum dots. Since the quantum dots were suspended in the PDMS, light would have to travel through both of these materials to encounter the solar cell. This measurement would calculate the total percentage of light that would be transmitted through the PDMS and quantum dots to the solar cell. In order to calculate this, the refractive index would need to be known. Another important calculation that could be made would be the extinction coefficient $(\mathrm{K})$ and also the amount of light that is absorbed $(\alpha)$ at $\lambda=620 \mathrm{~nm}$. The excitation coefficient measures how well a material scatters and absorbs electromagnetic radiation. If the excitation coefficient is low, electromagnetic waves, or light, will be able to pass through a material with minimal reflections. The reason for finding the absorption at $\lambda=620 \mathrm{~nm}$ is because this is the wavelength of fluorescence for the quantum dots. There are two different techniques used to measure the index of refraction for the materials. A Michelson Interferometer was built for this experiment that measured the index of refraction associated with PDMS in solid form. This device measures the phase difference that is observed when a laser passes through the material and is compared to a reference laser. Moreover, a digital refractometer made by Rudolph Research was employed with a model number J57 to measure the refractive index of the $\mathrm{CdSe} / \mathrm{ZnS}$ quantum dots suspended in toluene. I would expect the refractive index of the two materials to be much lower than the refractive index of silicon. This being the case the percent of reflection losses should also be minimal in order to increase the efficiency of the device. 


\subsection{1 - Michelson Interferometer}

The set up for Michelson interferometer was very difficult to calibrate. All of the components needed to be aligned properly in order for this device to work. The measurement had to be taken at night to reduce the amount of noise that the system encountered. Noise, in the form of foot traffic and talking, affected the system and had to be eliminated for the interferometer to provide accurate measurements. The physics department provided the components for this experiment which included: a HeNe laser, a 50/50 beam splitter, 2 mirrors, a beam expander, a convex lens, a photodiode, an oscilloscope and a vernier scale. The experiment was calibrated by having a HeNe laser beam enter a 50/50 beam splitter where half of the beam traveled toward mirror 1, reflected back to the beam splitter, and was sent into a beam expander. The other beam traveled toward mirror 2 and reflected back into the beam splitter and was also sent into the beam expander. The beams left the beam expander and entered lens, which had a focal length of $+20 \mathrm{~cm}$. The lens expanded the beams and sent the lasers to a photodiode. Please refer to figure 41 . 


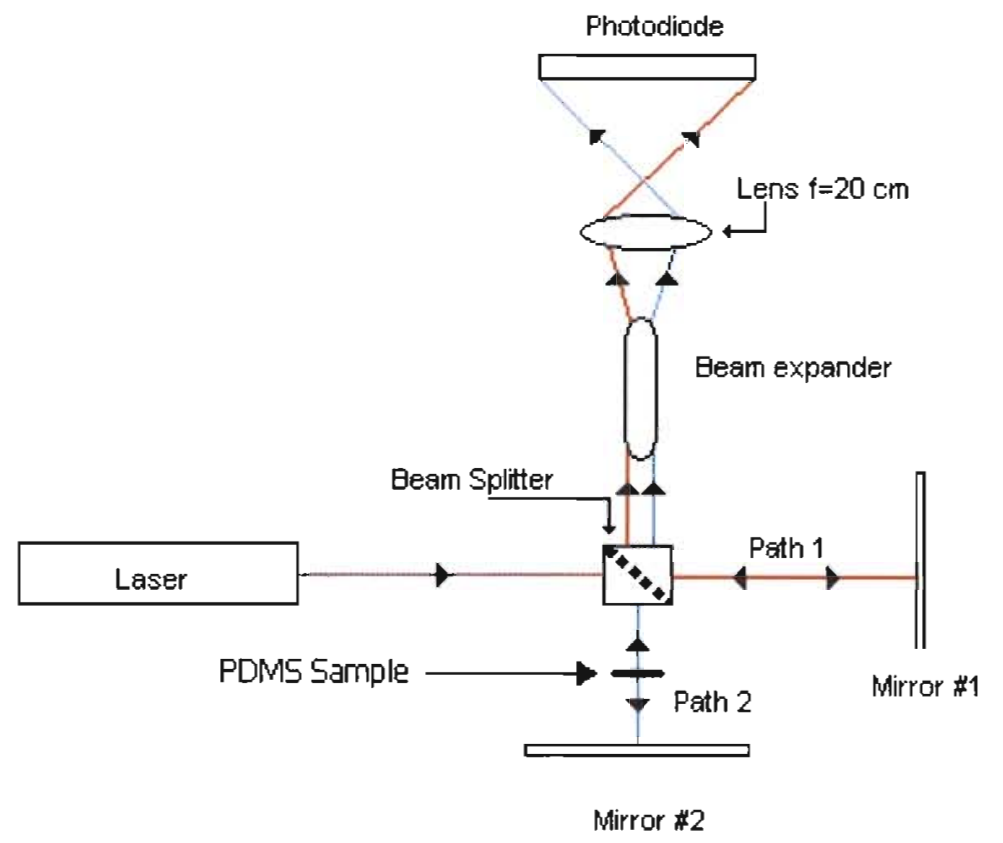

Figure 41 - Block Diagram of Michelson Interferometer

When the beams entered the lens, they inverted and then expanded. Since the image that exited the lens was symmetric it was acceptable to invert it without degrading the data. Please note that figure 41 uses two different color lines to represent the beams. This is to help distinguish what is going on in the system as there was no additional laser in the system. In front of mirror $\# 2$, was a vertical piece of PDMS which was $3 \mathrm{~mm}$ thick. The piece of PDMS was placed on top of a vernier scale at $0^{\circ}$ and 0 minutes. The benefit being that a vernier scale can measure between degrees accurately and move the position of the sample in very small increments. Between each degree there are tick marks ranging from 0 to 30 . These tick marks are known as "minutes". As the vernier scale was rotated, the output of the interferometer could be shifted across the photodiode. Below is the output of the Michelson Interferometer: 


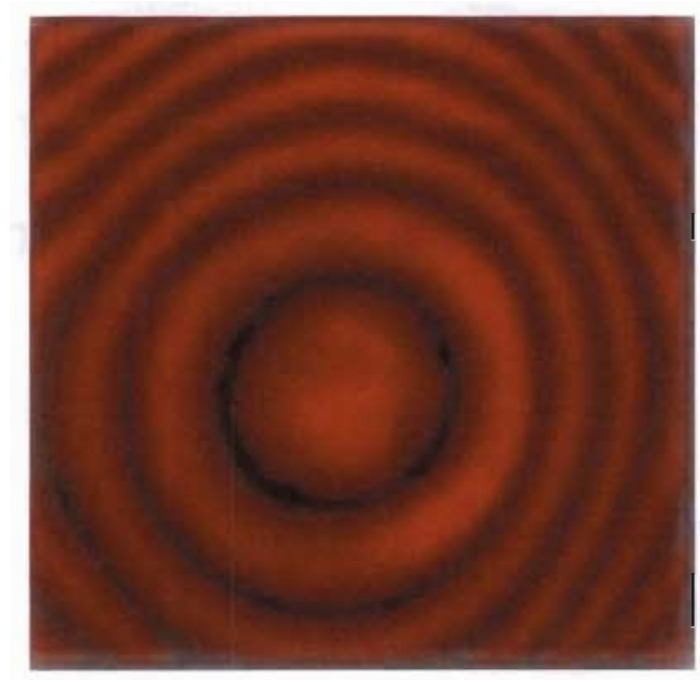

Figure 42 - Output of Michelson Interferometer

There are bright spots and dark spots in the image due to constructive and destructive interference. The laser that passed through towards mirror \#2 went through the PDMS sample 2 times which caused a change in the lasers phase due to passing through PDMS. The laser that went towards mirror \#1 was used as a reference, since it was unaffected. When the two lasers came in contact with each other there was a phase change between them. Where there were dark spots in the image is when destructive interference occurred with the two beams and constructive interference occurred when there were bright spots on the image. An oscilloscope was connected to the photodiode. Since a photodiode measures $\mathrm{DC}$ voltages it was easy to record when there was a bright spot due to the voltage being high and vice versa. Measuring the angles between bright fringes, and using those angles provided the calculation of the index of refraction associated with $3 \mathrm{~mm}$ of PDMS by using Equation 7.

$$
n=\frac{(2 t-M \lambda \text { air })(1-\cos \theta)}{(2 t(1-\cos \theta)-M \lambda \text { air })}
$$

Equation 7 - Index of Refraction Calculation [24] 
For equation $7 \lambda=632.8 \mathrm{~nm}$ and $M$ is the number of shifted fringes and $\mathrm{t}$ is the thickness of the PDMS and $\theta$ is the angle at which the fringes were observed. After using the equation above the index of refraction of PDMS found to be $n=1.403$. The index of refraction found in a polymer handbook was $n=1.4$, therefore, the measured data was valid [25].

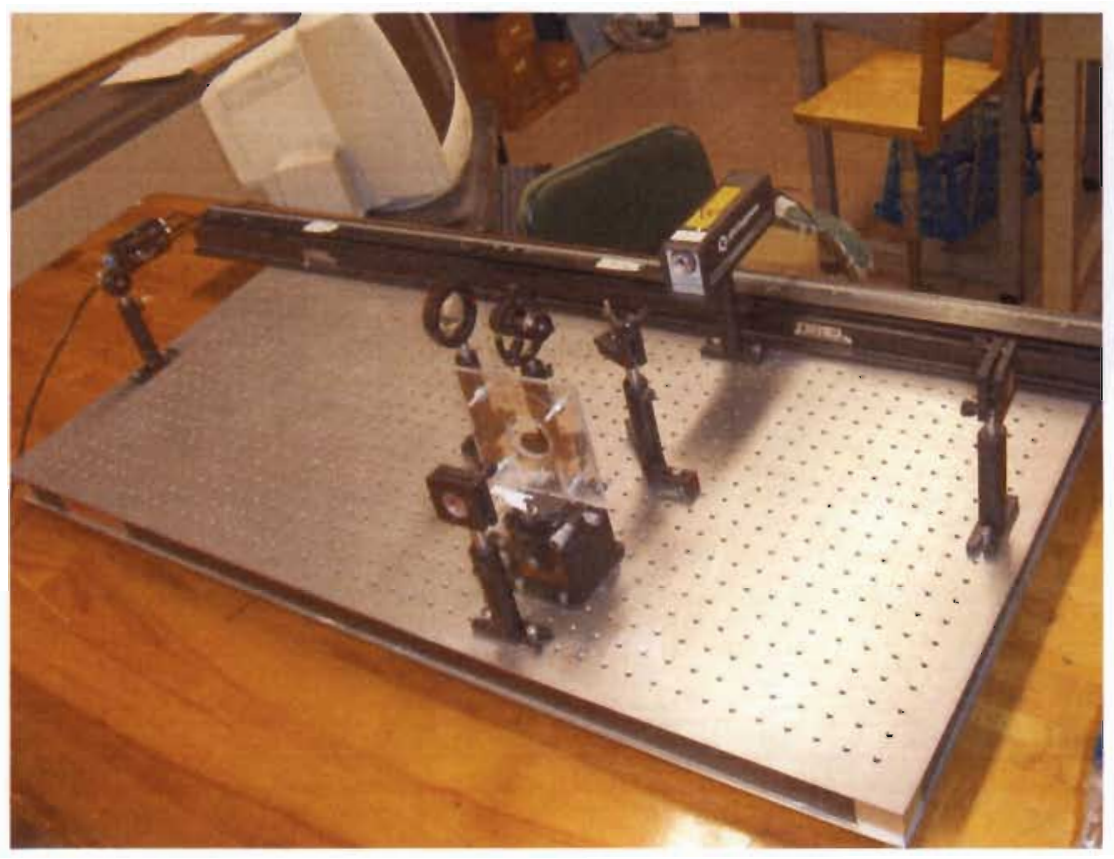

Figure 43 - Michelson Interferometer Top View 


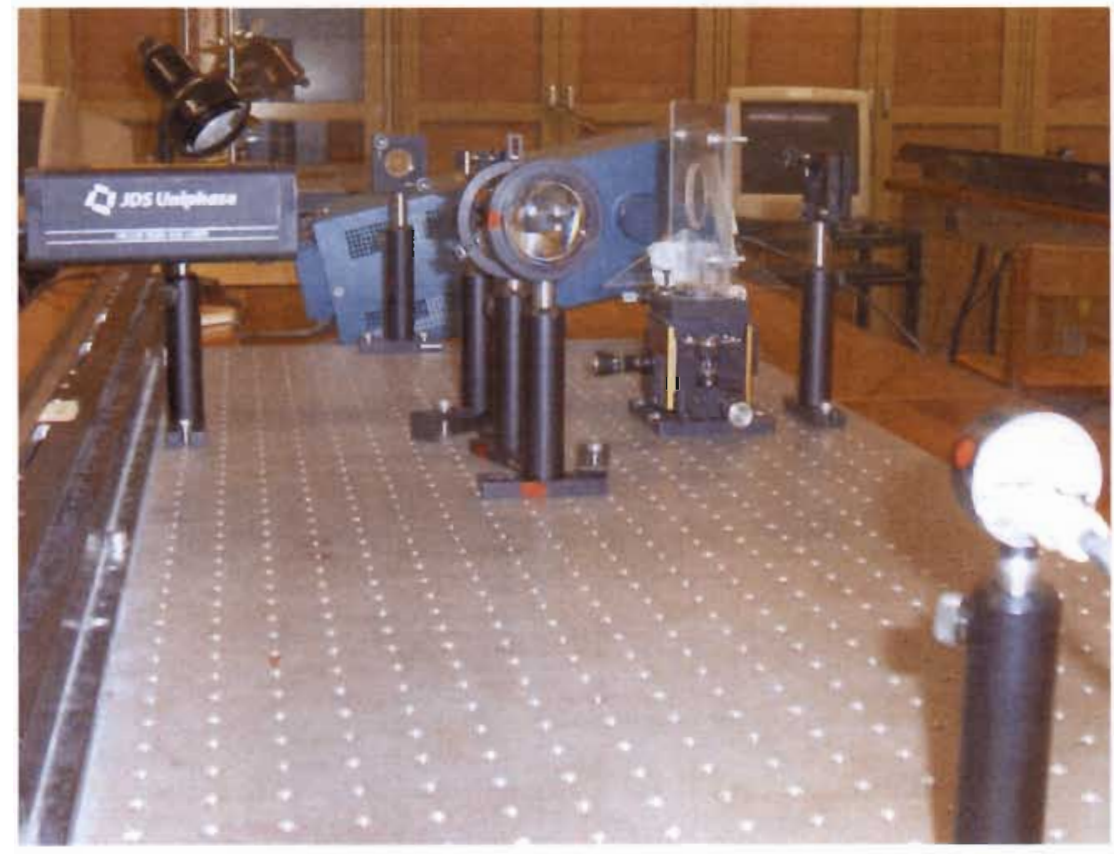

Figure 44 - Michelson Interferometer Side View

\subsection{2 - Refractometer}

Since $\mathrm{CdSe} / \mathrm{ZnS}$ quantum dots were in liquid toluene, the index of refraction could not be measured by using the Michelson Interferometer. Instead, I used a refractometer. The device I used was a Rudolph Research J57 Digital Refractometer, provided by the chemistry department. This device allows liquids to be measured for their index of refraction. A droplet of $\mathrm{CdSe} / \mathrm{ZnS}$ quantum dots suspended in toluene was placed onto the measuring device and the index of refraction associated with the quantum dots was $n=1.4969$. Pure toluene was also measured to see how much of an effect the quantum dots had on the index of refraction. The pure toluene had the same index of refraction as the toluene filled with quantum dots at $n=1.4969$. This is do to the quantum dots being too small to affect the index of refraction. As the toluene evaporated, it allowed the quantum dots to cluster together. This caused the index of refraction to increase to $n=1.5121$. It appeared that when the quantum dots were not surrounded by a liquid solution they clustered together. In 
clustering together the amount of fluorescence decreased which is do to less light being transmitted.

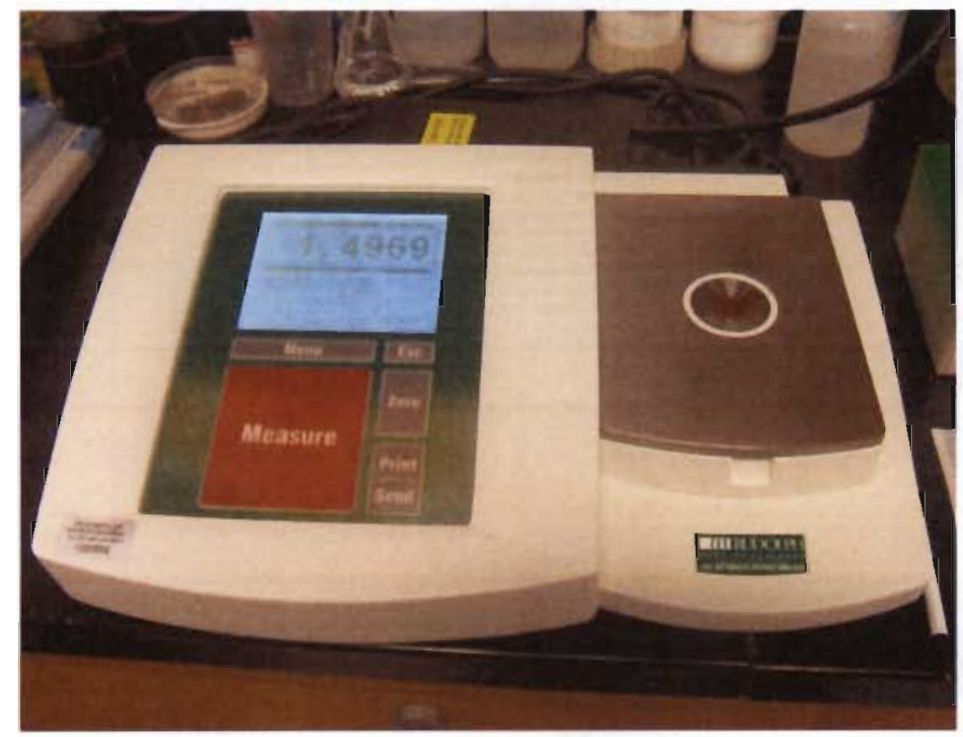

Figure 45 - Rudolph Research J57 Digital Refractometer 


\subsection{3- Calculated Reflections}

By knowing the index of refraction for PDMS and the CdSe/Zns quantum dots in toluene, the amount of light that is reflected off each surface could now be calculated, using the Fresnel Equation.

$$
R=\left|\frac{E r}{\mathrm{Ei}}\right|^{2}=\left(\frac{(n 2-n 1)}{n 2+n l}\right)^{2}
$$

Equation 8 - Fresnel Equation

This equation gives an estimate of the reflections and transmittance that occurs through different mediums by using the index of refraction for each material. In using this equation, a few assumptions were made. The first assumption is that the angle of incoming light is at normal incidence, or $0^{\circ}$. This assumption was necessary because the light incoming to a solar cell will range from $0^{\circ}$ to $+/-90^{\circ}$ depending on the time of day, the day of the year and the objects that reflect the sun's light. The highest intensity, therefore, is when the light is traveling at normal incidence. The next assumption is that the transmitted light is in terms of incident energy [26]. Finally, the thickness of the materials was not taken into account in this equation. This equation calculates the amount of reflections associated with a material due to the index of refraction. There were 3 different mediums that the light had to travel through in order to reach the solar cell. It first passed through the PDMS to get to the microfluidic channel. From there the light traveled through the $\mathrm{CdSe} / \mathrm{ZnS}$ quantum dots suspended in toluene and finally back through the PDMS. At the surface of each of the materials, light is either transmitted or reflected. Figure 46 shows the light that is transmitted in terms of $\mathrm{T}$ and the light that is reflected in terms of $\mathrm{R}$. The value of 0.97 percent of light transmitted, therefore, there was a $3 \%$ loss due to reflection. The excitation coefficient was 0.0014 and the absorption coefficient was $2.8 \times 10^{4} \mathrm{~m}^{-1}$. These calculations can be viewed in Appendix C. 


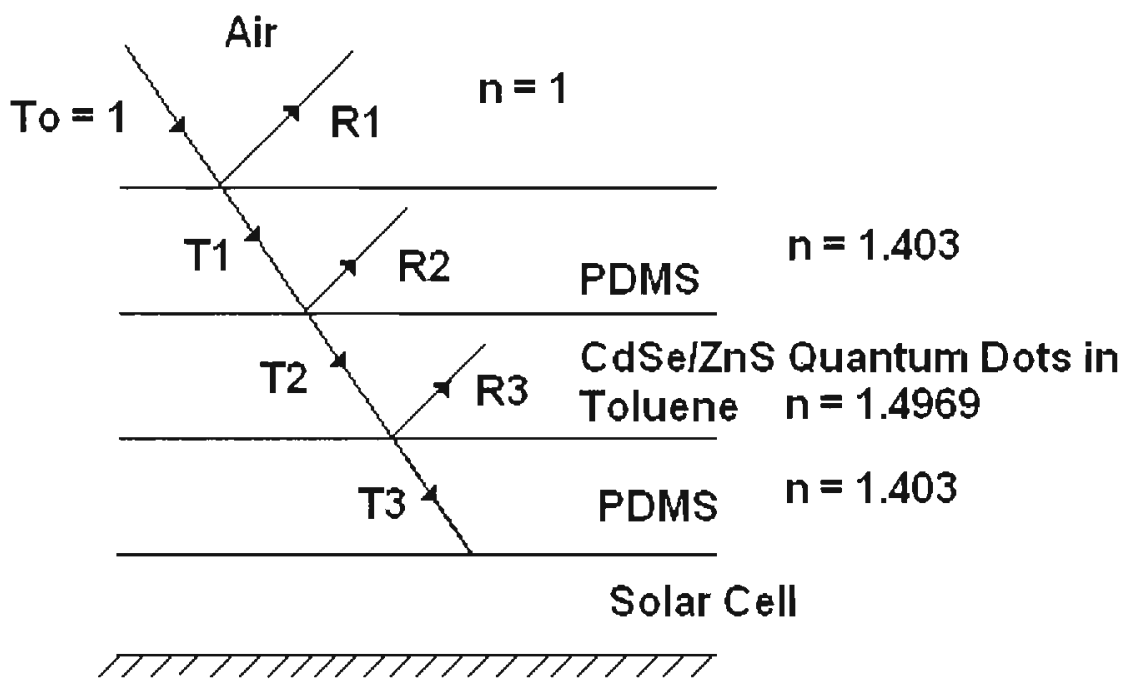

Figure 46 - Diagram of Reflections and Transmission Between Materials

These calculations confirm previous assumptions that the loss do to reflections was minimal.

Most of the light was transmitted through the polymer to the solar cell. Therefore, it was advantageous to continue with fabrication of the microfluidic channels. 


\section{CHAPTER 6 - SOFT LITHOGRAPHY}

In order to use the microfluidic channels to suspend the liquid quantum dots microfluidic channels were fabricated using a technique known as soft lithography. Soft lithography is a method of fabrication using elastomeric stamps, molds and conformable photomasks. This lithography method is called "soft" because of the use of the elastomeric material PDMS which is one of many types of polymers that could be used. These microfluidic channels will suspended quantum dots in them and ultimately be placed on top of a solar cell.

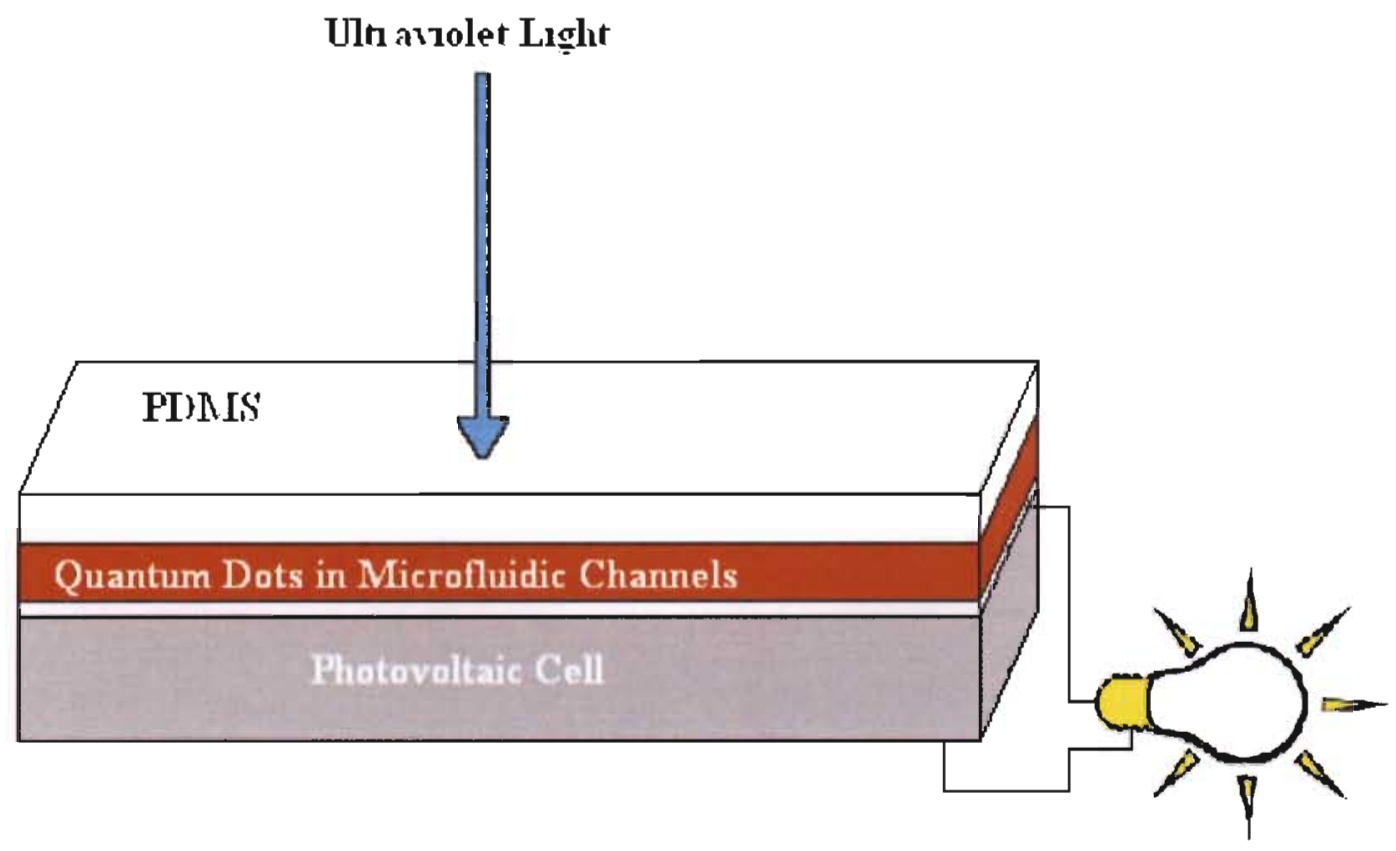

Figure 47 - Microfluidic Channels Filled with CdSe/ZnS Quantum Dots Placed on Top of a Photovoltaic Cell

\subsection{0 - Preparation Needed for Fabrication}

This fabrication process requires initial preparation before any type of fabrication can take place. It is important to remove the negative photoresist from its refrigeration at least 12 hours prior to use. This will allow the photoresist to be at room temperature or 
approximately $25^{\circ} \mathrm{C}$. Since the photoresist is very viscous it is hard to remove from the spin coater once the photoresist has been spun on. A thin layer of tin foil should be placed on the inside of the spin coater. This will help in cleaning any photoresist that is not left on the silicon wafer.

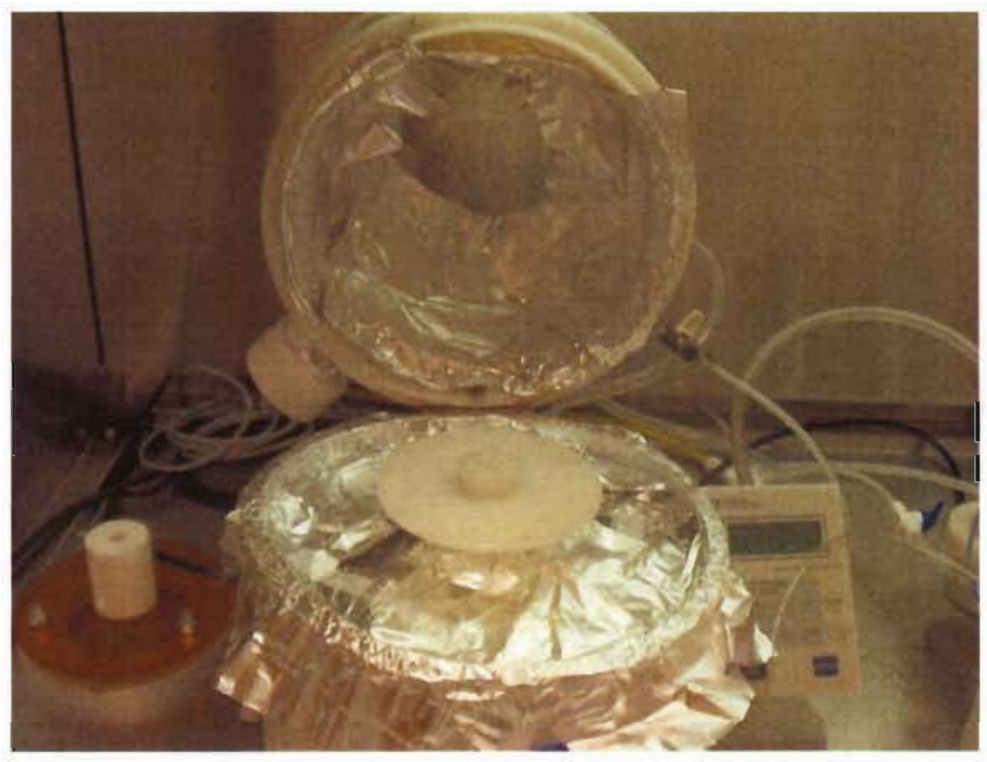

Figure 48 - Spin Coater Covered with Tin Foil

\subsection{1 - Fabrication of Microfluidic Channels Using Soft Lithography}

The fabrication process started out with a (100) bare silicon wafer. It was important to remove any type of oxide layer on the wafer. To do this, the wafer was placed in hydrofluoric acid until the oxide layer was removed. The wafer is then placed in deionized water to stop the acid from being reactive on the wafer [27]. The wafer is then cleaned of organic contaminants that might have been under the oxide layer using a (9:1) mixture of sulfuric acid $\left(\mathrm{H}_{2} \mathrm{SO}_{4}\right)$ and hydrogen peroxide $\left(\mathrm{H}_{2} \mathrm{O}_{2}\right)$, also known as a piranha solution, for approximately 20 minutes at a temperature of $75^{\circ} \mathrm{C}$. Next, the wafer is immersed in deionized water for 20 seconds and then transferred to the spin rinse dryer. 


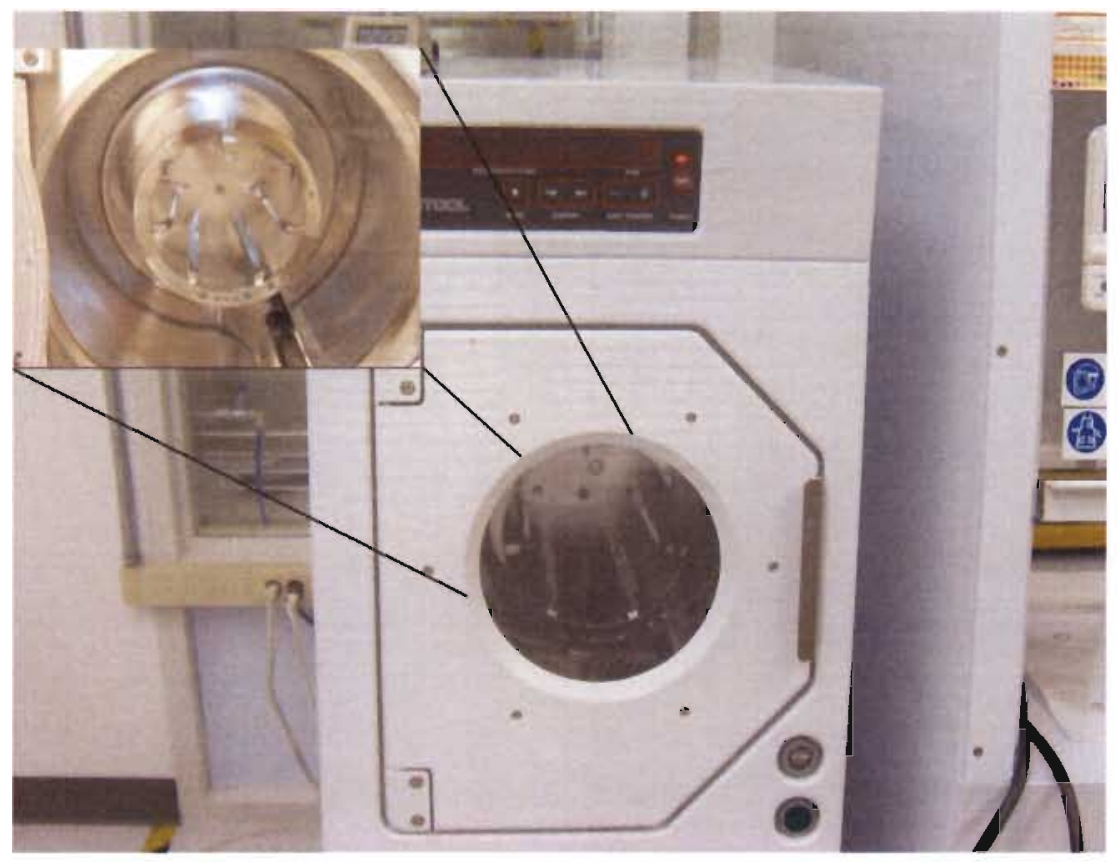

Figure 49 - Spin Rinse Dryer

The spin rinse dryer shoots jets of deionized water onto the silicon wafer, completely covering the wafer with deionized water. Once this process is finished, it spins the wafer at a very high speed as well as blasts the wafer with nitrogen. Fabrication of the mold that would ultimately create the microfluidic channels is the next process that followed. 

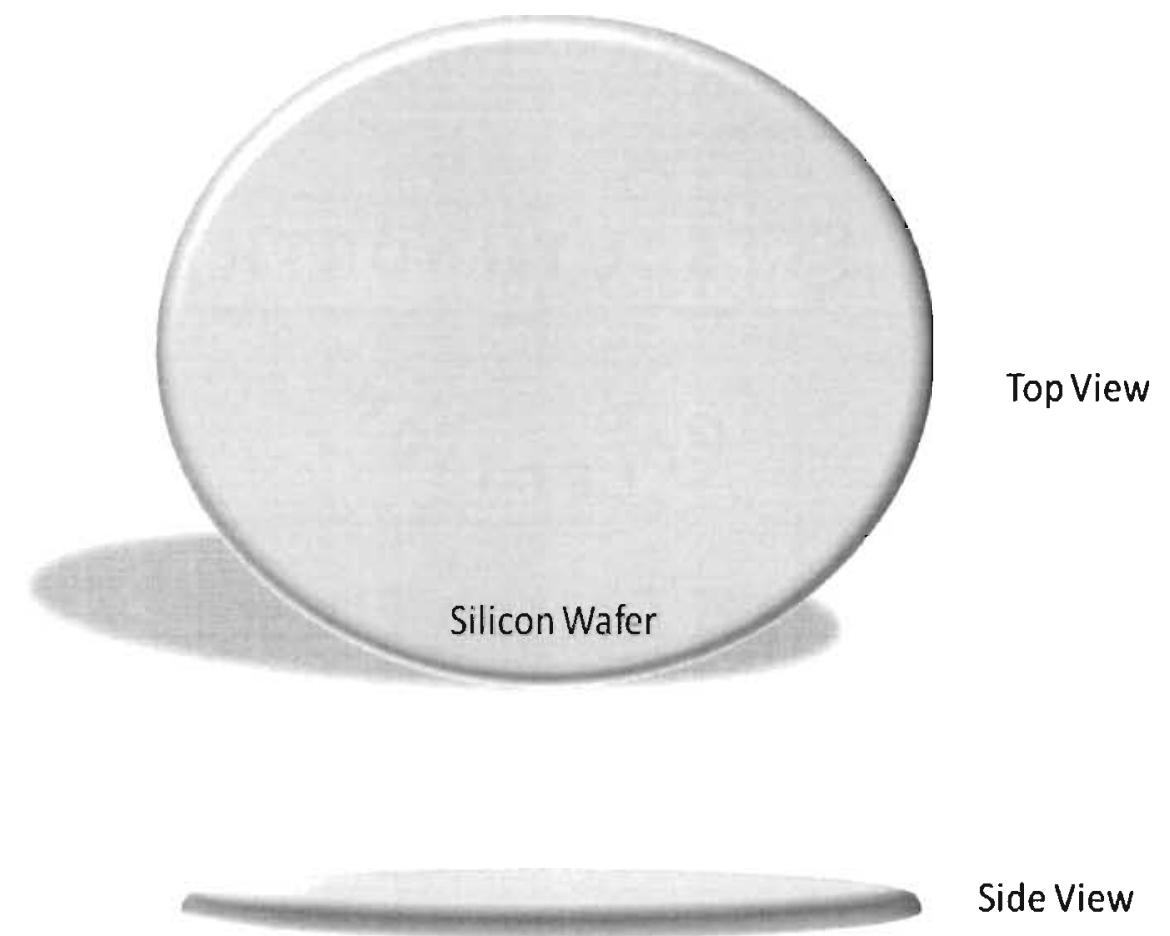

Figure 50 - Bare Silicon Wafer

To dehydrate the surface of the silicon wafer from any moisture that might have accumulated, the wafer was placed onto a hot plate for 3 minutes at $65^{\circ} \mathrm{C}$. Once the wafer was completely dehydrated, it is placed in the center of the spin coater. In order to center the wafer accurately, a centering tool was used. To ensure the wafer would not move during the spinning process a vacuum pull on the wafer was used. Negative photoresist (SU-8 2050) is then poured on the wafer the wafer is spun in a two-stage spin cycle. The first spin is for 20 seconds at $400 \mathrm{rpm}$ with an acceleration of $86 \mathrm{rpm} / \mathrm{second}$ to help spread out the SU-8. The second spin cycle is used to cerate the thickness of SU-8 2050. The desired thickness was $35 \mu \mathrm{m}$ obtained by setting the second spin cycle for 35 seconds at $4000 \mathrm{rpm}$ with an acceleration of $602 \mathrm{rpm} / \mathrm{second}$. These spin rates were obtained from a spin curve courtesy of Hans Mayer and can be seen in Appendix D. 

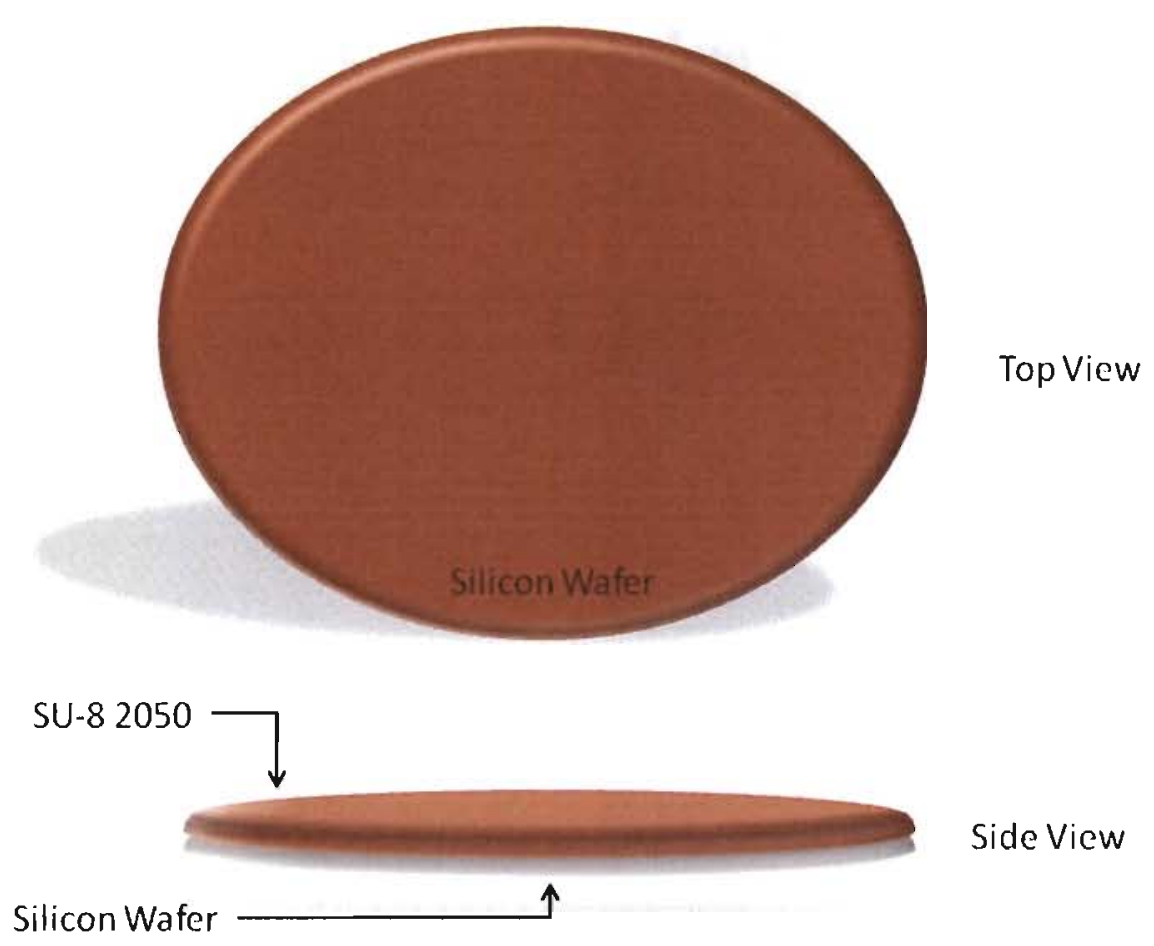

Figure 51 - Silicon Wafer with SU-8 Photoresist Applied

After the negative photoresist was applied to the silicon substrate, it must be soft baked to evaporate the solvent and make the film denser. The silicon wafer was placed onto a hot plate for 5 minutes at $95^{\circ} \mathrm{C}$ and then into the aligner to be exposed to ultraviolet light. See Appendix E for layout of all masks used. 


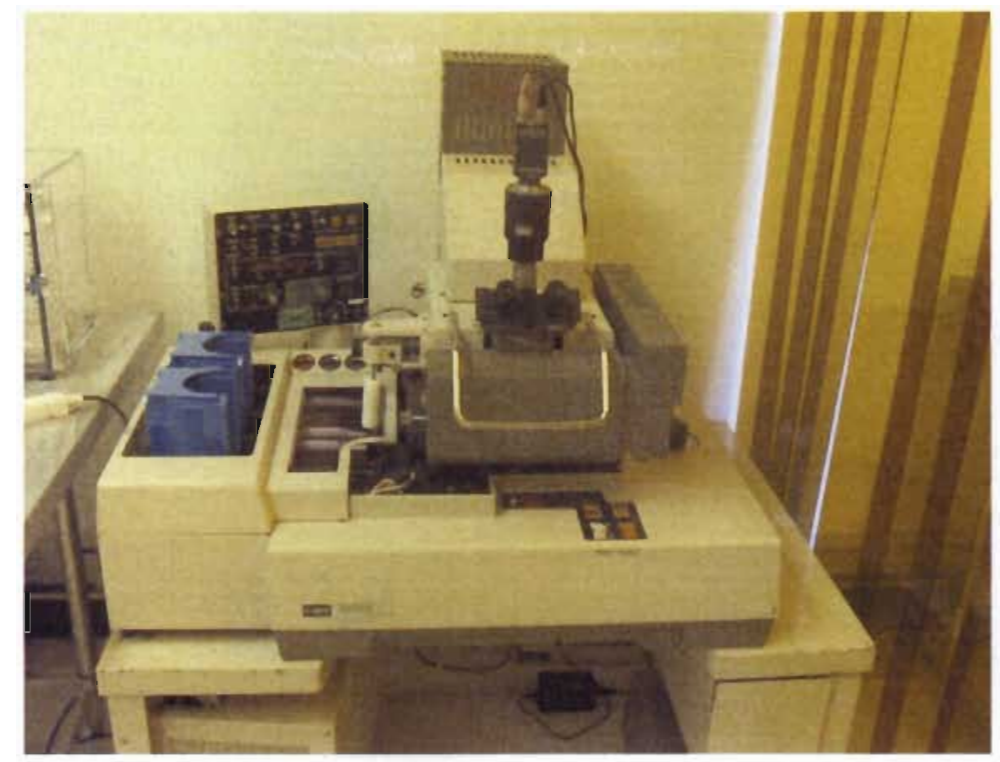

Figure 52 - Aligner Used to Expose the Negative Photoresist to Ultraviolet Light

To know the amount of time, or light integral, needed to prevent underexposure, an exposure matrix was taken. An exposure matrix consists of exposing a photoresist coated silicon wafer to different light integrals in different quadrants of the wafer. Using multiples of 5 for the light integral, it was found that the best exposure was between 10 and 40 light integrals. A light integral is the amount of time that the ultraviolet light is exposed to the wafer. 1 light integral is equal to 3 seconds. It appeared that it was very hard to overexpose the SU-8 photoresist, so a light integral of 25 was used. After the wafer was exposed to ultraviolet light in the aligner, it was placed on a hot plate for a post exposure bake. 


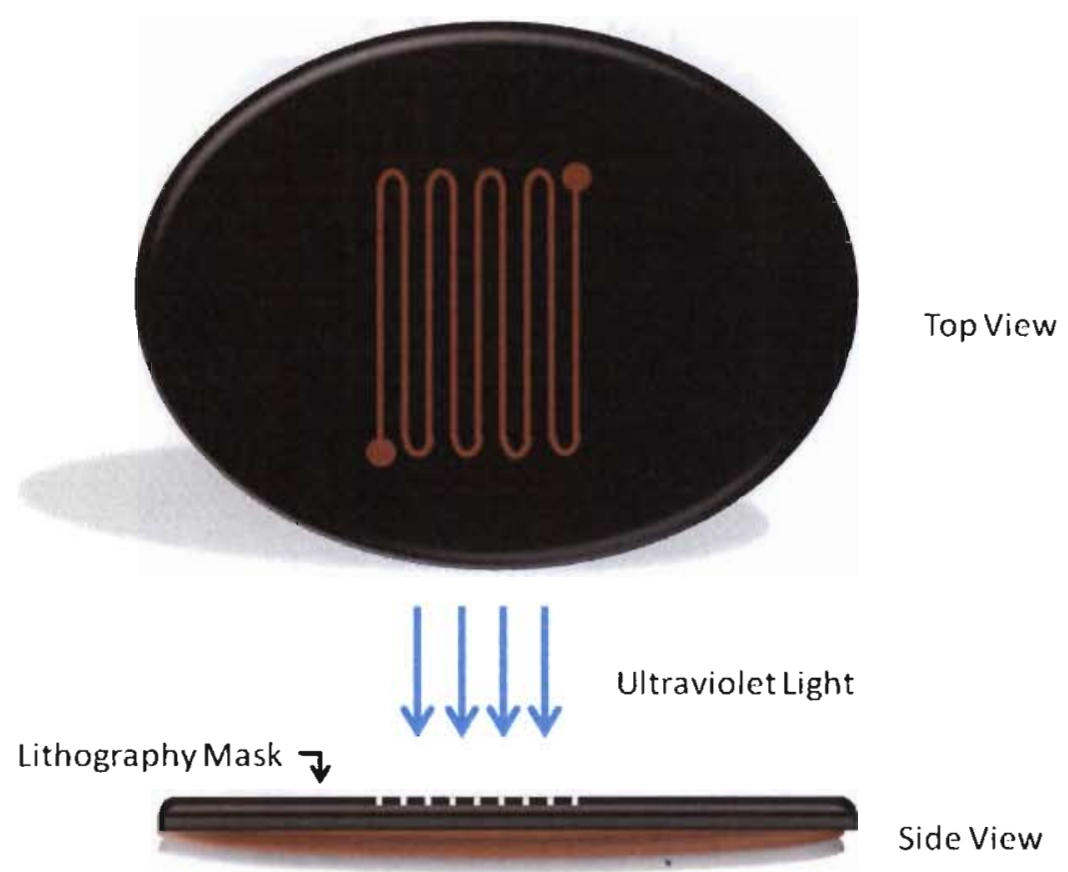

Figure 53 - Ultraviolet Light Exposure to SU-8

The purpose of the post exposure bake allowed the ultraviolet exposed photoresist to successfully cross-link, or harden. This bake was done for 1 minute at $65^{\circ} \mathrm{C}$ then transferred to another hot plate and baked for 6 minutes at $95^{\circ} \mathrm{C}$. 

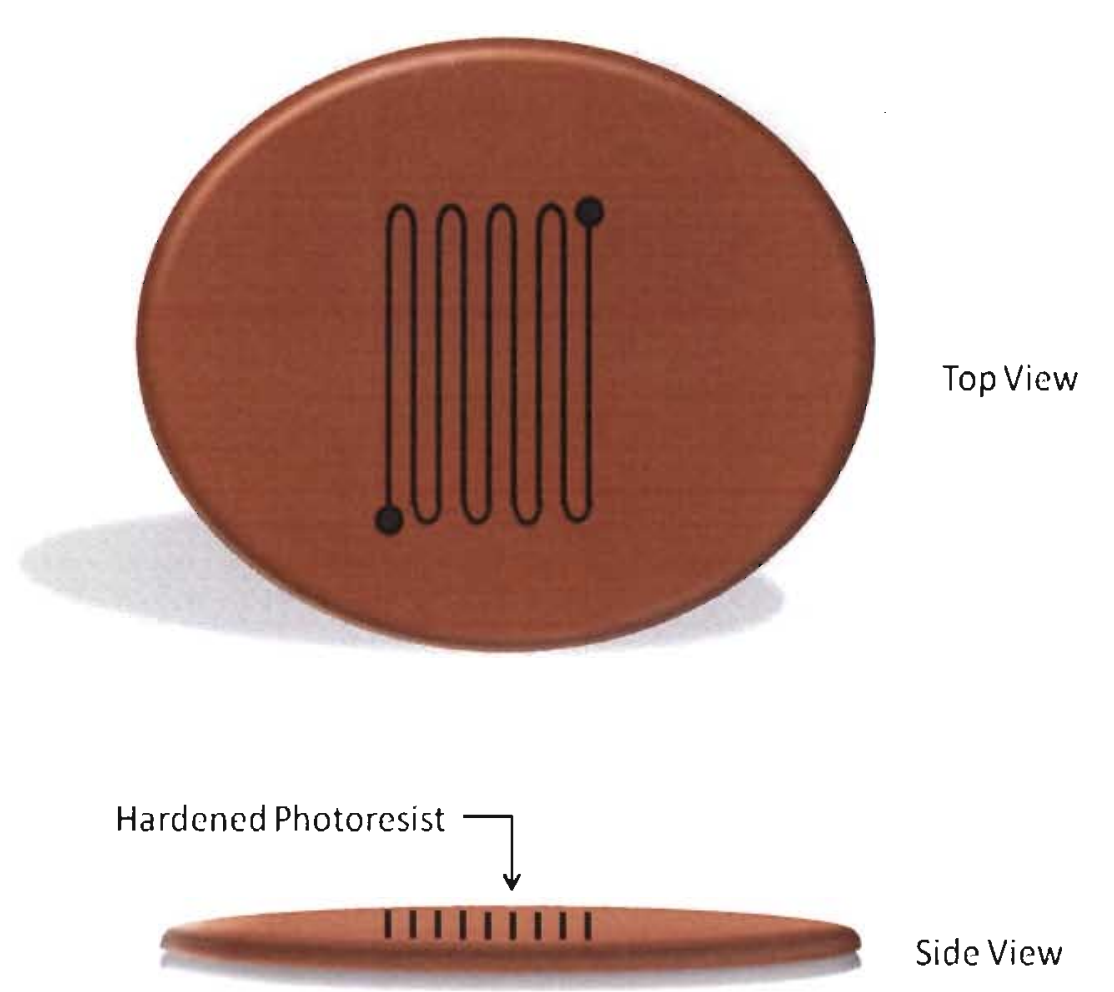

Figure 54 - Cross-linked (Hardened) Photoresist

To remove the unwanted areas of photoresist, the wafer was placed in an SU-8

developer. The wafer remained in the developer until the excess photoresist was removed. The wafer was removed from the developer, rinsed with isopropyl alcohol and dried using a nitrogen gun. 


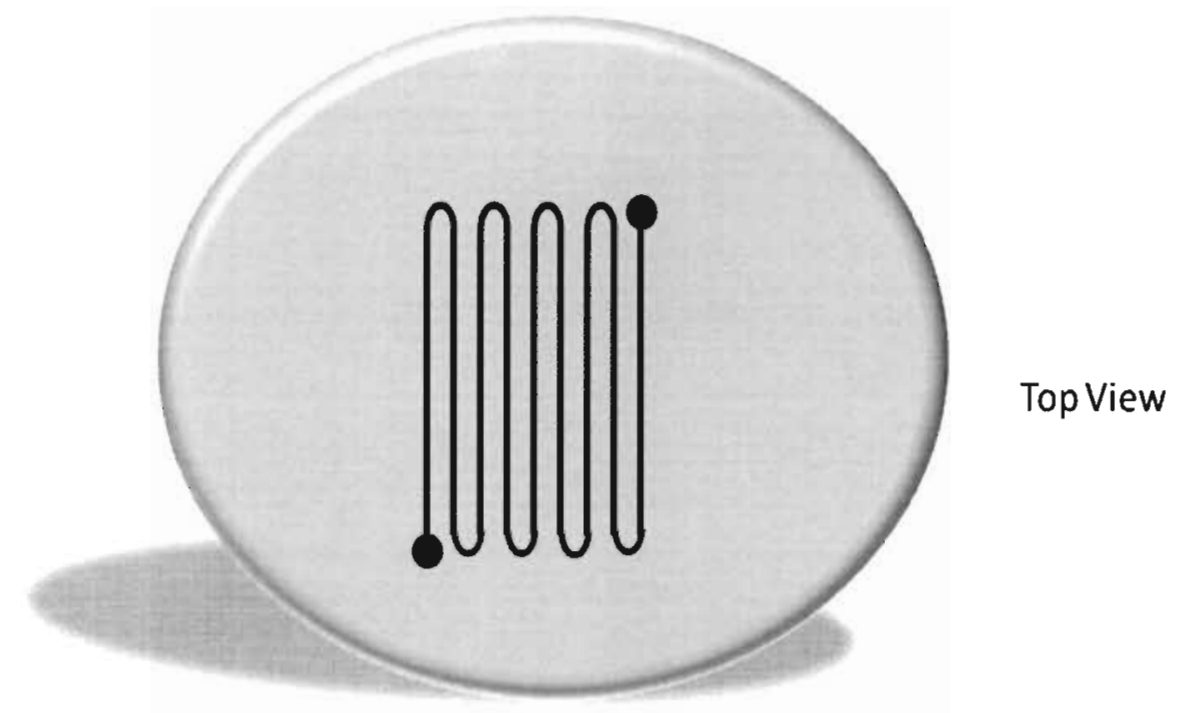

1401401 Side View

Figure 55 - Imprint Used to Create Microfluidic Channels

Now all that remained on the surface of the silicon wafer was the hardened

photoresist. This hardened photoresist acted as a mold that was used to create the microfluidic channels. Figure 55 is an image of the two fabricated wafers using the two different masks. The wafer on the left was created with mask \#1 and the wafer on the right was created with mask \#2. 


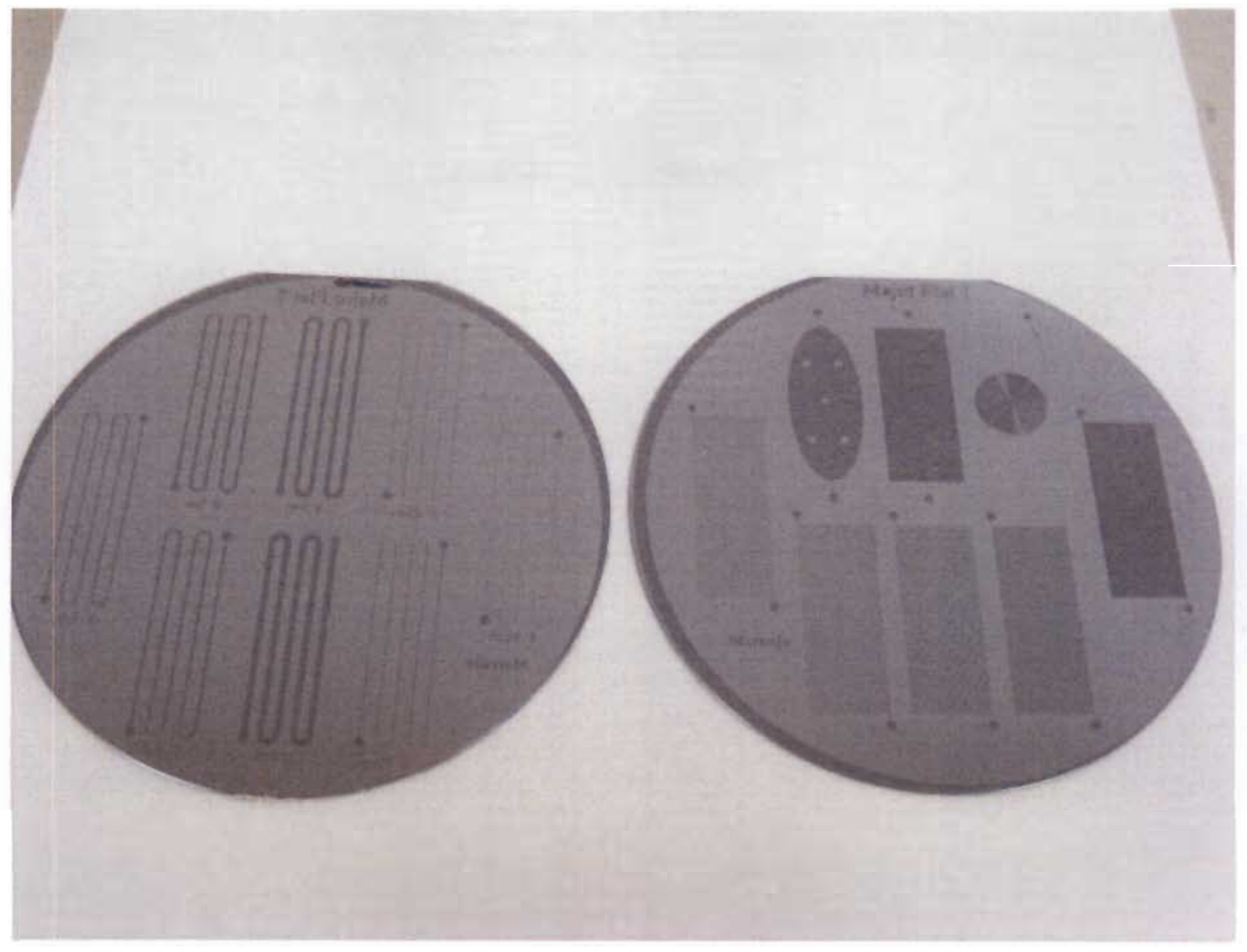

Figure 56 - Fabricated Wafers

The height of the hardened photoresist was measured using a profilometer to see if the desired height of $35 \mu \mathrm{m}$ was obtained. 


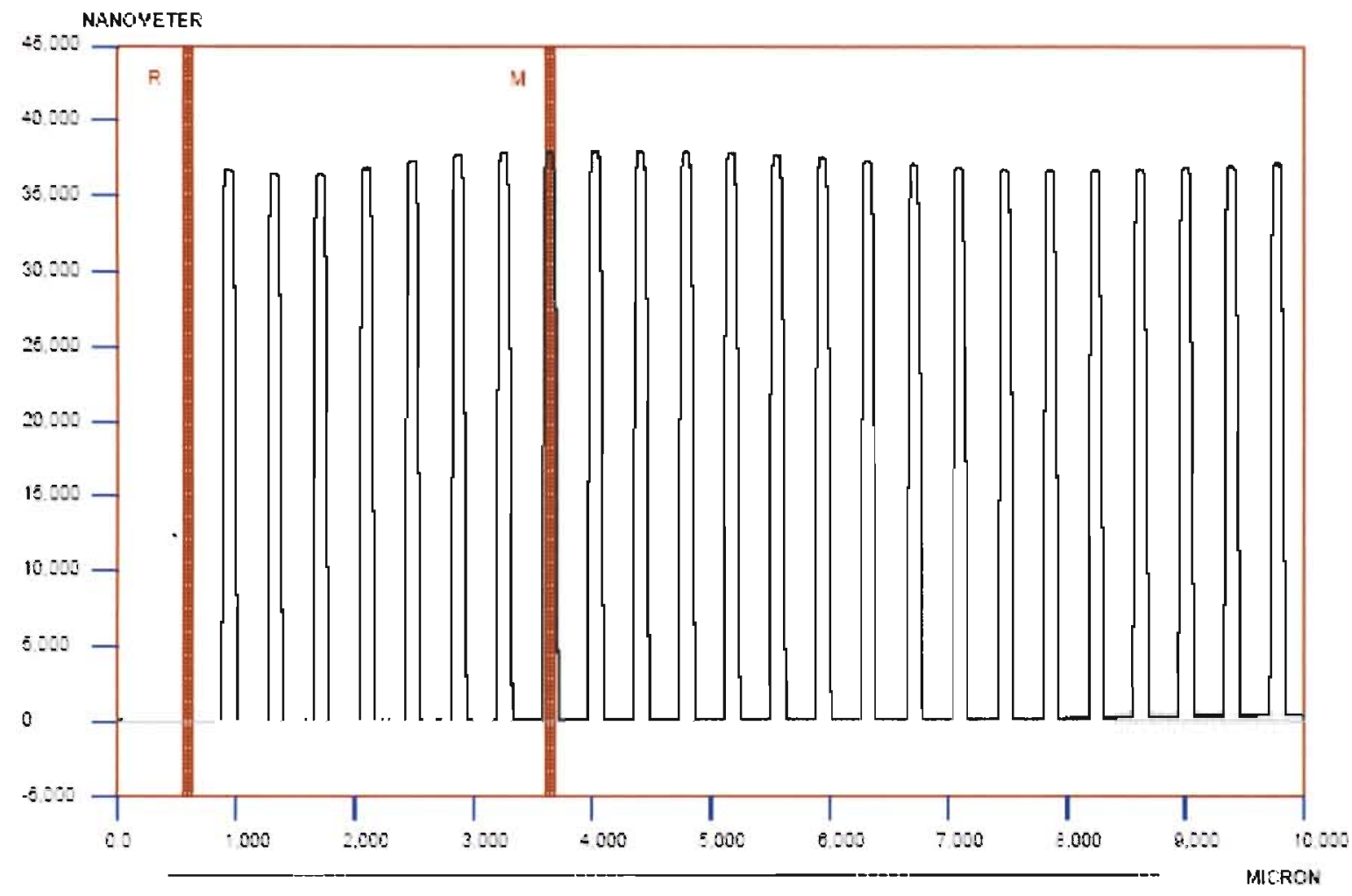

Figure 57 - Profilometer Height Measurement

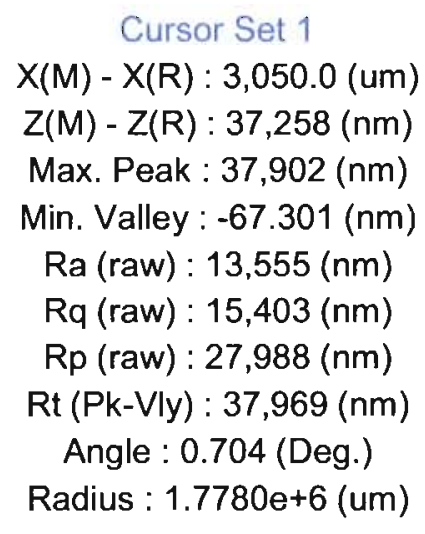

Table 2 - Profilometer Data

PDMS was chosen for a number of reasons over other polymers due to its optical properties which were stated earlier. The PDMS was purchased from Dow Corning and is 
called Sylgard 184. Sylgard 184 is a two part liquid mixture, a base and a curing agent mixed in a 10:1 solution respectively.

$$
V A=\frac{\pi D^{2} t}{4+\frac{4}{M R}}
$$

Equation 9 - Required $\mathrm{mL}$ of Base for Desired Thickness

$$
V B=\frac{V A}{M R}
$$

\section{Equation 10 - Required $\mathrm{mL}$ of Curing Age for Desired Thickness}

In order to create a layer thick enough to cover the mold on the silicon wafer, $35 \mathrm{~mL}$ of base to $3.5 \mathrm{~mL}$ of curing agent was employed. The values were obtained from the equations above where $\mathrm{D}$ is the Petri dish diameter, $\mathrm{t}$ is the desired thickness and MR is the mix ratio (i.e. 10 for 10:1). When the curing agent and the base were mixed together they were placed in a vacuum chamber to degas.

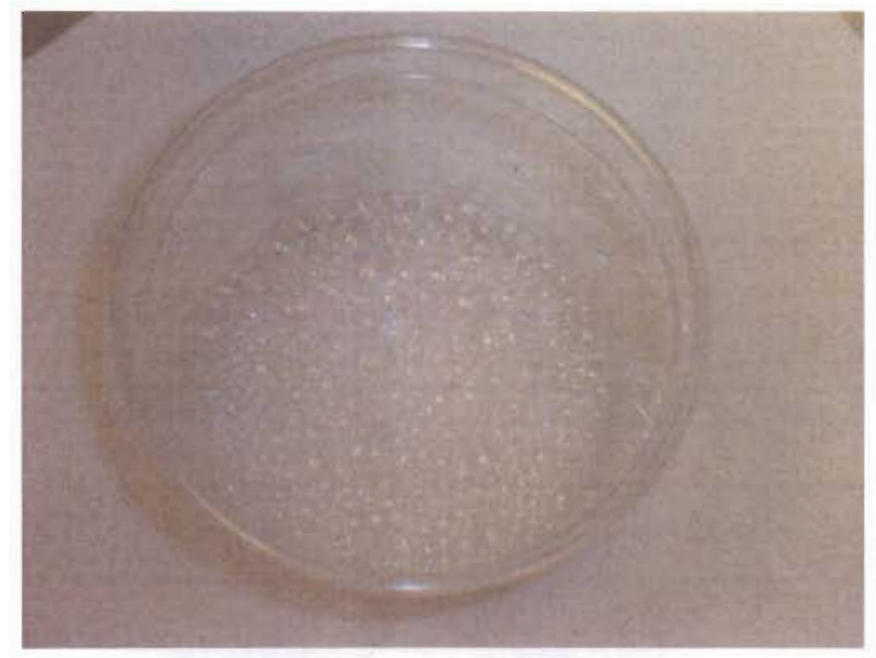

Figure 58 - PDMS Degassing in Vacuum Chamber

Degassing the PDMS helped to eliminate the amount of bubbles that were present when the polymer solidified. Eliminating bubbles helped to eliminate any defects in the 
microfluidic channels. After the PDMS was degassed, it was poured on top of the silicon wafer mold and placed into an oven at $80^{\circ} \mathrm{C}$ for an hour, which solidified the PDMS mold.

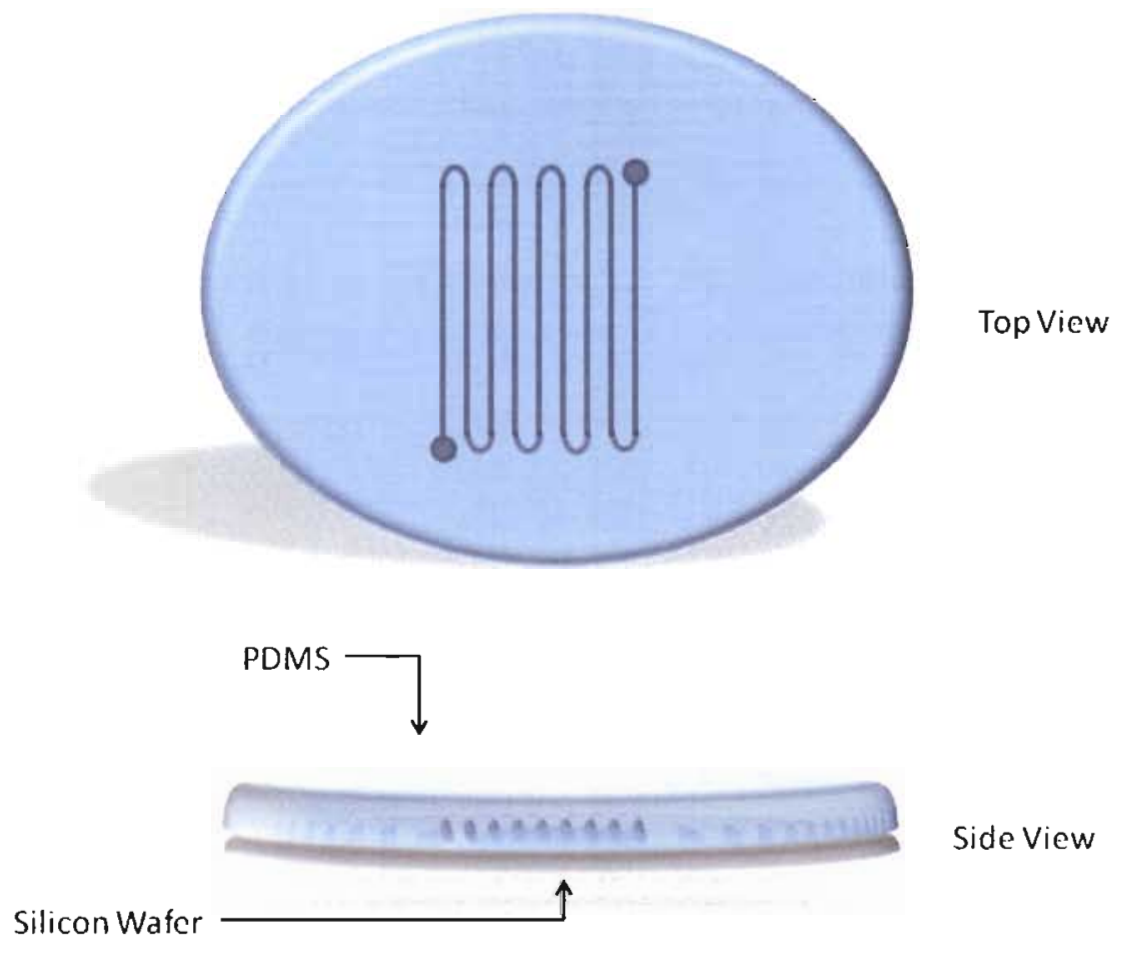

Figure 59 - Solidified PDMS on Top of Silicon Wafer Mold

The mold of PDMS was then pealed off of the wafer and cut into 1.5 inch $\mathrm{x} 0.5$ inch sections. These dimensions of the cut PDMS were used to match the dimensions of the solar cell that was characterized earlier. Ultimately the fabricated PDMS, filled with quantum dots, was placed on top of the solar cell. After cutting the individual sections, a small hole was punched into the PDMS. These holes are used to disperse liquid through the microfluidic channels. A hole was punched at both the top and bottom of the channel to allow the flow of liquid.

Another small piece of PDMS was then prepared in a petri dish the same size as the silicon wafer. This PDMS piece was fabricated the exact same way as stated above, the only difference being that the silicon wafer was not present in this process and, therefore, there 
was no imprint in the solidified PDMS. With the absence of the silicon wafer, the PDMS solidified as a flat substrate. The flat substrate was cut into slightly larger pieces than the 1.5 inch $\times 0.5$ inch sections. This made it easier to place one piece on top of the other when bonded together. In order to bond the two substrates together, a plasma treatment is needed. Each of the two pieces of PDMS are passed under a plasma gun for 2 seconds and then placed on top of each other to seal off the microfluidic channel.

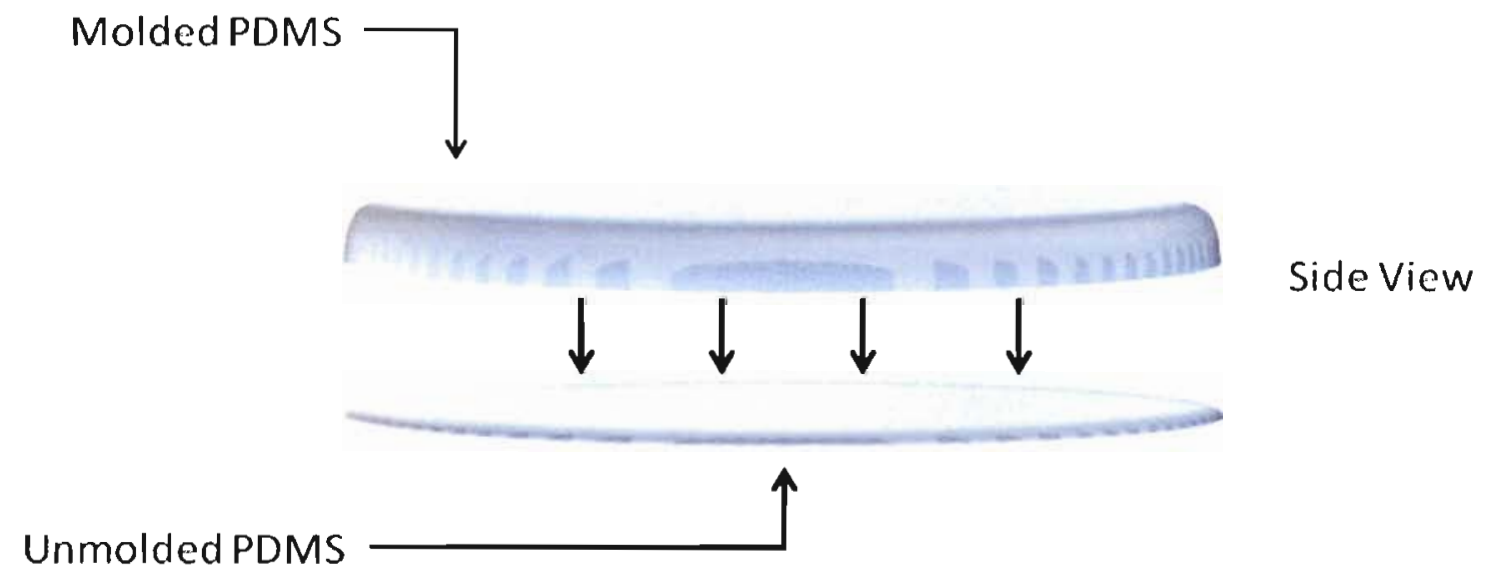

Figure 60 - Molded PDMS Placed on Top of Plane PDMS After Plasma Treatment

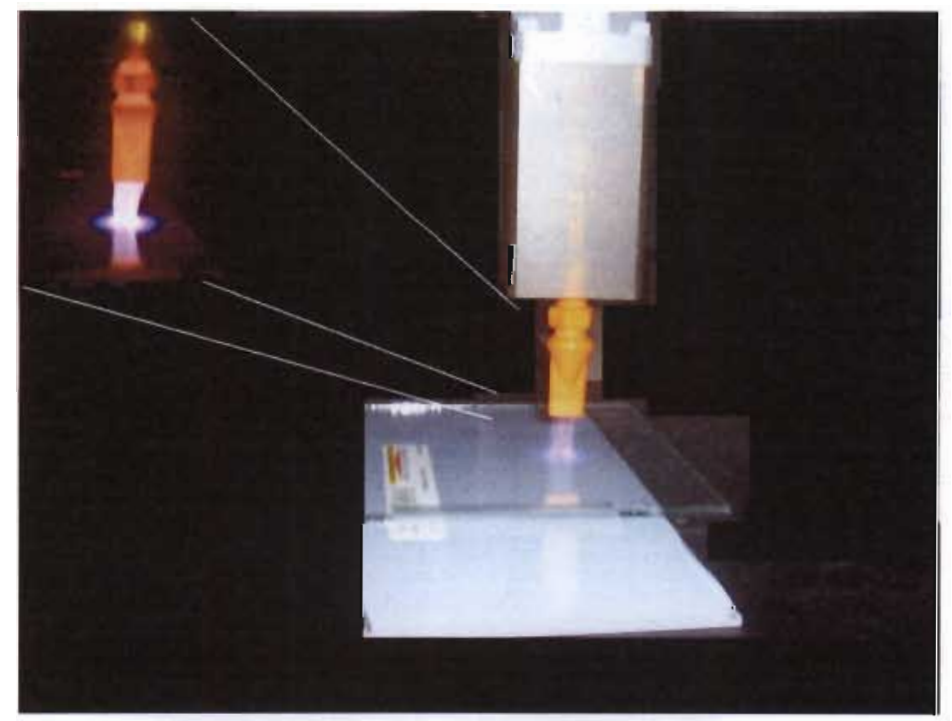

Figure 61 - Plasma Gun Used to Treat PDMS 
After the two pieces of PDMS have been placed, they are then baked for an hour at $80^{\circ} \mathrm{C}$, allowing the bond to completely set between the two pieces.

Next, a thin piece of plastic tubing was positioned into the punched holes to direct the solution into the microfluidic channels. Now the microfluidic channels were ready for the quantum dots to be injected into them.

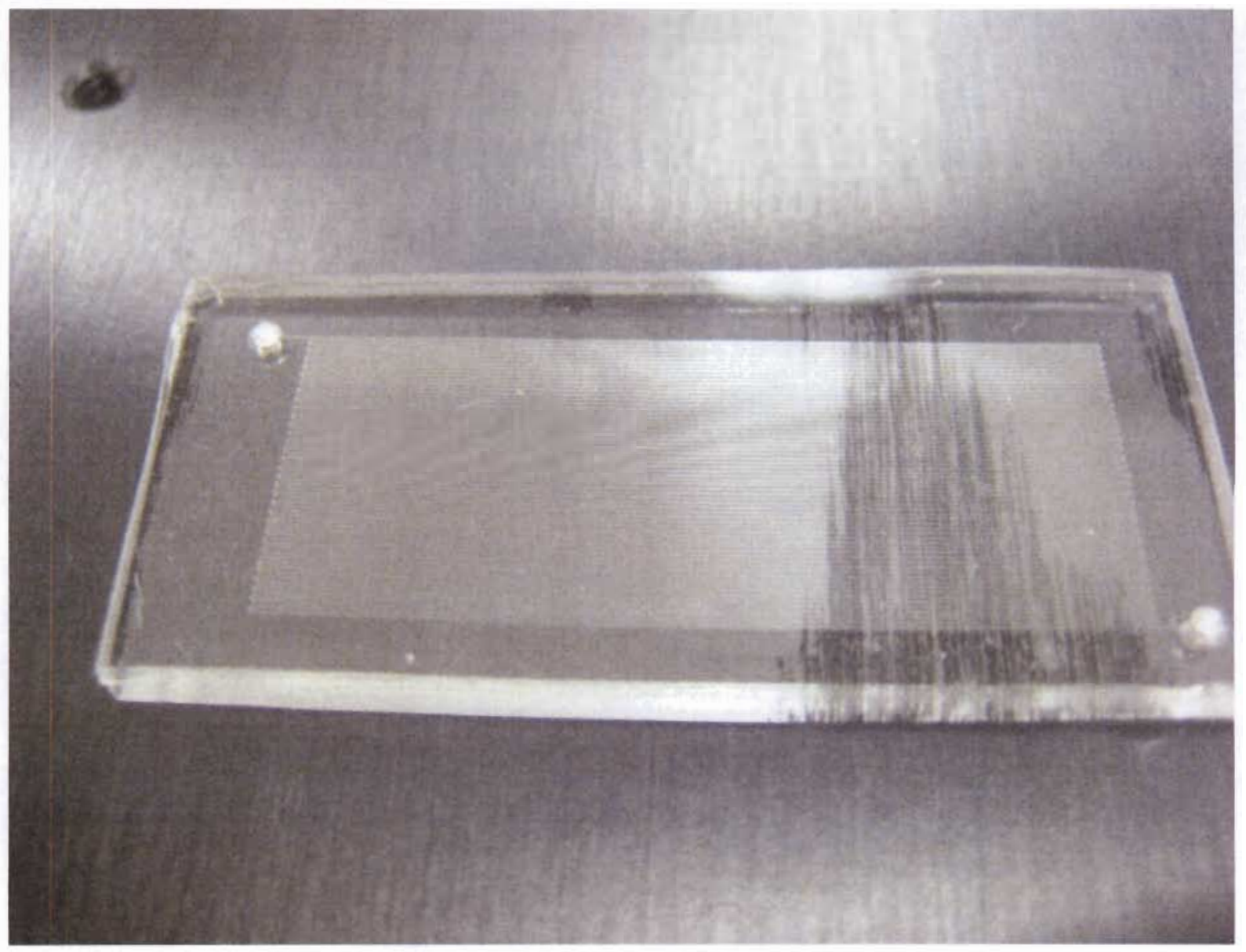

Figure 62 - PDMS Microfluidic Channel

\subsubsection{Observation in Fabrication Process}

The wafers that were used during this process had an oxide layer on the polished side of the wafer. Because the oxide layer was unknown the wafer was dipped in hydrofluoric acid for 20 minutes. This appeared to remove the entire oxide layer that was present on the 
wafer. Since it was only important to have a flat surface, investigating the presence of an oxide layer was not necessary.

When developing the negative photoresist, a white film was observed in certain areas of the wafer due to underdeveloped regions of photoresist. To solve this problem the wafer was put back into the SU-8 developer and the development process repeated, which removed this white film.

Before dispersing the $\mathrm{CdSe} / \mathrm{ZnS}$ quantum dots in toluene solution, a trial experiment was conducted by placing green food coloring through the microfluidic channels to see if the channels actually allowed liquid to flow through them and to ensure that the wafer that the mold was created on did not have any defects in it. The food coloring was dispersed right after the PDMS was plasma treated. The two pieces of PDMS that were bonded together tore apart. After observing this, the PDMS was baked for an hour at $75^{\circ} \mathrm{C}$ after plasma treatment and this eliminated this problem with future experiments. Another problem that occurred were breaks or tears in the microfluidic channels. Do to the number of channels that were fabricated, each time it was hard to produce channels that had no defects in them. Scratches or defects in the photoresist mold that was fabricated were believed to have caused these defects. To avoid this, 2 other wafers were fabricated that used the same mask during lithography and they resulted in a mold that had no defects in them. Finally, I observed that the spacing between each of the microfluidic channels could not be less than 0.005 inches between channels. When the PDMS was removed from the closely spaced channel, the structure was not rigid enough and did not keep its shape, therefore, the microfluidic channel flaked and did not retain its structure. 


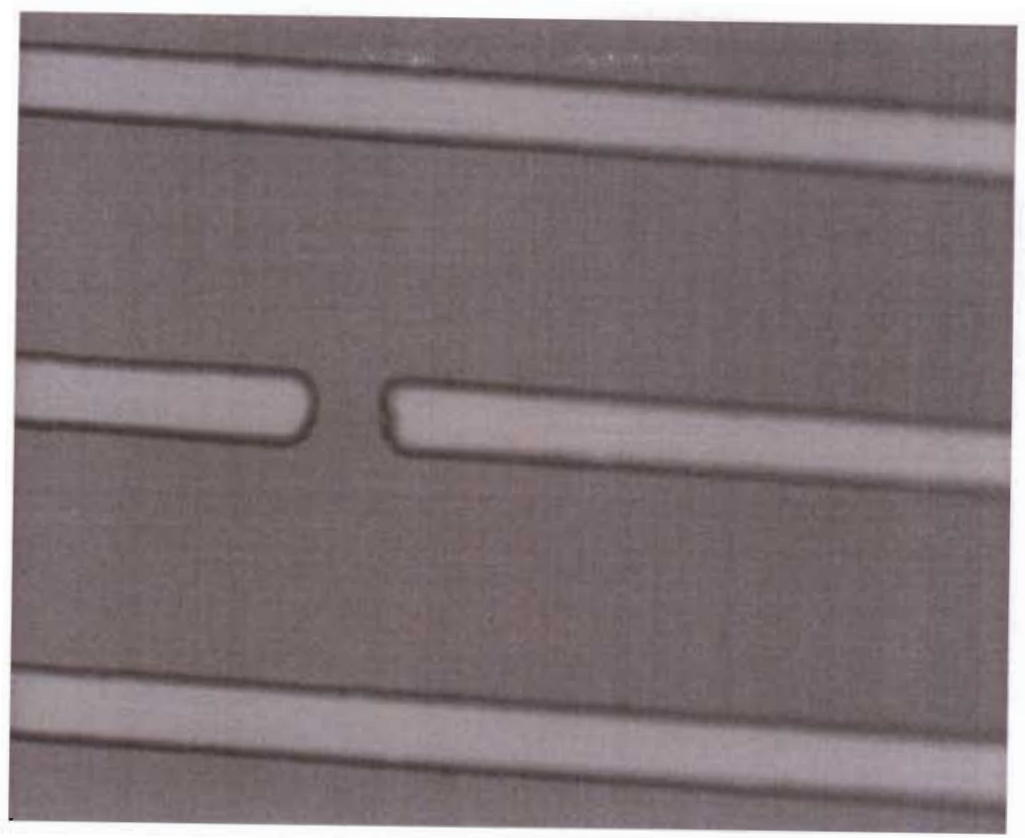

Figure 63 - Broken Microfluidic Channel

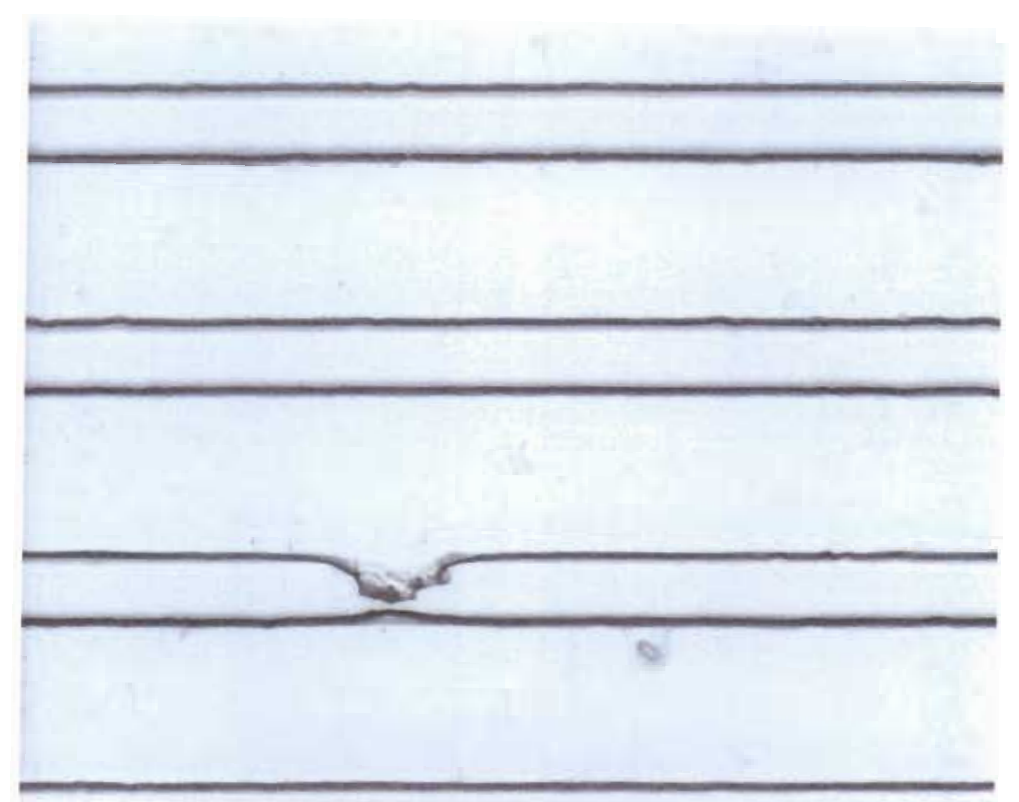

Figure 64 - Torn Microfluidic Channel

There also appeared to be a lot of impurities inside the channel. The small impurities that were found in the microfluidic channels were deposited inside the microfluidic channels 
during the fabrication process. Do to the high number of channels in the design, it was hard to eliminate these impurities. The amount of impurities was reduced when scotch tape was positioned on the channels prior to plasma treating them. By pealing the tape off the surface of the channels the large contaminates that were present on the surface were removed. If there are too many particles in the channels, they will decrease the flow rate of the liquid.

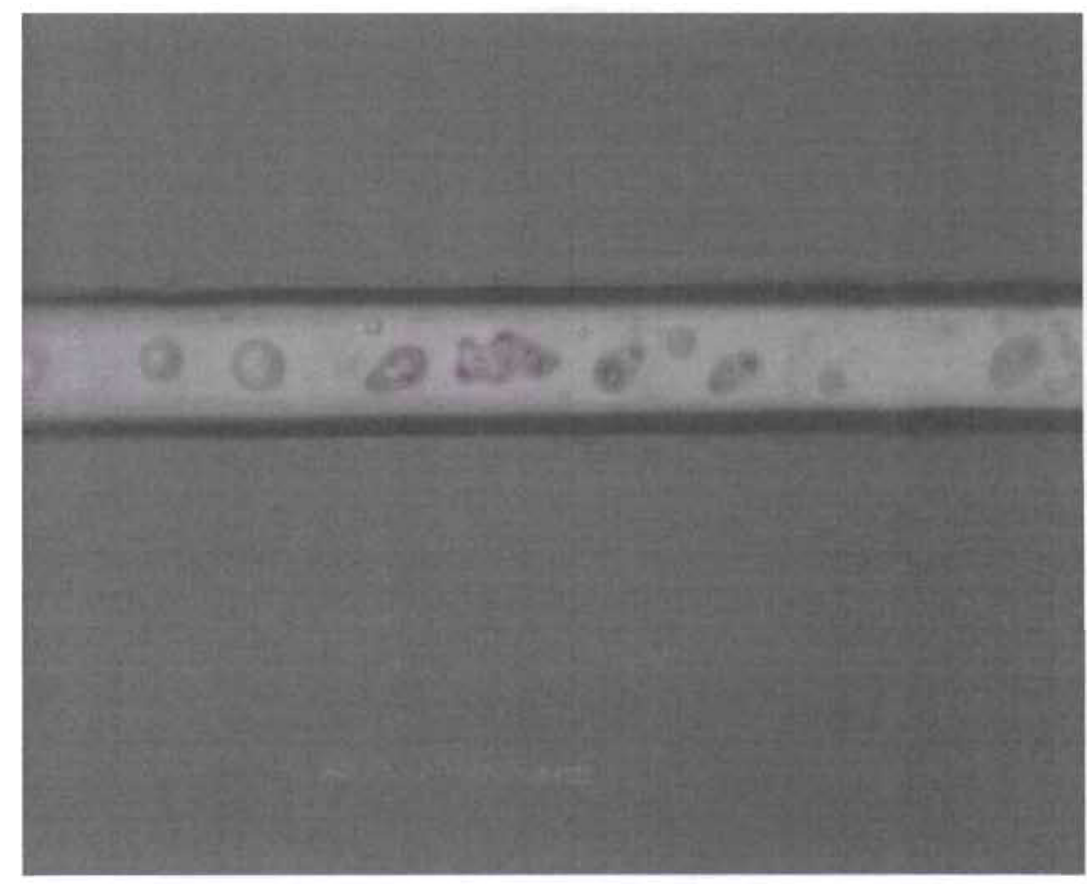

Figure 65 - Microscope Image of CdSe/ZnS Quantum Dots Suspended in toluene in PDMS Microfluidic Channel. 


\section{CHAPTER 7- CADMIUM SELENIUM ZINC SULFIDE CORE SHELL QUANTUM DOTS SUSPENDED IN TOLUENE DISPERSED INTO MICROFLUIDIC CHANNELS}

\subsection{0 - Dispersing Cadmium Selenium Zinc Sulfide Core Shell Quantum Dots Suspended in Toluene into Microfluidic Channels}

Once the microfluidic channels were fabricated the quantum dots suspended in toluene were dispersed into the channels. Using a syringe filled with the quantum dots I dispersed the $\mathrm{CdSe} / \mathrm{ZnS}$ quantum dots into the microfluidic channels. In figure 65 the toluene dried out in the channels, which caused the quantum dots to create a crust on the sidewalls of the microfluidic channels.

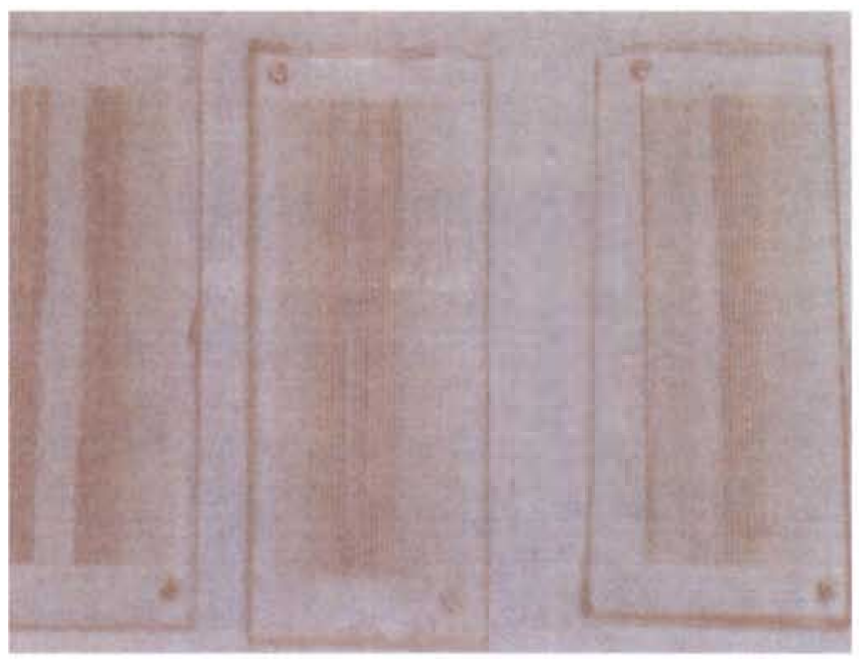

Figure 66 - CdSe/ZnS Quantum Dots Suspended in Toluene Solution Dispersed in Microfluidic Channels

When injecting the quantum dots into the microfluidic channels the toluene did not flow easily and it is believed that this is do to the plasma treatment of the PDMS that was used to bond two pieces of PDMS together in the final stage of fabrication of the micrfluidic channels. The plasma treatment made the PDMS hydrophilic. Since toluene is an organic solution, the toluene would not flow smoothly through the hydrophilic microfluidic channels. 
Toluene is a solvent for PDMS; this could be another reason that the solution was able to flow through the channels. Another complication was is that the toluene would swell the microfluidic channels while the solution was being injected. As the fluid flowed and the channels swelled, the fluid would decrease in flow and ultimately the channels would close shut. In order to determine if the toluene was the problem or if it was the quantum dots, toluene was dispersed through the microfluidic channel. It appeared that the toluene was the cause of the channel slowly swelling up and eventually closing as the channels deswelled once the toluene eventually evaporated. It appeared under the microscope that the channel opened up at an accelerated rate, to about 80 percent of its original size. After about 10 minutes, the channel returned to its original width do to the evaporation of the toluene.
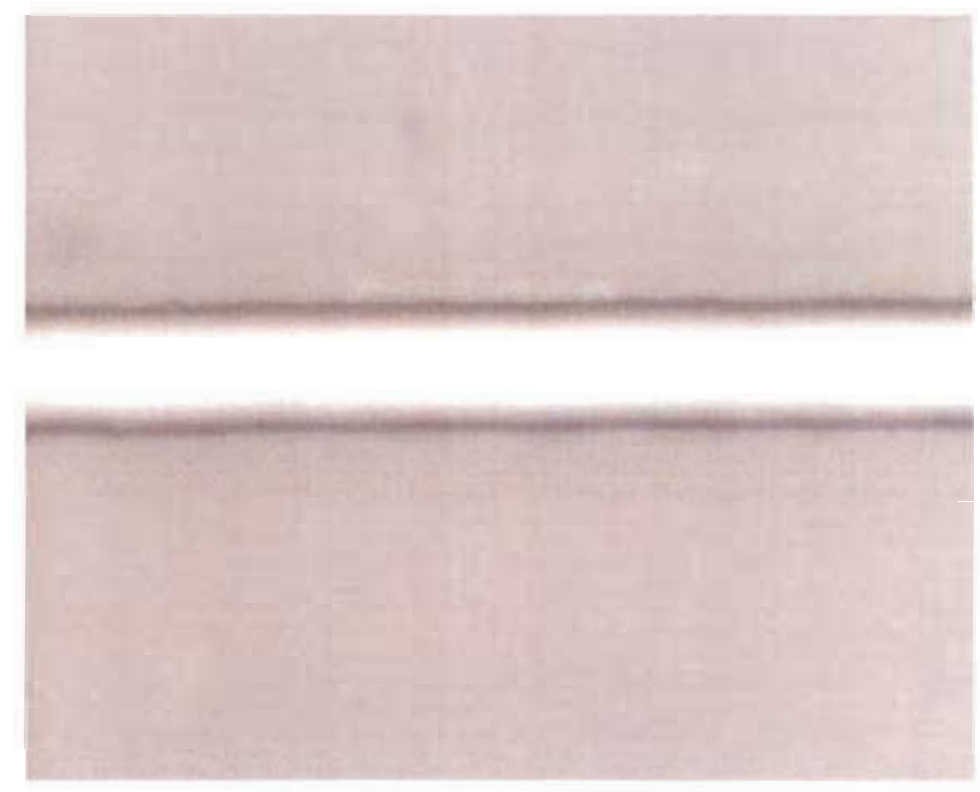

Figure 67 - Microfluidic Channel With no Toluene 


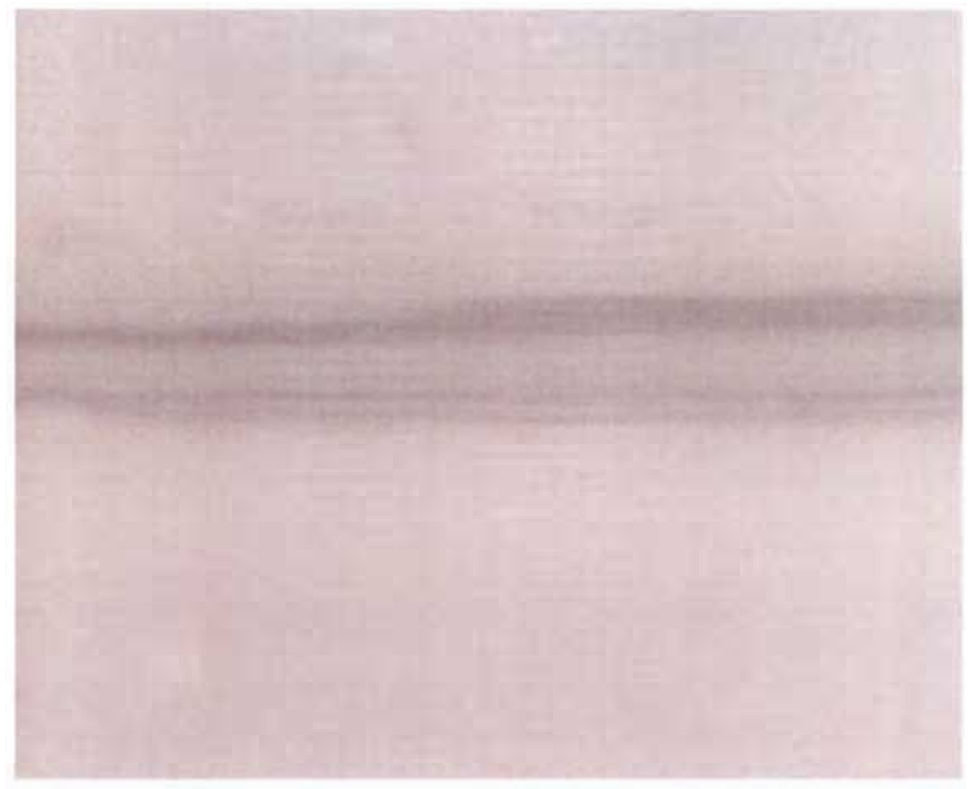

Figure 68 - Microfluidic Channel with Toluene for 20 Seconds

Figure 69 - Closed Microfluidic Channel With Toluene for 2 Minutes

After the $\mathrm{CdSe} / \mathrm{ZnS}$ quantum dots were dispersed in the microfluidic channels, the toluene evaporated and a red crust residue was observed on the sidewalls which are assumed to be clusters of $\mathrm{CdSe} / \mathrm{ZnS}$ quantum dots. This was do to the quantum dots clustering together. This crust decreased the transmittance of light causing more light to be reflected. Adding 
more reflections to the substrate decreased the efficiency of the design. The use of an alternate liquid that the quantum dots were suspended in was necessary.

Green food coloring was dispersed into the channels to see if a water based solution would flow nicely as well as stay in liquid form inside the channels. Since the food coloring did not cause the problem of swelling in the channels, investigation into the properties associated with quantum dots suspended in water followed. 


\section{CHAPTER 8: CADMIUM SELENIUM ZINC SULFIDE CORE SHELL QUANTUM DOTS SUSPENDED IN WATER}

\subsection{0 - Quantum Dots Suspended in Water}

Because the quantum dots suspended in toluene were not compatible with the PDMS microfluidic channels quantum dots suspended in water were investigated. Unfortunately, the quantum dots suspended in water had a lower concentration of quantum dots than the toluene solution. The $\mathrm{CdSe} / \mathrm{ZnS}$ quantum dots suspended in water had a concentration of $0.25 \mathrm{mg} / \mathrm{mL}$; this is $10 \mathrm{x}$ less concentration than the quantum dots suspended in toluene that had a concentration of $2.2 \mathrm{mg} / \mathrm{mL}$. This was one of the downsides of ordering the quantum dots opposed to fabricating them.

\subsection{0. - Florescence of Cadmium Selenium Zinc Sulfide Core Shell Quantum Dots in Water}

Just like with the $\mathrm{CdSe} / \mathrm{ZnS}$ quantum dots that were suspended in toluene, the quantum dots that were suspended in water had a fluorescence associated with them. Since the quantum dots suspended in water have $10 \mathrm{x}$ lower concentration of quantum dots than the quantum dots suspended in toluene, the florescence observed was lower.

The same set up was used as described in section 3.3.0 for measuring the florescence. There were only a few variations in the measurement process. Instead of using a cuvette that had a path length of $10 \mathrm{~mm}$, a smaller sample holder was used which had a path length of $1 \mathrm{~mm}$. There were two reasons for using such a smaller sample holder. First, this sample holder gave a better representation of the amount of fluid that was present in the microfluidic channels. The second reason is that the volume of solution that the quantum dots were in 
was much smaller than the quantum dots suspended in toluene and this method helped to preserve the volume of liquid I had available. Another variation observed change was the in florescence associated with different sections of the light spectrum. Measurements were taken with the deuterium light source only, the halogen light source only, and both light sources running at the same time. The deuterium light source, which output ultraviolet light ranging from $\lambda=200-350 \mathrm{~nm}$, produced the most amount of florescence from the quantum dots. Interestingly, the halogen light source, which output light ranging from $\lambda=400$ $700 \mathrm{~nm}$, produced some florescence as well. This proved that the quantum dots would fluoresce with any wavelength of high energy light as long as the energy of the light was greater than the band-gap of the quantum dot, which is $2 \mathrm{eV}(\lambda=620 \mathrm{~nm})$. When both of the light sources were turned on, the intensity observed was larger than the independent light measurements.

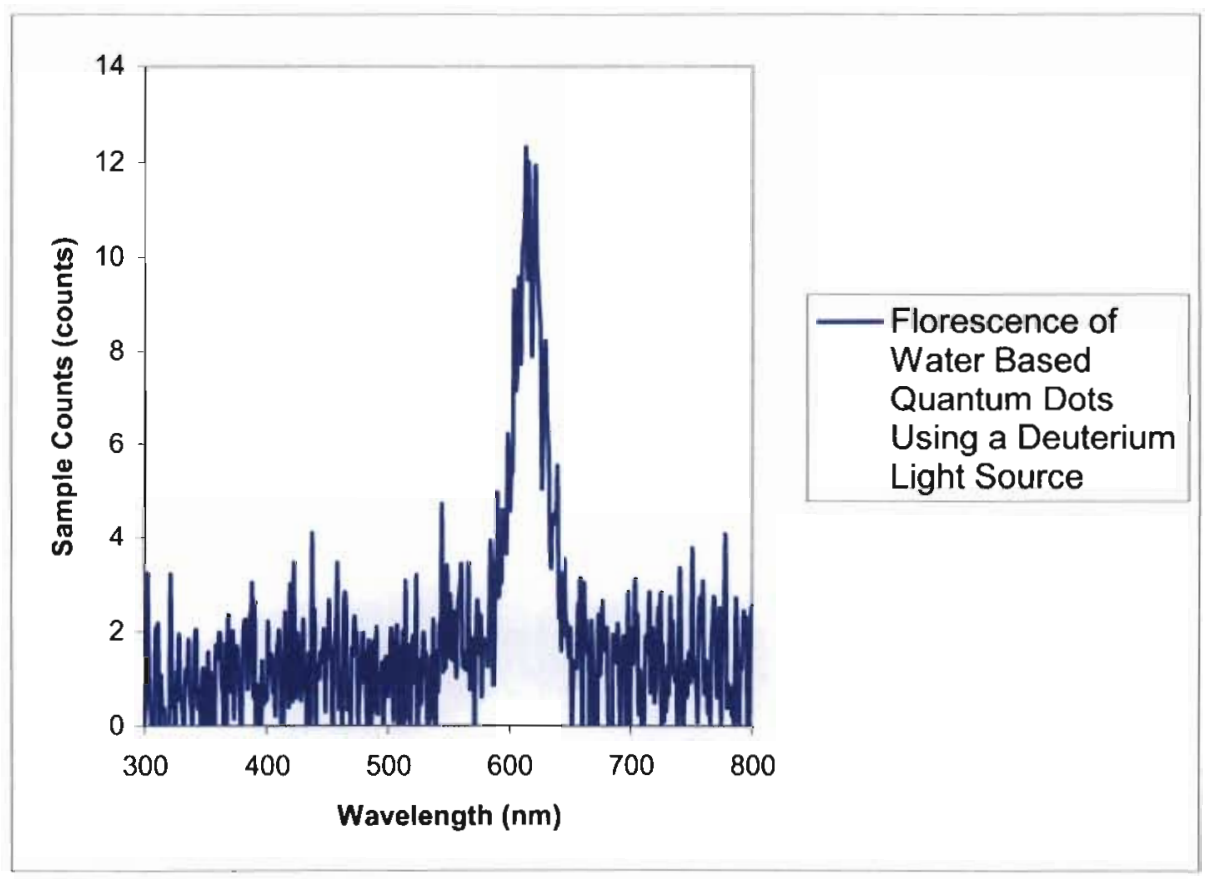

Figure 70 - Florescence of Quantum Dots Suspended in Water Using a Deuterium Light Source 


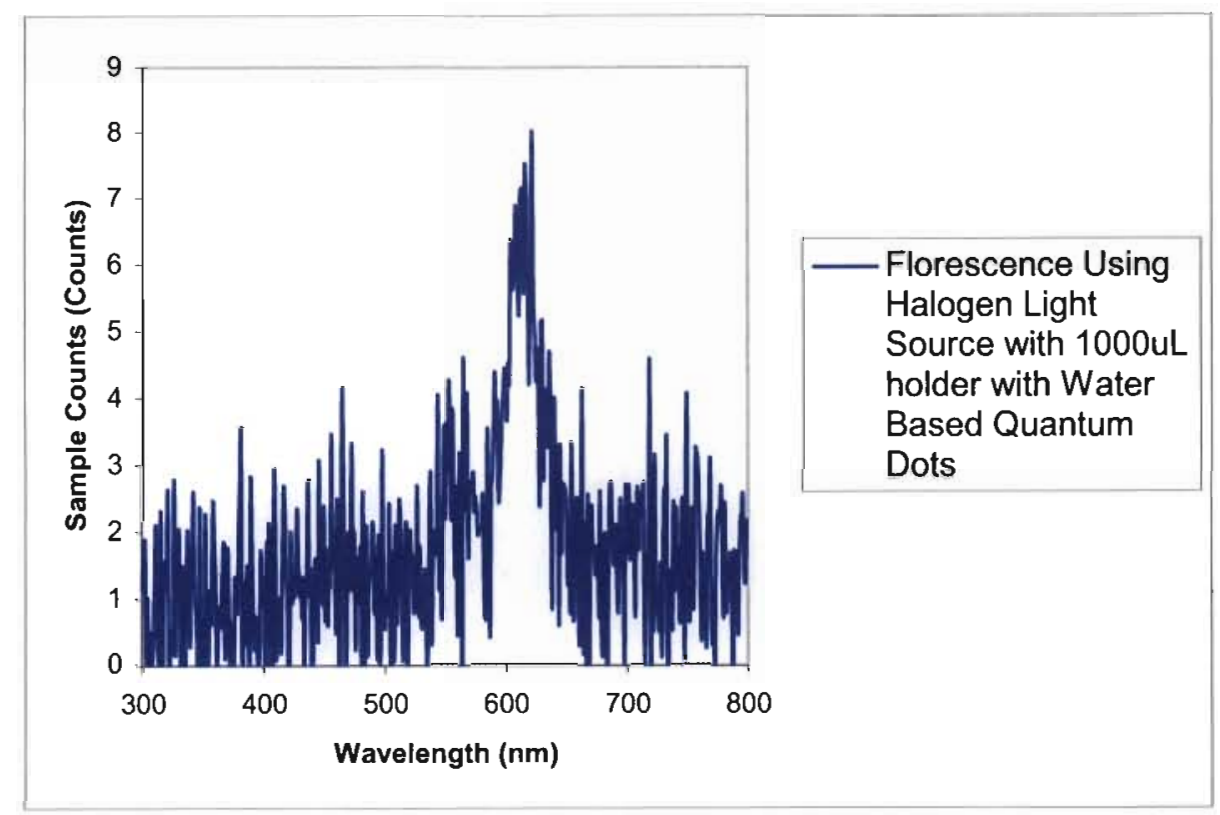

Figure 71 - Florescence of Quantum Dots Suspended in Water Using a Halogen Light Source

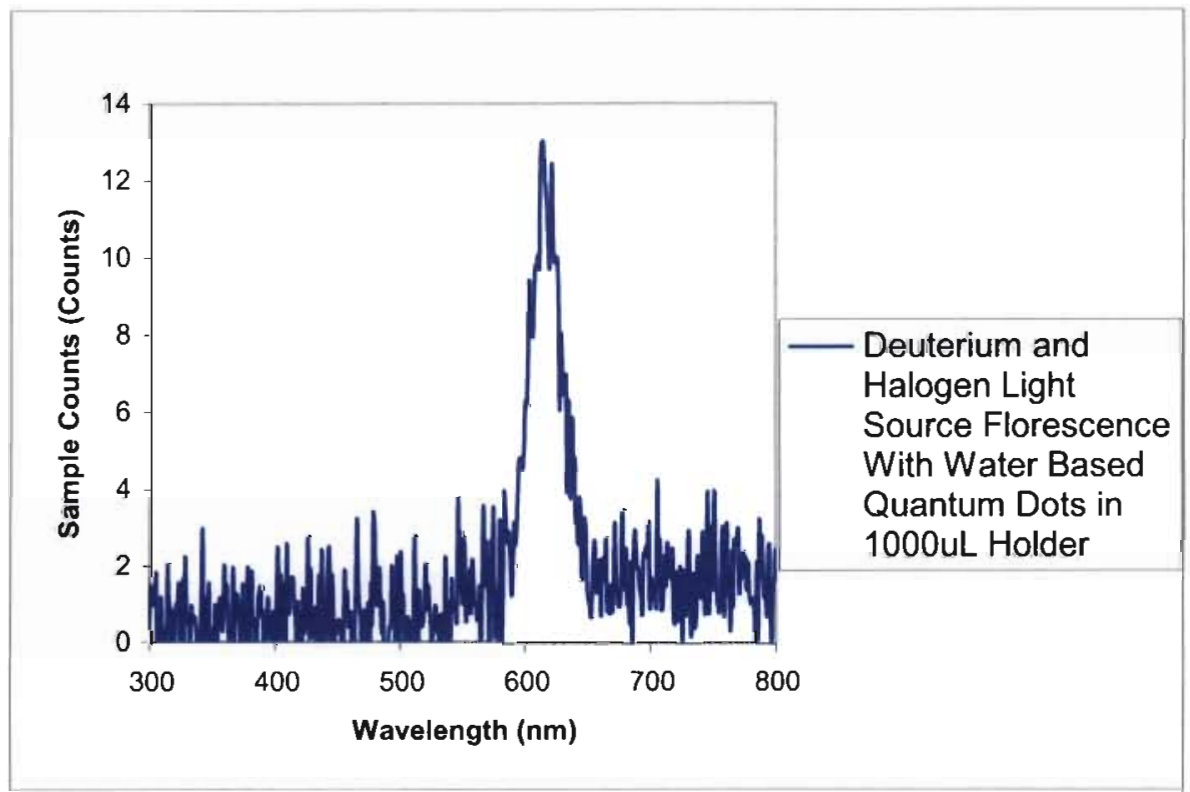

Figure 72 - Florescence of Quantum Dots Suspended in Water Using a Deuterium and Halogen Light Source

These plots show that the quantum dots are fluorescing at $\lambda=620 \mathrm{~nm}$ for each of the light sources. Although the quantum dots are down converting higher energy light into a lower energy light the amount of sample counts is extremely low. This could be because not 
enough higher energy photons were encountering the quantum dots. This extremely low number of sample counts was slightly above the noise region of the measurement. This amount of change, when observed by a photovoltaic cell, would not be observed. The amount of florescence was not enough to overcome the noise margin of the photovoltaic cell. In order to obtain a $10 \%$ increase in solar cell power it would require fluorescence from the quantum dots of approximately 1000 sample counts at $\lambda=620 \mathrm{~nm}$. Appendix $C$ shows the concentration of quantum dots that would be needed to obtain 1000 sample counts of fluorescence which is $8.92 \times 10^{7} \mathrm{mg} / \mathrm{mL}$.

$$
\mathrm{F}=\Phi_{\mathrm{o}}\left(1-\mathrm{e}^{-\varepsilon b c}\right)
$$

\section{Equation 11 - Fluorescence Equation}

This amount of fluorescence should overcome the reflections associated with the PDMS that the quantum dots were suspended in as well as increase the total power of the solar cell.

\subsection{0 - Transmission of Light Through Quantum Dots Suspended in Water}

Now that the florescence associated with the quantum dots suspended in water has been examined, it was important to investigate how light was affected as it was transmitted through the quantum dots suspended in water. For this experiment, the same set up was used as in section 3.2.0. Once again, the only changes were that instead of using a $3 \mathrm{~mL}$ cuvette a $1000 \mu \mathrm{L}$ sample holder was used, as well as the deuterium light source independently from the halogen and vice versa.

For measuring the transmittance of light through the quantum dots suspended in water, a measurement was first made of the light sources themselves. This gave an 
understanding of how many sample counts of light were going to be passing through the sample during the experiment.

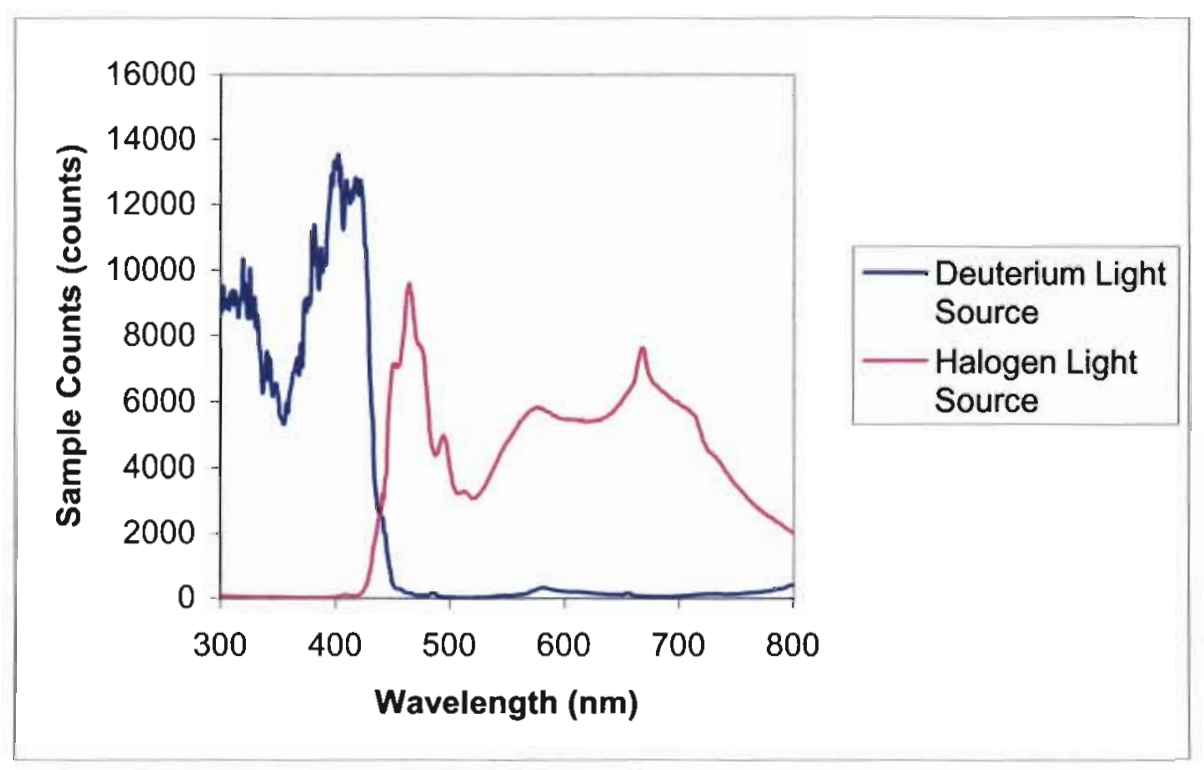

Figure 73 - Light Intensity of Deuterium Light Source and Halogen Light Source

In figure 72 the deuterium light source produced light that is was the ultraviolet range while the halogen light source produced light that was in the visible light range. There was a slight overlap between the two light sources as the deuterium light source droped off and the halogen light source started up. After measuring the light sources independently, an empty sample holder was positioned between the light sources to see how it affected the transmittance of light. 


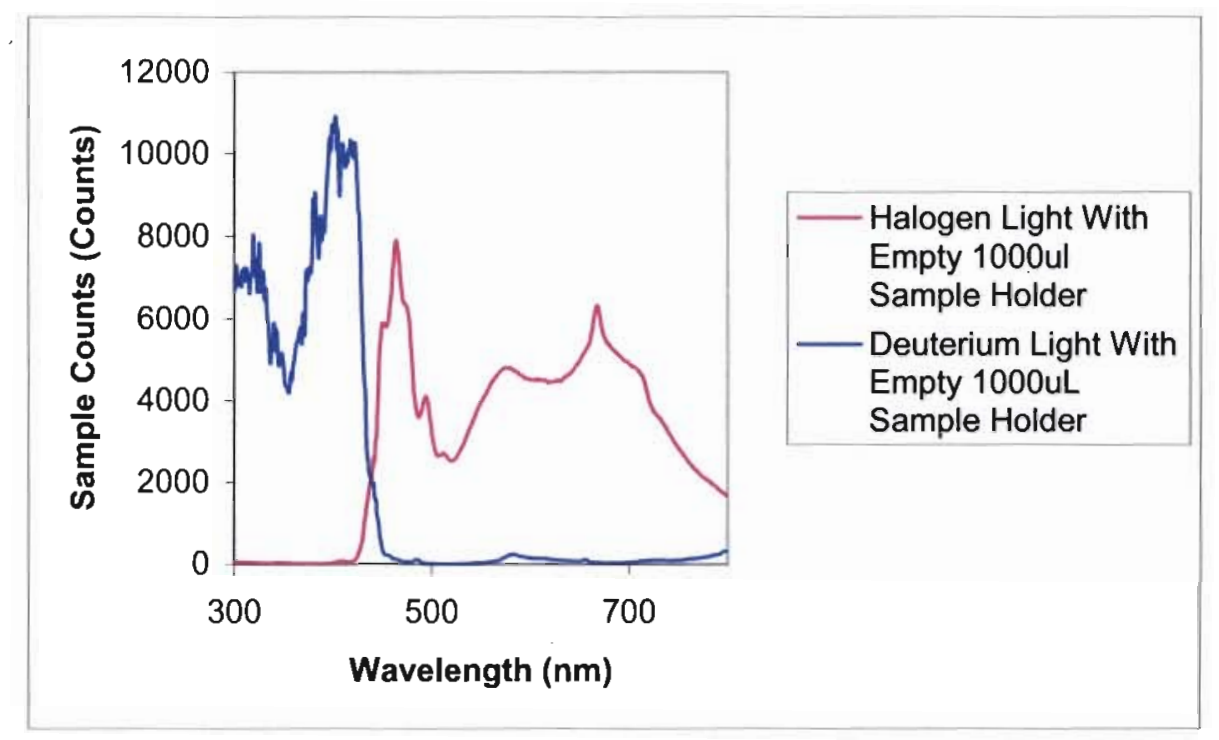

Figure 74 - Raw Counts of Light Through Empty 1000uL Sample Holder

After placing the $1000 \mathrm{uL}$ sample holder in front of the light source, there was a decrease of light intensity of about 2500 counts with the deuterium light source. Using the halogen light source, there was a decrease of 1600 sample counts. These are reflection losses that were encountered due to the sample holder. The next measurement taken was with deionized water in the sample holder.

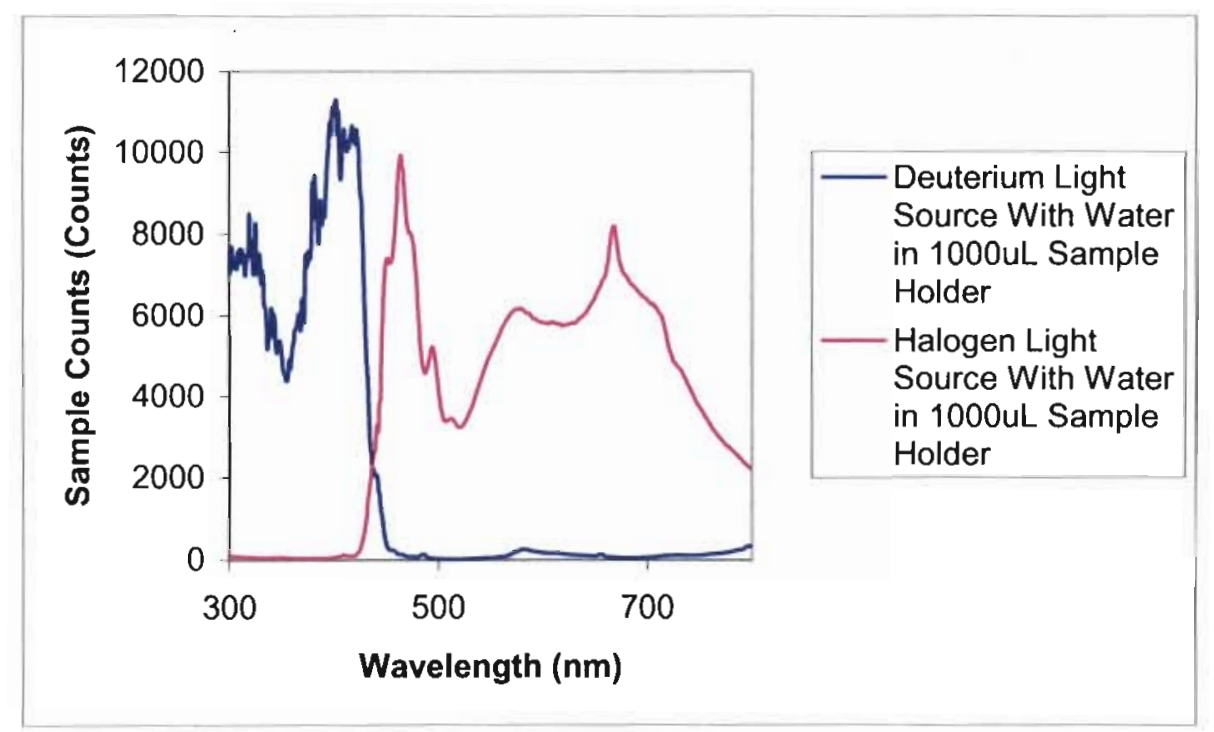

Figure 75 - Raw Counts of Light Through Water in 1000uL Sample Holder 
The change in transmission observed when placing the water in the sample holder was extremely small. Therefore, the amount of reflections associated with the water was not as great as the reflections due to the sample holder. Finally, the $\mathrm{CdSe} / \mathrm{ZnS}$ quantum dots were dispersed into the $1000 \mathrm{uL}$ sample holder and the amount of light measured that was transmitted.

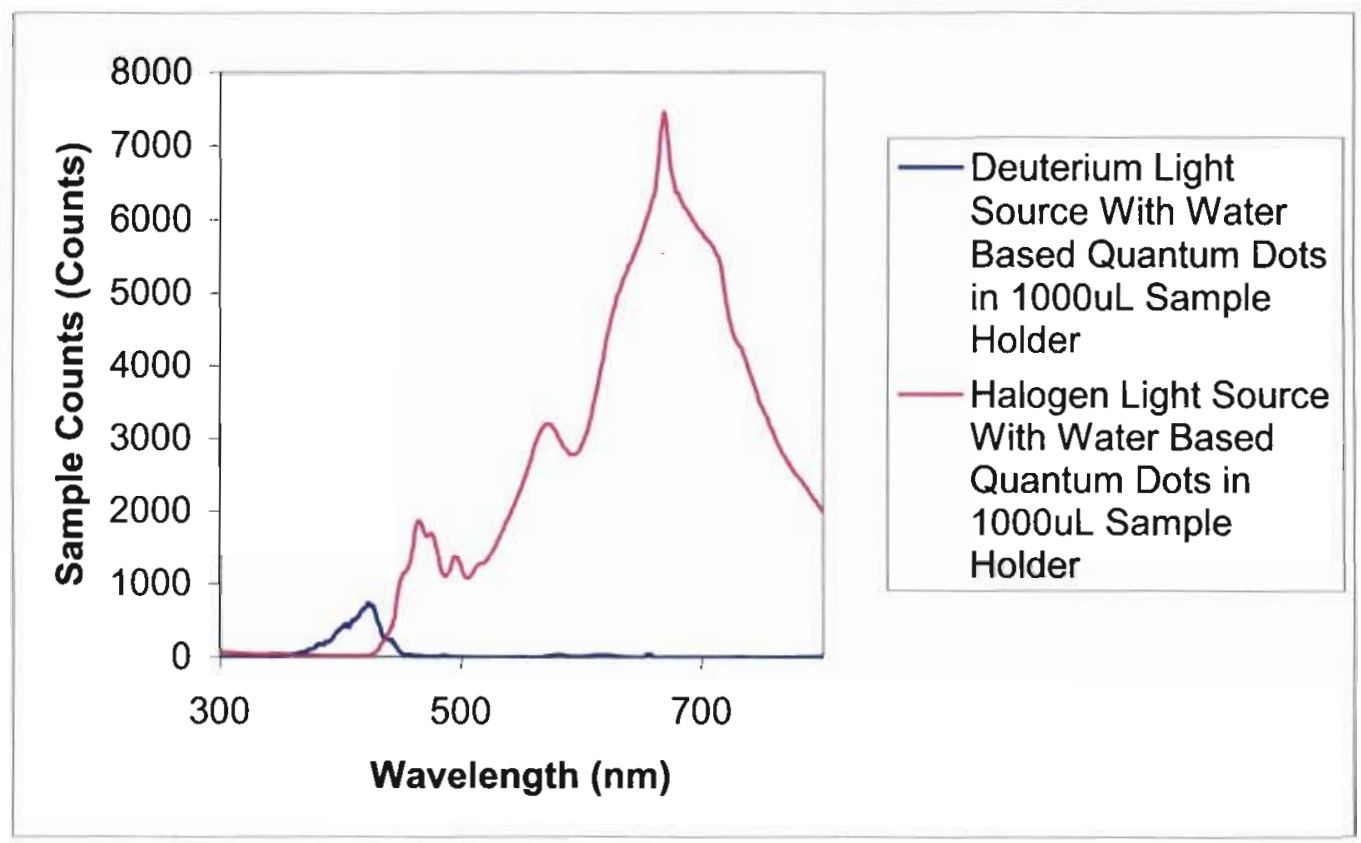

Figure 76 - Raw Counts of Light Through Quantum Dots suspended in water in 1000uL Sample Holder

Figure 75 shows that the quantum dots were absorbing almost all of the higher energy photons. This being the case, the quantum dots were down converting these higher energy photons and fluorescing at a lower energy wavelength. Since the quantum dots are supposed to fluoresce at $\lambda=620 \mathrm{~nm}$, it is important to investigate the change of transmission at this wavelength. 


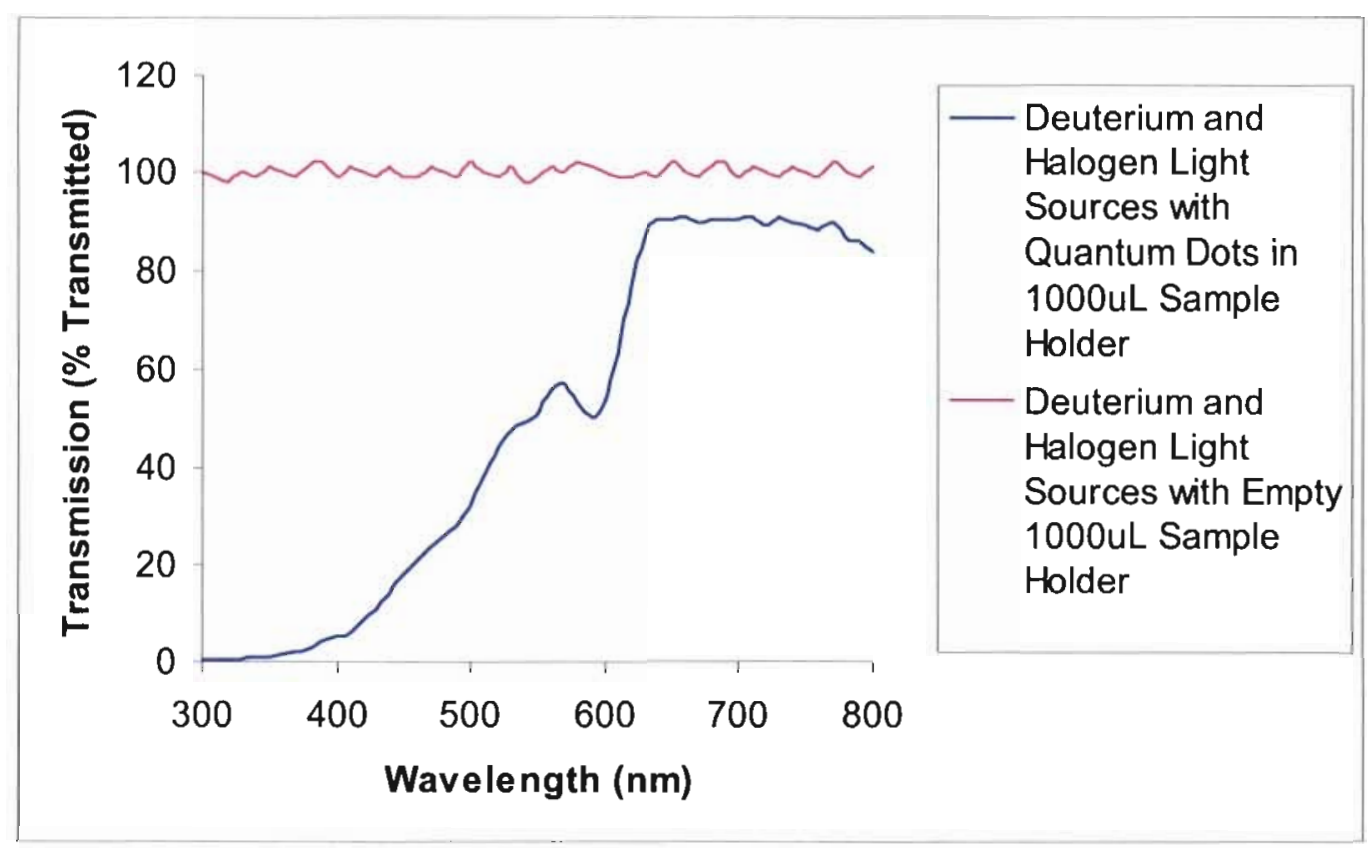

Figure 77 - Transmission of Light Using Deuterium and Halogen Light Sources

In figure 77 , the quantum dots did not seem to fluoresce enough to overcome the amount of reflections associated with the sample holder. It appears that the quantum dots fluorescence did not have enough intensity to replace light loss due to reflections. This is important because the goal of using the quantum dots is to create more photons that have energy close to the band gap of silicon. The deuterium light source was also unable to produce enough fluorescence to overcome the amount of reflections associated with the $1000 \mu \mathrm{L}$ sample holder. This is due to the low concentration of quantum dots that were in holder. According to the literature the concentration of quantum dots that was being used to observe an increase in lower energy light was $1 \times 10^{6}$ moles more than what was being used [28]. 


\subsection{0 - Dispersing Cadmium Selenium Zinc Sulfide Core Shell Quantum Dots Suspended in Water Into Microfluidic Channels}

The entire purpose of using the quantum dots suspended in water instead of the quantum dots suspended in toluene was to observe the compatibility of the solution with the microfluidic channels made from PDMS. Using the same technique to disperse the quantum dots suspended in toluene into microfluidic channels as mentioned in section 7.1.0, I dispersed quantum dots suspended in water into microfluidic channels. This was a much easier process because the microfluidic channels did not swell during this process. The entire channel was able to successfully fill with the quantum dots suspended in water. While the quantum dots suspended in water were dispersed into the microfluidic channels the liquid traveling through the channels was observable under a microscope.

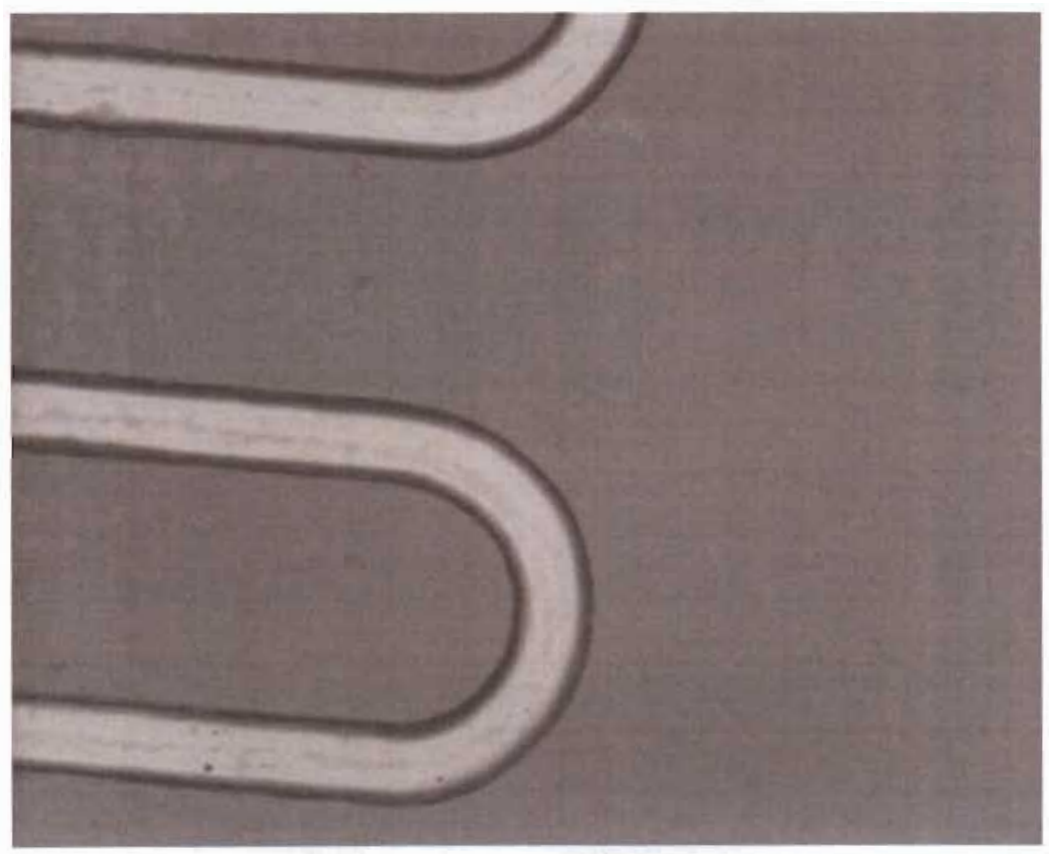

Figure 78 - Channel Prior to Being Filled With Quantum Dots Suspended in Water 


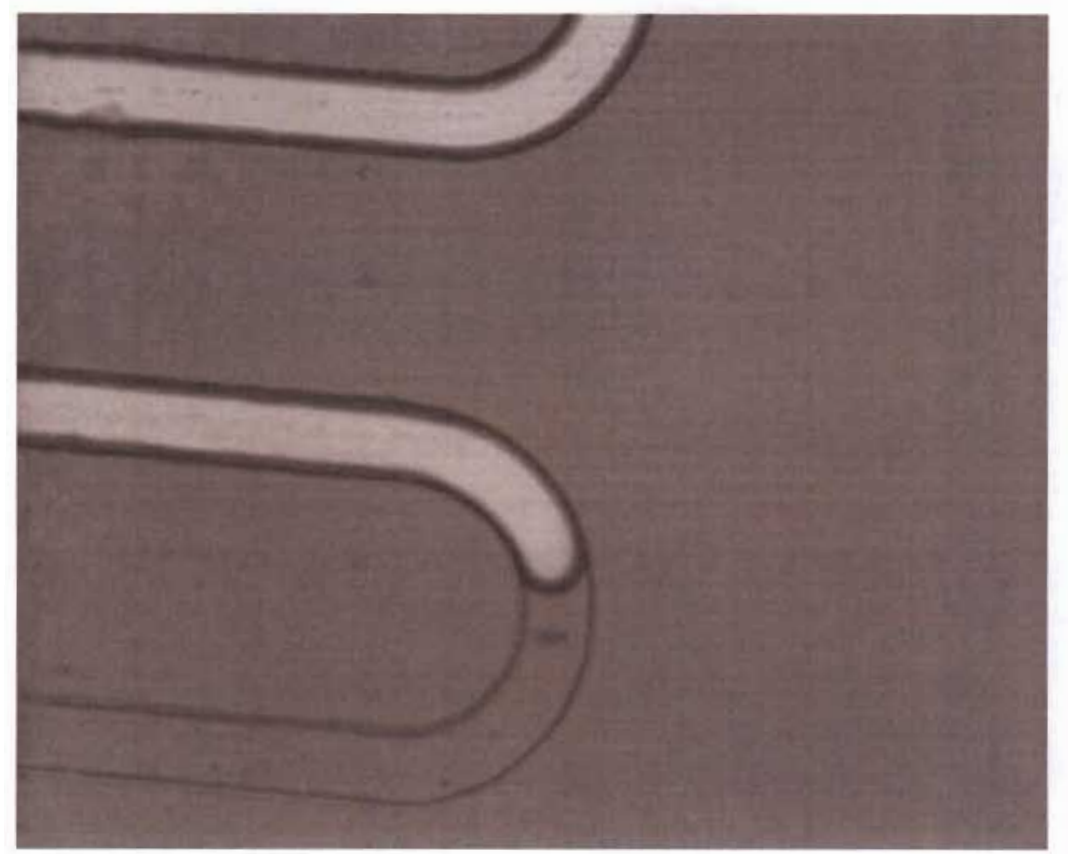

Figure 79 - Channel Being Filled With Quantum Dots Suspended in Water

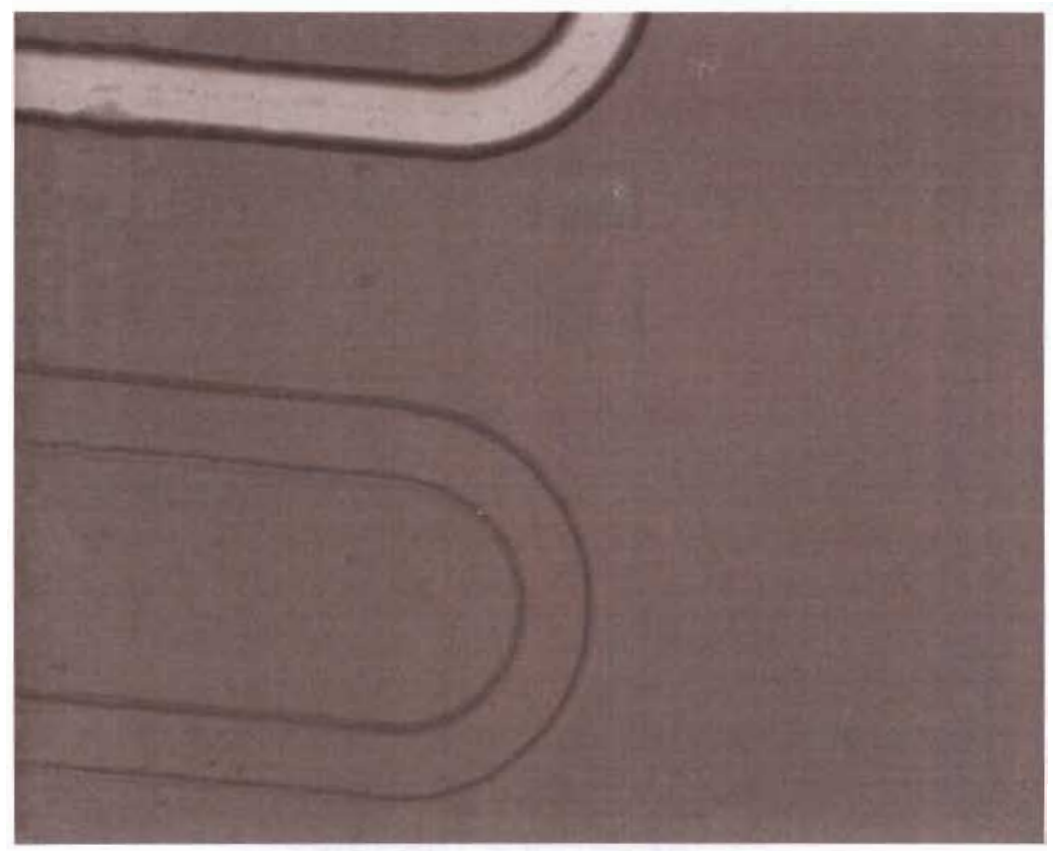

Figure 80 - Channel Filled With Quantum Dots Suspended in Water

Figure 77 through figure 79 show one of the microfluidic channels being filled with quantum dots suspended in water. There was no swelling of the channels and the liquid did 
not evaporate quickly like with the quantum dots suspended in toluene. The quantum dots suspended in water were more compatible with PDMS. When the quantum dots suspended in water were dispersed into the microfluidic channels the quantum dots were not visible by just using the light in the room. In order to observe the quantum dots in the microfluidic channels an ultraviolet light pen lamp had to be utilized. Using this light source allowed the quantum dots to fluoresce and be seen.

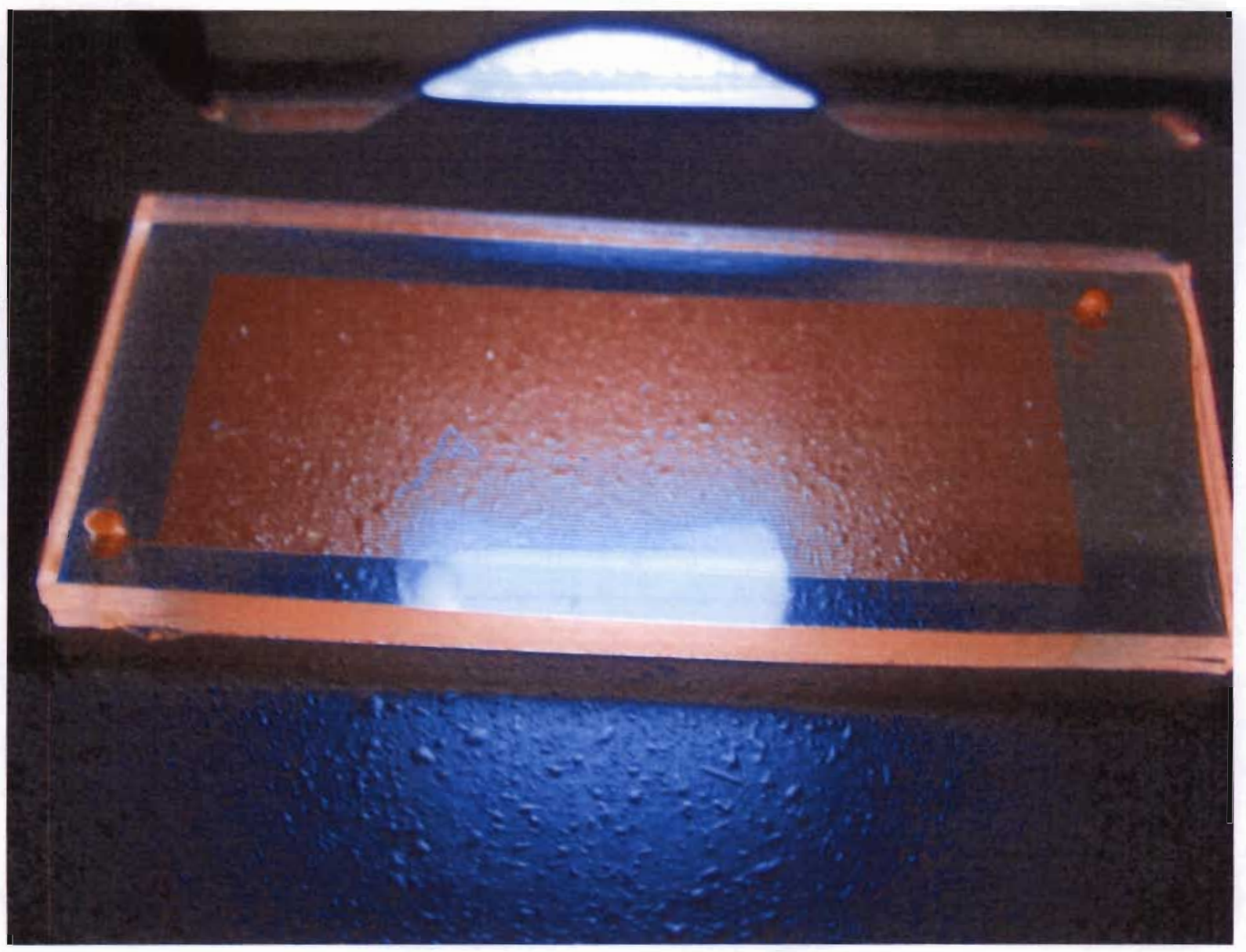

Figure 81 - CdSe/ZnS Quantum Dots Suspended in Water Dispersed in Microfluidic Channels and Excited by a UV Light Source

Since the quantum dots were observable when they were exposed to ultraviolet light, it was decided to place the device on top of the silicon solar cell and observe if there was any change in maximum power. 
CHAPTER 9- SOLAR CELL WITH PDMS AND QUANTUM DOTS SUSPENDED IN WATER

\subsection{0 - Solar Cell with Microfluidic Device Filled with Quantum Dots Suspended in Water}

Since the quantum dots fluoresced when ultraviolet light was placed over the device, the device was positioned onto the surface of the photovoltaic cell. Using this combination the I-V characteristics were measured associated with placing this substrate on top of a solar cell. The same set up was used to measure the I-V characteristics as in section 2.2.0. The only difference in this setup was that the PDMS filled with quantum dots was placed on top of the solar cell and a measurement was taken. There were 23 points taken to measure the I$\mathrm{V}$ characteristics with the substrate placed on top, the reason being that the maximum power was slightly more difficult to measure even though the same solar cell was used for this experiment. The raw data can be viewed in Appendix F. 


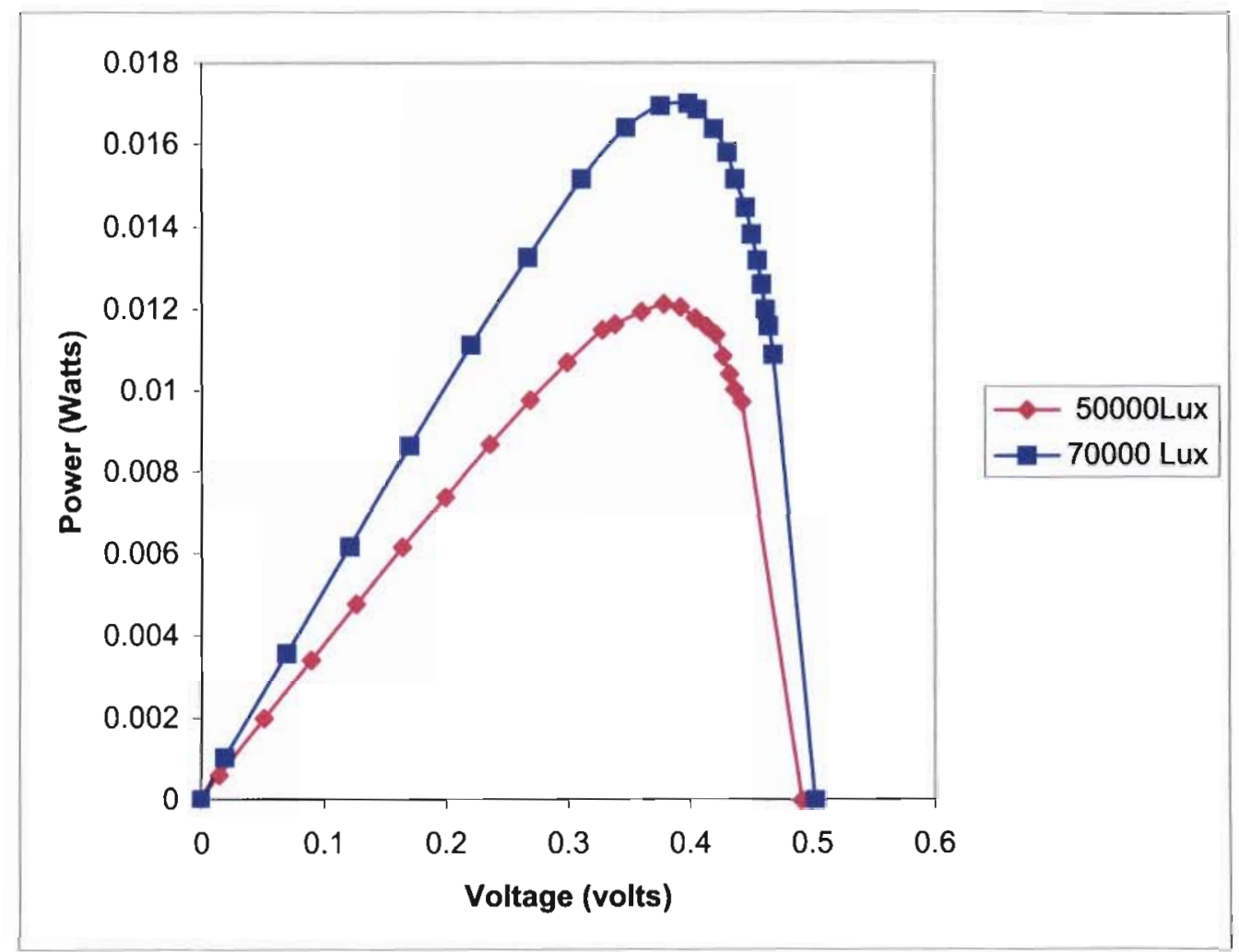

Figure 82 - Power Vs. Voltage Plot

The maximum power voltage for $50000 \mathrm{Lux}$ and $70000 \mathrm{Lux}$ is $0.3792 \mathrm{~V}$ and $0.3985 \mathrm{~V}$ respectively. Now knowing the maximum power voltage plotting an I-V curve the maximum power current could be obtained. 


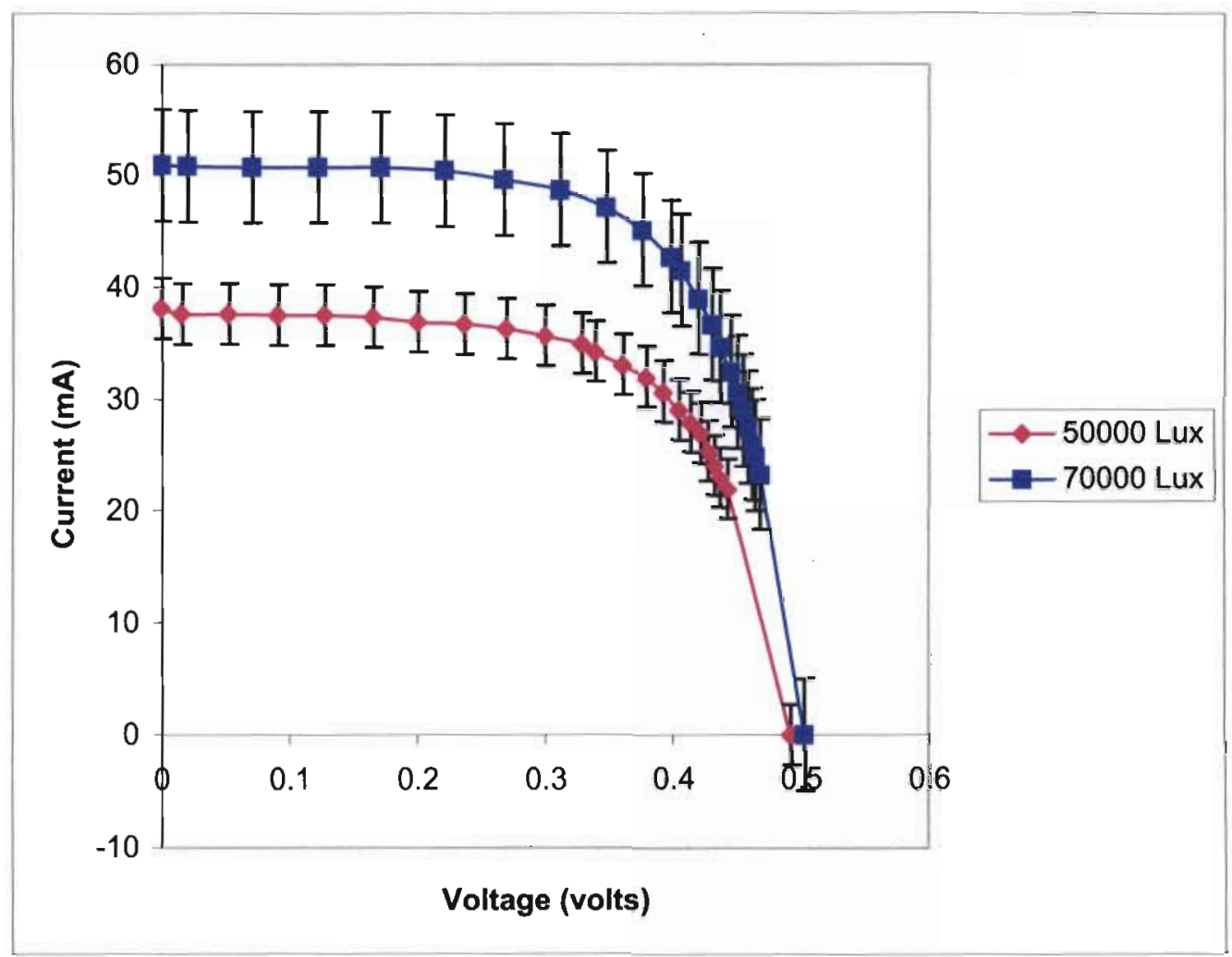

Figure 83 - I-V Curve of Solar Cell With PDMS Filled With CdSe/ZnS Quantum Dots Suspended in Water

Knowing the maximum power voltages at different light intensities, allowed the maximum power current to be calculated. For the $50000 \mathrm{Lux}$ and $70000 \mathrm{Lux}$ intensities, the maximum power current was found to be $0.032 \mathrm{~A}$ and $0.0427 \mathrm{~A}$ respectively. These values are less than the values obtained without any substrate placed on top of the solar cell. With no PDMS on top of the solar cell, the maximum power current at 50000 Lux and 70000 Lux was $0.04028 \mathrm{~A}$ and $0.0527 \mathrm{~A}$ respectively. Therefore, the fluorescence associated with the quantum dots suspended in water was not enough to overcome the reflection losses of the PDMS. 


\section{CHAPTER 10 - CONCLUSIONS}

The overall goal of this project is to increase the power that a photovoltaic cell produces by down converting ultraviolet light into visible light that had energy near the band gap of silicon. Using CdSe/ZnS quantum dots did this. Quantum dots suspended in toluene were first spun onto a silicon surface. Unfortunately, the toluene evaporated and the quantum dots did not fluoresce and clustered into a red crust on the surface of the silicon. A native oxide layer forming on top of the quantum dots once the toluene evaporated could be the reason for the quantum dots to not fluoresce. The red crust is believed to be CdSe/ZnS quantum dots by the data obtained from California Polytechnic's SEM and AFM measurements. The reason that a conclusion could not be made in using these devices is because no chemical analysis was done to confirm that the red crust was in fact $\mathrm{CdSe} / \mathrm{ZnS}$ core shell quantum dots.

Realizing that the quantum dots needed to be suspended in liquid for them to fluoresce, microfluidic channels were fabricated using PDMS. PDMS was used because of the high amount of ultraviolet light that transmitted through the polymer. Once the microfluidic channels were fabricated $\mathrm{CdSe} / \mathrm{ZnS}$ quantum dots suspended in toluene were dispersed into the channels. The toluene caused the channels to close shut and did not allow the fluid to travel. Also within a matter of minutes, the toluene evaporated and caused the quantum dots to cluster into a red crust on the side walls of the microfluidic channels.

Next, $\mathrm{CdSe} / \mathrm{ZnS}$ quantum dots suspended in water were used and dispersed into the microfluidic channels. This solution seemed to interact with the microfluidic channels much better than the quantum dots suspended in toluene. This allowed for successful dispersion of the liquid through the channels. The quantum dots suspended in water did not evaporate the 
water and the quantum dots were able to remain suspended in the liquid while in the microfluidic channels. This was do to the quantum dots suspended in water not being a solvent for PDMS like the toluene solution is. While the quantum dots were in the channels I was able to expose the device to ultraviolet light and the quantum dots fluoresced.

Since the concentration of quantum dots was not enough to overcome the reflections of the PDMS a calculation was made to estimate the amount that would be needed. Assuming the channel height remained the same the concentration that would be needed to observe a $10 \%$ increase in solar cell maximum power would need to be $8.92 \times 10^{7} \mathrm{mg} / \mathrm{mL}$. This is much larger than the concentration of quantum dots suspended in water which were $0.25 \mathrm{mg} / \mathrm{mL}$. The path length of the microfluidic channels could also be increased. Keeping the concentration at $0.25 \mathrm{mg} / \mathrm{mL}$ the path length would need to be $700 \mu \mathrm{m}$. Increasing both the concentration and path length of the microfluidic channels will allow for this fluorescence to improve the maximum power of a solar cell. If the channel height was increased to $100 \mu \mathrm{m}$ then the concentration that would be needed would only need to be $155 \mathrm{mg} / \mathrm{mL}$.

Hopefully this research paper was not only informative but also stimulating. Making the decision to pursue my master's has been the best decision made during my college career because it allowed me to become more of an independent thinker. Overcoming the challenges that this project presented and gaining a greater knowledge about this topic was an amazing experience. This project has given me an appreciation of the integration of science with engineering. Thank you for taking the time in reading my thesis work.

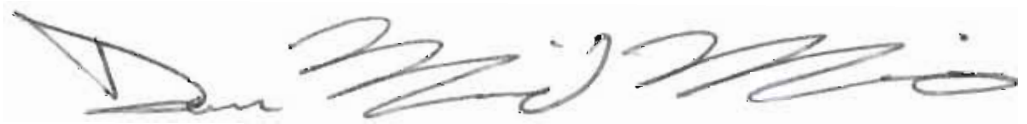

Dan Madrid Marrujo, June 2008 


\section{CHAPTER 11 - FUTUREWORK}

There are a lot of possibilities in terms of future work associated with increasing the efficiency of solar cells by using quantum dots. The first item I believe is important to investigate is fabrication of quantum dots. This would be good to investigate because it would allow for control of the concentration of the quantum dots in the liquid. Fabrication would allow for control of the size of the quantum dots. In having control of the quantum dots it will be easier to have them fluoresce at energy much closer to the band gap of the photovoltaic device.

Another interesting idea is to investigate the bonding properties associated with quantum dots. If the quantum dots are able to bond to a substrate and stay in a fixed position, the concentration could be controlled. Additionally, it would be beneficial to investigate if the direction that the quantum dot faces affects its efficiency.

Polymer photovoltaics are another area where quantum dots could be utilized. If one could mix in quantum dots into this polymer and use this combination as the photovoltaic, it will eliminate the amount of reflections present in my design. Since quantum dots output is dependent on their size it would be easy to tune the photovoltaic device. This would all be part of the active region of the solar cell, the portion that absorbs incoming light.

Finally, designing an antireflective coating that would be implemented with the microfluidic channels filled with quantum dots. This will increase the efficiency of the design and be a great way to conclude this research. 


\section{REFERENCES}

1. Messenger, Roger A. and Ventre, Jerry Photovoltaic Systems Engineering Florida: CRC Press LLC, 2004

2. See http://en.wikipedia.org/wiki/Ultraviolet

3. See http://en.wikipedia.org/wiki/Infrared_radiation

4. See http://en.wikipedia.org/wiki/Planck's_law_of_black_body_radiation

5. Fahrenbruch, Alan L. and Bube, Richard H. Fundamentals of Solar Cells. Photovoltaic Solar Energy Conversion. New York: Academic Press, Inc., 1983. P.9

6. Goetzberger, Adolf, Luther, Joachim and Willeke, Gerhard Solar cells: past, present, future Solar Energy Materials and Solar Cells, 2002 P. 1-11

7. Zweibel, Kenneth Basic Photovoltaic Principles and Methods New York: Van Nostrand Reinhold Company Inc., 1984. P.12-23

8. Kasap, S.O. Principles of Electronic Materials and Devices New York: McGraw-Hill, 2006 P. 551-559 and 804-811

9. Sittig, Marshall Solar Cells for Photovoltaic Generation of Electricity New Jersey: Noyes Data Corporation, 1979. P.3-7,126-129

10. W.G.J.H.M. van Sark, A.Meijerink, R.E.I. Schropp, J.A.M. van Roosmalen, and E.H.Lysen Modeling Improvement of Spectral Response of Solar Cells by Deployment of Spectral Converters Containing Semiconductor Nanocrystals St. Petersburg, Symposium on the Efficient Use of Solar Radiation in Photovoltaic Power Engineering, 2003 P. 962-969 and 1000-1006

11. Woggon, Ulrike Optical Properties of Semiconductor Quantum Dots New York: Springer, 1997. P.29,49,52-53,56,66

12. Gaponenko, S.V. Optical Properties of Semiconductor Nanocrystals New York: Cambridge University Press, 1998. P.27-54

13. http:/www.evidenttech.com/products/evidots/evidot-specifications.html

14. G. J. H. M. van Sark, Wilfried, Frederix, Patrick L. T. M., Van den Heuvel, Dave J., and Gerritsen, Hans C. Photooxidation and Photobleaching of Single CdSe/ZnS Quantum Dots Probed by Room-Temperature Time-Resolved Spectroscopy. Department of Molecular Biophysics, Debye Institute, 2001 P. 8281-8284 
15. Manual for Using Fluorescent Microspheres to Measure Regional Organ Perfusion Fluorescence Microsphere Resource Center, University of Washington, 1999 P.11-22

16. A. Zrenner A close look on single quantum dots Technische Universität München, 2000 Volume 112, Number 18

17. Basic SPM Training Course Digital Instruments Veeco, Inc. 2000 P. 2.4-2.29

18. Howland, Rebecca and Benatar, Lisa A Practical Guide to Scanning Probe Microscopy ThermoMicroscopes 2000 P. 5-13

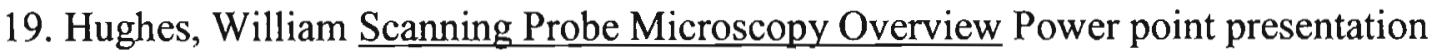

20. See www.dowcorning.com/content/sitech/sitechbasics/silanes_and_intermediates.asp

21. See www.dowcorning.com/content/sitech/sitechms/default.asp

22. See www.dowcorning.com/content/sitech/sitechbasics/siloxane_polymerization.asp

23. See http://www.dowcorning.com.content/sitech/sitechbasics/silicones.asp

24. See http://www.phy.duke.edu/courses/143/labs/michelson.pdf

25. O.Hutzinger The Handbook of Environmental Chemistry Volume 3 Anthropogenic Compounds Part H New York, Springer 1997 P. 185

26. Pedrotti, S.J. Frank L., Pedrotti, Leno S., and Pedrotti, Leno M. Introduction to Optics Third Edition, New Jersey, Prentice Hall 2007 P. 491-509

27. Mayer, Hans Microfluidic Device Fabrication San Luis Obispo: California Polytechnic State University, 2007

28. Murphy, Catherine J. and Coffer, Jeffery L. Quantum Dots: A Primer Volume 56, 2002 P.16-27

29. Lasnier, France and Gan Ang, Tony Photovoltaic Engineering Handbook Adam Hilger, Bristol and New York, 1990. P. 51

30. Brown, Ronald F Solid State physics: An Introduction for Scientists and Engineers San Luis Obispo: El Corral Bookstore, 2006

31. Bryant, Garnett W. and Solomon, Glenn S. Optics of Quantum Dots and Wires Norwood: Artech House, Inc., 2005

32. Efros, A.L. and Rosen, M. Ann. Rev. Material Science. 2002, 30, 475 
33. Gerdova, Irina and Alain Haché Third-order non-linear spectroscopy of CdSe and $\mathrm{CdSe} / \mathrm{ZnS}$ core shell quantum dots Science Direct, 2004

34. Strebel, Andrea Characterizing Solar Cell Spectral Response for the Purpose of Improving Efficiency San Luis Obispo: California Polytechnic State University, Materials Engineering Department, 2006

35. W.G.J.H.M. van Sark, A.Meijerink, R.E.I. Schropp, J.A.M. van Roosmalen, and E.H.Lysen Enhancing Solar Cell efficiency by Using Spectral Converters Elsevier B.V, 2004 P. 395-409

36. Nozik, A.J. Quantum Dot Solar Cell Center for Basic Sciences, National Renewable Energy Laboratory

37. Talapin, Dmitri V., Rogach, Andrey L., Kornowski, Andreas, Haase, Markus and Weller Horst Highly Luminescent Monodisperse CdSe and CdSe/ZnS Nanocrystals Synthesized in a Hexadecylamine-Trioctylphosphine Oxide-Trioctylphospine Mixture Institute of Physical Chemistry, University of Hamburg, Germany, 2001 P. 207-211

38. Klimov, Vicotr I. Nanocrystal Quantum Dots From fundamental photophysics to multicolor lasing Los Alamos Science, 2003

39. Sia, Samuel K. and Whitesides, George M. Microfluidic devices fabricated in poly(dimethylsiloxane) for biological studies Department of Chemistry and Chemical Biology, Harvard University, Cambridge, MA, 2003 P. 3563-3576 
Appendix A- SOLAR CELL DATA

\section{Characterization at 70,000 Lux}

Trial 1

$\begin{array}{ccccc}\text { Voltage (Volts) } & \text { Current (mA) } & \text { Current (A) } & \text { Resistance (Ohms) } & \text { Power (Watts) } \\ 0 & 59.4 & 0.0594 & \text { short circuit current } & 0 \\ 0.403 & 58 & 0.058 & \text { no resistance } & 0.023374 \\ 0.436 & 54.9 & 0.0549 & 1 & 0.0239364 \\ 0.452 & 53 & 0.053 & 2 & 0.023956 \\ 0.473 & 47.8 & 0.0478 & 3 & 0.0226094 \\ 0.485 & 43.9 & 0.0439 & 4 & 0.0212915 \\ 0.493 & 41 & 0.041 & 5 & 0.020213 \\ 0.497 & 39.3 & 0.0393 & 6 & 0.0195321 \\ 0.503 & 35.9 & 0.0359 & 7 & 0.0180577 \\ 0.507 & 33.9 & 0.0339 & 8 & 0.0171873 \\ 0.509 & 32.6 & 0.0326 & 9 & 0.0165934 \\ 0.512 & 30.9 & 0.0309 & 10 & 0.0158208 \\ 0.551 & 0 & 0 & \text { Open circuit voltage } & 0\end{array}$

Trial 2

Voltage (Volts)Current (mA)Current (A) Resistance (Ohms) Power (Watts)

$\begin{array}{llll}0 & 59.5 & 0.0595 & \text { short circuit current } 0\end{array}$

$\begin{array}{lllll}0.403 & 58.3 & 0.0583 & \text { no resistance } & 0.0234949\end{array}$

$\begin{array}{lllll}0.434 & 55 & 0.055 & 1 & 0.02387\end{array}$

$\begin{array}{lllll}0.449 & 52.8 & 0.0528 & 2 & 0.0237072\end{array}$

$\begin{array}{lllll}0.471 & 47.7 & 0.0477 & 3 & 0.0224667\end{array}$

$\begin{array}{lllll}0.483 & 43.9 & 0.0439 & 4 & 0.0212037\end{array}$

$\begin{array}{lllll}0.49 & 40.9 & 0.0409 & 5 & 0.020041\end{array}$

$\begin{array}{lllll}0.495 & 39.3 & 0.0393 & 6 & 0.0194535\end{array}$

$\begin{array}{lllll}0.501 & 35.9 & 0.0359 & 7 & 0.0179859\end{array}$

$\begin{array}{lllll}0.505 & 33.7 & 0.0337 & 8 & 0.0170185\end{array}$

$\begin{array}{lllll}0.507 & 32.5 & 0.0325 & 9 & 0.0164775\end{array}$

$\begin{array}{lllll}0.511 & 30 & 0.03 & 10 & 0.01533\end{array}$

0.545000 Open circuit voltage 0

Trial 3

Voltage (Volts) Current (mA) Current (A) Resistance (Ohms) Power (Watts)

$\begin{array}{ccccc}0 & 59.1 & 0.0591 & \text { short circuit current } & 0 \\ 0.398 & 58 & 0.058 & \text { no resistance } & 0.023084 \\ 0.431 & 54.8 & 0.0548 & 1 & 0.0236188 \\ 0.446 & 52.5 & 0.0525 & 2 & 0.023415 \\ 0.469 & 47.5 & 0.0475 & 3 & 0.0222775 \\ 0.481 & 43.7 & 0.0437 & 4 & 0.0210197 \\ 0.488 & 40.7 & 0.0407 & 5 & 0.0198616 \\ 0.492 & 39.1 & 0.0391 & 6 & 0.0192372 \\ 0.5 & 35.8 & 0.0358 & 7 & 0.0179 \\ 0.503 & 33.7 & 0.0337 & 8 & 0.0169511 \\ 0.506 & 32.4 & 0.0324 & 9 & 0.0163944 \\ 0.51 & 30 & 0.03 & 10 & 0.0153 \\ 0.543 & 0 & 0 & \text { Open circuit voltage } & 0\end{array}$


Appendix A- SOLAR CELL DATA

Trial 4

Voltage (Volts) Current (mA) Current (A) Resistance (Ohms) Power (Watts)

$\begin{array}{ccccc}0 & 59.4 & 0.0594 & \text { short circuit current } & 0 \\ 0.4 & 58.4 & 0.0584 & \text { no resistance } & 0.02336 \\ 0.432 & 55.1 & 0.0551 & 1 & 0.0238032 \\ 0.447 & 52.8 & 0.0528 & 2 & 0.0236016 \\ 0.47 & 47.8 & 0.0478 & 3 & 0.022466 \\ 0.482 & 43.9 & 0.0439 & 4 & 0.0211598 \\ 0.49 & 40.9 & 0.0409 & 5 & 0.020041 \\ 0.493 & 39.2 & 0.0392 & 6 & 0.0193256 \\ 0.5 & 35.8 & 0.0358 & 7 & 0.0179 \\ 0.504 & 33.7 & 0.0337 & 8 & 0.0169848 \\ 0.506 & 32.5 & 0.0325 & 9 & 0.016445 \\ 0.51 & 30 & 0.03 & 10 & 0.0153 \\ 0.543 & 0 & 0 & \text { Open circuit voltage } & 0\end{array}$

Trial 5

Voltage (Volts) Current (mA) Current (A) Resistance (Ohms) Power (Watts)

$\begin{array}{ccccc}0 & 59.8 & 0.0598 & \text { short circuit current } & 0 \\ 0.401 & 58.5 & 0.0585 & \text { no resistance } & 0.0234585 \\ 0.433 & 55.2 & 0.0552 & 1 & 0.0239016 \\ 0.447 & 52.9 & 0.0529 & 2 & 0.0236463 \\ 0.47 & 47.8 & 0.0478 & 3 & 0.022466 \\ 0.482 & 44 & 0.044 & 4 & 0.021208 \\ 0.489 & 40.9 & 0.0409 & 5 & 0.0200001 \\ 0.493 & 39.2 & 0.0392 & 6 & 0.0193256 \\ 0.5 & 35.8 & 0.0358 & 7 & 0.0179 \\ 0.504 & 33.7 & 0.0337 & 8 & 0.0169848 \\ 0.506 & 32.5 & 0.0325 & 9 & 0.016445 \\ 0.51 & 30 & 0.03 & 10 & 0.0153 \\ 0.544 & 0 & 0 & \text { Open circuit voltage } & 0\end{array}$

Trial 6

Voltage (Volts) Current (mA) Current (A) Resistance (Ohms) Power (Watts)

$\begin{array}{ccccc}0 & 59.6 & 0.0596 & \text { short circuit current } & 0 \\ 0.4 & 58.4 & 0.0584 & \text { no resistance } & 0.02336 \\ 0.433 & 55.2 & 0.0552 & 1 & 0.0239016 \\ 0.447 & 52.8 & 0.0528 & 2 & 0.0236016 \\ 0.47 & 47.7 & 0.0477 & 3 & 0.022419 \\ 0.482 & 43.9 & 0.0439 & 4 & 0.0211598 \\ 0.489 & 40.9 & 0.0409 & 5 & 0.0200001 \\ 0.493 & 39.2 & 0.0392 & 6 & 0.0193256 \\ 0.5 & 35.8 & 0.0358 & 7 & 0.0179 \\ 0.504 & 33.7 & 0.0337 & 8 & 0.0169848 \\ 0.506 & 32.5 & 0.0325 & 9 & 0.016445 \\ 0.51 & 30 & 0.03 & 10 & 0.0153 \\ 0.543 & 0 & 0 & \text { Open circuit voltage } & 0\end{array}$


Appendix A-SOLAR CELL DATA

Trial 7

$\begin{array}{ccccc}\text { Voltage (Volts) } & \text { Current (mA) } & \text { Current }(\mathrm{A}) & \text { Resistance (Ohms) } & \text { Power (Watts) } \\ 0 & 59 & 0.059 & \text { short circuit current } & 0 \\ 0.397 & 58 & 0.058 & \text { no resistance } & 0.023026 \\ 0.429 & 54.8 & 0.0548 & 1 & 0.0235092 \\ 0.444 & 52.4 & 0.0524 & 2 & 0.0232656 \\ 0.467 & 47.5 & 0.0475 & 3 & 0.0221825 \\ 0.479 & 43.7 & 0.0437 & 4 & 0.0209323 \\ 0.487 & 40.7 & 0.0407 & 5 & 0.0198209 \\ 0.491 & 39 & 0.039 & 6 & 0.019149 \\ 0.498 & 35.7 & 0.0357 & 7 & 0.0177786 \\ 0.502 & 33.6 & 0.0336 & 8 & 0.0168672 \\ 0.504 & 32.3 & 0.0323 & 9 & 0.0162792 \\ 0.508 & 29.9 & 0.0299 & 10 & 0.0151892 \\ 0.542 & 0 & 0 & \text { Open circuit voltage } & 0\end{array}$

Trial 8

Voltage (Volts) Current (mA) Current (A) Resistance (Ohms) Power (Watts)

$\begin{array}{ccccc}0 & 59.2 & 0.0592 & \text { short circuit current } & 0 \\ 0.398 & 58 & 0.058 & \text { no resistance } & 0.023084 \\ 0.431 & 54.8 & 0.0548 & 1 & 0.0236188 \\ 0.446 & 52.6 & 0.0526 & 2 & 0.0234596 \\ 0.468 & 47.6 & 0.0476 & 3 & 0.0222768 \\ 0.481 & 43.8 & 0.0438 & 4 & 0.0210678 \\ 0.488 & 40.8 & 0.0408 & 5 & 0.0199104 \\ 0.492 & 39.1 & 0.0391 & 6 & 0.0192372 \\ 0.499 & 35.7 & 0.0357 & 7 & 0.0178143 \\ 0.503 & 33.6 & 0.0336 & 8 & 0.0169008 \\ 0.505 & 32.4 & 0.0324 & 9 & 0.016362 \\ 0.509 & 30 & 0.03 & 10 & 0.01527 \\ 0.542 & 0 & 0 & \text { Open circuit voltage } & 0\end{array}$

Trial 9

Voltage (Volts) Current (mA) Current (A) Resistance (Ohms) Power (Watts)

$\begin{array}{ccccc}0 & 59.4 & 0.0594 & \text { short circuit current } & 0 \\ 0.399 & 58.2 & 0.0582 & \text { no resistance } & 0.0232218 \\ 0.431 & 54.9 & 0.0549 & 1 & 0.0236619 \\ 0.446 & 52.6 & 0.0526 & 2 & 0.0234596 \\ 0.469 & 47.7 & 0.0477 & 3 & 0.0223713 \\ 0.481 & 43.9 & 0.0439 & 4 & 0.0211159 \\ 0.488 & 40.9 & 0.0409 & 5 & 0.0199592 \\ 0.492 & 39.1 & 0.0391 & 6 & 0.0192372 \\ 0.499 & 35.8 & 0.0358 & 7 & 0.0178642 \\ 0.503 & 33.7 & 0.0337 & 8 & 0.0169511 \\ 0.505 & 32.4 & 0.0324 & 9 & 0.016362 \\ 0.509 & 29.9 & 0.0299 & 10 & 0.0152191 \\ 0.543 & 0 & 0 & \text { Open circuit voltage } & 0\end{array}$


Appendix A- SOLAR CELL DATA

Trial 10

Voltage (Volts)Current (mA)Current (A)Resistance (Ohms) Power (Watts)

0

0.398

$59.4 \quad 0.0594$

short circuit current

0.431

58.2

0.0582

0.446

55.1

no resistance

0

0.469

52.7

0.0551

0.481

47.7

0.0527

1

0.0231636

0.489

43.9

0.0477

40.9

0.0439

2

0.0237481

0.492

39.1

0.0409

0.0391

$\begin{array}{ll}35.8 & 0.0358\end{array}$

0.499

33.7

0.503

32.5

0.509

0.543

30

0

0.0337

0.0325

0.03

0

Open circuit voltage

0.0235042

0.0223713

0.0211159

0.0200001

0.0192372

0.0178642

0.0169511

0.0164125

0.01527

Average Values

Voltage (Volts)Current (mA)Current (A)Resistance (Ohms) Power (Watts)

$\begin{array}{ccccc}0 & 59.3777778 & 0.0593778 & \text { short circuit current } & 0 \\ 0.399667 & 58.1777778 & 0.0581778 & \text { no resistance } & 0.023251867 \\ 0.432111 & 54.9666667 & 0.0549667 & 1 & 0.023751822 \\ 0.447 & 52.7 & 0.0527 & 2 & 0.023557233 \\ 0.469556 & 47.6666667 & 0.0476667 & 3 & 0.022382278 \\ 0.481667 & 43.8555556 & 0.0438556 & 4 & 0.021123844 \\ 0.489 & 40.8555556 & 0.0408556 & 5 & 0.019978489 \\ 0.493 & 39.1555556 & 0.0391556 & 6 & 0.019303844 \\ 0.499889 & 35.8 & 0.0358 & 7 & 0.0178961 \\ 0.503778 & 33.7 & 0.0337 & 8 & 0.016977411 \\ 0.505889 & 32.4555556 & 0.0324556 & 9 & 0.016419 \\ 0.509778 & 30.0777778 & 0.0300778 & 10 & 0.015333233 \\ 0.544 & 0 & 0 & \text { Open circuit voltage } & 0\end{array}$


Appendix A- SOLAR CELL DATA

\section{Characterization at 50,000 Lux}

Trial 1

$\begin{array}{ccccc}\text { Voltage (Volts) } & \text { Current (mA) } & \text { Current (A) } & \text { Resistance (Ohms) } & \text { Power (Watts) } \\ 0 & 47.5 & 0.0475 & \text { short circuit current } & 0 \\ 0.325 & 47.5 & 0.0475 & \text { no resistance } & 0.0154375 \\ 0.363 & 46.3 & 0.0463 & 1 & 0.0168069 \\ 0.383 & 45.4 & 0.0454 & 2 & 0.0173882 \\ 0.42 & 42.7 & 0.0427 & 3 & 0.017934 \\ 0.44 & 40.2 & 0.0402 & 4 & 0.017688 \\ 0.454 & 38 & 0.038 & 5 & 0.017252 \\ 0.46 & 36.6 & 0.0366 & 6 & 0.016836 \\ 0.472 & 33.8 & 0.0338 & 7 & 0.0159536 \\ 0.477 & 32 & 0.032 & 8 & 0.015264 \\ 0.481 & 30.9 & 0.0309 & 9 & 0.0148629 \\ 0.488 & 28.7 & 0.0287 & 10 & 0.0140056 \\ 0.534 & 0 & 0 & \text { Open circuit voltage } & 0\end{array}$

Trial 2

Voltage (Volts) Current (mA) Current (A) Resistance (Ohms) Power (Watts)

$\begin{array}{ccccc}0 & 47.2 & 0.0472 & \text { short circuit current } & 0 \\ 0.319 & 47 & 0.047 & \text { no resistance } & 0.014993 \\ 0.358 & 46 & 0.046 & 1 & 0.016468 \\ 0.379 & 45.1 & 0.0451 & 2 & 0.0170929 \\ 0.416 & 42.5 & 0.0425 & 3 & 0.01768 \\ 0.437 & 40.1 & 0.0401 & 4 & 0.0175237 \\ 0.451 & 38 & 0.038 & 5 & 0.017138 \\ 0.458 & 36.6 & 0.0366 & 6 & 0.0167628 \\ 0.47 & 33.9 & 0.0339 & 7 & 0.015933 \\ 0.477 & 32.1 & 0.0321 & 8 & 0.0153117 \\ 0.481 & 31 & 0.031 & 9 & 0.014911 \\ 0.487 & 28.8 & 0.0288 & 10 & 0.0140256 \\ 0.534 & 0 & 0 & \text { Open circuit voltage } & 0\end{array}$

Trial 3

Voltage (Volts) Current (mA) Current (A) Resistance (Ohms) Power (Watts)

$\begin{array}{ccccc}0 & 47.3 & 0.0473 & \text { short circuit current } & 0 \\ 0.318 & 47.1 & 0.0471 & \text { no resistance } & 0.0149778 \\ 0.358 & 46.1 & 0.0461 & 1 & 0.0165038 \\ 0.379 & 45.2 & 0.0452 & 2 & 0.0171308 \\ 0.417 & 42.6 & 0.0426 & 3 & 0.0177642 \\ 0.438 & 40.2 & 0.0402 & 4 & 0.0176076 \\ 0.452 & 38 & 0.038 & 5 & 0.017176 \\ 0.458 & 36.7 & 0.0367 & 6 & 0.0168086 \\ 0.471 & 33.9 & 0.0339 & 7 & 0.0159669 \\ 0.478 & 32.1 & 0.0321 & 8 & 0.0153438 \\ 0.482 & 31.1 & 0.0311 & 9 & 0.0149902 \\ 0.488 & 28.9 & 0.0289 & 10 & 0.0141032 \\ 0.535 & 0 & 0 & \text { Open circuit voltage } & 0\end{array}$


Appendix A- SOLAR CELL DATA

Trial 4

$\begin{array}{ccccc}\text { Voltage (Volts) } & \text { Current (mA) } & \text { Current (A) } & \text { Resistance (Ohms) } & \text { Power (Watts) } \\ 0 & 47.9 & 0.0479 & \text { short circuit current } & 0 \\ 0.323 & 47.6 & 0.0476 & \text { no resistance } & 0.0153748 \\ 0.361 & 46.4 & 0.0464 & 1 & 0.0167504 \\ 0.383 & 45.6 & 0.0456 & 2 & 0.0174648 \\ 0.42 & 42.9 & 0.0429 & 3 & 0.018018 \\ 0.44 & 40.4 & 0.0404 & 4 & 0.017776 \\ 0.454 & 38.2 & 0.0382 & 5 & 0.0173428 \\ 0.461 & 36.9 & 0.0369 & 6 & 0.0170109 \\ 0.473 & 34.1 & 0.0341 & 7 & 0.0161293 \\ 0.479 & 32.2 & 0.0322 & 8 & 0.0154238 \\ 0.482 & 31.1 & 0.0311 & 9 & 0.0149902 \\ 0.489 & 28.94 & 0.02894 & 10 & 0.01415166 \\ 0.536 & 0 & 0 & \text { Open circuit voltage } & 0\end{array}$

Trial 5

Voltage (Volts) Current (mA) Current (A) Resistance (Ohms) Power (Watts)

$\begin{array}{ccccc}0 & 47.9 & 0.0479 & \text { short circuit current } & 0 \\ 0.323 & 47.7 & 0.0477 & \text { no resistance } & 0.0154071 \\ 0.362 & 46.6 & 0.0466 & 1 & 0.0168692 \\ 0.384 & 45.7 & 0.0457 & 2 & 0.0175488 \\ 0.421 & 43 & 0.043 & 3 & 0.018103 \\ 0.441 & 40.5 & 0.0405 & 4 & 0.0178605 \\ 0.454 & 38.2 & 0.0382 & 5 & 0.0173428 \\ 0.461 & 36.8 & 0.0368 & 6 & 0.0169648 \\ 0.473 & 34 & 0.034 & 7 & 0.016082 \\ 0.479 & 32.2 & 0.0322 & 8 & 0.0154238 \\ 0.483 & 31.1 & 0.0311 & 9 & 0.0150213 \\ 0.489 & 28.9 & 0.0289 & 10 & 0.0141321 \\ 0.536 & 0 & 0 & \text { Open circuit voltage } & 0\end{array}$

Trial 6

Voltage (Volts) Current (mA) Current (A) Resistance (Ohms) Power (Watts)

$\begin{array}{ccccc}0 & 48.1 & 0.0481 & \text { short circuit current } & 0 \\ 0.324 & 47.8 & 0.0478 & \text { no resistance } & 0.0154872 \\ 0.362 & 46.7 & 0.0467 & 1 & 0.0169054 \\ 0.384 & 45.7 & 0.0457 & 2 & 0.0175488 \\ 0.42 & 43 & 0.043 & 3 & 0.01806 \\ 0.441 & 40.6 & 0.0406 & 4 & 0.0179046 \\ 0.455 & 38.3 & 0.0383 & 5 & 0.0174265 \\ 0.461 & 36.9 & 0.0369 & 6 & 0.0170109 \\ 0.473 & 34.2 & 0.0342 & 7 & 0.0161766 \\ 0.48 & 32.3 & 0.0323 & 8 & 0.015504 \\ 0.482 & 31.2 & 0.0312 & 9 & 0.0150384 \\ 0.489 & 28.9 & 0.0289 & 10 & 0.0141321 \\ 0.536 & 0 & 0 & \text { Open circuit voltage } & 0\end{array}$


Appendix A- SOLAR CELL DATA

Trial 7

$\begin{array}{ccccc}\text { Voltage (Volts) } & \text { Current (mA) } & \text { Current (A) } & \text { Resistance (Ohms) } & \text { Power (Watts) } \\ 0 & 48 & 0.048 & \text { short circuit current } & 0 \\ 0.323 & 47.6 & 0.0476 & \text { no resistance } & 0.0153748 \\ 0.361 & 46.6 & 0.0466 & 1 & 0.0168226 \\ 0.383 & 45.7 & 0.0457 & 2 & 0.0175031 \\ 0.419 & 42.9 & 0.0429 & 3 & 0.0179751 \\ 0.44 & 40.4 & 0.0404 & 4 & 0.017776 \\ 0.454 & 38.2 & 0.0382 & 5 & 0.0173428 \\ 0.461 & 36.9 & 0.0369 & 6 & 0.0170109 \\ 0.472 & 34 & 0.034 & 7 & 0.016048 \\ 0.479 & 32.2 & 0.0322 & 8 & 0.0154238 \\ 0.482 & 31.1 & 0.0311 & 9 & 0.0149902 \\ 0.489 & 28.9 & 0.0289 & 10 & 0.0141321 \\ 0.536 & 0 & 0 & \text { Open circuit voltage } & 0\end{array}$

Trial 8

Voltage (Volts) Current (mA) Current (A) Re

$\begin{array}{ccccc}0 & 47.9 & 0.0479 & \text { short circuit current } & 0 \\ 0.322 & 47.6 & 0.0476 & \text { no resistance } & 0.0153272 \\ 0.361 & 46.6 & 0.0466 & 1 & 0.0168226 \\ 0.382 & 45.7 & 0.0457 & 2 & 0.0174574 \\ 0.42 & 43 & 0.043 & 3 & 0.01806 \\ 0.44 & 40.4 & 0.0404 & 4 & 0.017776 \\ 0.454 & 38.2 & 0.0382 & 5 & 0.0173428 \\ 0.46 & 36.9 & 0.0369 & 6 & 0.016974 \\ 0.472 & 34.1 & 0.0341 & 7 & 0.0160952 \\ 0.479 & 32.2 & 0.0322 & 8 & 0.0154238 \\ 0.482 & 31.1 & 0.0311 & 9 & 0.0149902 \\ 0.489 & 28.9 & 0.0289 & 10 & 0.0141321 \\ 0.536 & 0 & 0 & \text { Open circuit voltage } & 0\end{array}$

Trial 9

Voltage (Volts) Current (mA) Current (A) Resistance (Ohms) Power (Watts)

0

0.323

0.362

0.383

0.419

0.44

0.453

0.46

0.471

0.478

0.481

0.488

0.536
47.9

47.6

46.3

45.5

42.7

40.3

38

36.6

33.9

32.1

31

28.8

0
0.0479

0.0476

0.0463

0.0455

0.0427

0.0403

0.038

0.0366

0.0339

0.0321

0.031

0.0288

0 short circuit current

no resistance

1

2

3

4

5

6

7

8

9

10

Open circuit voltage
0.0153748

0.0167606

0.0174265

0.0178913

0.017732

0.017214

0.016836

0.0159669

0.0153438

0.014911

0.0140544

0 
Appendix A- SOLAR CELL DATA

Trial 10

$\begin{array}{ccccc}\text { Voltage (Volts) } & \text { Current (mA) } & \text { Current (A) } & \text { Resistance (Ohms) } & \text { Power (Watts) } \\ 0 & 47.7 & 0.0477 & \text { short circuit current } & 0 \\ 0.325 & 47.4 & 0.0474 & \text { no resistance } & 0.015405 \\ 0.363 & 46.4 & 0.0464 & 1 & 0.0168432 \\ 0.385 & 45.4 & 0.0454 & 2 & 0.017479 \\ 0.42 & 42.7 & 0.0427 & 3 & 0.017934 \\ 0.441 & 40.3 & 0.0403 & 4 & 0.0177723 \\ 0.454 & 38 & 0.038 & 5 & 0.017252 \\ 0.461 & 36.6 & 0.0366 & 6 & 0.0168726 \\ 0.471 & 33.8 & 0.0338 & 7 & 0.0159198 \\ 0.478 & 31.9 & 0.0319 & 8 & 0.0152482 \\ 0.481 & 30.9 & 0.0309 & 9 & 0.0148629 \\ 0.488 & 28.7 & 0.0287 & 10 & 0.0140056 \\ 0.535 & 0 & 0 & \text { Open circuit voltage } & 0\end{array}$

Average Values

Voltage (Volts) Current (mA) Current (A) Resistance (Ohms) Power (Watts)

$\begin{array}{ccccc}0 & 47.675 & 0.047675 & \text { short circuit current } & 0 \\ 0.32225 & 47.425 & 0.047425 & \text { no resistance } & 0.015283113 \\ 0.360875 & 46.3375 & 0.0463375 & 1 & 0.016722263 \\ 0.382125 & 45.45 & 0.04545 & 2 & 0.017367838 \\ 0.418875 & 42.75 & 0.04275 & 3 & 0.017907075 \\ 0.4395 & 40.2875 & 0.0402875 & 4 & 0.01770645 \\ 0.45325 & 38.075 & 0.038075 & 5 & 0.01725755 \\ 0.459875 & 36.725 & 0.036725 & 6 & 0.016888975 \\ 0.4715 & 33.9375 & 0.0339375 & 7 & 0.016001588 \\ 0.478125 & 32.1 & 0.0321 & 8 & 0.015347863 \\ 0.4815 & 31.025 & 0.031025 & 9 & 0.014938575 \\ 0.48825 & 28.83 & 0.02883 & 10 & 0.014076283\end{array}$

0.53525

0

0 Open circuit voltage

0 
Appendix B- CROSS-SECTION DATA OF CADMIUM SELENIUM ZINC SULFIDE

CORE SHELL QUANTUM DOTS USING ATOMIC FORCE MICROSCOPY

\section{Cross Section 1}
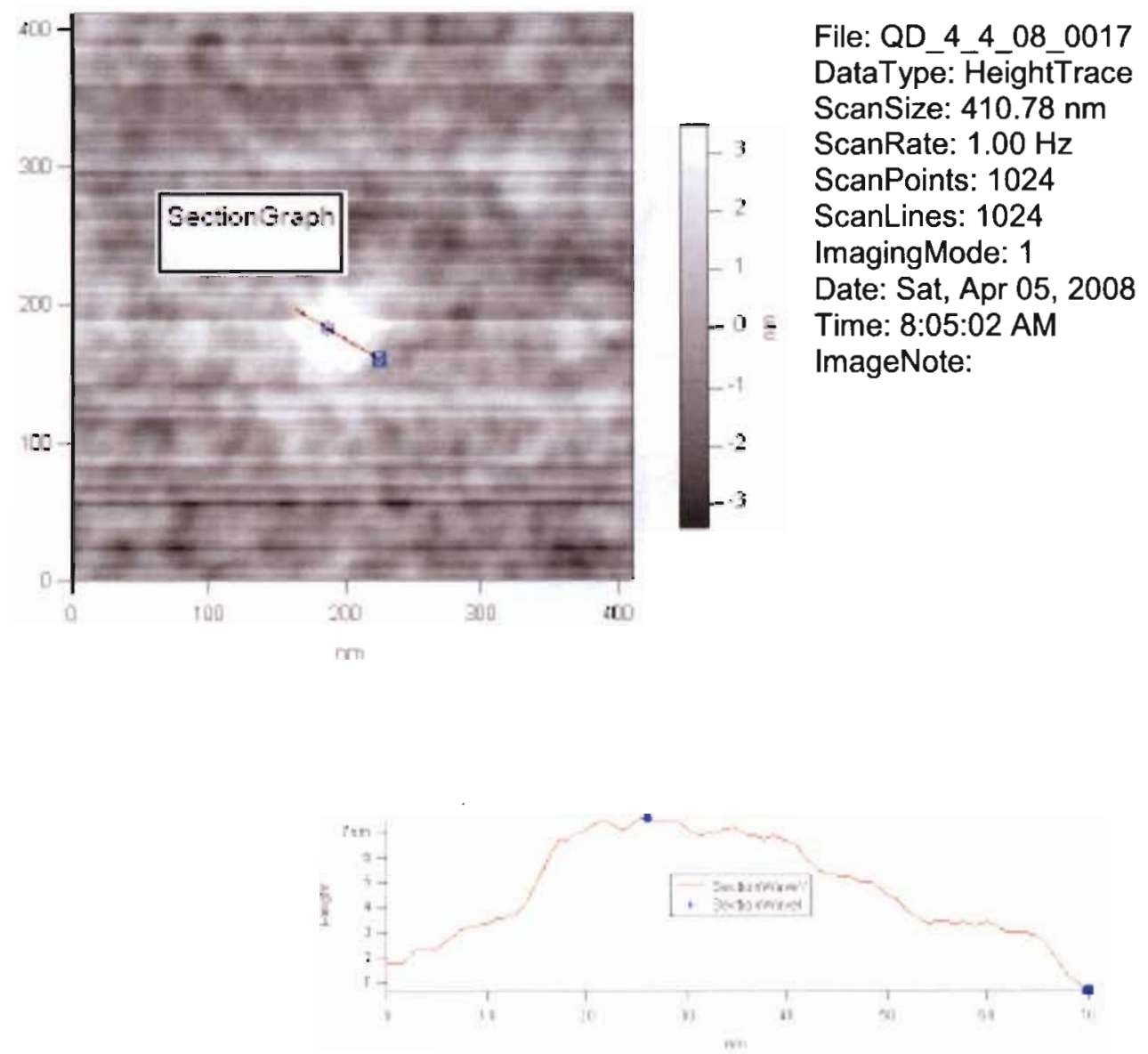

QD_4_4_08_0017HeightTrace

Xa $187.13 \mathrm{~nm}$

Ya $182.60 \mathrm{~nm}$

$\mathrm{Za} 7.52 \mathrm{~nm}$

$\mathrm{Xb} 224.86 \mathrm{~nm}$

Yb $160.22 \mathrm{~nm}$

Zb 649.95 pm

$\mathrm{dx} 37.73 \mathrm{~nm}$

dy $-22.39 \mathrm{~nm}$

$\mathrm{dz}-6.87 \mathrm{~nm}$

dxy $43.87 \mathrm{~nm}$

Surface $45.23 \mathrm{~nm}$

SurfaceSlope $-156.65 \mathrm{~mm} / \mathrm{m}$

SurfaceAngle $-8.9^{\circ}$ 


\section{CORE SHELL QUANTUM DOTS USING ATOMIC FORCE MICROSCOPY}

\section{Cross Section 2}

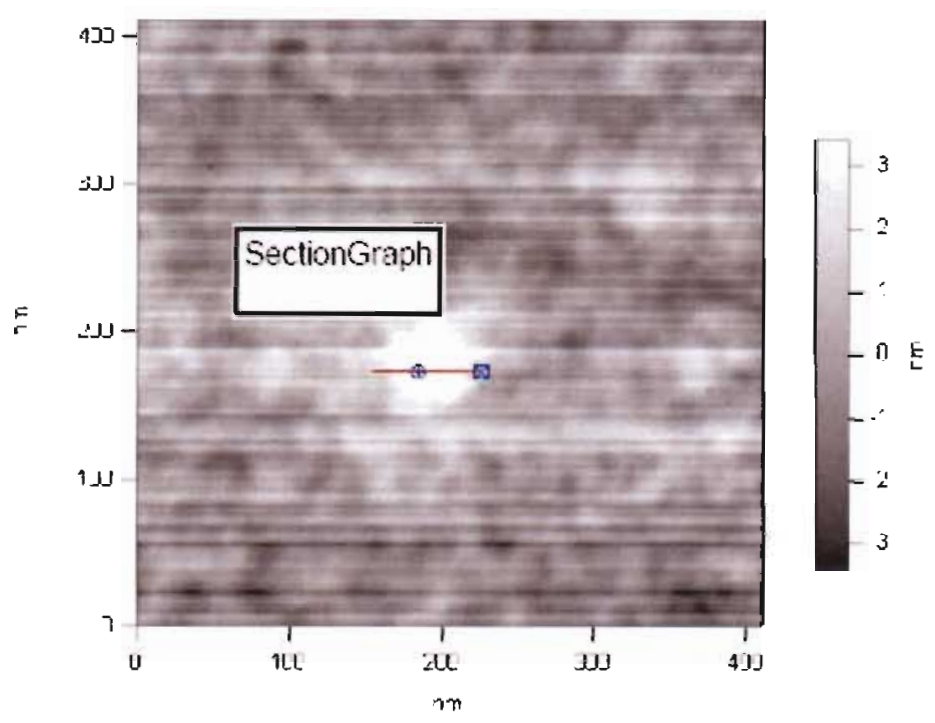

File: QD_4_4_08_0017

DataType: HeightTrace

ScanSize: $410.78 \mathrm{~nm}$

ScanRate: $1.00 \mathrm{~Hz}$

ScanPoints: 1024

ScanLines: 1024

ImagingMode: 1

Date: Sat, Apr 05, 2008

Time: 8:05:02 AM

ImageNote:

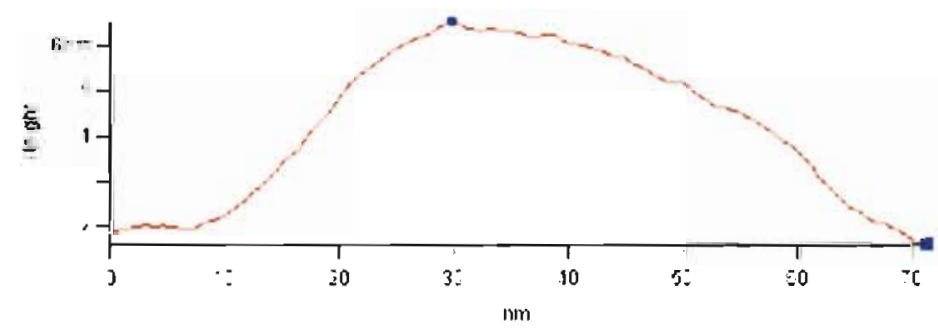

$$
\begin{gathered}
\text { QD_4_4_08_0017HeightTrace } \\
\text { Xa 184.71 nm } \\
\text { Ya 172.66 nm } \\
\text { Za } 6.54 \mathrm{~nm} \\
\text { Xb 226.07 nm } \\
\text { Yb } 172.66 \mathrm{~nm} \\
\text { Zb } 1.59 \mathrm{~nm} \\
\text { dx } 41.36 \mathrm{~nm} \\
\text { dy } 0.00 \mathrm{~m} \\
\text { dz }-4.95 \mathrm{~nm} \\
\text { dxy } 41.36 \mathrm{~nm} \\
\text { Surface } 41.80 \mathrm{~nm} \\
\text { SurfaceSlope }-119.65 \mathrm{~mm} / \mathrm{m} \\
\text { SurfaceAngle }-6.8^{\circ}
\end{gathered}
$$


Appendix B- CROSS-SECTION DATA OF CADMIUM SELENIUM ZINC SULFIDE

CORE SHELL QUANTUM DOTS USING ATOMIC FORCE MICROSCOPY

\section{Cross Section 3}

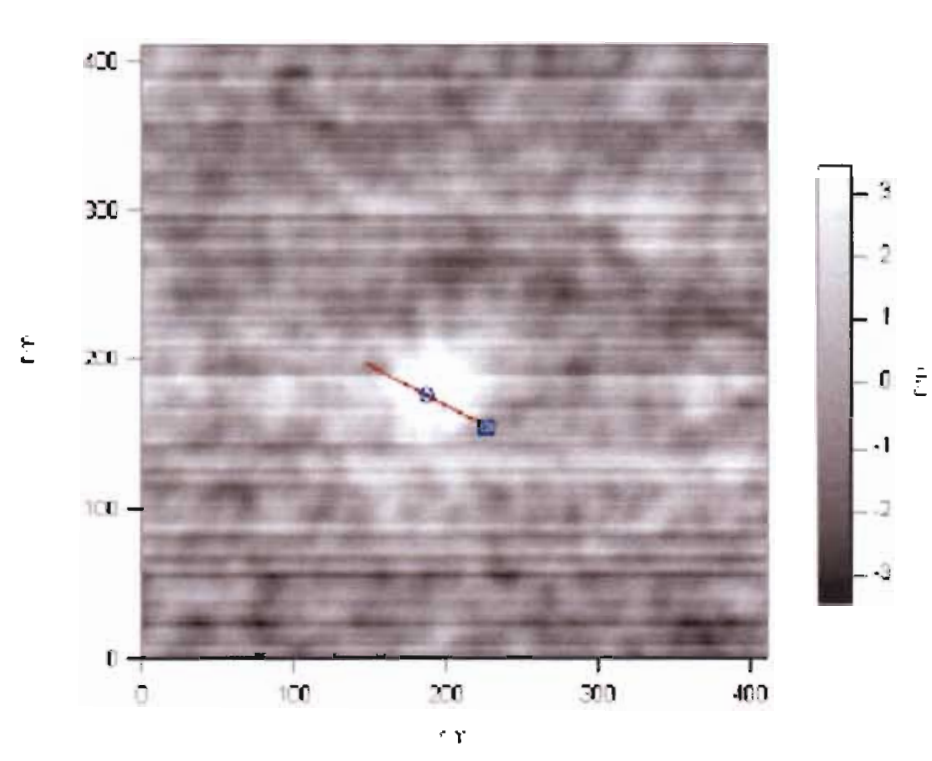

File: QD_4_4_08_0017

DataType: HeightTrace

ScanSize: $410.78 \mathrm{~nm}$

ScanRate: $1.00 \mathrm{~Hz}$

ScanPoints: 1024

ScanLines: 1024

ImagingMode: 1

Date: Sat, Apr 05, 2008

Time: 8:05:02 AM

ImageNote:

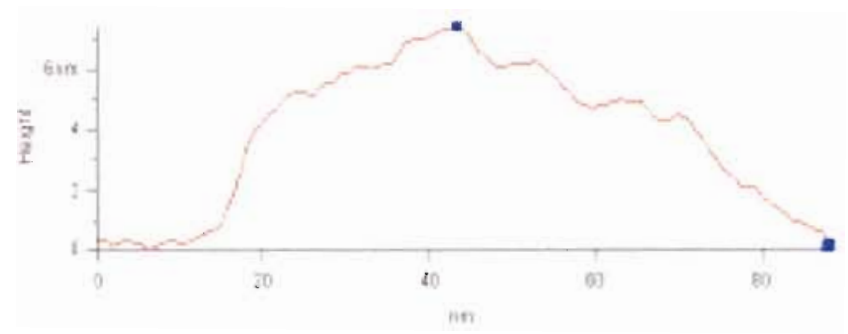

$$
\begin{gathered}
\text { QD_4_4_08_0017HeightTrace } \\
\text { Xa 186.59 nm } \\
\text { Ya 175.75 nm } \\
\text { Za } 7.42 \mathrm{~nm} \\
\text { Xb } 226.07 \mathrm{~nm} \\
\text { Yb } 155.00 \mathrm{~nm} \\
\text { Zb } 139.61 \mathrm{pm} \\
\text { dx } 39.48 \mathrm{~nm} \\
\text { dy }-20.76 \mathrm{~nm} \\
\text { dz }-7.28 \mathrm{~nm} \\
\text { dxy } 44.61 \mathrm{~nm} \\
\text { Surface } 45.99 \mathrm{~nm} \\
\text { SurfaceSlope }-163.13 \mathrm{~mm} / \mathrm{m} \\
\text { SurfaceAngle }-9.3^{\circ}
\end{gathered}
$$




\section{Cross Section 4}

File: QD_4_4_08_0017

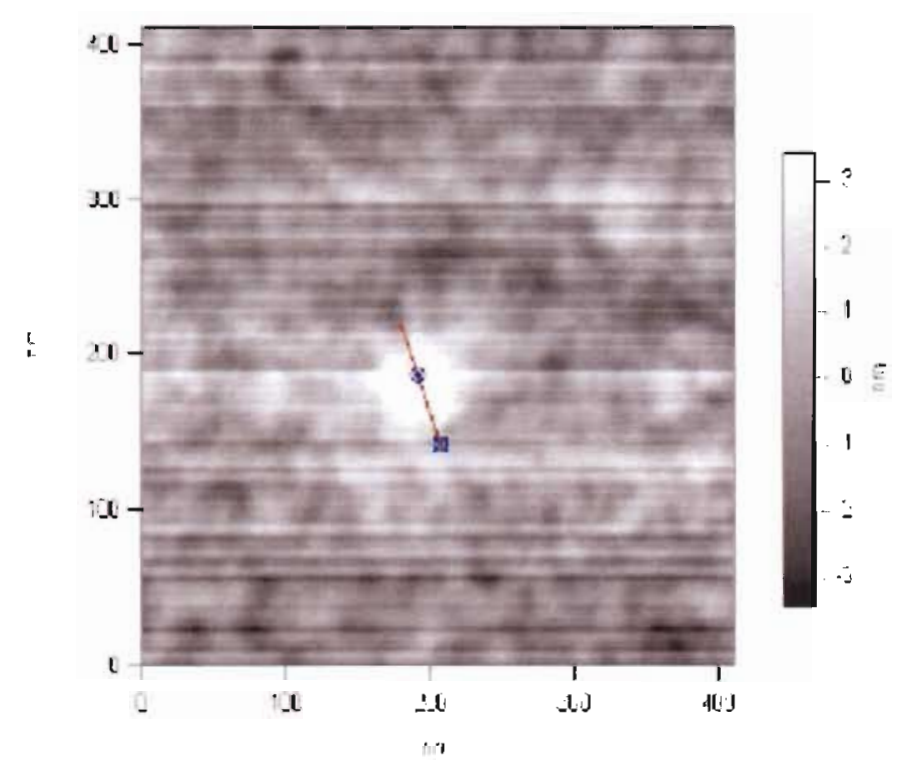

DataType: HeightTrace ScanSize: $410.78 \mathrm{~nm}$

ScanRate: $1.00 \mathrm{~Hz}$

ScanPoints: 1024

ScanLines: 1024

ImagingMode: 1

Date: Sat, Apr 05, 2008

Time: 8:05:02 AM

ImageNote:

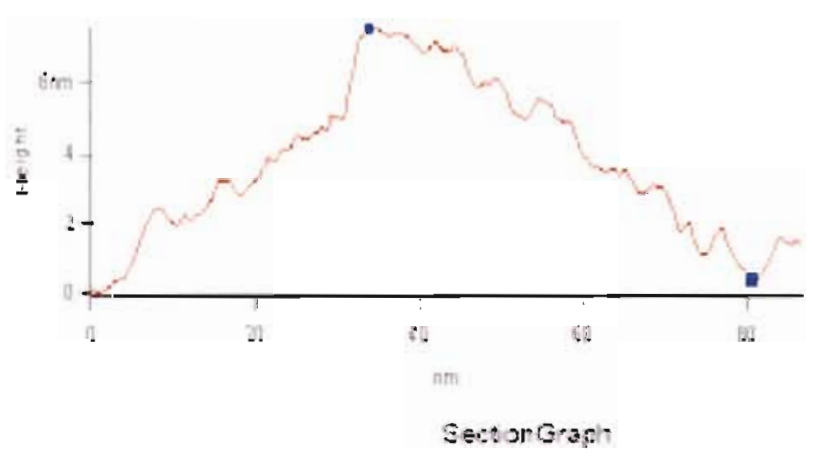

QD_4_4_08_0017HeightTrace

Xa $\overline{191.67 n m}$

Ya $185.80 \mathrm{~nm}$

$\mathrm{Za} 7.51 \mathrm{~nm}$

$\mathrm{Xb} 207.20 \mathrm{~nm}$

Yb $141.81 \mathrm{~nm}$

Zb $355.29 \mathrm{pm}$

$\mathrm{dx} 15.53 \mathrm{~nm}$

dy $-43.99 \mathrm{~nm}$

$\mathrm{dz}-7.15 \mathrm{~nm}$

dxy $46.65 \mathrm{~nm}$

Surface $49.55 \mathrm{~nm}$

SurfaceSlope $-153.34 \mathrm{~mm} / \mathrm{m}$

SurfaceAngle $-8.7^{\circ}$ 
Appendix B- CROSS-SECTION DATA OF CADMIUM SELENIUM ZINC SULFIDE

\section{CORE SHELL QUANTUM DOTS USING ATOMIC FORCE MICROSCOPY}

\section{Cross Section 5}

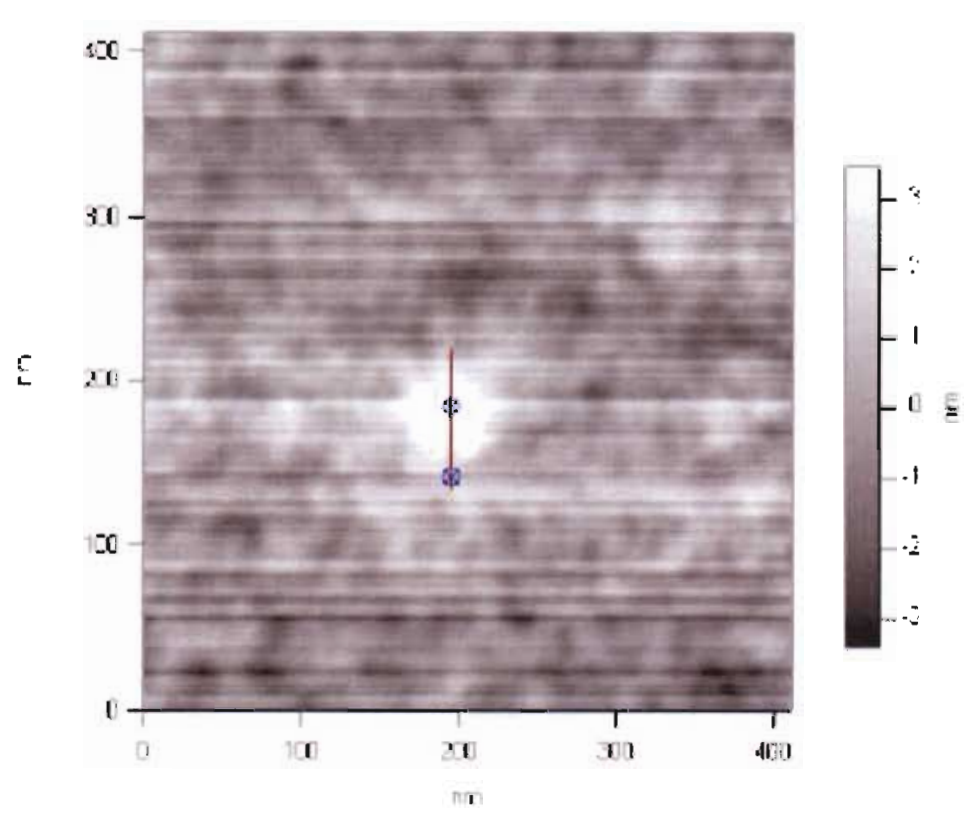

File: QD_4_4_08_0017

DataType: HeightTrace

ScanSize: $410.78 \mathrm{~nm}$

ScanRate: $1.00 \mathrm{~Hz}$

ScanPoints: 1024

ScanLines: 1024

ImagingMode: 1

Date: Sat, Apr 05, 2008

Time: 8:05:02 AM

ImageNote:

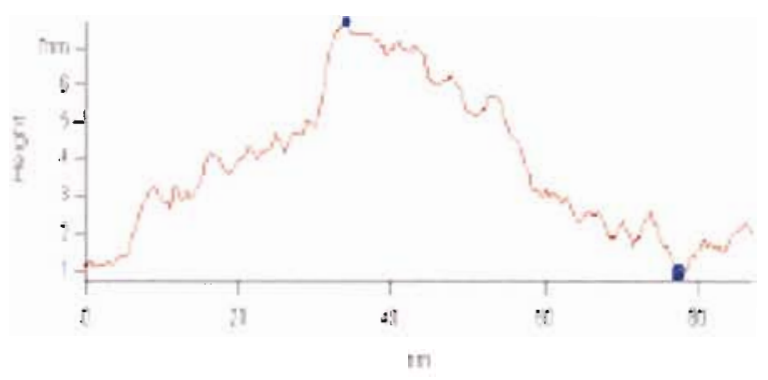

QD_4_4_08_0017HeightTrace

Xa $194.75 \mathrm{~nm}$

Ya $185.11 \mathrm{~nm}$

Za $7.69 \mathrm{~nm}$

Xb $194.75 \mathrm{~nm}$

Yb $141.74 \mathrm{~nm}$

Zb 957.24 pm

$\mathrm{dx} 0.00 \mathrm{~m}$

dy $-43.37 \mathrm{~nm}$

$\mathrm{dz}-6.73 \mathrm{~nm}$

dxy $43.37 \mathrm{~nm}$

Surface $46.96 \mathrm{~nm}$

SurfaceSlope $-155.15 \mathrm{~mm} / \mathrm{m}$

SurfaceAngle $-8.8^{\circ}$ 


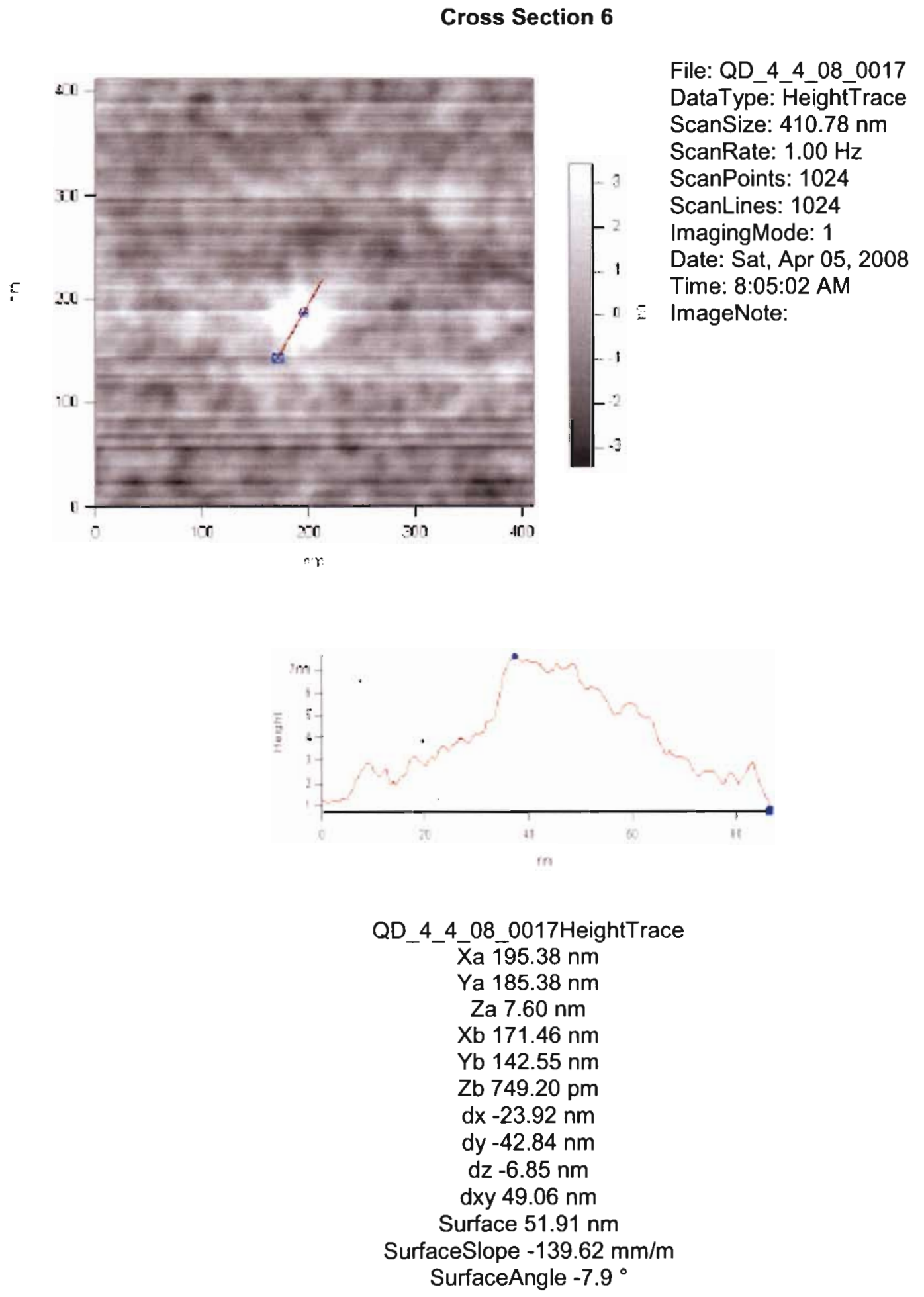


Appendix B- CROSS-SECTION DATA OF CADMIUM SELENIUM ZINC SULFIDE

CORE SHELL QUANTUM DOTS USING ATOMIC FORCE MICROSCOPY

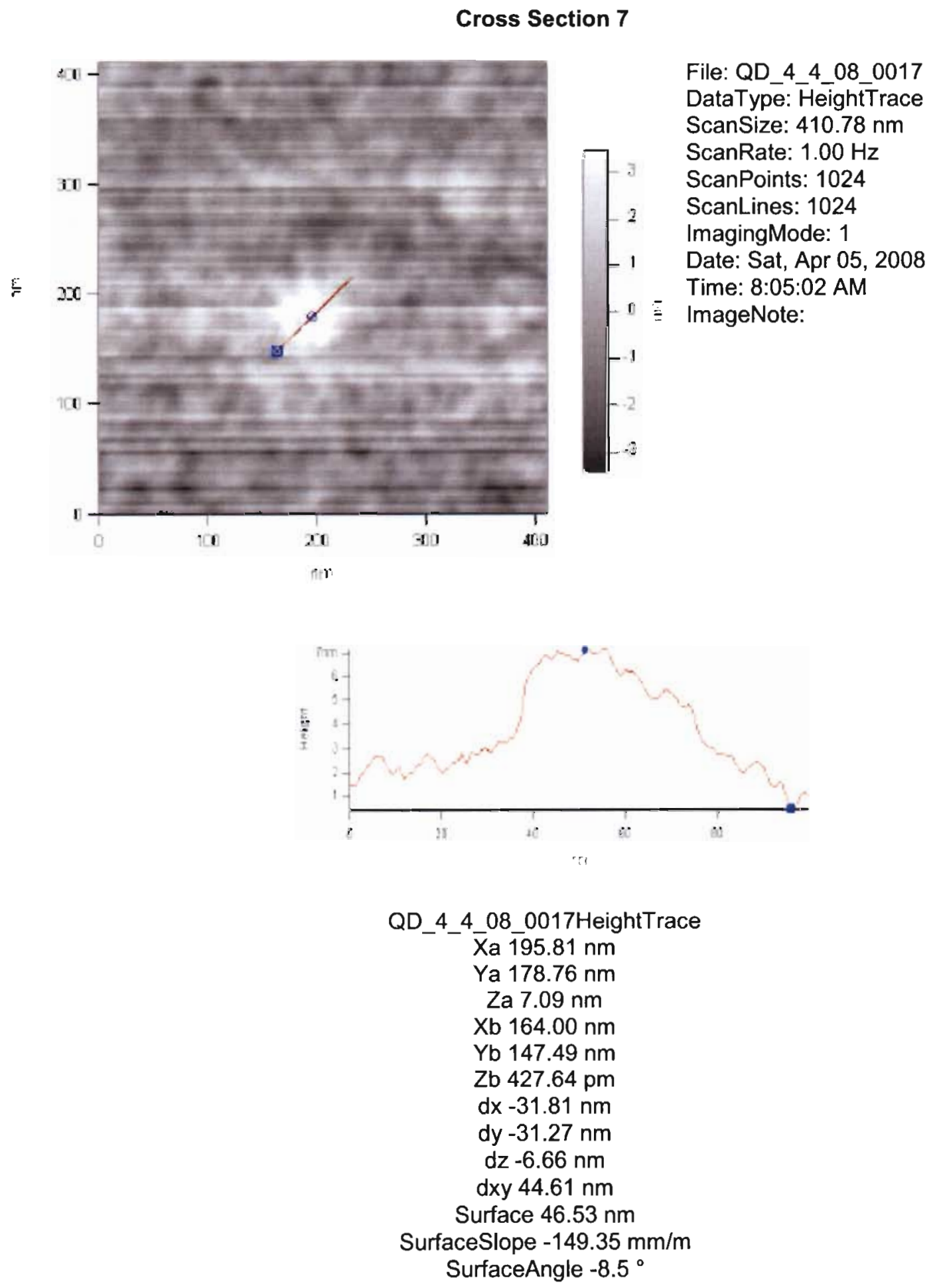


Appendix B-CROSS-SECTION DATA OF CADMIUM SELENIUM ZINC SULFDE

CORE SHELL QUANTUM DOTS USING ATOMIC FORCE MICROSCOPY
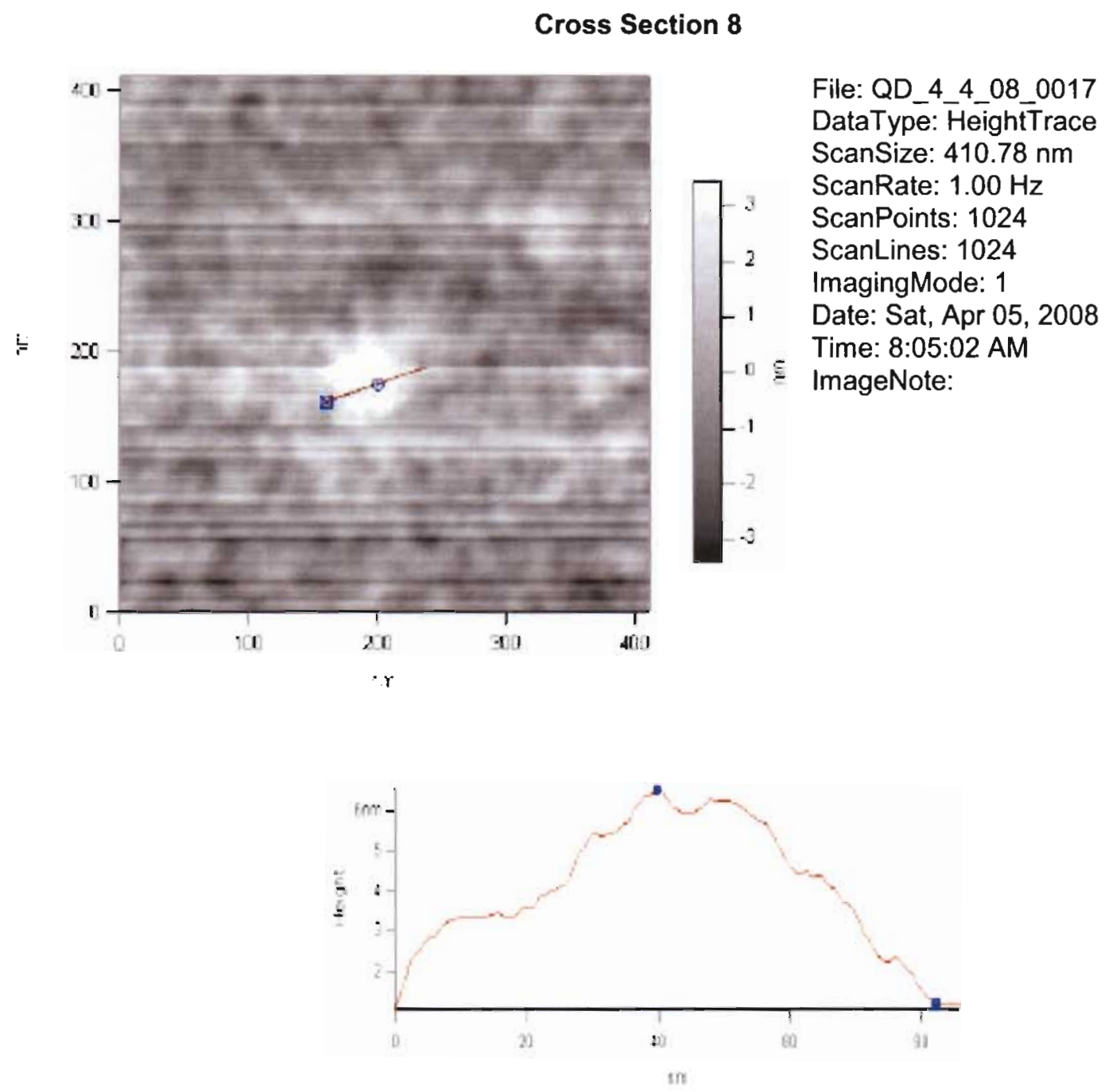
QD_4_4_08_0017HeightTrace
$\bar{X} \mathrm{a} 200.41 \mathrm{~nm}$
Ya $175.26 \mathrm{~nm}$
$\mathrm{Za} 6.49 \mathrm{~nm}$
$\mathrm{Xb} 160.43 \mathrm{~nm}$
Yb $161.40 \mathrm{~nm}$
$\mathrm{Zb} 1.17 \mathrm{~nm}$
$\mathrm{dx}-39.98 \mathrm{~nm}$
dy $-13.86 \mathrm{~nm}$
$\mathrm{dz}-5.33 \mathrm{~nm}$
dxy $42.32 \mathrm{~nm}$
Surface $43.02 \mathrm{~nm}$

SurfaceSlope $-125.93 \mathrm{~mm} / \mathrm{m}$

SurfaceAngle $-7.2^{\circ}$ 
Appendix C - IMPORTANT CALCULATIONS

$$
\begin{gathered}
\mathrm{R}=\text { light reflected } \\
\mathrm{T}=\text { light transmitted } \\
\text { Fresnel Equation } \\
\mathrm{R}=\left|\frac{\mathrm{E}_{\mathrm{r}}}{\mathrm{E}_{\mathrm{i}}}\right|^{2}=\left(\frac{\mathrm{n}_{2}-\mathrm{n}_{1}}{\mathrm{n}_{2}+\mathrm{n}_{1}}\right)^{2} \\
\mathrm{R}_{1}=\left(\frac{\mathrm{n}_{\mathrm{PDMS}}-\mathrm{n}_{\text {air }}}{\mathrm{n}_{\mathrm{PDMS}}+\mathrm{n}_{\text {air }}}\right)^{2}=\left(\frac{1.403-1}{1.403+1}\right)^{2} \\
\mathrm{~T}_{1}=\mathrm{T}_{\mathrm{o}}-\mathrm{R}_{1}=1-0.028126=0.971874
\end{gathered}
$$

PDMS to Quantum Dots Suspended in Toluene

$$
\begin{aligned}
\mathrm{R}_{2} & =\left(\frac{\mathrm{n}_{\text {Toluene }}-\mathrm{n}_{\text {PDMS }}}{\mathrm{n}_{\text {Toluene }}+\mathrm{n}_{\text {PDMS }}}\right)^{2} \\
& =\left(\frac{1.4969-1.403}{1.4969+1.403}\right)^{2}=0.001048 \\
\mathrm{~T}_{2} & =\mathrm{T}_{1}-\mathrm{R}_{2}=0.971874-0.001048=0.970826
\end{aligned}
$$




\section{Appendix C - IMPORTANT CALCULATIONS}

$$
\begin{aligned}
& \text { Quantum Dots Suspended in Toluene to PDMS } \\
& \begin{aligned}
\mathrm{R}_{2} & =\left(\frac{\mathrm{n}_{\text {Toluene }}-\mathrm{n}_{\text {PDMS }}}{\mathrm{n}_{\text {Toluene }}+\mathrm{n}_{\text {PDMS }}}\right)^{2} \\
& =\left(\frac{1.4969-1.403}{1.4969+1.403}\right)^{2}=0.001048 \\
\mathrm{~T}_{3}= & \mathrm{T}_{2}-\mathrm{R}_{3}=0.970826-0.001048=0.969778
\end{aligned}
\end{aligned}
$$

Total light transmitted $=\mathbf{9 7} \%$ 


\section{Appendix C - IMPORTANT CALCULATIONS}

\section{Reflection loss due to PDMS}

$$
\begin{aligned}
& \mathrm{R}=0.028126 \\
& \mathrm{~K}=\text { Extinction Coefficient } \\
& \mathrm{n}_{\mathrm{PDMS}}=1.403 \\
& R=\frac{\left((n-1)^{2}+K^{2}\right)}{(n+1)^{2}-K^{2}} \\
& 0.028126=\frac{\left((1.403-1)^{2}+\mathrm{K}^{2}\right)}{(1.403+1)^{2}-\mathrm{K}^{2}} \\
& 0.028126=\frac{\left((0.162409)^{2}+\mathrm{K}^{2}\right)}{(5.77441)^{2}-\mathrm{K}^{2}} \\
& 0.162411-0.028126 \cdot \mathrm{K}^{2}=0.162409+\mathrm{K}^{2} \\
& 0.00000203=1.028126 \mathrm{~K}^{2} \\
& 1.97207=\mathrm{K}^{2} \\
& K=0.001404
\end{aligned}
$$


Appendix C - IMPORTANT CALCLLATIONS

$$
\begin{gathered}
\text { Absorption Coefficient } \\
\alpha=\text { Absorption Coefficient } \\
\alpha=2 \cdot \mathrm{K}_{\mathrm{o}} \cdot \mathrm{K} \\
\mathrm{K}_{\mathrm{o}}=\frac{2 \cdot \pi}{\lambda_{o}}
\end{gathered}
$$

Assume $\lambda_{0}=620 \mathrm{~nm}$ due to the fluorescence wavelength of the CdSe/ $\mathrm{ZnS}$ quantum dots

$$
\begin{gathered}
\mathrm{K}=\text { Extinction Coefficient } \\
\mathrm{K}=0.001404 \\
\alpha=2\left(\frac{2 \pi}{620 \mathrm{~nm}}\right)(0.001404)
\end{gathered}
$$

$\alpha=28462.9 \mathrm{~m}^{-1}$ 


\section{Appendix C - IMPORTANT CALCULATIONS}

$$
\begin{gathered}
\mathrm{F}=\Phi_{\mathrm{o}}\left(1-\mathrm{e}^{-\varepsilon b c}\right) \\
\mathrm{F}=\text { Intensity of emitted light (fluorescence) } \\
\Phi=\text { quantum efficiency } \\
\mathrm{I}_{\mathrm{o}}=\text { incident radiant power } \\
\epsilon=\text { molar absorptivity } \\
\mathrm{b}=\text { path length of the cell } \\
\mathrm{c}=\text { molar concentration of quantum dots }
\end{gathered}
$$

Desired path length to obtain fluorescence of 1000 sample counts

$$
\begin{gathered}
\epsilon=3.4 \times 10^{5} \mathrm{Lm}^{-1} \mathrm{~cm}^{-1} \\
\Phi=50 \% \\
\mathrm{c}=12 \mathrm{nM} / \mathrm{mL} \\
\mathrm{I}_{0}=8000 \text { sample counts } \\
\frac{\mathrm{F}}{\Phi \mathrm{I}}=1-\mathrm{e}^{-\varepsilon b c} \\
1-\frac{\mathrm{F}}{\Phi I_{\mathrm{o}}}=\mathrm{e}^{-\varepsilon b c} \\
\ln \left(1-\frac{\mathrm{F}}{\Phi I_{\mathrm{o}}}\right)=\mathrm{e}^{-\varepsilon b c} \\
-\ln \left(1-\frac{\mathrm{F}}{\Phi I_{0}}\right)=\varepsilon b c
\end{gathered}
$$




$$
\begin{gathered}
-\frac{\ln \left(1-\frac{\mathrm{F}}{\Phi \mathrm{I}_{\mathrm{o}}}\right)}{\varepsilon \mathrm{c}}=\mathrm{b} \\
\frac{-\ln \left(1-\frac{1000 \text { counts }}{(.5 \cdot 8000 \text { counts })}\right)}{3.4 \cdot 10^{5}\left(\frac{\mathrm{L}}{\mathrm{M} \cdot \mathrm{cm}}\right) \cdot 12\left(\frac{\mathrm{nM}}{\mathrm{mL}}\right)}=\mathrm{b} \\
\mathrm{b}=700 \mu \mathrm{m}
\end{gathered}
$$




\section{Appendix C - IMPORTANT CALCULATIONS}

Desired concentration to obtain fluorescence of 1000 sample counts

$$
\begin{aligned}
& \epsilon=3.4 \times 10^{5} \mathrm{Lm}^{-1} \mathrm{~cm}^{-1} \\
& \Phi=50 \% \\
& \mathrm{~b}=37.9 \mu \mathrm{m} \\
& \mathrm{I}_{0}=8000 \text { sample counts } \\
& \frac{\mathrm{F}}{\Phi_{\mathrm{o}}}=1-\mathrm{e}^{-\varepsilon b c} \\
& 1-\frac{\mathrm{F}}{\Phi \mathrm{I}_{\mathrm{o}}}=\mathrm{e}^{-\varepsilon b c} \\
& \ln \left(1-\frac{\mathrm{F}}{\Phi \mathrm{I}_{\mathrm{o}}}\right)=\mathrm{e}^{-\varepsilon b c} \\
& -\ln \left(1-\frac{F}{\Phi I_{0}}\right)=\varepsilon b c \\
& \frac{-\ln \left(1-\frac{\mathrm{F}}{\Phi_{\mathrm{o}}}\right)}{\varepsilon \mathrm{b}}=\mathrm{c} \\
& \frac{-\ln \left(1-\frac{1000 \text { counts }}{(.5 \cdot 8000 \text { counts })}\right)}{3.4 \cdot 10^{5}\left(\frac{\mathrm{L}}{\mathrm{M} \cdot \mathrm{cm}}\right) \cdot 37.9(\mu \mathrm{m})}=c \\
& \mathrm{c}=223 \mathrm{mM}^{*} \mathrm{~mL}^{-1}
\end{aligned}
$$


Appendix D- PHOTORESIST THICKNESS VERSUS SPIN SPEED (2050)

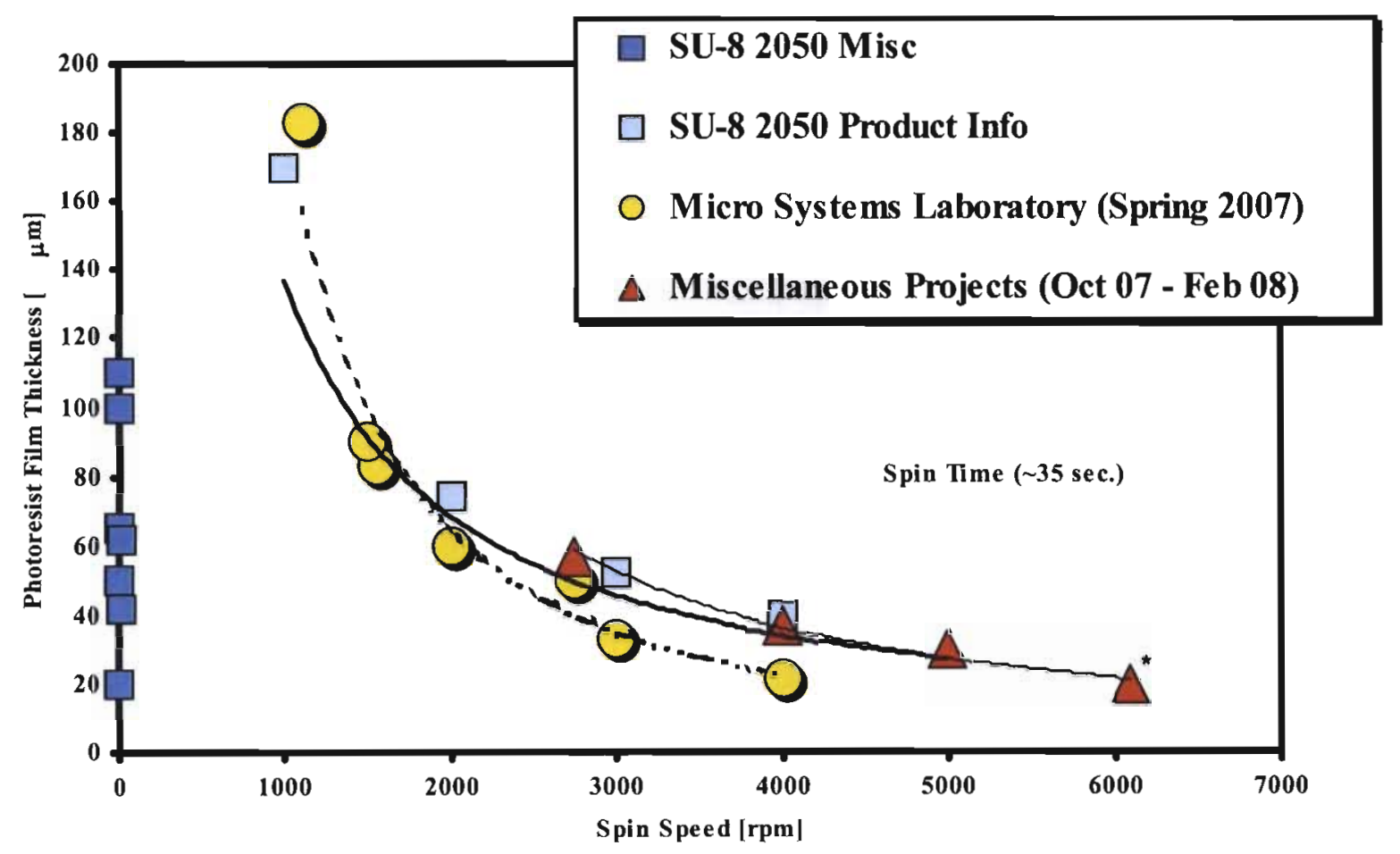

\begin{tabular}{|c|c|c|c|}
\hline $\begin{array}{l}\text { Data Point } \\
\text { (source) }\end{array}$ & $\begin{array}{l}\text { Spin Speed } \\
(\mathrm{rpm})\end{array}$ & $\begin{array}{l}\text { Film Thickness } \\
\text { (microns) }\end{array}$ & \\
\hline 4 & 1000 & 110 & MEMS talk \\
\hline 3 & 1300 & 100 & MEMS talk \\
\hline 1 & 1500 & 100 & MIT Microsystems Technology Lab website \\
\hline 5 & 3200 & 65 & Technical Article - Fu \& Huang \\
\hline 6 & 2500 & 50 & Technical Article - Diehl et al \\
\hline 7 & 5000 & 20 & Technical Article - Wheeler et al. \\
\hline 9 & 2000 & 62 & Technical Article - Unknown \\
\hline 2 & 1000 & 170 & Microchem Spin Speed - Thickness Curve \\
\hline 2 & 2000 & 74.5 & (extracted points) \\
\hline 8 & 2300 & 42 & Technical Article - Li, Tsu, Folch \\
\hline 10 & 1100 & 183 & Micro Systems Laboratory Spring 2007 \\
\hline 10 & 3000 & 33 & Micro Systems Laboratory Spring 2007 \\
\hline 10 & 1550 & 83 & Micro Systems Laboratory Spring 2007 \\
\hline 10 & 1500 & 90 & Micro Systems Laboratory Spring 2007 \\
\hline 10 & 2750 & 49.9 & Micro Systems Laboratory Spring 2007 \\
\hline 10 & 2000 & 59.9 & Micro Systems Laboratory Spring 2008 \\
\hline 10 & 4000 & 21.6 & Micro Systems Laboratory Spring 2009 \\
\hline 10 & 5000 & 30 & H Mayer \& R Rivers (Oct 26th 2007) \\
\hline 10 & 4000 & 37.2 & $\begin{array}{c}\text { D Marrujo (Feb } 19 \text { 2008) } \\
\text { 20 sec at 400 rpm (86rpm/s) } 35 \mathrm{sec} \text { at } 4000 \mathrm{rpm}(602 \mathrm{rpm} / \mathrm{sec})\end{array}$ \\
\hline 10 & 2750 & 57 & H Mayer \& R Rivers (Jan 26 2008) \\
\hline 10 & 6100 & 19.7 & S Meredith (Jan 28 2008) \\
\hline
\end{tabular}




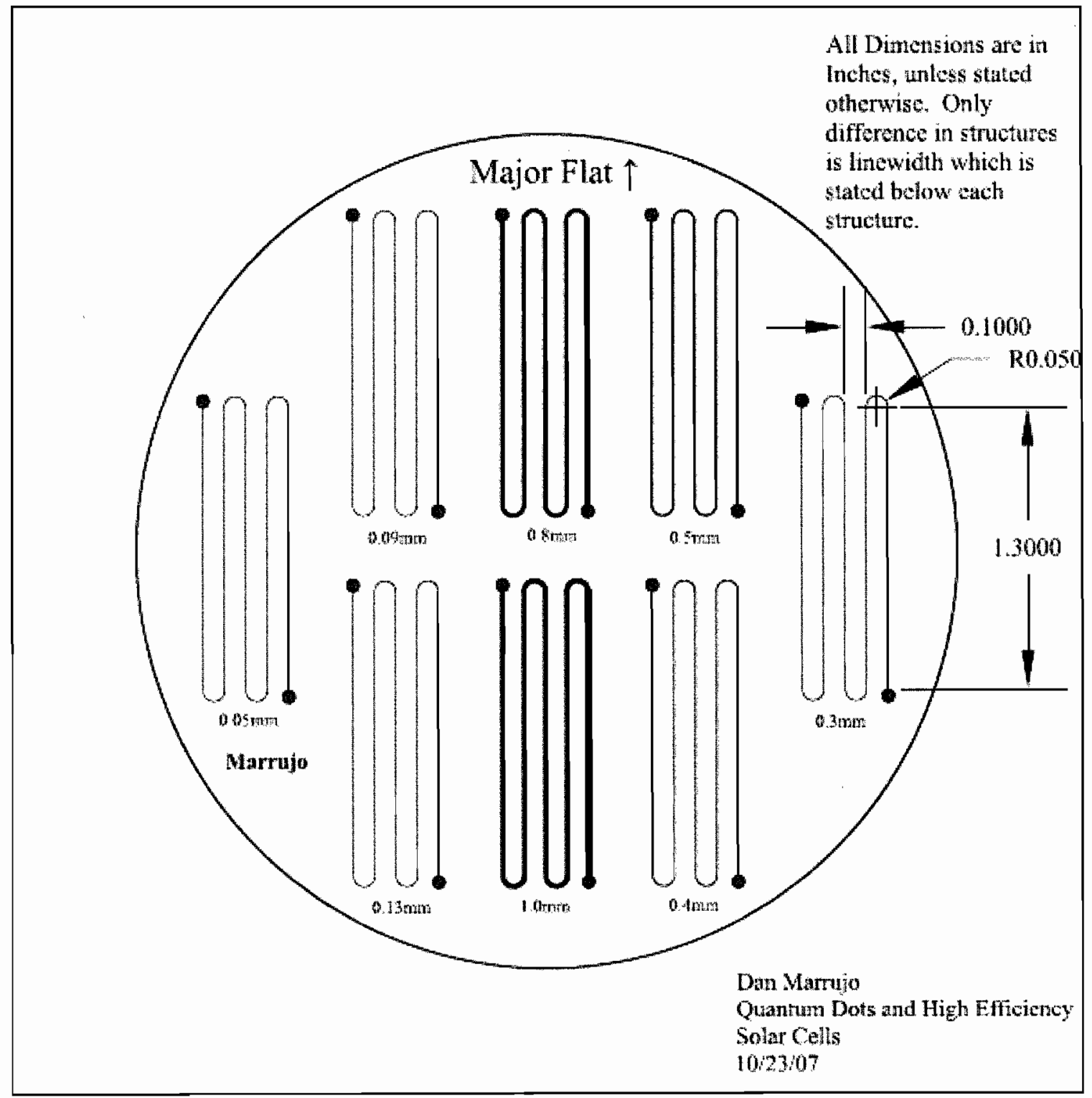

Figure 84 - Top View of First Mask Designed. The Numbers Below Each Channel are the Line Width Associated With That Channel. 
Appendix E - LITHOGRAPHIC MASKS

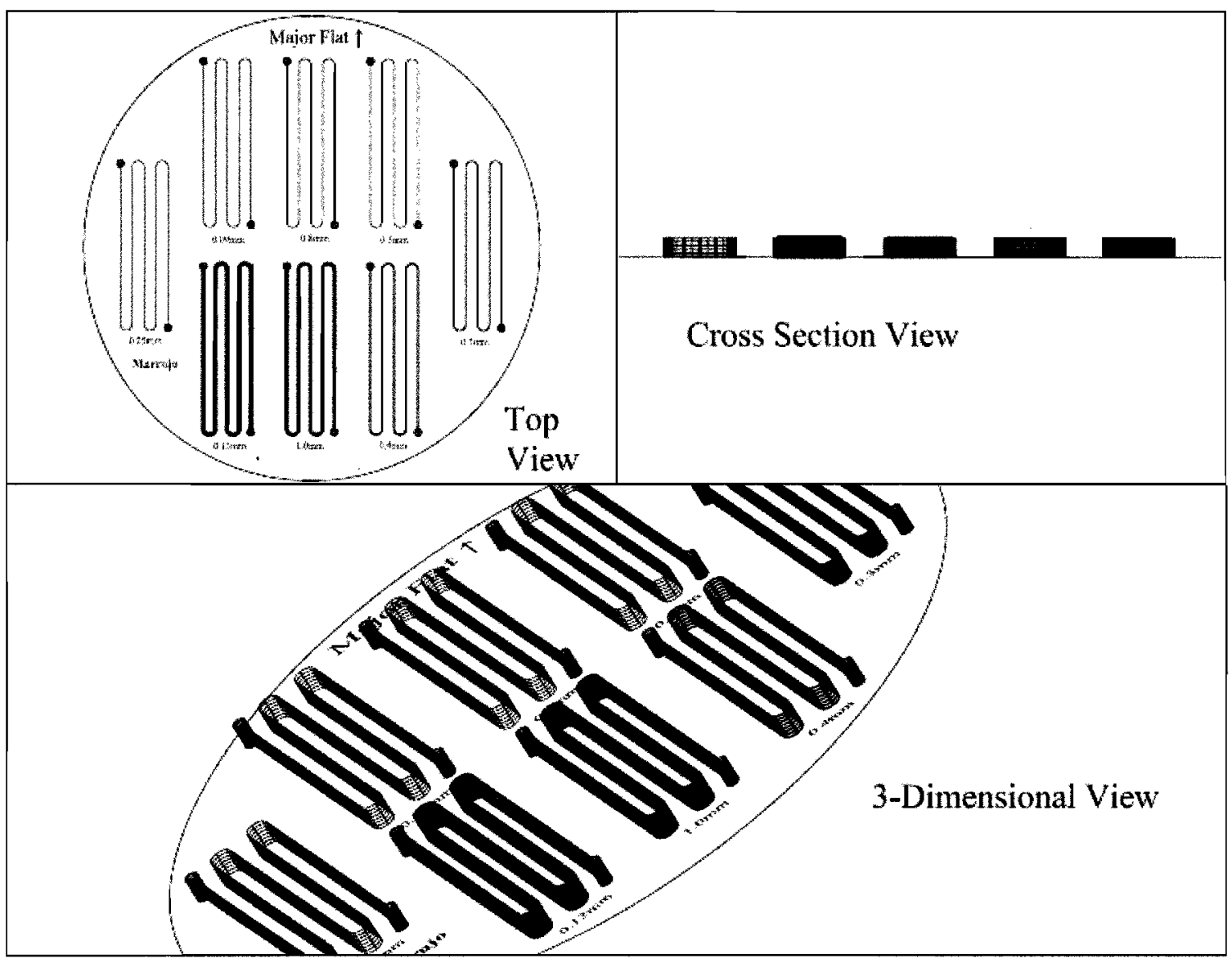

Figure 85 - Top View, Side View and 3-Dimention View of First Mask Drawn in Auto CAD. 
Appendix E - LITHOGRAPHIC MASKS

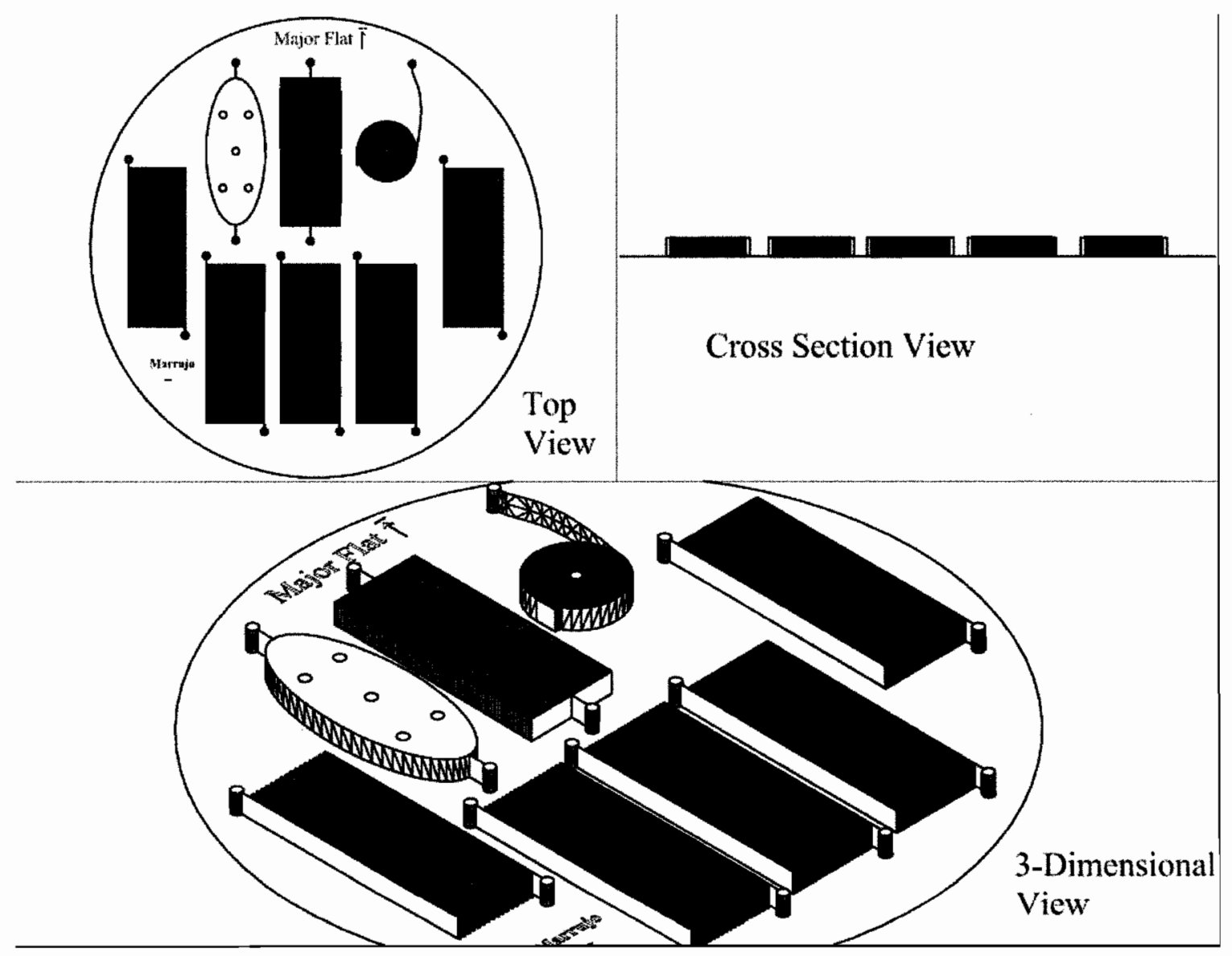

Figure 86 - Top View, Side View and 3-Dimention View of Mask 2 Drawn in Auto CAD 
Appendix E - LITHOGRAPHIC MASKS

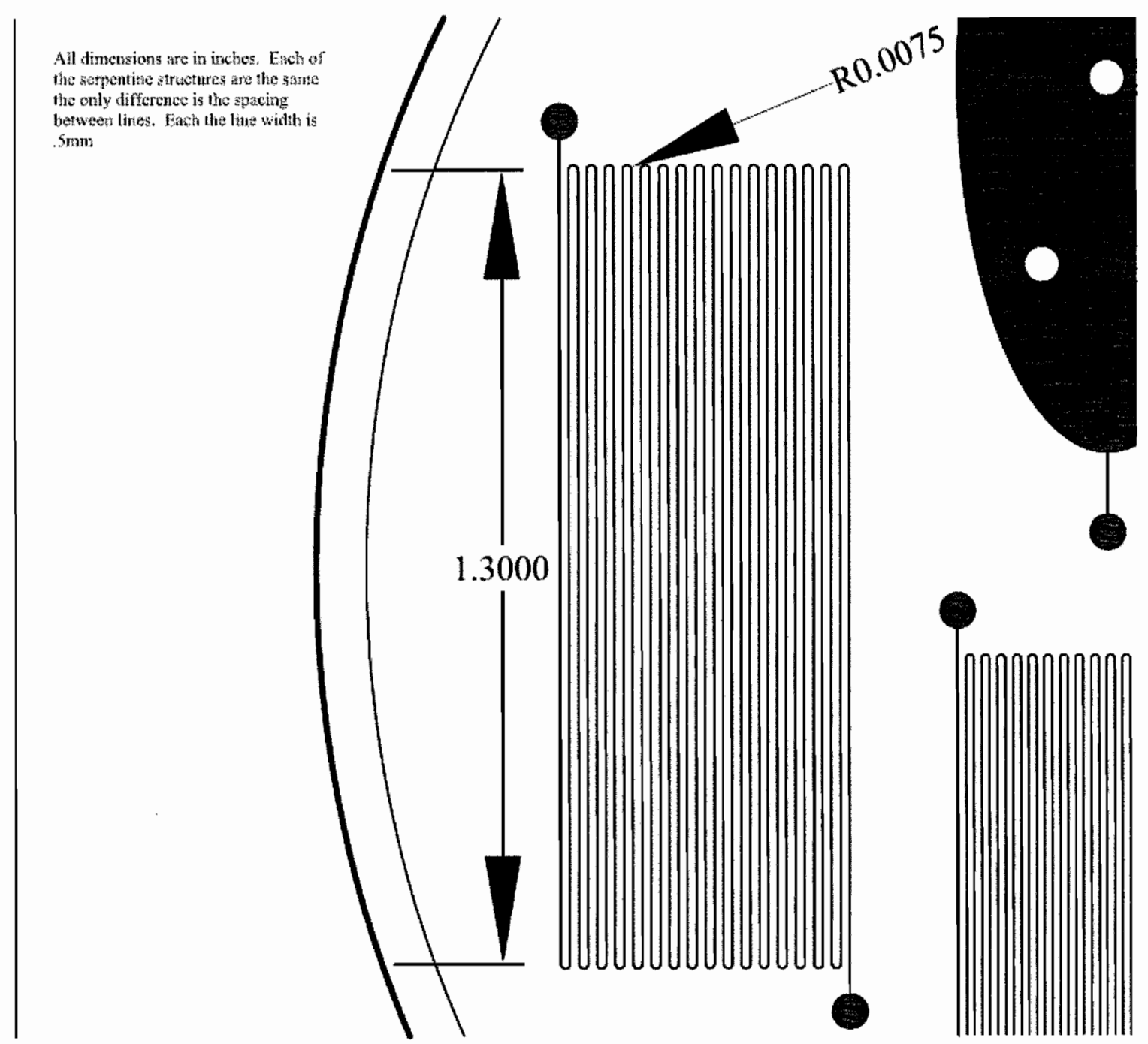

Figure 87 - Dimensions of Each Microfluidic Channel on Mask 2.

The only change in each of the channels on mask 2 was the distance between each channel. The length and radius of the curve stayed the same. 


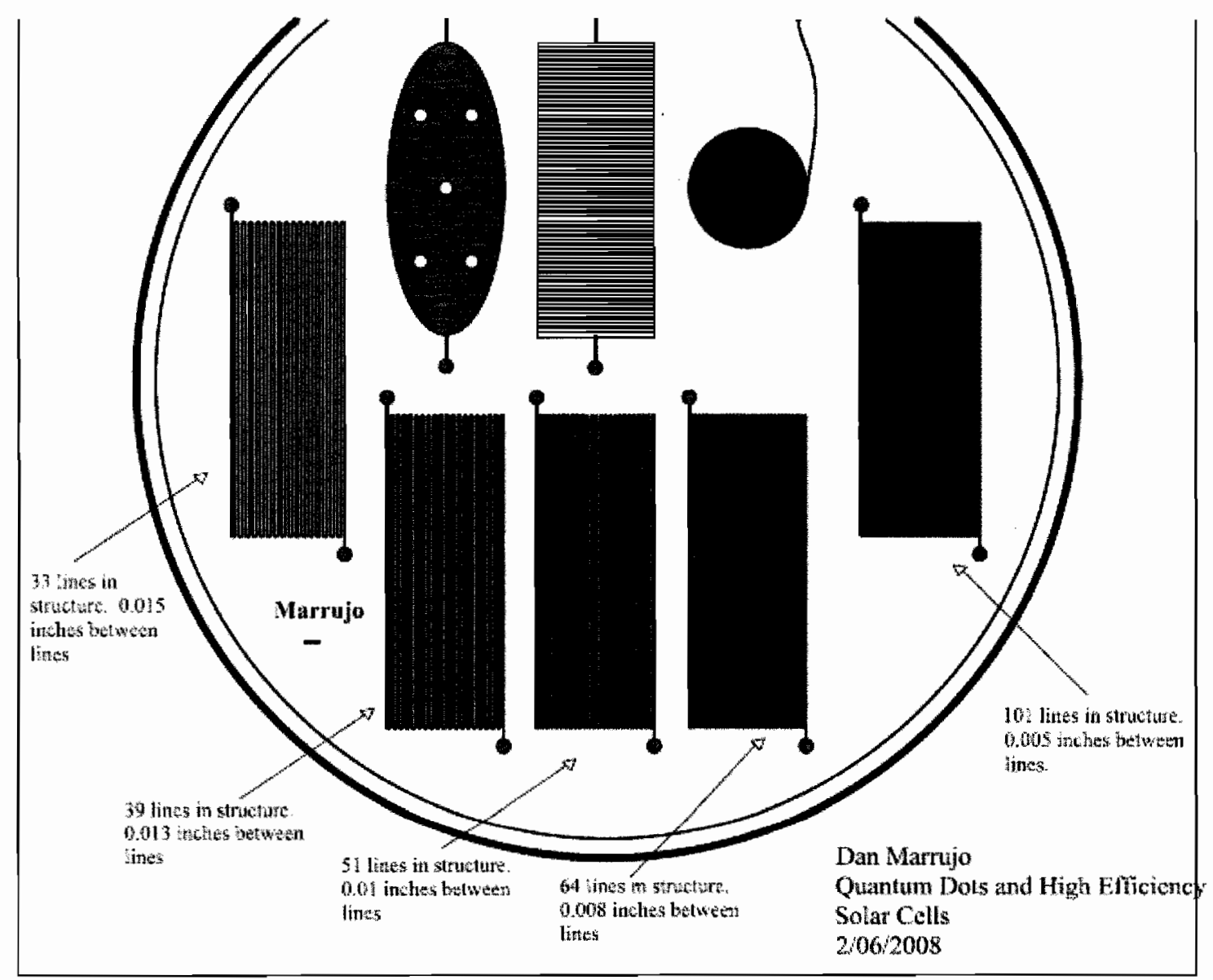

Figure 88 - Number of Lines In Each Set of Channels and the Spacing Between Each Line 
Appendix F - PDMS SUBSTRATE FILLED WITH CADMIUM SELENIUM ZINC

\section{SULFIDE CORE SHELL QUANTUM DOTS}

\section{Characterization at 70,000 Lux}

\begin{tabular}{ccccc}
\multicolumn{5}{c}{ Trial 1 } \\
Voltage (Volts) & Current (mA) & Current (A) & Resistance (Ohms) & Power (Watts) \\
0 & 51 & 0.051 & short circuit current & 0 \\
0.02 & 51 & 0.051 & no resistance & 0.00102 \\
0.071 & 51 & 0.051 & 1 & 0.003621 \\
0.123 & 51 & 0.051 & 2 & 0.006273 \\
0.172 & 51 & 0.051 & 3 & 0.008772 \\
0.222 & 51 & 0.051 & 4 & 0.011322 \\
0.269 & 50 & 0.05 & 5 & 0.01345 \\
0.313 & 49 & 0.049 & 6 & 0.015337 \\
0.35 & 48 & 0.048 & 7 & 0.0168 \\
0.379 & 46 & 0.046 & 8 & 0.017434 \\
0.401 & 43 & 0.043 & 9 & 0.017243 \\
0.409 & 42 & 0.042 & 10 & 0.017178 \\
0.422 & 39 & 0.039 & 11 & 0.016458 \\
0.433 & 37 & 0.037 & 12 & 0.016021 \\
0.422 & 35 & 0.035 & 13 & 0.01477 \\
0.448 & 33 & 0.033 & 14 & 0.014784 \\
0.453 & 31 & 0.031 & 15 & 0.014043 \\
0.457 & 29 & 0.029 & 16 & 0.013253 \\
0.461 & 28 & 0.028 & 17 & 0.012908 \\
0.464 & 26 & 0.026 & 18 & 0.012064 \\
0.467 & 25 & 0.025 & 19 & 0.011675 \\
0.47 & 23 & 0.023 & 20 & 0.01081 \\
0.505 & 0 & 0 & Open circuit voltage & 0
\end{tabular}


Appendix F - PDMS SUBSTRATE FILLED WITH CADMIUM SELENIUM ZINC

\section{SULFIDE CORE SHELL QUANTUM DOTS}

Trial 2

$\begin{array}{ccccc}\text { Voltage (Volts) } & \text { Current (mA) } & \text { Current (A) } & \text { Resistance (Ohms) } & \text { Power (Watts) } \\ 0 & 51 & 0.051 & \text { short circuit current } & 0 \\ 0.02 & 51 & 0.051 & \text { no resistance } & 0.00102 \\ 0.07 & 51 & 0.051 & 1 & 0.00357 \\ 0.122 & 51 & 0.051 & 2 & 0.006222 \\ 0.171 & 51 & 0.051 & 3 & 0.008721 \\ 0.222 & 50 & 0.05 & 4 & 0.0111 \\ 0.268 & 50 & 0.05 & 5 & 0.0134 \\ 0.313 & 49 & 0.049 & 6 & 0.015337 \\ 0.349 & 48 & 0.048 & 7 & 0.016752 \\ 0.378 & 45 & 0.045 & 8 & 0.01701 \\ 0.401 & 43 & 0.043 & 9 & 0.017243 \\ 0.409 & 42 & 0.042 & 10 & 0.017178 \\ 0.422 & 39 & 0.039 & 11 & 0.016458 \\ 0.433 & 37 & 0.037 & 12 & 0.016021 \\ 0.441 & 35 & 0.035 & 13 & 0.015435 \\ 0.447 & 33 & 0.033 & 14 & 0.014751 \\ 0.453 & 31 & 0.031 & 15 & 0.014043 \\ 0.457 & 29 & 0.029 & 16 & 0.013253 \\ 0.461 & 28 & 0.028 & 17 & 0.012908 \\ 0.464 & 26 & 0.026 & 18 & 0.012064 \\ 0.466 & 25 & 0.025 & 19 & 0.01165 \\ 0.47 & 23 & 0.023 & 20 & 0.01081 \\ 0.504 & 0 & 0 & \text { Open circuit voltage } & 0\end{array}$


Appendix F - PDMS SUBSTRATE FILLED WITH CADMIUM SELENIUM ZINC

\section{SULFIDE CORE SHELL QUANTUM DOTS}

Trial 3

$\begin{array}{ccccc}\text { Voltage (Volts) } & \text { Current (mA) } & \text { Current (A) } & \text { Resistance (Ohms) } & \text { Power (Watts) } \\ 0 & 51 & 0.051 & \text { short circuit current } & 0 \\ 0.02 & 51 & 0.051 & \text { no resistance } & 0.00102 \\ 0.071 & 51 & 0.051 & 1 & 0.003621 \\ 0.122 & 51 & 0.051 & 2 & 0.006222 \\ 0.172 & 51 & 0.051 & 3 & 0.008772 \\ 0.222 & 50 & 0.05 & 4 & 0.0111 \\ 0.268 & 50 & 0.05 & 5 & 0.0134 \\ 0.313 & 49 & 0.049 & 6 & 0.015337 \\ 0.349 & 47 & 0.047 & 7 & 0.016403 \\ 0.377 & 45 & 0.045 & 8 & 0.016965 \\ 0.4 & 43 & 0.043 & 9 & 0.0172 \\ 0.408 & 42 & 0.042 & 10 & 0.017136 \\ 0.422 & 39 & 0.039 & 11 & 0.016458 \\ 0.433 & 37 & 0.037 & 12 & 0.016021 \\ 0.441 & 35 & 0.035 & 13 & 0.015435 \\ 0.447 & 33 & 0.033 & 14 & 0.014751 \\ 0.452 & 31 & 0.031 & 15 & 0.014012 \\ 0.457 & 29 & 0.029 & 16 & 0.013253 \\ 0.46 & 28 & 0.028 & 17 & 0.01288 \\ 0.463 & 26 & 0.026 & 18 & 0.012038 \\ 0.466 & 25 & 0.025 & 19 & 0.01165 \\ 0.469 & 24 & 0.024 & 20 & 0.011256 \\ 0.504 & 0 & 0 & \text { Open circuit voltage } & 0\end{array}$


Appendix F - PDMS SUBSTRATE FILLED WITH CADMIUM SELENIUM ZINC

SULFIDE CORE SHELL QUANTUM DOTS

Trial 4

$\begin{array}{ccccc}\text { Voltage (Volts) } & \text { Current (mA) } & \text { Current (A) } & \text { Resistance (Ohms) } & \text { Power (Watts) } \\ 0 & 52 & 0.052 & \text { short circuit current } & 0 \\ 0.02 & 51 & 0.051 & \text { no resistance } & 0.00102 \\ 0.07 & 51 & 0.051 & 1 & 0.00357 \\ 0.122 & 51 & 0.051 & 2 & 0.006222 \\ 0.171 & 51 & 0.051 & 3 & 0.008721 \\ 0.222 & 51 & 0.051 & 4 & 0.011322 \\ 0.269 & 50 & 0.05 & 5 & 0.01345 \\ 0.313 & 49 & 0.049 & 6 & 0.015337 \\ 0.349 & 47 & 0.047 & 7 & 0.016403 \\ 0.378 & 46 & 0.046 & 8 & 0.017388 \\ 0.4 & 43 & 0.043 & 9 & 0.0172 \\ 0.409 & 42 & 0.042 & 10 & 0.017178 \\ 0.421 & 39 & 0.039 & 11 & 0.016419 \\ 0.433 & 37 & 0.037 & 12 & 0.016021 \\ 0.441 & 35 & 0.035 & 13 & 0.015435 \\ 0.447 & 33 & 0.033 & 14 & 0.014751 \\ 0.452 & 31 & 0.031 & 15 & 0.014012 \\ 0.457 & 29 & 0.029 & 16 & 0.013253 \\ 0.46 & 28 & 0.028 & 17 & 0.01288 \\ 0.463 & 26 & 0.026 & 18 & 0.012038 \\ 0.465 & 25 & 0.025 & 19 & 0.011625 \\ 0.469 & 24 & 0.024 & 20 & 0.011256 \\ 0.504 & 0 & 0 & \text { Open circuit voltage } & 0\end{array}$


Appendix F - PDMS SUBSTRATE FILLED WITH CADMIUM SELENIUM ZINC

\section{SULFIDE CORE SHELL QUANTUM DOTS}

Trial 5

$\begin{array}{ccccc}\text { Voltage (Volts) } & \text { Current (mA) } & \text { Current (A) } & \text { Resistance (Ohms) } & \text { Power (Watts) } \\ 0 & 51 & 0.051 & \text { short circuit current } & 0 \\ 0.021 & 51 & 0.051 & \text { no resistance } & 0.001071 \\ 0.072 & 51 & 0.051 & 1 & 0.003672 \\ 0.123 & 51 & 0.051 & 2 & 0.006273 \\ 0.172 & 51 & 0.051 & 3 & 0.008772 \\ 0.222 & 51 & 0.051 & 4 & 0.011322 \\ 0.269 & 50 & 0.05 & 5 & 0.01345 \\ 0.313 & 49 & 0.049 & 6 & 0.015337 \\ 0.349 & 47 & 0.047 & 7 & 0.016403 \\ 0.378 & 45 & 0.045 & 8 & 0.01701 \\ 0.399 & 43 & 0.043 & 9 & 0.017157 \\ 0.407 & 42 & 0.042 & 10 & 0.017094 \\ 0.421 & 39 & 0.039 & 11 & 0.016419 \\ 0.432 & 37 & 0.037 & 12 & 0.015984 \\ 0.44 & 35 & 0.035 & 13 & 0.0154 \\ 0.446 & 33 & 0.033 & 14 & 0.014718 \\ 0.452 & 31 & 0.031 & 15 & 0.014012 \\ 0.456 & 29 & 0.029 & 16 & 0.013224 \\ 0.46 & 27 & 0.027 & 17 & 0.01242 \\ 0.463 & 26 & 0.026 & 18 & 0.012038 \\ 0.465 & 25 & 0.025 & 19 & 0.011625 \\ 0.469 & 23 & 0.023 & 20 & 0.010787 \\ 0.503 & 0 & 0 & \text { Open circuit voltage } & 0\end{array}$


Appendix F - PDMS SUBSTRATE FILLED WITH CADMIUM SELENIUM ZINC

\section{SULFIDE CORE SHELL QUANTUM DOTS}

Trial 6

Voltage (Volts) Current (mA) Current (A) Resistance (Ohms) Power (Watts)

0

0.02

0.071

0.123

0.173

0.223

0.27

0.314

0.351

0.374

0.398

0.406

0.419

0.43

0.438

0.446

0.45

0.455

0.458

0.461

0.464

0.468

0.503
51

51

51

51

51

51

50

49

48

45

43

41

39

37

35

32

30

29

27

26

25

24

0
0.051

0.051

0.051

0.051

0.051

0.051

0.05

0.049

0.048

0.045

0.043

0.041

0.039

0.037

0.035

0.032

0.03

0.029

0.027

0.026

0.025

0.024

0 short circuit current no resistance

0.00102

0.003621

0.006273

0.008823

0.011373

0.0135

0.015386

0.016848

0.01683

0.017114

0.016646

0.016341

0.01591

0.01533

0.014272

0.0135

0.013195

0.012366

0.011986

0.0116

0.011232

0 


\section{SULFIDE CORE SHELL QUANTUM DOTS}

Trial 7

Voltage (Volts) Current (mA) Current (A) Resistance (Ohms) Power (Watts)

$\begin{array}{ccccc}0 & 51 & 0.051 & \text { short circuit current } & 0 \\ 0.02 & 51 & 0.051 & \text { no resistance } & 0.00102 \\ 0.07 & 51 & 0.051 & 1 & 0.00357 \\ 0.121 & 51 & 0.051 & 2 & 0.006171 \\ 0.169 & 51 & 0.051 & 3 & 0.008619 \\ 0.219 & 50 & 0.05 & 4 & 0.01095 \\ 0.264 & 49 & 0.049 & 5 & 0.012936 \\ 0.308 & 48 & 0.048 & 6 & 0.014784 \\ 0.345 & 47 & 0.047 & 7 & 0.016215 \\ 0.375 & 45 & 0.045 & 8 & 0.016875 \\ 0.397 & 43 & 0.043 & 9 & 0.017071 \\ 0.405 & 41 & 0.041 & 10 & 0.016605 \\ 0.419 & 39 & 0.039 & 11 & 0.016341 \\ 0.429 & 37 & 0.037 & 12 & 0.015873 \\ 0.438 & 35 & 0.035 & 13 & 0.01533 \\ 0.445 & 32 & 0.032 & 14 & 0.01424 \\ 0.45 & 31 & 0.031 & 15 & 0.01395 \\ 0.454 & 29 & 0.029 & 16 & 0.013166 \\ 0.458 & 28 & 0.028 & 17 & 0.012824 \\ 0.461 & 26 & 0.026 & 18 & 0.011986 \\ 0.464 & 25 & 0.025 & 19 & 0.0116 \\ 0.468 & 23 & 0.023 & 20 & 0.010764 \\ 0.502 & 0 & 0 & \text { Open circuit voltage } & 0\end{array}$


Appendix F - PDMS SUBSTRATE FILLED WITH CADMIUM SELENIUM ZINC

\section{SULFIDE CORE SHELL QUANTUM DOTS}

Trial 8

$\begin{array}{ccccc}\text { Voltage (Volts) } & \text { Current (mA) } & \text { Current (A) } & \text { Resistance (Ohms) } & \text { Power (Watts) } \\ 0 & 50 & 0.05 & \text { short circuit current } & 0 \\ 0.02 & 50 & 0.05 & \text { no resistance } & 0.001 \\ 0.07 & 50 & 0.05 & 1 & 0.0035 \\ 0.121 & 50 & 0.05 & 2 & 0.00605 \\ 0.171 & 50 & 0.05 & 3 & 0.00855 \\ 0.22 & 50 & 0.05 & 4 & 0.011 \\ 0.267 & 49 & 0.049 & 5 & 0.013083 \\ 0.31 & 48 & 0.048 & 6 & 0.01488 \\ 0.345 & 47 & 0.047 & 7 & 0.016215 \\ 0.374 & 45 & 0.045 & 8 & 0.01683 \\ 0.397 & 42 & 0.042 & 9 & 0.016674 \\ 0.405 & 41 & 0.041 & 10 & 0.016605 \\ 0.419 & 39 & 0.039 & 11 & 0.016341 \\ 0.43 & 36 & 0.036 & 12 & 0.01548 \\ 0.438 & 34 & 0.034 & 13 & 0.014892 \\ 0.445 & 32 & 0.032 & 14 & 0.01424 \\ 0.449 & 30 & 0.03 & 15 & 0.01347 \\ 0.454 & 29 & 0.029 & 16 & 0.013166 \\ 0.458 & 27 & 0.027 & 17 & 0.012366 \\ 0.461 & 26 & 0.026 & 18 & 0.011986 \\ 0.463 & 25 & 0.025 & 19 & 0.011575 \\ 0.467 & 23 & 0.023 & 20 & 0.010741 \\ 0.502 & 0 & 0 & \text { Open circuit voltage } & 0\end{array}$


Appendix F - PDMS SUBSTRATE FILLED WITH CADMIUM SELENIUM ZINC

\section{SULFIDE CORE SHELL QUANTUM DOTS}

Trial 9

$\begin{array}{ccccc}\text { Voltage (Volts) } & \text { Current (mA) } & \text { Current (A) } & \text { Resistance (Ohms) } & \text { Power (Watts) } \\ 0 & 51 & 0.051 & \text { short circuit current } & 0 \\ 0.021 & 51 & 0.051 & \text { no resistance } & 0.001071 \\ 0.071 & 50 & 0.05 & 1 & 0.00355 \\ 0.122 & 50 & 0.05 & 2 & 0.0061 \\ 0.171 & 50 & 0.05 & 3 & 0.00855 \\ 0.221 & 50 & 0.05 & 4 & 0.01105 \\ 0.267 & 49 & 0.049 & 5 & 0.013083 \\ 0.311 & 49 & 0.049 & 6 & 0.015239 \\ 0.347 & 47 & 0.047 & 7 & 0.016309 \\ 0.375 & 45 & 0.045 & 8 & 0.016875 \\ 0.397 & 42 & 0.042 & 9 & 0.016674 \\ 0.404 & 41 & 0.041 & 10 & 0.016564 \\ 0.419 & 39 & 0.039 & 11 & 0.016341 \\ 0.429 & 36 & 0.036 & 12 & 0.015444 \\ 0.437 & 34 & 0.034 & 13 & 0.014858 \\ 0.442 & 32 & 0.032 & 14 & 0.014144 \\ 0.448 & 31 & 0.031 & 15 & 0.013888 \\ 0.453 & 29 & 0.029 & 16 & 0.013137 \\ 0.457 & 27 & 0.027 & 17 & 0.012339 \\ 0.46 & 26 & 0.026 & 18 & 0.01196 \\ 0.462 & 25 & 0.025 & 19 & 0.01155 \\ 0.467 & 23 & 0.023 & 20 & 0.010741 \\ 0.502 & 0 & 0 & \text { Open circuit voltage } & 0\end{array}$


Appendix F - PDMS SUBSTRATE FILLED WITH CADMIUM SELENIUM ZINC

\section{SULFIDE CORE SHELL QUANTUM DOTS}

Trial 10

$\begin{array}{ccccc}\text { Voltage (Volts) } & \text { Current (mA) } & \text { Current (A) } & \text { Resistance (Ohms) } & \text { Power (Watts) } \\ 0 & 50 & 0.05 & \text { short circuit current } & 0 \\ 0.02 & 50 & 0.05 & \text { no resistance } & 0.001 \\ 0.069 & 50 & 0.05 & 1 & 0.00345 \\ 0.12 & 50 & 0.05 & 2 & 0.006 \\ 0.168 & 50 & 0.05 & 3 & 0.0084 \\ 0.218 & 50 & 0.05 & 4 & 0.0109 \\ 0.264 & 49 & 0.049 & 5 & 0.012936 \\ 0.307 & 48 & 0.048 & 6 & 0.014736 \\ 0.344 & 46 & 0.046 & 7 & 0.015824 \\ 0.373 & 44 & 0.044 & 8 & 0.016412 \\ 0.395 & 42 & 0.042 & 9 & 0.01659 \\ 0.403 & 41 & 0.041 & 10 & 0.016523 \\ 0.417 & 39 & 0.039 & 11 & 0.016263 \\ 0.427 & 36 & 0.036 & 12 & 0.015372 \\ 0.436 & 34 & 0.034 & 13 & 0.014824 \\ 0.443 & 32 & 0.032 & 14 & 0.014176 \\ 0.448 & 30 & 0.03 & 15 & 0.01344 \\ 0.453 & 29 & 0.029 & 16 & 0.013137 \\ 0.456 & 27 & 0.027 & 17 & 0.012312 \\ 0.46 & 26 & 0.026 & 18 & 0.01196 \\ 0.462 & 25 & 0.025 & 19 & 0.01155 \\ 0.466 & 23 & 0.023 & 20 & 0.010718 \\ 0.502 & 0 & 0 & \text { Open circuit voltage } & 0\end{array}$


Appendix F - PDMS SUBSTRATE FILLED WITH CADMIUM SELENIUM ZINC

\section{SULFIDE CORE SHELL QUANTUM DOTS}

\begin{tabular}{rrrrr}
\multicolumn{5}{c}{ Average Values } \\
Voltage & Current (mA) & Current (A) & Resistance (Ohms) & Power (Watts) \\
0 & 50.9 & 0.0509 & short circuit current & 0 \\
0.0202 & 50.8 & 0.0508 & no resistance & 0.0010262 \\
0.0705 & 50.7 & 0.0507 & 1 & 0.0035745 \\
0.1219 & 50.7 & 0.0507 & 2 & 0.0061806 \\
0.171 & 50.7 & 0.0507 & 3 & 0.00867 \\
0.2211 & 50.4 & 0.0504 & 4 & 0.0111439 \\
0.2675 & 49.6 & 0.0496 & 5 & 0.0132688 \\
0.3115 & 48.7 & 0.0487 & 6 & 0.015171 \\
0.3478 & 47.2 & 0.0472 & 7 & 0.0164172 \\
0.3761 & 45.1 & 0.0451 & 8 & 0.0169629 \\
0.3985 & 42.7 & 0.0427 & 9 & 0.0170166 \\
0.4065 & 41.5 & 0.0415 & 10 & 0.0168707 \\
0.4201 & 39 & 0.039 & 11 & 0.0163839 \\
0.4309 & 36.7 & 0.0367 & 12 & 0.0158147 \\
0.4372 & 34.7 & 0.0347 & 13 & 0.0151709 \\
0.4456 & 32.5 & 0.0325 & 14 & 0.0144827 \\
0.4507 & 30.7 & 0.0307 & 15 & 0.013837 \\
0.4553 & 29 & 0.029 & 16 & 0.0132037 \\
0.4589 & 27.5 & 0.0275 & 17 & 0.0126203 \\
0.462 & 26 & 0.026 & 18 & 0.012012 \\
0.4644 & 25 & 0.025 & 19 & 0.01161 \\
0.4683 & 23.3 & 0.0233 & 20 & 0.0109115 \\
0.5031 & 0 & 0 & Open circuit voltage & 0
\end{tabular}


Appendix F - PDMS SUBSTRATE FILLED WITH CADMIUM SELENIUM ZINC

SULFIDE CORE SHELL QUANTUM DOTS

Characterization at 50,000 Lux

\begin{tabular}{ccccc}
\multicolumn{5}{c}{ Trial 1 } \\
Voltage (Volts) & Current (mA) & Current (A) & Resistance (Ohms) & Power (Watts) \\
0 & 37.05 & 0.03705 & short circuit current & 0 \\
0.018 & 37 & 0.037 & no resistance & 0.000666 \\
0.055 & 37 & 0.037 & 1 & 0.002035 \\
0.093 & 37 & 0.037 & 2 & 0.003441 \\
0.13 & 37 & 0.037 & 3 & 0.00481 \\
0.167 & 37 & 0.037 & 4 & 0.006179 \\
0.202 & 37 & 0.037 & 5 & 0.007474 \\
0.238 & 37 & 0.037 & 6 & 0.008806 \\
0.271 & 36 & 0.036 & 7 & 0.009756 \\
0.301 & 36 & 0.036 & 8 & 0.010836 \\
0.33 & 35 & 0.035 & 9 & 0.01155 \\
0.34 & 34 & 0.034 & 10 & 0.01156 \\
0.362 & 33 & 0.033 & 11 & 0.011946 \\
0.38 & 32 & 0.032 & 12 & 0.01216 \\
0.394 & 31 & 0.031 & 13 & 0.012214 \\
0.406 & 29 & 0.029 & 14 & 0.011774 \\
0.415 & 28 & 0.028 & 15 & 0.01162 \\
0.423 & 27 & 0.027 & 16 & 0.011421 \\
0.429 & 25 & 0.025 & 17 & 0.010725 \\
0.434 & 24 & 0.024 & 18 & 0.010416 \\
0.439 & 23 & 0.023 & 19 & 0.010097 \\
0.445 & 22 & 0.022 & 20 & 0.00979 \\
0.494 & 0 & 0 & Open circuit voltage & 0
\end{tabular}


Appendix F - PDMS SUBSTRATE FILLED WITH CADMIUM SELENIUM ZINC SULFIDE CORE SHELL QUANTUM DOTS

Trial 2

$\begin{array}{ccccc}\text { Voltage (Volts) } & \text { Current (mA) } & \text { Current (A) } & \text { Resistance (Ohms) } & \text { Power (Watts) } \\ 0 & 39 & 0.039 & \text { short circuit current } & 0 \\ 0.017 & 37 & 0.037 & \text { no resistance } & 0.000629 \\ 0.053 & 37 & 0.037 & 1 & 0.001961 \\ 0.091 & 37 & 0.037 & 2 & 0.003367 \\ 0.127 & 37 & 0.037 & 3 & 0.004699 \\ 0.164 & 36 & 0.036 & 4 & 0.005904 \\ 0.199 & 36 & 0.036 & 5 & 0.007164 \\ 0.234 & 36 & 0.036 & 6 & 0.008424 \\ 0.266 & 36 & 0.036 & 7 & 0.009576 \\ 0.297 & 35 & 0.035 & 8 & 0.010395 \\ 0.324 & 35 & 0.035 & 9 & 0.01134 \\ 0.334 & 34 & 0.034 & 10 & 0.011356 \\ 0.357 & 33 & 0.033 & 11 & 0.011781 \\ 0.376 & 32 & 0.032 & 12 & 0.012032 \\ 0.391 & 30 & 0.03 & 13 & 0.01173 \\ 0.403 & 29 & 0.029 & 14 & 0.011687 \\ 0.412 & 28 & 0.028 & 15 & 0.011536 \\ 0.42 & 27 & 0.027 & 16 & 0.01134 \\ 0.426 & 25 & 0.025 & 17 & 0.01065 \\ 0.432 & 24 & 0.024 & 18 & 0.010368 \\ 0.436 & 23 & 0.023 & 19 & 0.010028 \\ 0.443 & 22 & 0.022 & 20 & 0.009746 \\ 0.493 & 0 & 0 & \text { Open circuit voltage } & 0\end{array}$


Appendix F - PDMS SUBSTRATE FILLED WITH CADMIUM SELENIUM ZINC

SULFIDE CORE SHELL QUANTUM DOTS

Trial 3

$\begin{array}{ccccc}\text { Voltage (Volts) } & \text { Current (mA) } & \text { Current (A) } & \text { Resistance (Ohms) } & \text { Power (Watts) } \\ 0 & 39 & 0.039 & \text { short circuit current } & 0 \\ 0.016 & 37 & 0.037 & \text { no resistance } & 0.000592 \\ 0.052 & 37 & 0.037 & 1 & 0.001924 \\ 0.091 & 37 & 0.037 & 2 & 0.003367 \\ 0.127 & 37 & 0.037 & 3 & 0.004699 \\ 0.164 & 37 & 0.037 & 4 & 0.006068 \\ 0.198 & 37 & 0.037 & 5 & 0.007326 \\ 0.235 & 36 & 0.036 & 6 & 0.00846 \\ 0.268 & 36 & 0.036 & 7 & 0.009648 \\ 0.295 & 35 & 0.035 & 8 & 0.010325 \\ 0.326 & 35 & 0.035 & 9 & 0.01141 \\ 0.337 & 34 & 0.034 & 10 & 0.011458 \\ 0.359 & 33 & 0.033 & 11 & 0.011847 \\ 0.377 & 32 & 0.032 & 12 & 0.012064 \\ 0.392 & 31 & 0.031 & 13 & 0.012152 \\ 0.404 & 29 & 0.029 & 14 & 0.011716 \\ 0.413 & 28 & 0.028 & 15 & 0.011564 \\ 0.421 & 27 & 0.027 & 16 & 0.011367 \\ 0.427 & 26 & 0.026 & 17 & 0.011102 \\ 0.432 & 24 & 0.024 & 18 & 0.010368 \\ 0.437 & 23 & 0.023 & 19 & 0.010051 \\ 0.443 & 22 & 0.022 & 20 & 0.009746 \\ 0.493 & 0 & 0 & \text { Open circuit voltage } & 0\end{array}$


Appendix F - PDMS SUBSTRATE FILLED WITH CADMIUM SELENIUM ZINC

\section{SULFIDE CORE SHELL QUANTUM DOTS}

Trial 4

$\begin{array}{ccccc}\text { Voltage (Volts) } & \text { Current (mA) } & \text { Current (A) } & \text { Resistance (Ohms) } & \text { Power (Watts) } \\ 0 & 39 & 0.039 & \text { short circuit current } & 0 \\ 0.016 & 37 & 0.037 & \text { no resistance } & 0.000592 \\ 0.053 & 37 & 0.037 & 1 & 0.001961 \\ 0.09 & 37 & 0.037 & 2 & 0.00333 \\ 0.125 & 37 & 0.037 & 3 & 0.004625 \\ 0.164 & 37 & 0.037 & 4 & 0.006068 \\ 0.198 & 37 & 0.037 & 5 & 0.007326 \\ 0.234 & 36 & 0.036 & 6 & 0.008424 \\ 0.267 & 36 & 0.036 & 7 & 0.009612 \\ 0.298 & 35 & 0.035 & 8 & 0.01043 \\ 0.326 & 35 & 0.035 & 9 & 0.01141 \\ 0.338 & 34 & 0.034 & 10 & 0.011492 \\ 0.36 & 33 & 0.033 & 11 & 0.01188 \\ 0.378 & 32 & 0.032 & 12 & 0.012096 \\ 0.391 & 30 & 0.03 & 13 & 0.01173 \\ 0.403 & 29 & 0.029 & 14 & 0.011687 \\ 0.412 & 28 & 0.028 & 15 & 0.011536 \\ 0.421 & 27 & 0.027 & 16 & 0.011367 \\ 0.427 & 25 & 0.025 & 17 & 0.010675 \\ 0.432 & 24 & 0.024 & 18 & 0.010368 \\ 0.434 & 23 & 0.023 & 19 & 0.009982 \\ 0.441 & 22 & 0.022 & 20 & 0.009702 \\ 0.494 & 0 & 0 & \text { Open circuit voltage } & 0\end{array}$


Appendix F - PDMS SUBSTRATE FILLED WITH CADMIUM SELENIUM ZINC

\section{SULFIDE CORE SHELL QUANTUM DOTS}

\begin{tabular}{ccccc}
\multicolumn{5}{c}{ Trial 5} \\
Voltage (Volts) & Current (mA) & Current (A) & Resistance (Ohms) & Power (Watts) \\
0 & 37 & 0.037 & short circuit current & 0 \\
0.016 & 38 & 0.038 & no resistance & 0.000608 \\
0.052 & 38 & 0.038 & 1 & 0.001976 \\
0.091 & 37 & 0.037 & 2 & 0.003367 \\
0.127 & 37 & 0.037 & 3 & 0.004699 \\
0.164 & 37 & 0.037 & 4 & 0.006068 \\
0.2 & 37 & 0.037 & 5 & 0.0074 \\
0.237 & 37 & 0.037 & 6 & 0.008769 \\
0.269 & 36 & 0.036 & 7 & 0.009684 \\
0.3 & 36 & 0.036 & 8 & 0.0108 \\
0.329 & 35 & 0.035 & 9 & 0.011515 \\
0.34 & 34 & 0.034 & 10 & 0.01156 \\
0.359 & 33 & 0.033 & 11 & 0.011847 \\
0.378 & 32 & 0.032 & 12 & 0.012096 \\
0.392 & 30 & 0.03 & 13 & 0.01176 \\
0.404 & 29 & 0.029 & 14 & 0.011716 \\
0.413 & 28 & 0.028 & 15 & 0.011564 \\
0.42 & 27 & 0.027 & 16 & 0.01134 \\
0.427 & 25 & 0.025 & 17 & 0.010675 \\
0.432 & 24 & 0.024 & 18 & 0.010368 \\
0.436 & 23 & 0.023 & 19 & 0.010028 \\
0.442 & 22 & 0.022 & 20 & 0.009724 \\
0.491 & 0 & 0 & Open circuit voltage & 0
\end{tabular}


Appendix F - PDMS SUBSTRATE FILLED WITH CADMIUM SELENIUM ZINC

SULFIDE CORE SHELL QUANTUM DOTS

Trial 6

Voltage (Volts) Current (mA) Current (A) Resistance (Ohms) Power (Watts)

$\begin{array}{ccccc}0 & 38 & 0.038 & \text { short circuit current } & 0 \\ 0.015 & 38 & 0.038 & \text { no resistance } & 0.00057 \\ 0.052 & 38 & 0.038 & 1 & 0.001976 \\ 0.09 & 38 & 0.038 & 2 & 0.00342 \\ 0.128 & 38 & 0.038 & 3 & 0.004864 \\ 0.166 & 37 & 0.037 & 4 & 0.006142 \\ 0.202 & 37 & 0.037 & 5 & 0.007474 \\ 0.237 & 37 & 0.037 & 6 & 0.008769 \\ 0.27 & 36 & 0.036 & 7 & 0.00972 \\ 0.3 & 36 & 0.036 & 8 & 0.0108 \\ 0.329 & 35 & 0.035 & 9 & 0.011515 \\ 0.34 & 34 & 0.034 & 10 & 0.01156 \\ 0.361 & 33 & 0.033 & 11 & 0.011913 \\ 0.379 & 32 & 0.032 & 12 & 0.012128 \\ 0.392 & 31 & 0.031 & 13 & 0.012152 \\ 0.405 & 29 & 0.029 & 14 & 0.011745 \\ 0.414 & 28 & 0.028 & 15 & 0.011592 \\ 0.422 & 27 & 0.027 & 16 & 0.011394 \\ 0.428 & 26 & 0.026 & 17 & 0.011128 \\ 0.433 & 24 & 0.024 & 18 & 0.010392 \\ 0.437 & 23 & 0.023 & 19 & 0.010051 \\ 0.443 & 22 & 0.022 & 20 & 0.009746 \\ 0.492 & 0 & 0 & \text { Open circuit voltage } & 0\end{array}$


Appendix F - PDMS SUBSTRATE FILLED WITH CADMIUM SELENIUM ZINC

\section{SULFIDE CORE SHELL QUANTUM DOTS}

Trial 7

$\begin{array}{ccccc}\text { Voltage (Volts) } & \text { Current (mA) } & \text { Current (A) } & \text { Resistance (Ohms) } & \text { Power (Watts) } \\ 0 & 38 & 0.038 & \text { short circuit current } & 0 \\ 0.016 & 38 & 0.038 & \text { no resistance } & 0.000608 \\ 0.053 & 38 & 0.038 & 1 & 0.002014 \\ 0.091 & 38 & 0.038 & 2 & 0.003458 \\ 0.128 & 38 & 0.038 & 3 & 0.004864 \\ 0.165 & 38 & 0.038 & 4 & 0.00627 \\ 0.201 & 37 & 0.037 & 5 & 0.007437 \\ 0.238 & 37 & 0.037 & 6 & 0.008806 \\ 0.271 & 36 & 0.036 & 7 & 0.009756 \\ 0.301 & 36 & 0.036 & 8 & 0.010836 \\ 0.33 & 35 & 0.035 & 9 & 0.01155 \\ 0.339 & 34 & 0.034 & 10 & 0.011526 \\ 0.362 & 33 & 0.033 & 11 & 0.011946 \\ 0.38 & 32 & 0.032 & 12 & 0.01216 \\ 0.394 & 31 & 0.031 & 13 & 0.012214 \\ 0.406 & 29 & 0.029 & 14 & 0.011774 \\ 0.416 & 28 & 0.028 & 15 & 0.011648 \\ 0.423 & 27 & 0.027 & 16 & 0.011421 \\ 0.428 & 25 & 0.025 & 17 & 0.0107 \\ 0.433 & 24 & 0.024 & 18 & 0.010392 \\ 0.437 & 23 & 0.023 & 19 & 0.010051 \\ 0.443 & 22 & 0.022 & 20 & 0.009746 \\ 0.492 & 0 & 0 & \text { Open circuit voltage } & 0\end{array}$


Appendix F - PDMS SUBSTRATE FILLED WITH CADMIUM SELENIUM ZINC

\section{SULFIDE CORE SHELL QUANTUM DOTS}

Trial 8

$\begin{array}{ccccc}\text { Voltage (Volts) } & \text { Current }(\mathrm{mA}) & \text { Current }(\mathrm{A}) & \text { Resistance (Ohms) } & \text { Power (Watts) } \\ 0 & 38 & 0.038 & \text { short circuit current } & 0 \\ 0.015 & 38 & 0.038 & \text { no resistance } & 0.00057 \\ 0.052 & 38 & 0.038 & 1 & 0.001976 \\ 0.091 & 38 & 0.038 & 2 & 0.003458 \\ 0.127 & 38 & 0.038 & 3 & 0.004826 \\ 0.166 & 38 & 0.038 & 4 & 0.006308 \\ 0.202 & 37 & 0.037 & 5 & 0.007474 \\ 0.239 & 37 & 0.037 & 6 & 0.008843 \\ 0.271 & 37 & 0.037 & 7 & 0.010027 \\ 0.301 & 36 & 0.036 & 8 & 0.010836 \\ 0.33 & 35 & 0.035 & 9 & 0.01155 \\ 0.34 & 35 & 0.035 & 10 & 0.0119 \\ 0.361 & 33 & 0.033 & 11 & 0.011913 \\ 0.381 & 32 & 0.032 & 12 & 0.012192 \\ 0.394 & 31 & 0.031 & 13 & 0.012214 \\ 0.406 & 29 & 0.029 & 14 & 0.011774 \\ 0.414 & 28 & 0.028 & 15 & 0.011592 \\ 0.422 & 27 & 0.027 & 16 & 0.011394 \\ 0.428 & 26 & 0.026 & 17 & 0.011128 \\ 0.433 & 24 & 0.024 & 18 & 0.010392 \\ 0.438 & 23 & 0.023 & 19 & 0.010074 \\ 0.443 & 22 & 0.022 & 20 & 0.009746 \\ 0.492 & 0 & 0 & \text { Open circuit voltage } & 0\end{array}$


Appendix F - PDMS SUBSTRATE FILLED WITH CADMIUM SELENIUM ZINC

\section{SULFIDE CORE SHELL QUANTUM DOTS}

Trial 9

$\begin{array}{ccccc}\text { Voltage (Volts) } & \text { Current (mA) } & \text { Current (A) } & \text { Resistance (Ohms) } & \text { Power (Watts) } \\ 0 & 38 & 0.038 & \text { short circuit current } & 0 \\ 0.015 & 38 & 0.038 & \text { no resistance } & 0.00057 \\ 0.052 & 38 & 0.038 & 1 & 0.001976 \\ 0.091 & 38 & 0.038 & 2 & 0.003458 \\ 0.128 & 38 & 0.038 & 3 & 0.004864 \\ 0.166 & 38 & 0.038 & 4 & 0.006308 \\ 0.2 & 37 & 0.037 & 5 & 0.0074 \\ 0.238 & 37 & 0.037 & 6 & 0.008806 \\ 0.271 & 37 & 0.037 & 7 & 0.010027 \\ 0.303 & 36 & 0.036 & 8 & 0.010908 \\ 0.331 & 35 & 0.035 & 9 & 0.011585 \\ 0.342 & 35 & 0.035 & 10 & 0.01197 \\ 0.363 & 33 & 0.033 & 11 & 0.011979 \\ 0.381 & 32 & 0.032 & 12 & 0.012192 \\ 0.394 & 31 & 0.031 & 13 & 0.012214 \\ 0.406 & 29 & 0.029 & 14 & 0.011774 \\ 0.414 & 28 & 0.028 & 15 & 0.011592 \\ 0.422 & 27 & 0.027 & 16 & 0.011394 \\ 0.428 & 25 & 0.025 & 17 & 0.0107 \\ 0.433 & 25 & 0.025 & 18 & 0.010825 \\ 0.438 & 23 & 0.023 & 19 & 0.010074 \\ 0.443 & 22 & 0.022 & 20 & 0.009746 \\ 0.492 & 0 & 0 & \text { Open circuit voltage } & 0\end{array}$


Appendix F - PDMS SUBSTRATE FILLED WITH CADMIUM SELENIUM ZINC

\section{SULFIDE CORE SHELL QUANTUM DOTS}

\begin{tabular}{ccccc}
\multicolumn{5}{c}{ Trial 10} \\
Voltage (Volts) & Current (mA) & Current (A) & Resistance (Ohms) & Power (Watts) \\
0 & 38 & 0.038 & short circuit current & 0 \\
0.016 & 38 & 0.038 & no resistance & 0.000608 \\
0.053 & 38 & 0.038 & 1 & 0.002014 \\
0.091 & 38 & 0.038 & 2 & 0.003458 \\
0.128 & 38 & 0.038 & 3 & 0.004864 \\
0.167 & 38 & 0.038 & 4 & 0.006346 \\
0.203 & 37 & 0.037 & 5 & 0.007511 \\
0.239 & 37 & 0.037 & 6 & 0.008843 \\
0.272 & 37 & 0.037 & 7 & 0.010064 \\
0.302 & 36 & 0.036 & 8 & 0.010872 \\
0.331 & 35 & 0.035 & 9 & 0.011585 \\
0.342 & 35 & 0.035 & 10 & 0.01197 \\
0.364 & 34 & 0.034 & 11 & 0.012376 \\
0.382 & 32 & 0.032 & 12 & 0.012224 \\
0.394 & 31 & 0.031 & 13 & 0.012214 \\
0.407 & 30 & 0.03 & 14 & 0.01221 \\
0.417 & 28 & 0.028 & 15 & 0.011676 \\
0.424 & 27 & 0.027 & 16 & 0.011448 \\
0.428 & 26 & 0.026 & 17 & 0.011128 \\
0.433 & 24 & 0.024 & 18 & 0.010392 \\
0.438 & 23 & 0.023 & 19 & 0.010074 \\
0.444 & 22 & 0.022 & 20 & 0.009768 \\
0.492 & 0 & 0 & Open circuit voltage & 0
\end{tabular}


Appendix F - PDMS SUBSTRATE FILLED WITH CADMIUM SELENIUM ZINC

SULFIDE CORE SHELL QUANTUM DOTS

\begin{tabular}{ccccc}
\multicolumn{5}{c}{ Average Values } \\
Voltage & Current (mA) & Current (A) & Resistance (Ohms) & Power (Watts) \\
0 & 38.105 & 0.038105 & short circuit current & 0 \\
0.016 & 37.6 & 0.0376 & no resistance & 0.0006013 \\
0.0527 & 37.6 & 0.0376 & 1 & 0.0019813 \\
0.091 & 37.5 & 0.0375 & 2 & 0.0034124 \\
0.1275 & 37.5 & 0.0375 & 3 & 0.0047814 \\
0.1653 & 37.3 & 0.0373 & 4 & 0.0061661 \\
0.2005 & 36.9 & 0.0369 & 5 & 0.0073986 \\
0.2369 & 36.7 & 0.0367 & 6 & 0.008695 \\
0.2696 & 36.3 & 0.0363 & 7 & 0.009787 \\
0.2998 & 35.7 & 0.0357 & 8 & 0.0107038 \\
0.3286 & 35 & 0.035 & 9 & 0.011501 \\
0.3392 & 34.3 & 0.0343 & 10 & 0.0116352 \\
0.3608 & 33.1 & 0.0331 & 11 & 0.0119428 \\
0.3792 & 32 & 0.032 & 12 & 0.0121344 \\
0.3928 & 30.7 & 0.0307 & 13 & 0.0120594 \\
0.405 & 29.1 & 0.0291 & 14 & 0.0117857 \\
0.414 & 28 & 0.028 & 15 & 0.011592 \\
0.4218 & 27 & 0.027 & 16 & 0.0113886 \\
0.4276 & 25.4 & 0.0254 & 17 & 0.0108611 \\
0.4327 & 24.1 & 0.0241 & 18 & 0.0104281 \\
0.437 & 23 & 0.023 & 19 & 0.010051 \\
0.443 & 22 & 0.022 & 20 & 0.009746 \\
0.4925 & 0 & 0 & Open circuit voltage & 0
\end{tabular}

